\title{
Safeguards and Security Progress Report January-December 1984
}

\author{
Compiled by \\ Darryl B. Smith
}

\section{PISCLAIMER}

This report was prepared as an account of work sponsored by an agency of the United States Government. Neither the United States Government nor any agency thereof, nor any of their employees, makes any warranty, express or implied, or assumes any legal liability or responsibility for the accuracy, completeness, or usefulness of any information, apparatus, product, or process disclosed, or represents that its use would not infringe privately owned rights. Reference herein to any specific commercial product, process, or service by trade name, trademark, manufacturer, or otherwise does not necessarily constitute or imply its endorsemeni, recommendation, or favoring by the United States Government or any agency thereof. The views and opinions of authors expressed herein do not necessarily state or reflect those of the United States Government or any agency thereof. 


\section{CONTENTS}

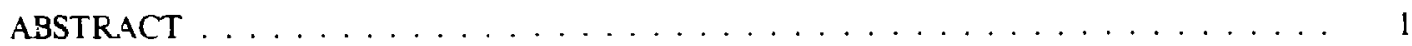

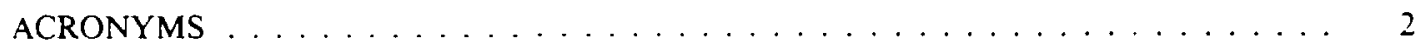

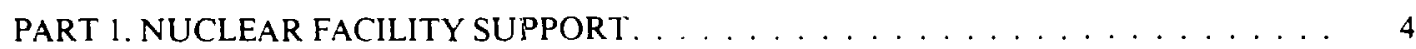

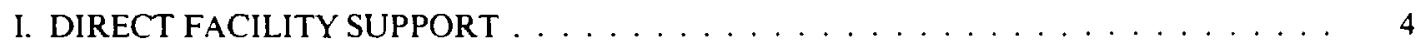

A. Albuquerque/Los Alamos National Laboratory . . . . . . . . . . . . . . . . . . 4

1. Measurement Control Program for Solution Assay Instruments . . . . . . . . . . . 4

2. Plutonium Process Control with an On-Line Gamma Monitor For Uranium,

Plutonium, and Americium. . . . . . . . . . . . . . . . . . . 4

3. Materials Accounting Enhancements at Los Alamos . . . . . . . . . . . . . . . . 4

B. Idaho/Idaho National Engineering Laboratory (INEL) . . . . . . . . . . . . . . . 5

1. Operational Check-Out of the Fluorinel Dissolution and Fuel Storage (FAST)

Facility Delayed-Neutron Interrogator . . . . . . . . . . . . . . . 5

2. Idaho Fuel Processing Restoration Project (FPRP) . . . . . . . . . . . . . . . . 6

C. Idaho/Three-Mile Island (TMI) Nuclear Power Plant Unit 2 (TMI-2) . . . . . . . . . . . 6

.. Transuranic (TRU) Assay. . . . . . . . . . . . . . . . . . . 6

2. TMI-2 Core Removal Consultation . . . . . . . . . . . . . . . . . 6

3 Make-Up Demineralizer Fuel Measurements. . . . . . . . . . . . . . . . . . 6

D. Nevada/Nevada Test Site (NTS). . . . . . . . . . . . . . . . . . . . . . 7

1. SNM Vehicle Portal Monitor. . . . . . . . . . . . . . . . . . . . . . 7

2. Device SNM Verification . . . . . . . . . . . . . . . . . . . . 8

3. SNM Monitoring at Ground Zero . . . . . . . . . . . . . . . . . . . 8

E. Oak Ridge $/ \mathrm{Y}-12$ Plant. . . . . . . . . . . . . . . . . . . . . . . 8

1. Introduction . . . . . . . . . . . . . . . . . . . 8

2. Maintenance and Documentation of the EUREKA, Evaporator Monitor, and 2300 System 'Ionitor Instruments . . . . . . . . . . . . . . . . . . 8

3. Ada $\mathrm{Al}_{\mathrm{k}}$ tion of One of the 2300 Mnnitor Measurement Heads for Automatic Control of the Solvent-Extraction System . . . . . . . . . . . . . . . . . . 8

4. An Empirical Model of the Solvent-Extraction Columns . . . . . . . . . . . . . 10

5. Design of Two New NDA Instruments for Measurement of HEU Holdup . . . . . . 12

a. The Chip Burner Filter Monitor . . . . . . . . . . . . . . . . 12

b. The Powder Transfer Holdup Assay Instrument . . . . . . . . . . . . . . 12

F. Oak Ridge/Portsmouth Gaseous Diffusion Plant (GDP) $\ldots \ldots \ldots \ldots \ldots \ldots \ldots$

1. Inventory Difference Contributions from Waste Streams . . . . . . . . . . . . . . 12

2. Holdup Measurements . . . . . . . . . . . . . . . . . . . . 13

3. Active-Well Coincidence Counter (AWCC) Applications . . . . . . . . . . . 13

G. Oak Ridge/Portsmouth Gas Centrifuge Enrichment Plant (GCEP): Crated Waste Assay

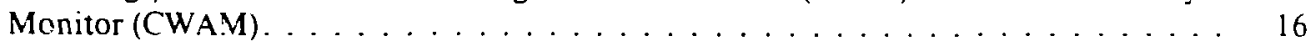

H. Richland/Fuel and Materials Examination Facility (FMEF) . . . . . . . . . . . . . 19

1. Secure Automated Fabrication (SAF) Line . . . . . . . . . . . . . . . . . 19

2. Measurement of Uranium/Plutonium Blending Ratio. . . . . . . . . . . . . . . . 19

I. Richland/Hanford PUREX Rotary Calciner Holdup Monitor . . . . . . . . . . . . . 21

J. Savannah River/New Special Recovery (NSR) Facility . . . . . . . . . . . . 21

1. Introduction . . . . . . . . . . . . . . . . . . . . . 21

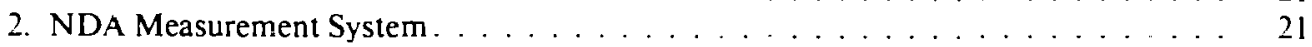

3. NDA Instrument Development . . . . . . . . . . . . . . . . . . 22

a. Feed Coincidence Counter $(\mathrm{FCC}) \ldots \ldots \ldots \ldots . \ldots \ldots 24$

b. Low-Concentration Plutonium Solution Assay Instrument (LOSAI). . . . . . . . 25

c. Waste Coincidence Counter (WCC) . . . . . . . . . . . . . . . 25

d. Sodium Iodide (NaI) Monitor Array. . . . . . . . . . . . . . . . . . 26 


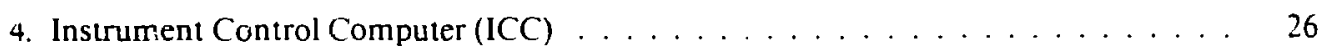

5. System Integration and Future Plans . . . . . . . . . . . . . . . . . . 28

K. Savannah River/Highly Enriched Uranium (HEU) Assay Instrumentation. . . . . . . 28

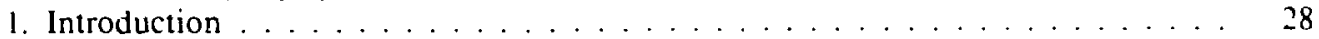

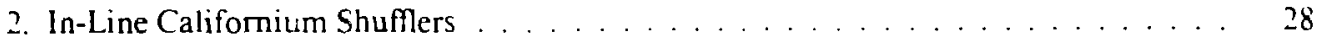

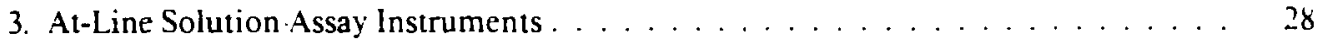

4. High-Density Waste Shumler . . . . . . . . . . . . . . . . . . . . . 28

5. Low-Density Waste Assay System . . . . . . . . . . . . . . . . . . 28

6. Low-Density Scrap Assay System . . . . . . . . . . . . . . . . . . . . . . . . 29

7. Receipts Assay Monitor . . . . . . . . . . . . . . . . . . . . . . . . . 29

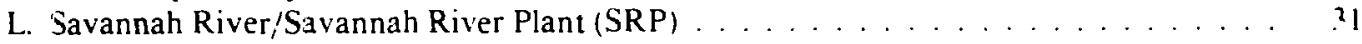

1. Variance C.Iculations for the Savannah River FB-Line . . . . . . . . . . . 31

2. Plutonium Isotopics Assay for SRP/FB-Line . . . . . . . . . . . . . 31

M. Ad Hoc Field Assistance . . . . . . . . . . . . . . . . . . . . . . 31

1. DOE Albuquerque Operatiuns Office: BSAM Evaluation . . . . . . . . . . . . 31

2. Los Alamos Measuremerit Assistance . . . . . . . . . . . . . . . . . 31

3. Rocky Flats: Shipper-Receiver Confirmatory Measurements . . . . . . . . . . . . . 32

4. Rocky Flats: MC\&A System Consultation . . . . . . . . . . . . . . . . 32

5. Oak Ridge Y-12: Evaluation of the Los Alamos AWCC . . . . . . . . . . . . . 32

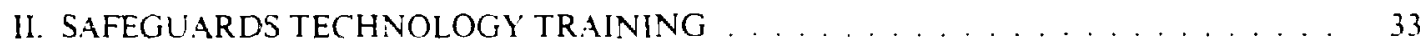

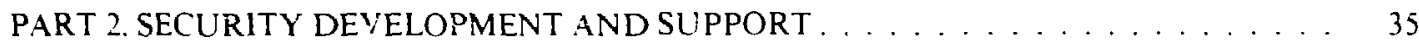

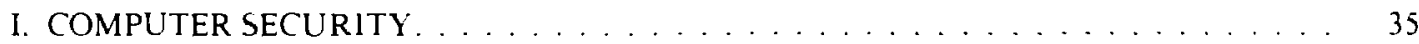

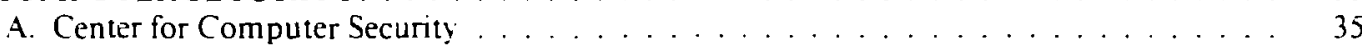

1. CSSO Classes. . . . . . . . . . . . . . . . . . . . . . 35

2. Advice and Assistance. . . . . . . . . . . . . . . . . . . 35

3. Center for Computer Security Newsletter . . . . . . . . . . . . . . . . . . 35

4. Security Products Listing . . . . . . . . . . . . . . . . . . . . 36

5. Security Education and Training Listing . . . . . . . . . . . . . . 36

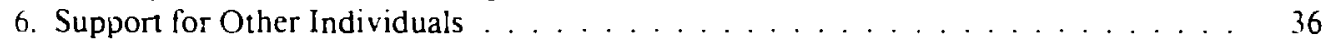

7. Hard Disk Security Shield. . . . . . . . . . . . . . . . . . . . . . 36

8. Department of Defense (DoD)-Sponsored Computer Classes . . . . . . . . . . . . 36

9. Advice and Assistance Outside the DOE . . . . . . . . . . . . . . . . . . 37

10. Other Support . . . . . . . . . . . . . . . . . . . . . . 37

11. Management Support Tools . . . . . . . . . . . . . . . . . . . 37

12. LAVA: An Automated Computer Security Vulnerability Assessment Tool . . . . . . 38

B. Secure Computer Systems . . . . . . . . . . . . . . . . . . . . . 38

1. Secure Communication Processor Operating System (SCOMP) . . . . . . . . . . . 38

a. Hardware Description. . . . . . . . . . . . . . . . . . . . 38

b. Software Description . . . . . . . . . . . . . . . . . . . . . . 38

c. SCOMP At Los Alamos . . . . . . . . . . . . . . . . . . . . . . . . 39

C. Secure Computer Networks. . . . . . . . . . . . . . . . . . . . . . . . . . . . . . 40

1. Lirk Access Control and Encryption System . . . . . . . . . . . . . . . . . 40

2. The New Link Ace II . . . . . . . . . . . . . . . . . . . . . . . . . . . . . 4

3. Trusted Interface for Local Area Networks . . . . . . . . . . . . . . . . . . . . . 40

a. Security Requirements . . . . . . . . . . . . . . . . . . . . . . 41

b. The Trusted Interface . . . . . . . . . . . . . . . . . . . . . . . . . . . 41

c. Trusted LAN Controller. . . . . . . . . . . . . . . . . . . . . . +1

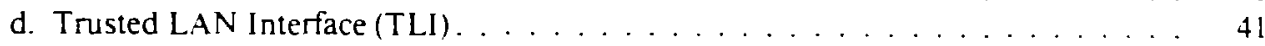

e. Implementaticn ................................ 42

D. Secure Computer Communications . . . . . . . . . . . . . . . . . . 42

1. Wideband Communication Network . . . . . . . . . . . . . 42 
II. OPERATIONS SECURITY (OPSEC) AND VULNEKABILITY ASSESSMENTS (VAS).

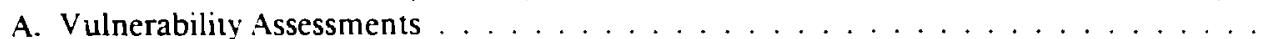

B. Advice and Assistance.

C. Education and Training.

D. DOE Security Operations Bulletin

E. OPSEC Guidance

F. OPSEC Workshop.

PART 3. SAFEGUARDS TECHNOLOGY DEVELOPMENT

1. EQUIPMENT DEVELOPMENT AND ENGINEERING . . . . . . . . . . . . . . 44

A. NDA Technology Development . . . . . . . . . . . . . . . . . . . . . . . 44

1. Flowing Fissile Assay System . . . . . . . . . . . . . . . . . . . . . . . . . 44

2. Surface Analysis of Plutonium Metal by Energy-Dispersive X-Ray Fluorescence. . . 44

3. A Compact Continuum $\mathrm{L}_{111}$-Edge Densitometer . . . . . . . . . . . . . 46

4. Discrete-Source $\mathrm{L}_{\mathrm{lII}}$ Edge Densitometry . . . . . . . . . . . . . . . . . . 46

5. Test and Evaluation of TEWA System. . . . . . . . . . . . . . . . . . 51

6. Test and Fvaluation of Plutonium Solution Densitometer at SRP . . . . . . . . . 5

7. Feasibility Study of Plutonium Isotopic Analysis of Resin Beads by Nondestructive Ciamma-Ray Spectroscopy

8. Advances in High-Counting-Rate Electronics for Neutron Coincidence Counters
a. Detector Design
b. Detector Electronics.
c. Counting Rate and Deadtime.
d. Counting Stability
e. Gamma-Ray Sensitivity.
f. Noise Sensitivity
g. Performance Parameters

9. Cerenkov Glow Technique for Spent-Fuel Monitoring . . . . . . . . . . . . .

10. Thermal Imaging.

11. Neutron Monitoring During Conversion of $\mathrm{PuO}_{2}$ to $\mathrm{PuF}_{4}$.

12. Applications of NDA to Robotics Automation of the Process of Direct Reduction of $\mathrm{PuO}_{2}$.

13. Multifunction Electronics Controller Board.

14. NDA Software Development

a. GENERIC NDA Software

b. Computer Communications

c. Extended Memory (XM), Multiterminal, and Program Overlays

d. Multifuriction Controller Board Softuare.

e. Portable Multichannel Analyzer (PMCA) Software

f. BASIC Code for Portable Computers

B. Containment and Surveillance Technology Development.

1. SNM Monitor R\&D .

a. Pajarito SNM Monitor.

b. Commercial SNM Monitor Evaluation .

c. Radiation So!rce Verification and Identification.

d. SNM Monitors at DOE Facilities

2. Reac*or Power Monitor

C. Chemical and Isotope Analysis

1. Automated Complexometric Titrator for Uranium . . . . . . . . . . . . . 70

2. Laser-Excitation Fluorescence Uranium Analyzer . . . . . . . . . . . . . . . 70

3. Adranced Automated Controlled-Potential Coulometric Analyzer. . . . . . . . . . . 70

4. Laser-Abetted Mass Spectrometer for Measuring Uranium and Plutoniurn Isotopic

Distributions

5. Controlled-Potential Coulometric Determination of Uranium . . . . . . . . . 
II. MC\&A TECHNOLOGY AND APPLICATIONS DEVELOPMENT . . . . . . . . 72

A. Safeguards System Integration . . . . . . . . . . . . . . . . . . . . . . . 72

B. Advanced Materials Measurement and Accounting Systems . . . . . . . . . . . 72

1. Voice-Venification System . . . . . . . . . . . . . . . . . . . . 72

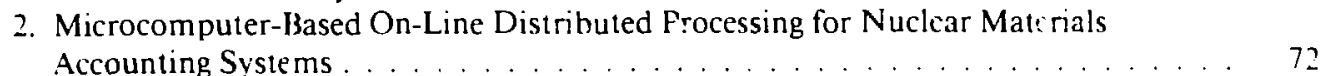

C. MC\&A Technology Development . . . . . . . . . . . . . . . . . 73

1. Application of Artificial Intelligence (AI) Techniques . . . . . . . . . . 73

a. A Computer Program for Symbolic Materials Balance Variance Calculation . . . . 73

b. MACSYMA Applied to Variance Calculations . . . . . . . . . . . . . . 74

2. Statistical Methods for Materials Accounting . . . . . . . . . . . . . . . . . . 74

a. Error Propagation/Inquiry Code (EPIC) . . . . . . . . . . . . . . . 74

b. Improved Sample-Size Determination for Attributes and Variables Sampling . . . 75

3. Headquarters Initiative: Shipper-Receiver Differences . . . . . . . . . . . . 76

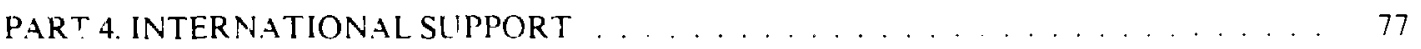

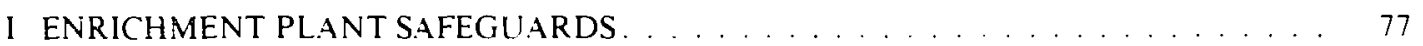

A. Portsmouth Gas Centrifuge Enrichment Plant (GCEP) . . . . . . . . . . . . . . 77

1. Limited-Frequency-Unannounced-Acess Inspection Strategy . . . . . . . . . . . . 7 ?

a. Passive Observation of Low-Pressure Uranium Gas . . . . . . . . . . . . . . 77

b. Liranium Enrichment Measurement. . . . . . . . . . . . . . . . . . . 78

c. Uranium Enrichment Verificaton . . . . . . . . . . . . . . . . . . . 80

¿. 1AEA Inspector's Computer System . . . . . . . . . . . . . . . . . . . 81

3. In-Line Enrichment Monitor . . . . . . . . . . . . . . . . . . . . 83

4. IAEA Detection Sensitivity and Attributes/Variables Sample Sizes . . . . . . . . . 84

5. Neutron Energy Response of an Area Neutron Monitor . . . . . . . . . . . . . . . . 85

B. Compact ${ }^{252} \mathrm{Cf}$ Shuffler for UF $\mathrm{F}_{6}$ Measurements . . . . . . . . . . . . 85

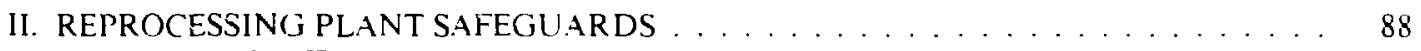

A. Dounreay Shuffler. . . . . . . . . . . . . . . . . . . . . . . . . $\ldots$

B. Compact K-Edge Densitometer . . . . . . . . . . . . . . . . . . 91

C. iokai-Mura K-Edge Densitometer Software Update. . . . . . . . . . . . . . . . . . 91

III. INTERNATIONAL TECHNICAL EXCHANGES . . . . . . . . . . . . . 9I

A. Program of Technical Assistance to IAEA Safeguards (POTAS) . . . . . . . . . . 91

1. Overview . . . . . . . . . . . . . . . . . . . . . . . 91

2. Quality Assurance for Inspection Planning . . . . . . . . . . . . 92

B. Commission of the European Communities, Joint Research Centre (JRC), Ispra, Italy. . . 92

1. Intercomparison of the Active Well Coincidence Counter and PHONID-II . . . . . . 92

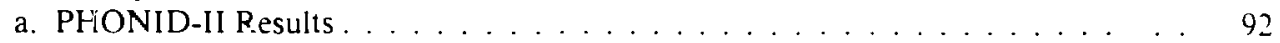

h. AWCC Results. . . . . . . . . . . . . . . . . . . . . . 94

c. Stimmary . . . . . . . . . . . . . . . . . . . . . . . . . . 94

2. ESARDA/INMM C inference on NDA Statistical Problems . . . . . . . . . . 944

C. US-European Economic Community (EEC) Technical Exchange Program . . . . . . . . 95

1. Test and Evaluation of Spent-Fuel Equipment . . . . . . . . . . . . . . . . 95

2. Field Exercises at Belgonucleaire. Nukem, and Riso . . . . . . . . . . . . . . . . 95

a. Belgonucleaire Fuel Fahrication Plant, Dessel, Belgium . . . . . . . . . . . . . 95

b. Nukem. Hanau. FRG . . . . . . . . . . . . . . . . . . . . . . . . 95

c. Danish Atomic Energy Commission Research Establishment. Riso, Denmark . . . of

D. lAEA Advisory/Working Groups . . . . . . . . . . . . . . . . . 96

1. Quality of NDA Data . . . . . . . . . . . . . . . . . . . . . 96

2. Reprocessing Working Group . . . . . . . . . . . . . . . . . . . . 96

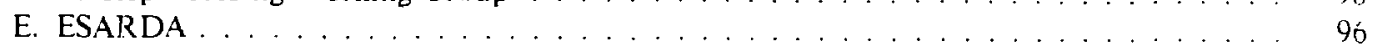

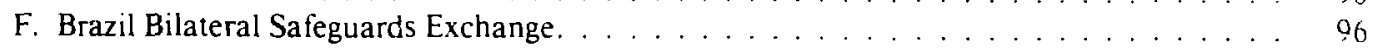




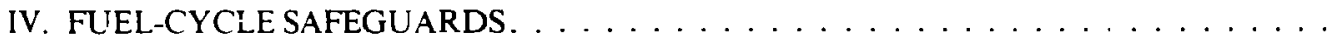

V. INTERNATIONAL TRAINING COURSES ON IMPLEMENTATION OF STATE SYSTEMS OF ACCOUNTING FOR AND CONTROL OF NUCLEAR MATERIAL . . . .

PART 5. RELATED SAFEGUARDS PROJECTS

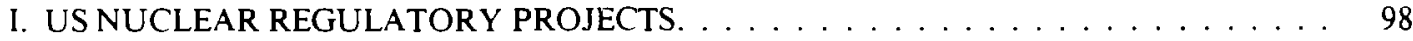

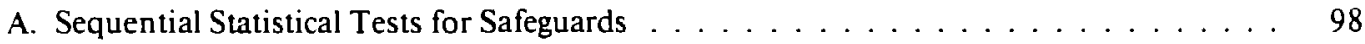

B. Estimation Methods for the Process Holdup of Special Nuclear Materials. . . . . . . . . . 99

1. Use of Historical Data . . . . . . . . . . . . . . . . . . . . . . . 99

2. Controlled Experiments . . . . . . . . . . . . . . . . . . . . . . . . . . . . . . . . . . . . . . .

3. Modeling Approaches . . . . . . . . . . . . . . . . . . . . . . . . . 99

4. Conclusions . . . . . . . . . . . . . . . . . . . . . . . . . . . 99

C. Passive Nondestructive Assay Reference Manual . . . . . . . . . . . . . . . 100

II. THE ATOMIC SPECTRUM OF PLUTONIUM $\ldots \ldots \ldots \ldots \ldots$

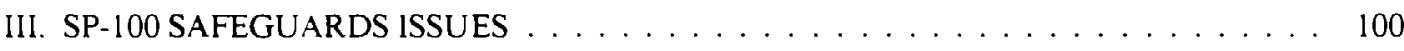

IV. TRU W

V. SUPPORT TO SRP/HB-LINE SODIUM IODIDE MONITOR ARRAY. . . . . . . . . 101

VI. TECHNICAL ASSISTANCE FOR THE LOS ALAMOS NATIONAL LABORATORY

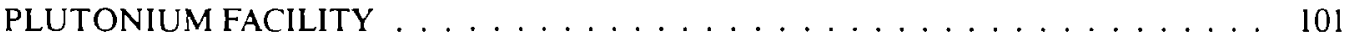

A. Caustic Waste Tank Measurement Instrument. . . . . . . . . . . . . . . . . 102

B. Segmented Gamma Scanner for TA-55 . . . . . . . . . . . . . . . . . i03

C. Add-on NDA Training . . . . . . . . . . . . . . . . . . . . 103

D. Model of the Los Alamos Plutonium Facility . . . . . . . . . . . . . . . . . . . 103

E. Database Design and Applications Support for Los Alamos Plutonium Facility . . . . . 103

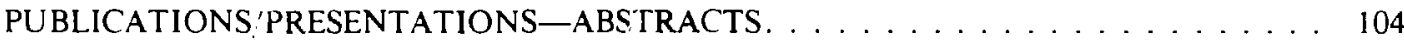

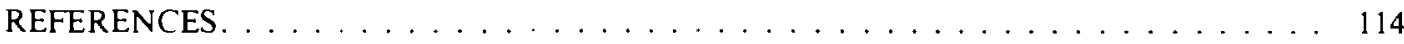




\title{
SAFEGUARDS AND SECLRITY PROGRESS REPORT
}

\author{
January - December 1984 \\ Compiled by \\ Darryl B. Smith
}

\begin{abstract}
From January to December 1984, the Los Alamos Safeguards and Security Program was involved in the activities described in the first four parts of this report: Nuclear Facility Support, Security Development and Support, Safeguards Technology Development, and International Safeguards. Part 1 cuvers efforts of direct assistannce to the Departenent of Energy (DOE) and Nuclear Regulatory Commission (NRC) licensee facilities. This assistance includes consultation on materials accounting problems, development of specialized techniques and instruments, and comprehensive participation in the design and implementation of advanced safeguards systems. In addition, a series of training courses in various aspects of safeguards makes the technology more accessible to those who must apply it. Part 2 treats activities aimed at the security of information and computer systems. Our focus this period was on continuing the activities of the Computer Security Center, which provides the basis for encouraging and disseminating this emerging technology, and on the development and demonstration of secure computer systems. Part 3 describes the broad development efforts essential to continuing improvements in the practice of safeguards. Although these projects are properly classified as developmental, they address recognized problems that cornmonly occur in operating facilities. Finally, Part 4 covers international safeguards activities, including both support to the International Atomic Energy Agency and bilateral exchanges. Enrichment plant safeguards, especially those concerning the Gas Centrifuge Enrichment Plant, required a significant portion of our resources. These efforts are beginning to provide substantial returns on our investment in technology transfer, not only in raising the level of safeguards effectiveness but also in benefiting from field experiences in operating environments.

While most projects described in this report were sponsored by DOE Office of Safeguards and Security, safeguards-related activities that have other sponsors are reported in Part 5. The final part of this report lists titles and abstracts of Los Alamos safeguards $R \& D$ reports, technical journal articles, and conference papers that were publishod in 1984.
\end{abstract}




\begin{tabular}{|c|c|c|c|}
\hline $\mathrm{ACE}$ & access, control, and encryption & FAPs & false alarm probabilities \\
\hline ADU & ammonium diuranate & FAR & Feed Assay Room \\
\hline AI & artificial intelligence & FAST & Fluorinel Dissolution and Fuel Storage \\
\hline ALARA & as low as reasonably achievable amounts & $\mathrm{FCC}$ & Feed Coincidence Counter \\
\hline ASCII & American Standard Code for Information & FFTF & Fast Flux Test Facility \\
\hline ASTM & $\begin{array}{l}\text { Interchange } \\
\text { American Society for Testing and } \\
\text { Materials }\end{array}$ & $\begin{array}{l}\text { FMEF } \\
\text { FPRP }\end{array}$ & $\begin{array}{l}\text { Fuel and Materials Examination Facility } \\
\text { Fuel Processing Restoration Project }\end{array}$ \\
\hline AWCC & Active-Well Coincidence Counter & GAC & Goodyear Atomic Curporation \\
\hline BCR & Building Control Room & GCEP & Gas Centrifuge Enrichment Plant \\
\hline BSAM & Portable gamma-ray spectrometer & GDP & Gaseous Diffusion Plant \\
\hline $\mathrm{CMC}$ & confirmatory measurement counters & GSs & green salts \\
\hline CNEN & National Nuclear Energy Commission & HDRs & high-derısity residues \\
\hline $\mathrm{CPCl}$ & Central Personnel Clearance Index & HEU & Highly Enriclied Uranium \\
\hline CRT & cathode ray tube & $\mathrm{HF}$ & hydrogen fluoride \\
\hline CSERs & computer security enhancement reviews & HLNCC & high-level neutron coincidence courter \\
\hline CSOMs & computer security operations managers & HVAC & heating, ventilating, and air conditioning \\
\hline CSSOs & Computer System Security Officers & IAEA & International Atomic Energy Agency \\
\hline CVD & Cerenkov viewing device & ICC & instrument control computer \\
\hline CWAM & Crated Waste Assay Monitor & ICP & inductively coupled plasma \\
\hline DBMS & database management system & ICPP & Idaho Chemical Processing Plant \\
\hline DBR & descriptor base root & ICVD & improved Cerenkov viewing device \\
\hline DEC & Digital Equipment Corporation & ID & identification number \\
\hline DECNET & Digital Equipment Corporation Network & IDA & Institute for Defense Analyses \\
\hline DES & Data Encryption Standard & IDs & inventory differences \\
\hline DoD & Department of Defense & IDAS & integrated data acquisition system \\
\hline DOE & Department of Energy & $I \& E$ & instrument and electronics \\
\hline $\mathrm{DOE} / \mathrm{AL}$ & DUE Albuquerque Operations Office & IER & Instrument Electronics Room \\
\hline $\mathrm{DOE} / \mathrm{HQ}$ & DOE Headquarters & IFPF & Idaho Fuel Processing Facility \\
\hline DOE/OSS & LOE/Office of Safeguards and Security & INEL & Idaho National Engineering Laboratory \\
\hline DOR & direct oxide reduction & INGRES & $\begin{array}{l}\text { Interactive Graphics and Retrieval } \\
\text { System }\end{array}$ \\
\hline $\begin{array}{l}\text { DP } \\
\text { DPE }\end{array}$ & detection probability & INVS & inventory sample coincidence count \\
\hline $\begin{array}{l}\text { DPE } \\
\text { DT }\end{array}$ & distributed-processing environment & $\mathrm{I} / \mathrm{O}$ & input/output \\
\hline DT & deuterium-tritium & ION & $\begin{array}{l}\text { Input/output } \\
\text { spent-fuel measurement instrun }\end{array}$ \\
\hline $\begin{array}{l}\text { EEC } \\
\text { EMP }\end{array}$ & European Economic Community & JRC & $\begin{array}{l}\text { spent-fuel measurement instrun } \\
\text { Joint Research Centre }\end{array}$ \\
\hline EMP & enrichment monitor processor & LAN & $\begin{array}{l}\text { Joint Research Centre } \\
\text { local area network }\end{array}$ \\
\hline EPIC & error propagation/inquiry code & & $\begin{array}{l}\text { local area network } \\
\text { light-emitting diode }\end{array}$ \\
\hline EPROM & erasable programmable read-only & LEL & light-emitting diode \\
\hline & & LEID & limit-of-error inventory difference \\
\hline ESARDA & $\begin{array}{l}\text { European Safeguards Research and } \\
\text { Development Association }\end{array}$ & LFUA & $\begin{array}{l}\text { limited-frequency-unannounced-access } \\
\text { strategy }\end{array}$ \\
\hline EURI & Enriched Uranium Recovery Improve- & LIBS & laser-induced breakdown spectroscopy \\
\hline & & LINAC & electron linear accelerator \\
\hline
\end{tabular}


Link ACE Link Access Control and Encryption

LLNL Lawrence Livermore National Laboratory

LMFBR Liquid-Metal Fast Breeder Reactor

LOSAI Low-Concentration Plutonium Solution Assidy Instrument

LWR Light-Water Reactor

MB materials balance

MBA materials balance area

MBs metal buttons

MC\&A Materials Control and Accounting

MCP measurement control program

MCS

MCU

MIPs

MOX

MUF

NASA

NBS

NDA

NDP

NMC and A Nuclear Materials Control and Accounting

NNC National Nuclear Corporation

NNPA Nuclear Nonproliferation Act of 1978

NRC Nuclear Regulatory Commission

NSR New Special Recovery

NTS Nevada Test Site

OLAM on-line alpha monitor

OPSEC operations security

PCs personal computers

PFR Prototype Fast Keactor

PIV physical inventory verification

PMCA portable multichannel analyzer

POTAS Program of Technical Assistance to IAEA Safeguards

PROM programmable read only memory

PWR Pressurized Water Reactor

RAM receipts assay monitor

R\&D research and development
RD/USAS Random Driver/Uranium Solution Assay System

ROI regions-of-interest

ROM read-only memory

RT1 Relational Technology, Inc.

SAF Secure Automated Fabrication

SAIs solution assay instruments

SAL Seibersdorf Analytical Laboratory

SAR Sample Assay Room

SARA service acadenyy research associate

SCOMP secure communication processor

SGS segmented gamma-ray scanner

SIR Safeguards Implementation Report

SKIP SCOMP kernel interface package

SNL Sandia National Laboratories

SNM special nuclear material

SPM Security Protection Module

SPRT Sequential Probability Ratio Test

SRL Savannah River Laboratory

SRP Savannah River Plant

SSAC State Systems of Accounting for and Control of Nuclear Material

STOP SCOMP Trusted Operating Program

TEWA technique for effluent waste assay

T\&E test and evaluation

TLC Trusted LAN Controller

TLI Trusted LAN Interface

TMI Three-Mile Island Nuclear Power Plant

TM!-2 Three-Mile Island Nuclear Power Plant Unit 2

TRU transuranic

TWSO Transuranic Waste Support Office

UNCC Uranium Neutron Coincidence Collar

VA vulnerability assessment

VHEU very highly enriched uranium

WBCN wideband communication network

WCC waste coincidence counter

WINCO Westinghouse Idaho Nuclear Company

WIPP Waste Isolation Pilot Plant

XM extended memory

XRF $\quad \mathrm{x}$-ray fluorescence 


\section{PART 1. NUCLEAR FACILITY SUPPORT}

\section{DIRECT FACILITY SUPPORT}

\section{A. Albuquerque/Los Alamos National Laboratory}

\section{Measurement Control Program for Solution Assay} Instruments (A. S. Goldman, Q-4). The Department of Energy (DOE) Order 5630.2 for Materials Control and Accounting (MC\&A) requires a measurement control program (MCP) to ensure that "nondestructive assay (NDA) instrumentation shall be calibrated with appropriate standards and monitored pe:iodicully t" ensure proper function within established control limits." We have completed a study of four solution assay instruments (SAIs) at the Los Alamos Plutonium Processing Facility (T.4-55) and have suggested modifications to the current MCP. The study was based on data accumulated over 2 yr from daily measurcments of plutonium foil standards on the SAIs. Foils are used in place of liquid calibration standards because of the evaporation of the liquid through plastic bottles. Principal findings and recommendations are

- Technicians enter data into a log book and the accountability computer. The observed data-entry error rate is $\sim 17 \%$; however. only $1 \%$ of these errors would affect decisions made in MCP tests. We recommend that direct data transmission from the instrument to the computer be considered.

- Small. eersistent negative biases ranging from $-0.0021 \mathrm{~g}$ to $-0.0109 \mathrm{~g}$ and relative biases ranging from $0.1 \%$ to $0.47 \%$ were observed. Alihough these biases are not significant for materials accounting. we recommend that biases be tested monthly wnd an investigation be made when they are found to be statistically. significantly different from zero.

- An accuracy test is conducted daily in which a single measurement is compared with the foil standard. We recommend this test be continued in its present form.

- A precision test is conducted weekly by comparing the variance of 15 consecutive measurements with the average of 15 propagated variances. Accuracy tests are not conducted on these measurements; consequently, measurements that would fail the accuracy test go unnoticed. We recommend that the weekly test be replaced by a daily precision test based on 15 previous daily measurements. The daily test would be made in conjunction with the accuracy test and provide more timely decisions.

- All of the tests used in the MCP are based on the assumption that the data are normally distributed.
We tested some data and verified this assumption. We recommend periodic tesis for normality.

2. Plutonium Process Control with an On-Line Gamma Monitor For Uranium, Plutonium, and Americium (S. F. Marsh, MST-12; S.-T. Hsue, Q-1). We have developed an on-line measurement system tc monitor uranium, plutonium, and americium in the effluent s: :eam of an anion exchange process used to purify plutonium at TA-55. In this process, plutonium is sorbed on the resin from nitric acid, while americium (which has no affinity for the resin) passes through. Uranium, by contrast. is weakly sorbed and requires extensive washing to ersure its complete removal. Continuous monitoring of americium and uranium signals the complete temovil of these impurities, thus avoiding unnccessary washing that can generate large volumes of contaminated liquid waste. Simultaneous on-line measurement of plutonium in the effluent stream provides an immediate indication of plut'snium breakthrough or other abnormal process condition and facilitates prompt corrective action.

The on-line monitor system employs passive gamma spectrometry 4mericium and plutonium measurements are based on the 59.5- and 414-keV gamma rays of ${ }^{241} \mathrm{Am}$ and ${ }^{239} \mathrm{Pu}$. respectively. Natural and depleted uranium have no suitable ganmma rays and must bc measured uring a novel and less direct technique. Plutonium-241. alwavs present in the plutonium that is processed, decays primarily to ${ }^{241} \mathrm{Am}$ by beta emission. However, a small fraction of ${ }^{241}$ Pu alpha decays to 6.8 day ${ }^{237} \mathrm{U}$. The short half-life and $208-\mathrm{keV}$ gamma ray of ${ }^{237} \mathrm{U}$ make it an ideal radiotracer to mark the position of macro amounts of uranium in the process. A stripchartrecorder output from this instrument provides real-time display of the uranium, plutonium, and americium content in the effluent solution, as well as a permanent record of their bchavior during each separation.

3. Materials Accounting Enhancements at Los Alamos (H. S. Vaccaro, Q-4). The MASS computer system is the current Los Alamos nuclear materials accounting system. It was implemented in its present version by the Los Alamos Nuclear Materials Accountability Group (OS-2) in April 1983 as an evolution of the PF/LASS system. PF/LASS and its parent DYMAC first became operational at Los Alamos 6 yr ago. Since that time, the level of materials accounting activity has increased several fold. At the same time, the DOE has bersun to rely on accounting as a highest-priority nuclear materials safeguard, and tremendous changec have occurred in the availability, power, and cosi of data processing hardware. 
In FY 1984, a long-term, collaborative effort among several Los Alamos groups (OS-2, Q-4, MST-10, and S-1) was begun to explore the inost promising enhancements to materials accounting at Los Alamos. This effort is expected to produce a new or greatly augmented materials accounting system to replace MASS. Oi1 current work is focused on methods for automated detection of anomalies in the accounting system and is intended to discover errors, abnormal process condjtions, abnormal values for inaterials in process (MIPs), and loss of material. Initial work completed in FY 1984 shows significant promise for halting the nresent trend of rapidly increasing manpower expenditivis for ia; to-day identification of anomalies and correction of errors. We are working on two approaches in this problem. One relies on a relational database management system (INGRES) to analyze in istorical materials transactions searching for "normal" patterns or templates. Any new transaction noi matching at least one of these normal templates is flagged as suspect. The al ernative approach uses FORTRAN programs we 'ave developed to create historical likelihond statistic for pairs and triplets of transaction field values and then evaluate new transactions against these likelihood statistics. This method produces a relative evaluation for each new transaction and pinpoints suspect fields.

These two methods have shown comparable cffectiveness in detecting erroneous iransactions, and each requires a similar tradeoff between detection sensitivity and the frequency of false indications of anomalies. Future efforts will attempt to establish appropriate sensitivity compromises for specific operating environments. In early tests, between ene-half and one-fifth of flagged transactions were found, on manual inspection, to contain probable errors. The programs find many of the same errors, but each has distinct strengths. (No estimate is yet available as to the number of erroneous transactions missed by the programs.) After additional testing, the remaining flagged transactions will be analyzed in depth to determine effectiveness in spotting abnormal process conditions, ur usual MIPs, and unexplained materials losses.

Either method appears applicable to "tail-end," endof-day anomaly processing and reporting. However, the FORTRAN approach has been shown to be capable of real-time, front-end processing as well. Tests show that the current prototype programs can error check between two and four transactions per second on a VAX/11-780. Assuming a future 5000-transaction-per-day accounting system, the software would use between 4 and $8 \%$ of a similar class machine over an $8 \mathrm{~h}$ day. In a distributed processing mode, the software could be installed on local microcomputers and would require several seconds to check a transaction. Moreover, because $t^{2}$.
FORTRAN method yields relative measures of likelihood and pinpoints suspicious fields, it should be well suited to a system of graded responses to attempted transactions.

\section{B. Idaho/Idaho National Engineering Laboratory (INFL)}

1. Operational Check-Out of the Fluorinel Dissolution and Fuel Storage (FAST) Facility Delayed-Neutron

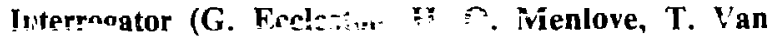
iyssei, $\mathbf{Q}-1)$. We are contınuing operational check-out of the dual-assay shuffler in the FAST facility at INEL. This facility receives, stores, and dissolves zirconium clad fuel from government research reactors and from the US naval nuclear ship propulsion program $T t_{\mathrm{c}} \mathrm{c}$ shuffler is designed to measure the ${ }^{235} \mathrm{U}$ content of irradiated, highly enriched uranium fuels anu of waste solids resulting from fuel dissolution. ${ }^{1}$

Recently, installation of the material-handling crane in the dissolution cell was completed. The crane's verical position readout was wired to the shuffler, and testing indicared grounding problems in the crane wiring. The communications panel was rewired, and the grounding problems were corrected. The shuffler software also was modified to latch the crane data before reading. The shuffler can row read the crane vertical position to $\pm 0.1 \mathrm{~cm}$.

We also tested the communications iink between the shutfler computer and the mair. facility computer. Problems encountered on parity computations of transmitted data were corrected by modifications to the software in the main facility computer, and data are now being transmitted and received correctly.

Initial measurements were completed using $\mathrm{AmLi}$ neutron sources supplied by INEL. These sources were lowered through the center of the fuel tube and used to set discriminator levels on the amplifier/single-channel analyzers for both the fuel and waste measurement electronics. The ${ }^{3} \mathrm{He}$ neutron detectors were also checked and found to be operating properly.

A large ${ }^{252} \mathrm{Cf}$ neutron source $(3 \mathrm{mg}$ ) has been prepared by Savannah River Laboratories (SRL) for use in the shuffler. The dual transport and storage source cask. designed by Los Alamos, has been sent to SRL to transport the source to the FAST facility. The source will arrive at the facility in February 1985 for installation in the shuffler.

Initial fuel dissolution is scheduled for March 1985. Calibration and assay measurement of fucl samples val! begin before fuel dissolution. Fuel calibra ion stand rds will be developed and selested concurrently with facility operations. 
2. Idaho Fuel Processing Restoration Project (FPRE; 'J. W. Barnes, R. G. Gutmacher, D. Stirpe, Q-4; W. Eccleston, Q-1). We have continued to assist Idaho Operations Office and Westinghouse Idaho Nuclear Co. (WVINCO) by studies of the proposed materials corrtrol and accounting system, limit-uf-error inventory difference (LEID) calculations, and the effect of process tank configurations on mixing, sampling, and uulk measurernenis at the FPRP. A Los Alamos staff member attencied tank-mixing demonstrations held at INEL in August 1984, and com. rents or. dra!! report WIN-123, "Design Criteria for the IFPF Fuel Processing Restora:ion Project, Revision 0," were sent to Idaho Operations Office in November 1984.

A representative of WINCO visited Los Alamos in April 1984 to discuss the problem of detecting low concentrations of uraniuin $(0.01-0.1 \mathrm{~g}$ uranium/ $l$ ) in process lines that normally contain litule or no uranium. WINCO needs a system that can detect uranium in aquecus and organic streams in $200 \mathrm{~s}$ or less for both the exisuing Idaho Chemical Processing. Plant (ICPP) and the FPRP. The uranium measurements must be made in the presence of high concentrations of fission products. Several possiole solutions tc this measurement problem weri identified, and WINCO personnel have expressed interest in acquiring a compact shuffler.

At the request of DOE/idaho Operecions Office, we performed materials balance variance calculations for the FPRP' for several possible operating conditions. The intent of these calculations was to determine which oneraing conditions would give values of the LEID less than or equal to $1 \%$ of facility thioughput.

Utider the assumption that the various storage tanks. process columins, and evaporators are full at accounting timıs, the LEID obtained was about $2.1 \%$ of throughput for a 60-day atcounting period. With the assumption that this equipment is only one-quarter till at accounting times, the LEID decreased to $\sim 1.8 \%$ of ihror ghput.

The calculations showed that the major contributions to the LEID would be caused by the relativelv poor measurements of material inventory in the first-cycle concentrate storage tank, the first- and third-cycle evaporators, and the denitrator. To decrease these contributions to the LEID, we did another variance calculation under the assumptions that the evaporators are allowed to cool at accounting times, that samples from the first-cycle evaporator and concentrate storage tank can be remotely titrated in a hot cell, and that the denitrator is emptied. These assumptions permit considerable reduction in the measurement uncertainty associated with the determination of the concentration of these solutions and eliminate the denitrator variance contribution entirely.

With these assumptions and the additional assumption that the process and storage equipment is full at accourting times, the LEID decreases to $\sim 0.8 \%$ of throughput. If this equipment is only one-quarter full at the 60 -day accounting times, the LEID becomes $0.4 \%$ of throughput. Because these latter LEIDs are in the range of acceptable values, we recommend tha: Westunghouse and DOE personnel examine both the results and their underlying assumptions for validity anci the feasibility of implementing the necessary process modifications.

\section{Idsho/Three-Mile Island ( $\left.T M^{M} I\right)$ Nuclear Power Pirnt Unit 2 (TMiI-2) (J. K. Heibig, Q-1)}

1. Transuranic (TRL) Asjay. We developed a proposal for a detector to assay the amount of TRU material in a water suspension. The target use was the disposal of make-ıp demineralizer resins and basement sludge.

The detector proposed was similar to the $\operatorname{Be}(\alpha, n)$ detector ised to determine the amount of fuel in the make-up demineralizers, ${ }^{2}$ except in this detector the fission chambers surrounded the beryllium and a small 1 J0- to $200 \mathrm{ml}$ sample was to be placed in the certer of the beryllit ?. We used Monte Carlo calculations to optimize the design. Based on these calculations and the known efficiency of the $B e(\alpha, n)$ detector used with the make-up demineralizer measurements, necessary crint times were predicted to be in the several-thousandsecord range, well within the $24 \mathrm{~h}$ thai was reciuested.

No action was taken on the proposal sent to EG\&G at TMI

2. TMI-2 Core Removal Cunsultation. We have conwilted with EG\&G regarc ig two problems associated with the TMI-2 core removal.

We recommended against the proposed design of the canister to be used for transport of core debris because of the difficulty of accurately assaying its contents. In addition, we provided calculations to shrow the insensitivity of an ION chamber to determine the fuel content of these canisters.

We also were asked to comment on the problem: of verification of the integrity of the poison plates in the canisters during storage at Idaho. We proposed to measure each canister at a time when the integrity of the plates was known. Subsequent measurements would follow a known decay curve. If measurements gave results that did not follow the decay curve, it:e conclusion would be that the integrity of the poison plates would not be verified.

3. Make-Up Demintralizer Fuel Measurements. We received the results of analysis of the samples of resin removed from the make-up demineralizers from $E G \& G$. These results showed $2420 \mathrm{ppm}$ 
uranium in the resin sample* indicating a fuel load of $3.3 \mathrm{~kg} .{ }^{3}$ Our $\mathrm{m}$ easurements and source modeling ranged from $2.7 \mathrm{~kg}$ to $6.1 \mathrm{~kg}$. The large range was caused by uncertainties in the source model.

D. Nevada/Nevada Test Site (NTS) (P. E. Fehlau, $K$. L. Coop, C. Garcia, J?., C. E. Moss, Q-2)

1. SNM Vehicle Portal Monitor. During calendar year 1983, we developed a microprccessur-controlled SNM vehicle portal monitor for NTS device assembly areas. ${ }^{4}$ This monitor (Fig. 1) is a gamma-ray detection system that senses radiation emitted by one or more of the nuclear components of a test device to detect removal of the item from the assembly area in a motor vehicle. In calendar year 1984, we completed evaluation

This information was provided by J. Thompson, TWX EG\&G ldaho/ TMI, May 22, 1984. of the prototype monitor, purchased a commercially fabricated duplicate of the prototype, and participated in plans to integrate both monitors into the NTS area perimeter security system.

Prototype monitor evaluation at Los Alamos consisted of intensity measurements for typical shielded and !nshielded weapos components passing through the monitor in motor vehicles. Recorded intensity profiles were analyzed to establish optimum parameters for the detection logic and to establish detection limits for shielded weapoi. components. Operational evaluation of a similar monitor installed at a US naval weapons storage facility provided information on the adequacy of iraining and documentation for operators and maintenance technicians, in addition to information on the adequacy of the monitor itself. This operational experience led io simplification of the monitur's occupancy sensor and elaboration of its calibration anc maintenance manual.

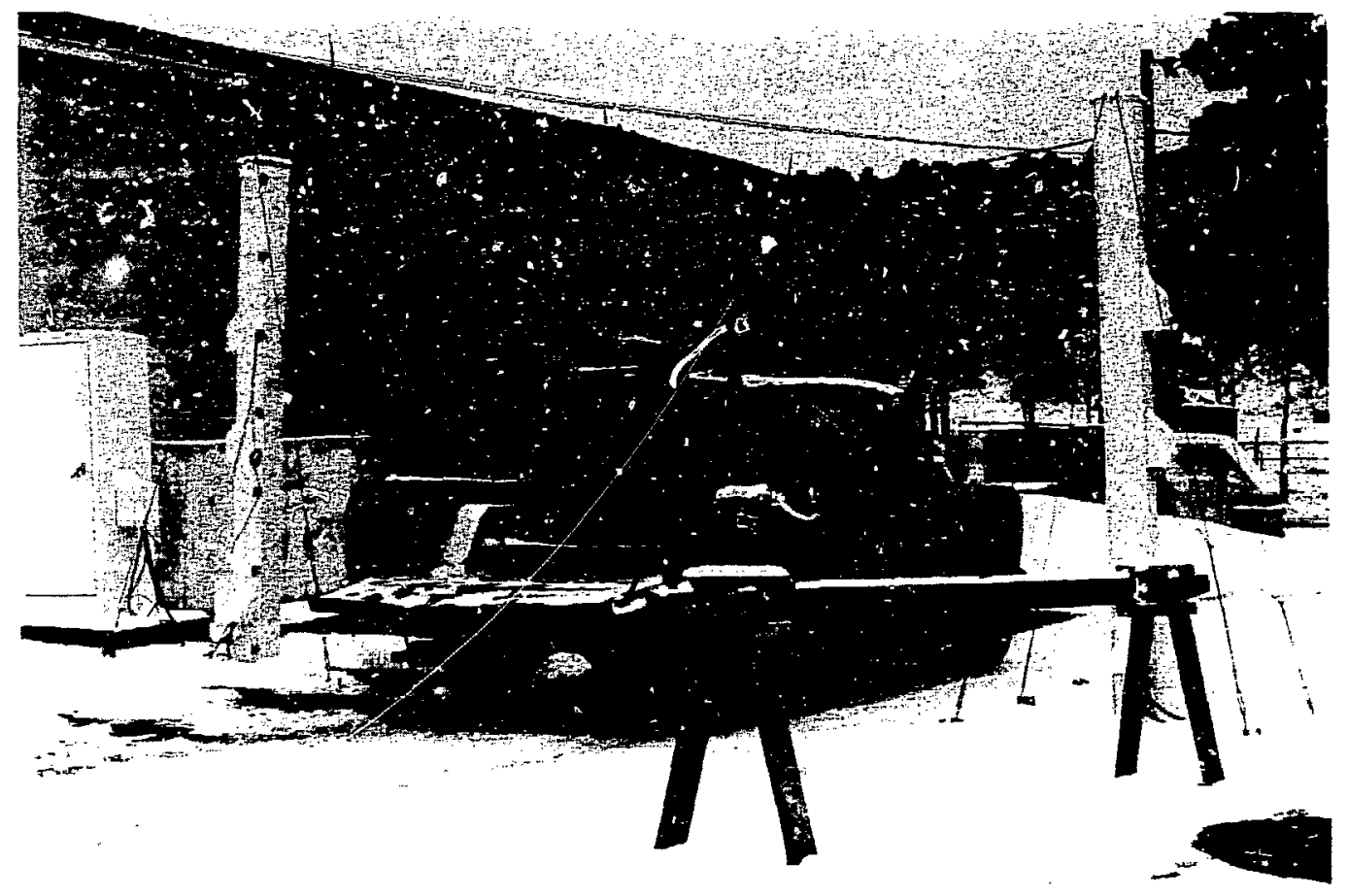

Fig. 1. The NTS vehicle SNM portal monitor to be installed furing Spring 1985 to detect removal of nuclear weapon components from device assembly areas. 
2. Device SNM Verification. Device verification by interrogation with electron linear accelerator (LINAC) radiation remains a candidats for further investigation as a rapid and accurate methud to assay independently the nuclear material contained in a nuclear device as it is being emplaced for a test shot. We anticipate a LINAC heing available at Los Alamos for preliminary evaluation of the technique within the next few months.

3. SNM Monitoring at Ground Zero. Hand-held monitors will be used to provicie SNM monitoring at grcund-zero locations during the short period between device emplacement and stot time. We developed a user's manual, for the hand-held monitors, that describes the monitors and the proper way to use them for searching pedestrians and vehicles. ${ }^{5}$ This manual is being used at NTS as a training aid, and we also have distributed it to other DOE facilities that use hand-held monitors.

E. Oak Ridge/Y'-12 Plant (P. A. Pusso, M. M. Stephens, G. Walton, Q-1)

1. Introduction. Los Alamos participation in the cooperative NDA insirumentation program with the Oak :2idge Y-i 2 plant operated by Martin Marietta Energy Systems has been effertive in upgrading NDA applied to nuclear materials accounting at the $\mathrm{Y}-12$ enriched uraniun scrap recovery facility. The $Y-12$ Nuclear Materials Control and Accounting (NMC and A) Department continues to provide technical liaison with other Y-12 organizations for maintenance, installation, and plant operation needs associated with new and existing Los Alamos instruments, in addition to sirect technical support in measurement control, calibration. and operational evaluation efforts for these instruments. In 1984 the program comprised four distinct efforts:

- maintenance and documentation of three Los Alamos NDA instruments in routine use,

- adaptation of an existing Los Alamos NDA monitor head for automated control of solventextraction system operation,

- evaluation of the correlation of EUREKA concentration with HEU inventory (an empirical model of the solvent-extractirn columns), and

- design of two new NDA instruments for holdup measurements at the scrap recovery facility.

2. Maintenance and Documentation of the EUREKA, Evaporator Monitor, and 2300 System
Monitor Instruments. The EUREKA instrument $t^{6-8}$ has been in routine use for monthly inventory of HEU in the 1300 serondary solvent-extraction system throughout 1984. Measurement control and update of the calibration normalization are carried out routinely by the Y-12 NMC and A staff. Yearly measurements of reference solutions in the standard cell for verification of the solution assay calibration are performed by Y-12 and Los Alamos. Final documentation of the EUREKA operatiorial evaluation by $Y-12^{9}$ and Los Alamos ${ }^{10}$ is now complete.

The uranium concentration monitor for the secondary intermediate evaporator ${ }^{6-8}$ also has been in routine use throughout 1984 for continuous, near-real-tirae readout of uranium concentration in the evaporator solution. The information readout is used by the operator for manual control of evaporator operation to avoid overconcentration and precipitation of uranium a former concern of high priority to the NMC and A organization. Measurement control, calibration normaiization, and calibration verification are carried oul as described for the EUREKA instrumint. Final documentation of monitor operatici ${ }^{11}$ and of the operational evaluation ${ }^{10,11}$ is now complete.

The uranium concentration monitor for the 230 . secondary solvent-extraction system ${ }^{6}$ has been in routine use throughout 1.984 for continuous, near-real-time readout of urenium concentration at two locations in the system. The information readout is used by the operator for manual control of the solvent-extraction system. Optimized operation can stabilize the syster inventory, reduce the average extraction column inven tory by a factor of 2 , and greatly reduce the concentra tion of HEU in the raffinate (waste) stream. All of thes possibilities are of interest to NMC and A. Because o concurrent efforts on the part of the Y-12 Developmen Division to test the feasibility of automatic control o the solvent-extraction system, the 2300 monitor wa designed to provide automatic readeut of the near-real time concentration results to the computer controllin: the automation. Measurement control, calibration nor malization, and calioration verification are carried ou as described for the EUREKA instrument. Fina documentation of the monitor operation and of th operational evaluation ${ }^{12}$ is now complete.

3. Adaptation of One of the $\mathbf{2 3 0 0}$ Monitor Measure ment Heads for Automatic Control of the Solvent-Ex traction System. The data obtained from the opera tional evaluation of EUREKA have had a substantia impact on the direction of the $Y-12$ program to evaluat the feasibility of automatic control of the solvent-extrac tion system. The variable acidity and uranium concen trátion of feed solutions have resulted in a large sprea in the inventory of HEU in the extraction column unde 
manual control. This is illustrated in Fig. 2, which shows the pulsed and static EUREKA concentrations vs column height for the extraction column of the 1300 solvent-extraction system. The area under each curve is proportional to the column HEU inveniory. Extraction column inventories determined by EUREKA vary from 3.9 to $10.3 \mathrm{~kg}$ of HEU. Excessively large or variable column inventories are $\mu$ roblems for both production and nuclear materials accountiug.

The Y-12 Development Division has been testing the capability for automatic control of the solvent-extraction system using the 2300 system (parallel to the 1300 system) extraction column. The Los Alamos 2300 monitor ${ }^{12}$ outputs were used, along with other near-realtime data, in this evaluation. The control scheme was designed initially to rely on the measured uranium concentrations of the organic extract and aqueous raffinate to govern the adjustment of the feed flow rate.

From Fig. 2, it is apparent that the organic extract concentration (EUREKA detector 6, at the top of the extraction column) is relatively independent of the column HEU inventory because the organic extract saturates even at the lowest HEU column loadings. The raffinate concentration (EUREKA detector 1 , at the bottom of the extraction column) will eventually reflect the inventory buildup, but this happens only gradually after the buildup has taken place. The data in Fig. 2 suggest this, but the experience during the initial automatic control has demonstrated it conclusively.

The concentration of uranium in a range of heights within the active portion of the extraction column is extremely sensitive to the column HEU inventory. The Y-12 Development Division recognized this fact from the EUREKA data and subsequently requested that the second head of the Los Alamos two-headed 2300 monitor be moved, from its original location where it measures the aqueous product concentration at the bottom of the backwash column, to the extraction column at a height of $160 \mathrm{~cm}$ from the bottom. This position on the 2300 system is equivalent to one-third the distance between EUREKA detectors 3 and 4 (third and fourth detectors from the bottcm, respectively) on the 1300 system extraction column. Because the eva!ıation of this monitor hear for aqueous product assay was complete, ${ }^{12}$ the detector u'as moved, and the calibration was adjusted to compensate for the change in acid

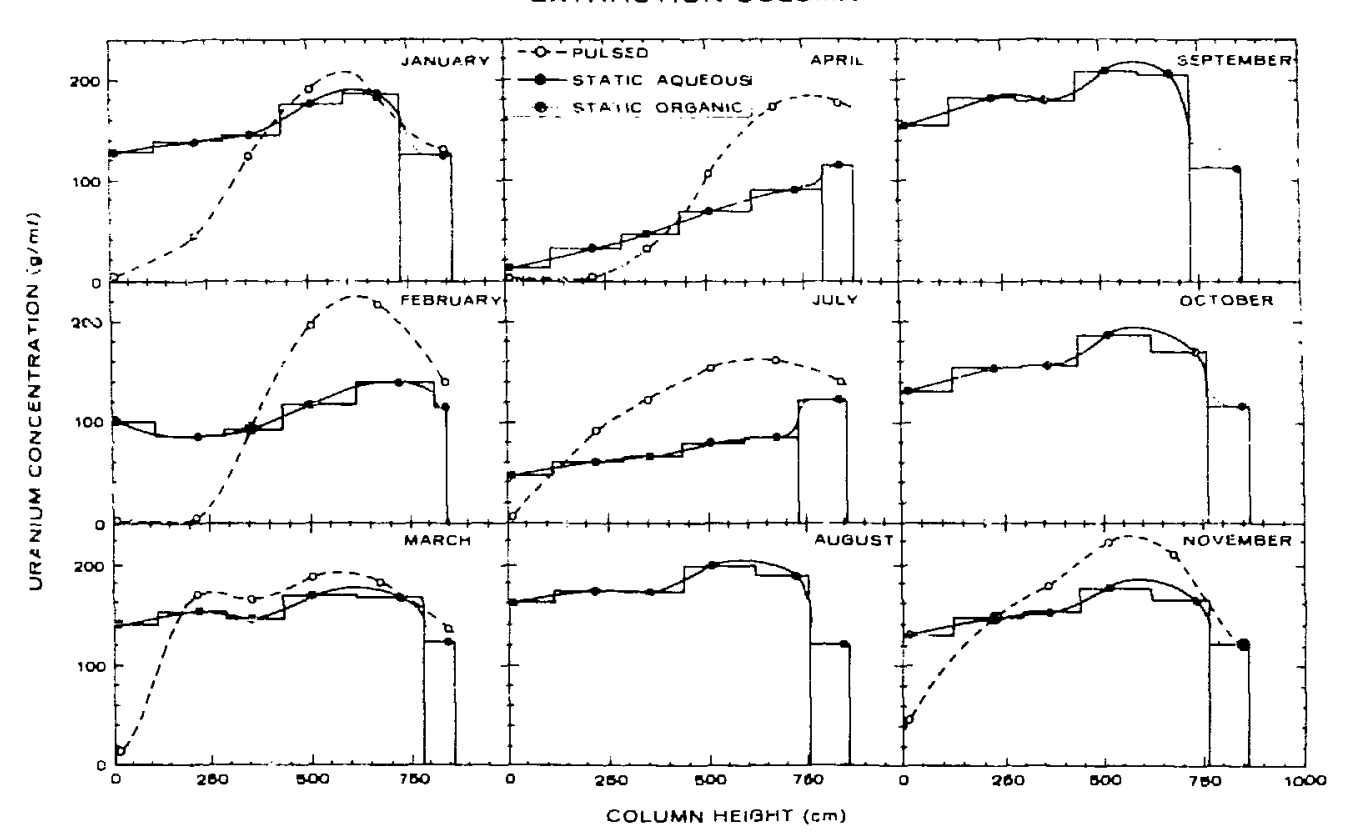

Fig. 2. Uranium concertration vs extraction column height for pulsed and static EUREK_A assays for HEU inventory. Smooth curves are drawn to approximate the pulsed and static profiles. The histograms used by the EUREKA code for inventory determination are shown for the static inventory data. The results shown correspond to the 1983 inventory measurements of the 1300 solvent-extraction system following operation for the indicated months. Pulsed measurements performed before shutdown for the June inventory are nut shown bscalise no static measurements were made for that inventory period. 
molarity, the two-phase rather than single-phase solution, and the presence of sieve plates at the new location. The Development Division has named this detector the "profile monitor."

Figure 3 shows uranium concentration as a function of time in the 1300 system extraction column raffinate, organ: $c$ extract, and "profile," measured during automatic control of the operation. The latter two measurements were performed by the two heads of the Los Alamos 2300 monitor. The raffinate concentration was measured by the photometric uranium monitor ${ }^{13}$ that is installed in a bypass on the raffinate stream. Also shown in Fig. 3 is the solution feed flow rate that was adjusted automatically during this test of the automatic control. The automation of the feed flow rate was based entirely on the near-real-time results prcvided by the profile monitor. ${ }^{14}$

The use of the profile monitor as the basis for automatic contrel of the cxtraction column is now specified for the Enriched Uranium Recovery Improvements (EURI) program. The Los Alamos instrument and assay designs are being reproduced, using the existing docunientation at $Y-12$, and implemented for EURI by the Y-12 Development Division. The noninirusive nature of the 2300 monitor has been the most impurtant factor in the success of this implementation.

\section{An Empirical Model of the Solvent-Extraction} Columns. We are evaluating the capability for the online real-time determination of the inventory of HEU in the solvent-extraction system and have examined an empirical correlation that relies on the sensitivity of the column HEU inventory to the average uranium concentration at a specific height in the active region of each column. Data from the ELREKA measurements on the 1300 solvent-extraction columins in 7 months of 1983 were searched for a correlation between the concentraLion measured by EUREKA detector 3 (third from the bottom of each column) and the column inventory determined by EUREKA. Figure 4 shows the results (inventory vs concentration) for the extraction column. Because the organic extract is saturated regardiess of the operating conditions, it is reasonable to expect a substantial constant positive term in the correlation for the extraction column. The solid line in Fig. 4 is the linear fit to the data.

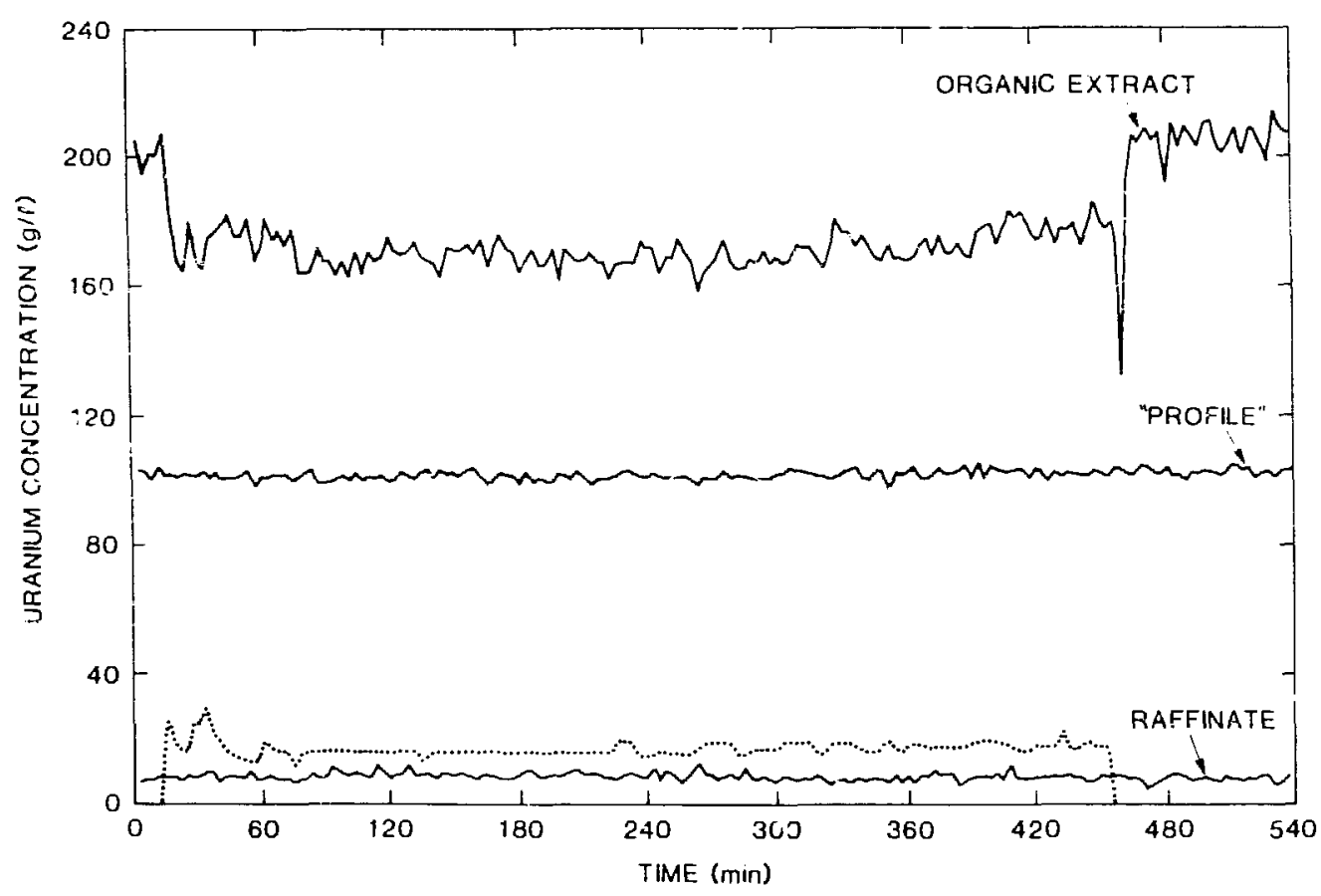

Fig. 3. The 2300 extraction column process data vs time for one 8-h shift when computerized automatic control of the column operation was in effect. The solid lines show the organir extract, "profile," and raffinate concentrations. The profile and the organic extract concentrations are measured by the two heads of the Los Alamos 2300 monitor. The dotted line indicates the feed flow rate (arbitrary scale). Feed flow is manually shut down by the operator between shifts. During this shutdown, automation is disabled. Automatic control of the feed fluw rate on the extraction column is based solely on the profile concentration readout. 


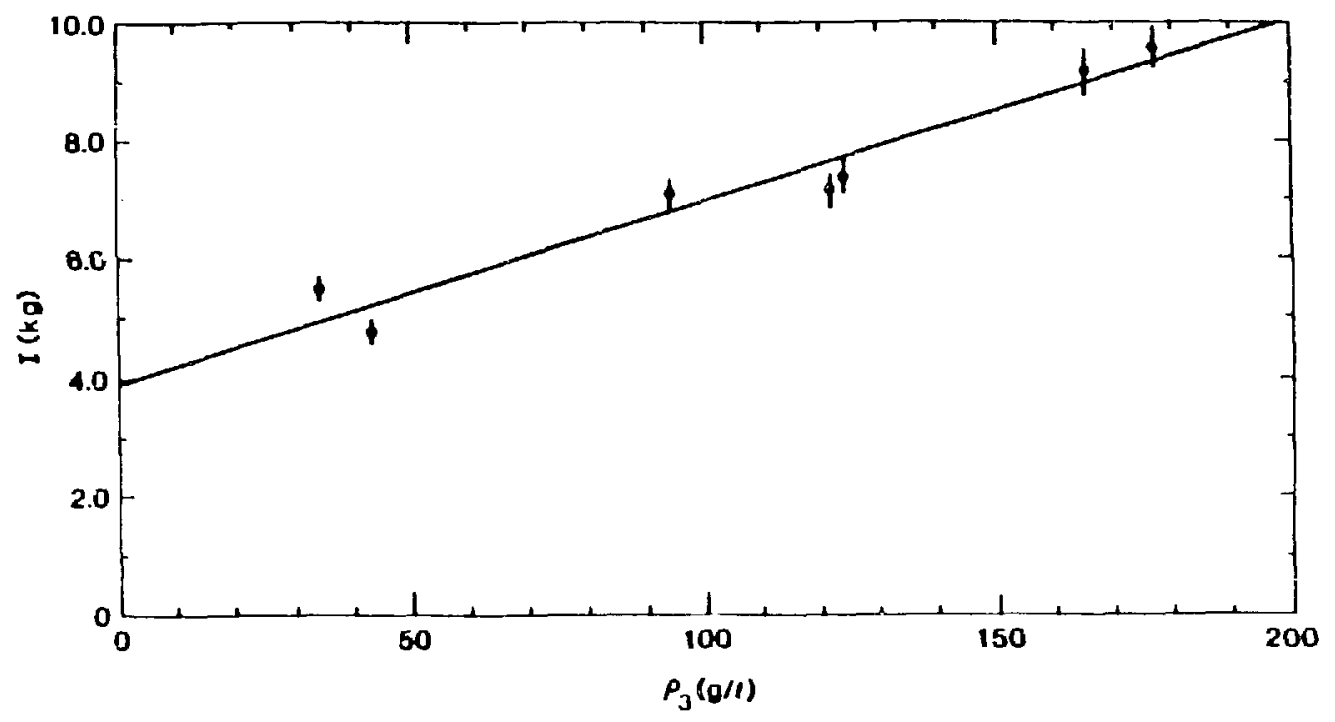

Fig. 4. Column inventory determined by ELREKA during pulsed operation vs ine EUREKA detector 3 concentration for the extraction column of the 1300 solvent-extraction system. The solid line is a linear fil to the data.

The average absolute per cent deviation between the seven measured inventories and the linear fit is $5.7 \%$. The $4 \%$ vertical error bars on the data points were obtained from an evaluation of the EUREKA static inventory measurements ${ }^{9.10}$ where $3.7 \%$ was the standard deviation in the relative inventory resuits (rario of EUREKA to coluran dump) ior 14 static single-column inventory comparisons. Because the randem ancertainty in the pulsed EUREKA inventory might be larger than that for the static inventory, the average absolute difference of $5.7 \%$ between the linear fit and the EUREKA measurements is an encouraging result.

Even more enccuraging are the analogous results of thw application of the same linear correlation between detector 3 and column inventory applied to the strip and backwash columns where the average absolute difference between the fit and the EUREKA result is $2.0 \%$ and $2.4 \%$, respectively. These results are summarized in Table I.

The overall agreement between the linear fit and the pulsed EUREKA inventory measurements of the individual columns is as good as might be expected, given uncertainties in the EUREKA inventory results. This is promising because manual operation of the 1300 system has resulted in large variations in the column inventories $( \pm 24 \%$ and $\pm 28 \%, 1 \sigma$, for the extraction and backwash columns, as shown in Table I). If column inventories were more stable, which is likely with the implementation of automatic control, the agreement should improve.
The NMC and A organization will paricipate in a joint evaluation with Los Alamos of near-real-time solvent-extraction system HEU inventory determination. Empirical correlations such as those just described will be tested with additional data that will be obtained during pulsed operation of the manually controlled 1300 solvent-extraction system. Meanwhile, brackets and clamps fo- EUREKA detectors will be mounted on the 2300 solvent-extraction system. The correlations will then be evaluated on the automatically controlled system. The success of such an evaluation could lead to

\section{TABLE I. Summary of Correlations Between Eureka Concentration and Column Inventory}

\begin{tabular}{|c|c|c|c|}
\hline & \multicolumn{3}{|c|}{$\begin{array}{c}1300 \text { System } \\
\text { Solvent-Extraction Column }\end{array}$} \\
\hline & Extraction & Strip & Backwash \\
\hline $\mathbf{1}, \mathbf{k g}$ & 7.26 & 8.68 & 3.75 \\
\hline $1 \sigma(I)_{\mathrm{REI}}, \%$ & 24 & 5.1 & 28 \\
\hline$\overline{\mid \text { Fit }-} \overline{I \mid+I, \%}$ & 5.7 & 2.0 & 2.4 \\
\hline
\end{tabular}


a substantial reduction in the number of detectors required to deduce the solvent-extraction system inventory.

The effectiveness of computerized chemical models of pulsed columns ${ }^{15}$ for prediction of column inventories can also be evaluated using the data obtaine? from these planned exercises on the automatically controlled solvent-extraction system. However, because the automation is geared toward a stabilized product (rather than stabilized feed), variations in HEU concentration and acid molarity of feed solution batches may limit the periods of steady-state operation during which the chemical models can be anolied.

\section{Design of Two New NDA Instruments for Meas- urement of HEU Holdup.}

a. The Chip Burner Filter Monitor. Ass mbly of the electronics and fabrication of mechanical hardware for an automated real-time monitor of HEU hoidup in the metal chip bumer filter at the scrap recovery facility are in progress. The three-headed Nal-based monitor will provide a continurius readout of the mass of HEU accumulated in the filter system. Because of the erratic nature of particulate buildup resulting from this burning process, th- measurement has been requested for criticality safer $y$ : well as nuclear materials accounting. The monitor alarm will be designed to signal HEU buildup that approaches $1 \mathrm{~kg}$.

Preliminary calibration of the detectors will be performed using a variable-mass filter standard that has been fabricated and characterized by the $Y-12$ NMC and A persct.nel. The tinal calibration will be based on data with the in-line monitor inst-alled on the chip burner filter. Reference values will be obtained by segmented gamma scanninis of the filters removed from the process. Installation for operalional evaluation at $\mathrm{V}_{-} 12$ is scheduled for 1985 .

b. The Powder Transfer Holdup Assay Instrument. We have completed the mechanical design for a portablc instrument to measure holdup of HEU in the powder-transfer piping of the fluid bed converter processes at the scrap recovery facility. The NaI measurement head will be mounted on an extender pols. The detector will attach to the pipe by a tungsten holder that also serves as a radiation shield.

The powder-transfer piping varies in diameter from 1 to $2.5 \mathrm{in}$. The total length of the piping is approximately $200 \mathrm{ft}$. The nicasurements will be performed at prescribed, marked locations along the piping. Appropriate locations will be determined during the operational evaluation of the instrument.

Automation of the measurement will be accomplished using a portable microprocessor-based multichannel analyzer. This equipment sits on a cart that is pushed to each measurement location. The meas- urement head also will reside on the cart when not in position for a pipe measurement.

Calibration of the quantitative assay will be based on measurements of known standards. Interpolation between measurement points will be performed automatically. During the operational evaluation, the holdiup results determined by the instrument will be compared with the external assay of material that is flushed out of the powder transfer lines. Insiallation for operational evaluation at Y-12 is scheduled for 1985 .

\section{F. Dak Ridge/Portsmouth Gaseous Diffusion Plant (GDP)}

1. Inventory Difference Contributions from Waste Streams (R. G. Gutmacher, D. Stirpe, Q-4; R. R. Picard, S-I1; G. W. Eccleston, Q-1; L. S. Blair, CHM-DO; D. A. Cremers, CHM-4). Normal quar:ities of uranium in waste streams at the Portsmouth Gaseous Diffusion Plant are small relative to plant throughput, but not small relative to inventory differences. Historically, the uranium loss has not been credited to the materials accounting uncertainty but appears in the cumuiative inventory difference for the plant. We have studied the waste streams-solutions from decontamination of equipment, vent gas releases, chemical trap materials, contaminated oils, and combustible waste--and have examined and evaluated present and past sampling and analysis practices.

A report ${ }^{16}$ summarizing the results of this study was issued in April 1984. We concluded that errors in flow measurements of the waste solutions and vent gas releases produce the largest contributions to the overall uncertainty. Sampling errors are important for all waste streams. While flow measurement and sampling errors cannot be quantified at present, errors in analytical laboratory measurements are well known and well controlled. New instrumentation for flow measurement and better sampling practices are needed if major improvements in materials accounting for waste are to be realized. The report contains specific recommendations and suggestions for instrumentation that can continuously measure the uranium concentration in vent gas sireams.

We submitted a proposal to design, construct, and instal 3 an engineered proto $i$ pe instrument in July 1984. The instrument would provide accurate measurement of uranium losses in gascous effluents during excursions as well as under normal operating conditions. It would employ one of two atomic emission spectroscopic techniques: laser-induced breakdown spectroscopy (LIBS) or inductively coupled plasma (ICP) spectrometry. Atomic emission spectroscopic techniques have two 
advantages for this application. The rich uraninil emission spectrum makes it highly probable tha: uranium lines free of spectral interferences can be selectec for monitoring. In a vent stream, uranium may be preseni as various chemical rompounds, such as fine particles of uraryl difluoride, in addition to gas:ous uranium hexaflvoride. Atomic emission spectroscopic techniques, however, are compound insensitive but element specific.

A discussion of these spectroscopic techniques, as well as the design criteria and the steps to be taken in the development of a prototype instrument, was preserited at the Gaseous Effluent Analytical Instrumentation Information Meeting ${ }^{17}$ The techniques also may be suitable fo- measurement of uranium and other constituents of gaseous effluznts from other DOE facilities besides gaseous diffusion plants.

2. Holdyp Measurements (R. H. Augustson, Q-1). The holdup ! neasurements made in the Goodyear Atomic Gaseous Diffusion Plant have been described and summarized.

3. Active-Well Coincidence Counter (AWCC) Applications (J. E. Stewart, H. O. Menlove, Q-1). In April 1984, we went to the Portsmoutin Gaseous Diffusion
Plant, operated by Goodyear Atomic Corporation (GAC), to test an $\mathrm{AWCC}^{18}$ for two measurement applications: self-interrogation of $U_{6}$ cylinders and active assay of spent alumina trap material.

For the first application, the AWCC was configured as a passive well counter with a removable cadmium liner and with the active end plugs removed. A set of $305 \mathrm{~A}$ $U F_{6}$ cylinders containing very highly enrichea uranium (VHEU) were selected for passive measurements. The self-interrogation technique ${ }^{19}$ infers a direct fissile assay from the random (in time) neutrons produced in $(a, n)$ reactions in the $U F_{6}$. These random neutrons cause some ${ }^{235} \mathrm{U}$ atoms to fission, releasing nevtrons in bursts that can be counted using coincidence circuitry. The rate of coincidence events is thus a measure of the inssile conient of the sample and is obtained without an external driving source. The ratio of the real-coircidencecounts to totals-counts $(R / T)$ is !1sed as a signature of ${ }^{235} \mathrm{U}$ mass that is independent of the $(\alpha, n)$ neutron source strength in the sample.

The fissile resfonse $(R / T)$ is influenced by the bulk density and fill height of $U_{6}$ in the sample. The chringe in totals neutron couni rate from the sample due to removal of the cadmium liner can be used to correct $R / T$ tor bulk density and fill height changes. Figure 5 shows the relationship between $\mathrm{R} / \mathrm{T}$ (with the cadmium

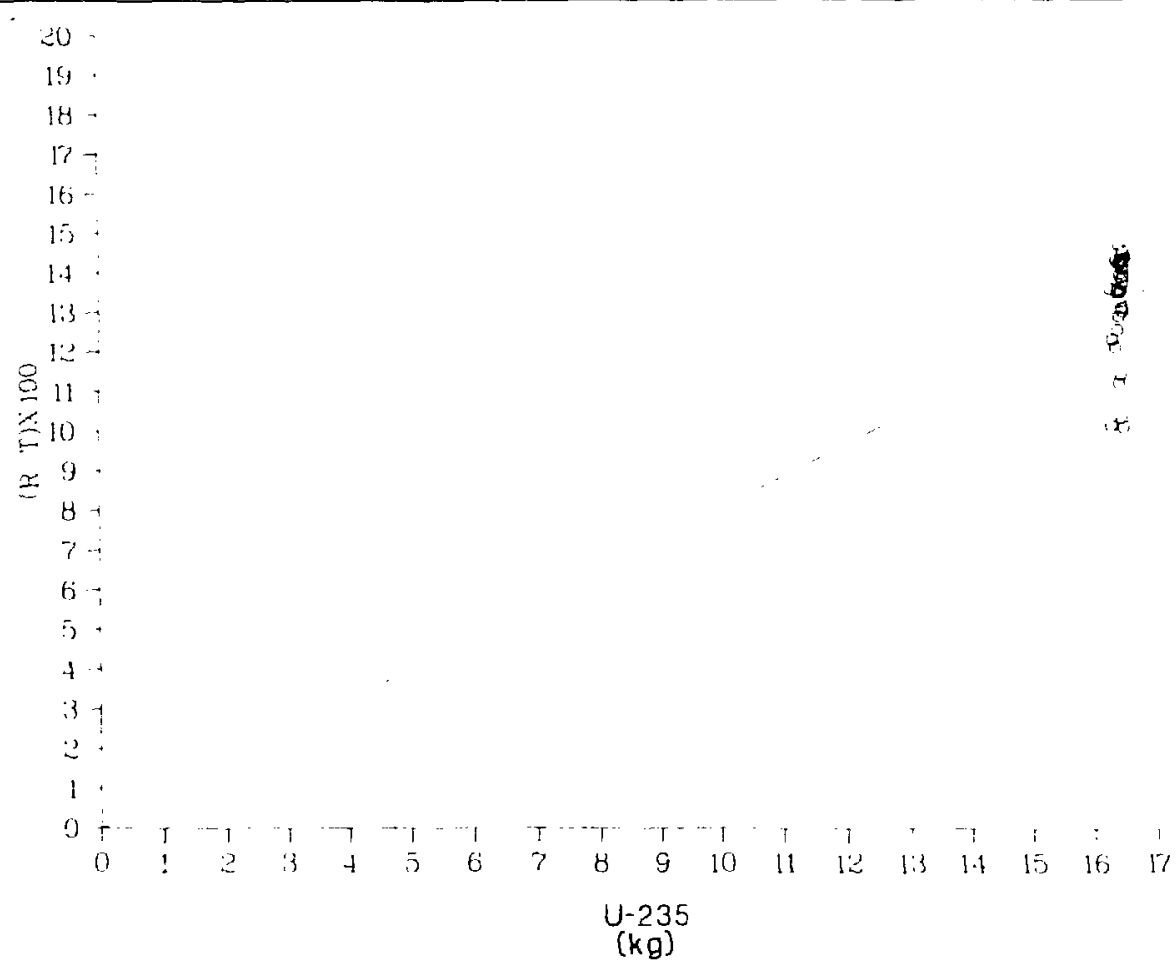

Fig. 5. Reals-tu-lotals passive fissile signalure with cadmium liner in place for $305 \mathrm{~A} \mathrm{UF}_{6}$ cy'inders containing VHEU. 
liner in place) and ${ }^{235 \mathrm{~J}}$ mass. The estimated assay accuracy (assuming a linear fit through the origin) is $10 \%(1 \sigma)$. This large scatter is attributed primarily to bulk density and fill height differences among the 30 samples. Figure 6 shows corrected R/T vs fissile mass. The correction ${ }^{19}$ involves an additional passive measurement of the cylinder with the cadmium liner removed. The assay accuracy of $\mathrm{R} / \mathrm{T}$ (corrected) is $2.5 \%$ $(1 \sigma)$. Results of these measurements led to acceptance of a proposal for a receipts assay monitor (RAM) for measurement of VHEU at the Savannah River Plant (SRP). Also, GAC nas expressed interest in using the technique for previously irradiated materials that present difficulties for gamma-ray-based NDA because of fission products.

The second AWCC application tested was the assay of the fissile content of spent alumina chemical trap material. Both passive and active assay modes were tested. In the passive mode, the active end plugs were removed, and the $R / T$ response was measured both with and without the cadmium liner. Results are shown in Fig. 7. From the standpoint of counting statistics, the $(R / T)_{\text {no } C d}$ response is preferred over $(\mathrm{R} / \mathrm{T})_{\mathrm{Cd}}$ because counting rates are higher. However, the $(R / T)_{n o} c$ response is more suhject to self-shielding effects than is $(R / T)_{C d}$. For the former, the assay accuracy is approximately $10 \%$ ( $1 \sigma)$. This is determined from tag values obtained at the facility. The tag values are not known with high accuracy, although they are consistent with our NDA results with two exceptions. Counting times varied between 200 and $600 \mathrm{~s}$.

In the active mode, a specially fabricated source holder was used in the sample cavity. Two AmLi neutron sources were located along an axis perpendicular to the sample axis. This arrangement is shown in Fig. 8. These measurements were made in the thermal-interrogation mode (no Cd liner). Results are shown in Fig. 9 and are consistent with the passive results. Assay accuracy $(1 \sigma)$ is $\sim 10 \%$ for the $(R / T)_{C d}$ response. Counting times were from 200 to $500 \mathrm{~s}$. Generally, the active method allows shorter counting times for the same measurement precision. However, the passive methisi allows for a more uniform fissile in: in thion because the interrogating source nicutrons are homogeneously distributed in the sample.

The AWCC unit used for these tests was loaned to GAC for 4 months. Approximately $905 A$ cylinders were verified during the loan period. These contained VHEU and previously irradiated materials. GAC is interested in acquiring an $A W C C$ for verification and accountancy

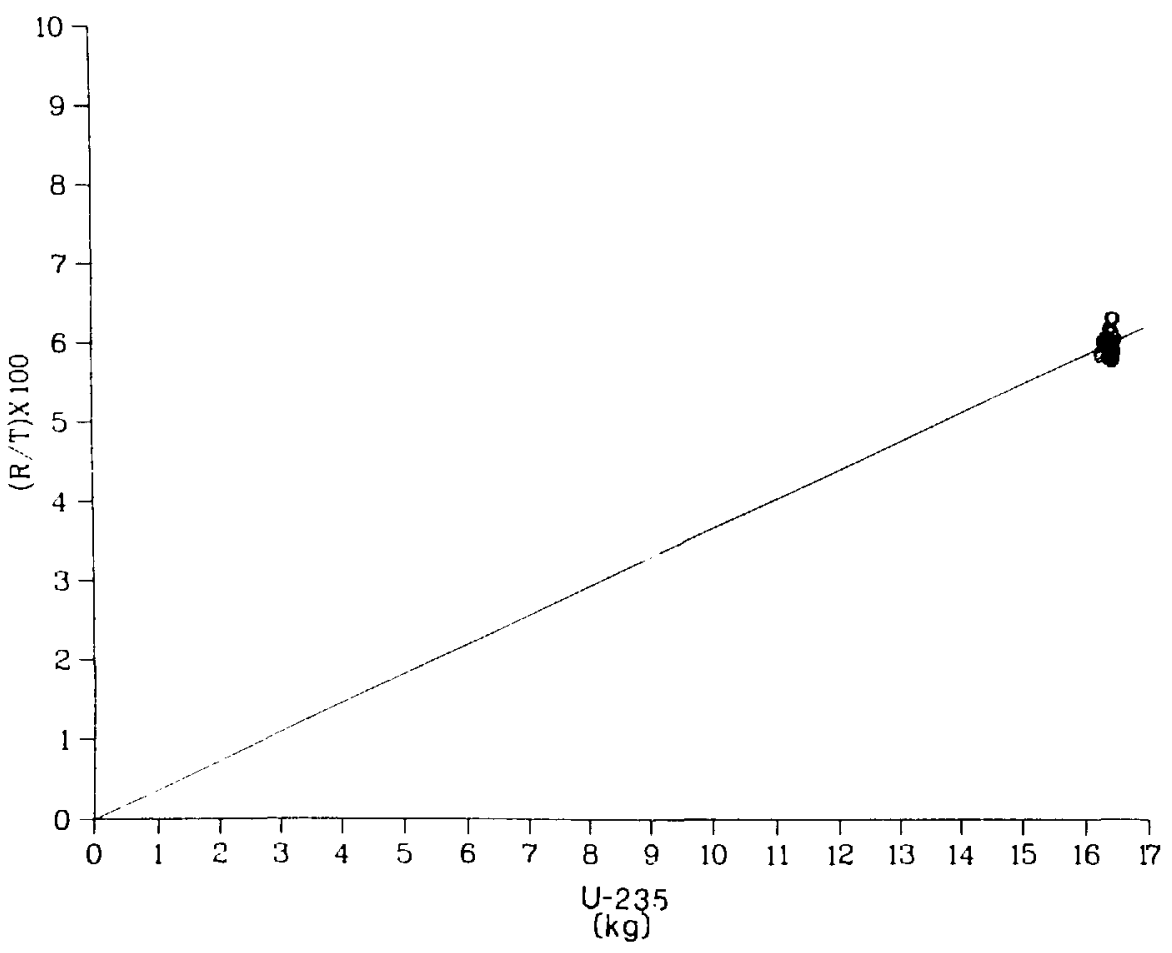

Fig. 6. Reals-to-totals passive fissile signature with cadmium liner in place for $305 \mathrm{~A} \mathrm{UF}_{6}$ cylinders containing VHEU. Results have been corrected using cadmium-difference technique. 


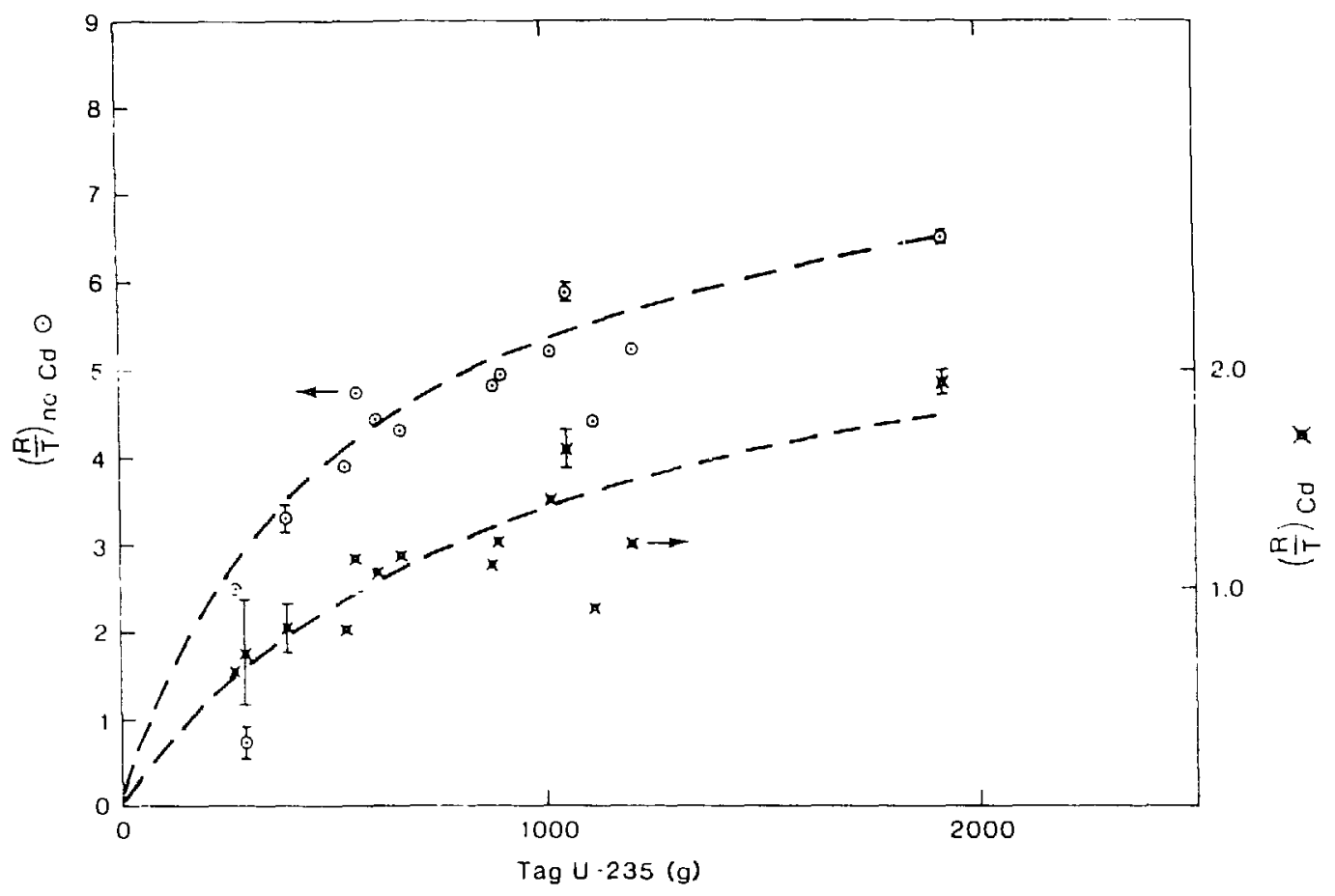

Fig. 7. Reals-to-totals passive fissile signatures for 14 spent alumina trap material containers ("asparagus cans") with and without cadmium liner in counter cavity.

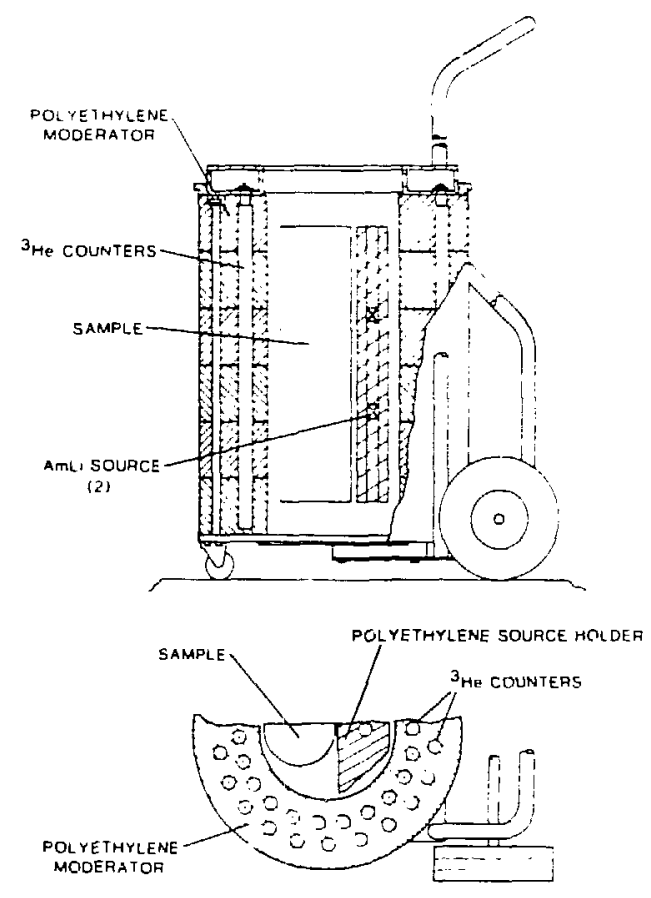

Fig. 8. Schematic oî AWCC showing sample and source holder arrangement for active assay of spent alumina trap material containers. 


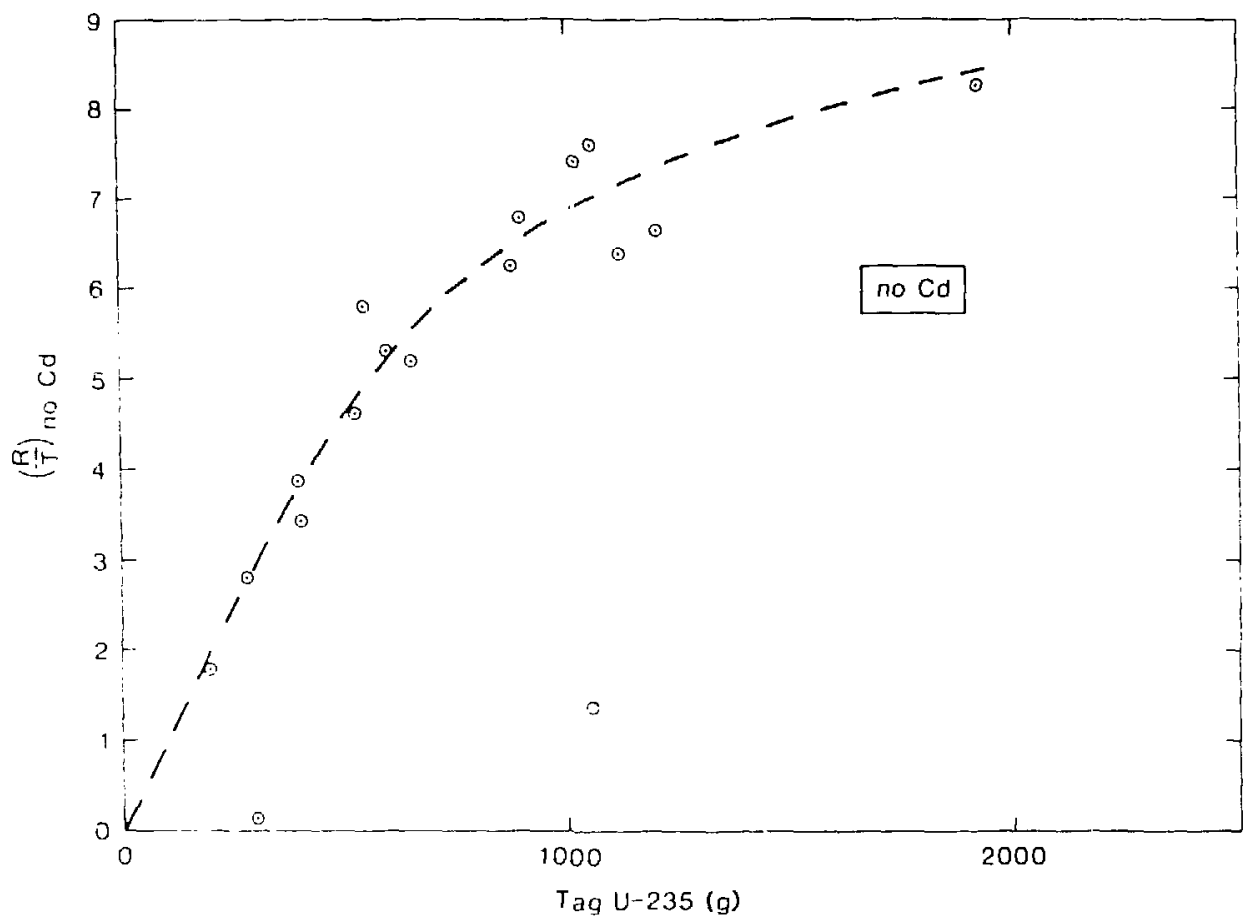

Fig. 9. Reals-to-totals active fissile signature for 14 spent alumina trap miaterial containers without cadmium liner in cavity.

measuremenis of these cylinders and of spent alumina trap containers. The unit would thus be used in both the passive (cylinders) and active (trap material) modes.

With coincidence counters at both GAC and SRP, shipper-receiver values could be confirmed easily for $5 \mathrm{~A}$ $\mathrm{UF}_{6}$ cylinders containing VHEU.

G. Oak Ridge/Portsmouth Gas Centrifuge Enrichment Plant (GCEP): Crated Waste Assay Monitor (CWAM) (J. T. Caldwell, W. E. Kunz, E. D. Shunk, W. Bernard, H. F. Atwater, J. M. Bieri, G. S. Brunson, K. L. Coop, S. W. France, R. D. Hastings, G. C. Herrera, Q-2)

We completed a detailed final design and the major portion of construction of the CWAM during 1984. This assay instrument will be the primary uranium waste accountability tool at GCEP. Waste forms scheduled to be assayed include (1) spent alumina from $\mathrm{UF}_{6}$ chemical traps; (2) nonburnable solids such as reject equipment; (3) burnable solids such as gloves, shoe covers, rags, and wipes; and (4, liquids from decontamination and related operations. Waste packages will be either wooden cubic boxes ( $1.3 \mathrm{~m}$ on a side) or standard $208-8$ steel drums.

The final design of this system contains a,$\angle$-idded cylinder-like assay chamber lined with granhite and polyethylene for neutron moderation. The sides, top, and bottom are individual aluminum-framed modules that are interconnected and secured after assembly. Figure 10 shows several of the individual modules partiaily assembled. The final assembly will be $2.62-\mathrm{m}$ high and have an outer diamet or of $2.84 \mathrm{~m}$.

To enhance assay accuracy (targe $c$ goals are $\pm 20 \%$ for the $1.3-\mathrm{m}$ cube boxes and $\pm 10 \%$ for $208-\ell$ drums), all waste packages will be rotatiu in the assay chamber during measurement. This will produce a considerably more uniform irradiation than is possible in a stationary geometry.

The large waste boxes will be moved into the assay chamber with an air pallet loading fixture. The 208- $\ell$ drums will be moved with a standard loading dolly. Specially designed package position sensors will assure proper centering of the waste packages prior to rotation.

Assay rneasurements in the CWAM are accomplished with an in:ernal, pulsed 14-MeV neutron irradiation produced by a $10^{6}$ neutron-per-pulse zetatron neutro 7 generator. The ${ }^{235} \mathrm{U}$ assay is based on the differential dieaway technique. ${ }^{20-25}$ In this method, the original pulse of $14-\mathrm{MeV}$ neutrons is moderated within the graphite and polyethylene walls of the assay chamber, and in the time domain from approximately 0.5 to 5.0 ms following each pulse, the resulting thermalized neutrons produce fission reactions in ${ }^{235} \mathrm{U}$. The resulting prompt fission neutrons are measured with specially 


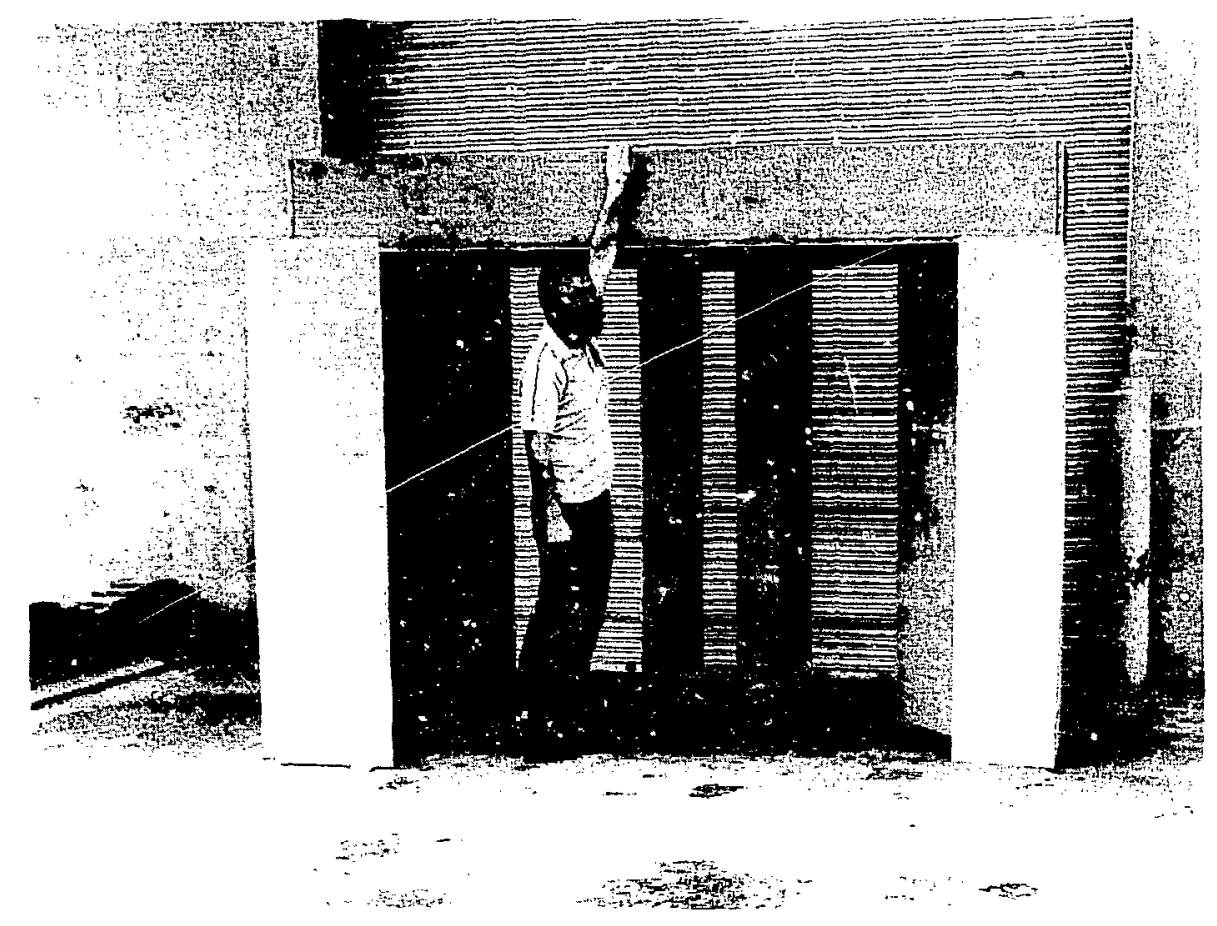

Fig. 10. Several of the CWAM modules partially assembled. Total height will be $2.62 \mathrm{~m}$, and outer diameter will be $2.84 \mathrm{~m}$ when totally assembled.

designed fast neutron detectors embedded in the assay chamber walls. These detectors are insensitive to the interrogating thermal neutrons to about 1 part in $10^{8}$ bu: are sensitive to prompt fission spectrum neutrons to about 1 part in 10.

Concurrently with the differential dieaway measurement of ${ }^{235} \mathrm{U}$, the initial pulse of $14-\mathrm{MeV}$ neutrons also produces direct fast rieutron fission reactions in ${ }^{238} \mathrm{U}$. For the expected low-enriched material at GCEP $(<5 \%)$, these high-energy fission reactions in ${ }^{238} U$ will produce a delayed neutron flux that can be readily distinguished from the corresponding delayed neutron flux produced by the differential dieaway thermal neutron reactions in ${ }^{235} \mathrm{U}$.

Both the prompt neutron flux $\left({ }^{235} \mathrm{U}\right)$ and delayed neutron flux $\left({ }^{238} U\right.$ plus ${ }^{235} U$ ) are measured in a single multichannel scale (MCS) time history record of the system's fast neutron detectors. An example of this is shown in Fig. 11 , which is an experimental record (200-s irradiation) of $1 \mathrm{~kg}$ of depleted uranium placed in a $208-\ell$ drum of alumina trap filter material. The measurement was performed in a $14-\mathrm{MeV}$ differential dieaway assay system similar to the CWAM. The MCS time history shown covers the period up to $10 \mathrm{~ms}$ foliowing each initial $14-\mathrm{MeV}$ pulse. The initial 0 - to 0.5-ms period is dominated by detection systei, iccovery from the direct effects of the $14-\mathrm{MeV}$ pulse. The time period trom 0.5 to $5 \mathrm{~ms}$ is dominated by prompt fission neutron detection $\left({ }^{235} \mathrm{U}\right.$ thermal fission events), and the time period from 5 to $10 \mathrm{~ms}$ is dominated by delayed neutron detection events from both ${ }^{215} \mathrm{U}$ thermal fission and ${ }^{238} \mathrm{U} 14-\mathrm{MeV}$ fission. The pulsed fission kinematics are such that the expected delayed neutron response is constant in the "between pulses" time scale shown. The observed prompt neutron response mirrors the interrogation thermal neutron flux dieaway time, which for typical CWAM measurements will have a lifetiri $z\left(T_{1 / 2}\right)$ in the range from 0.5 to $1.0 \mathrm{~ms}$. The prompt fission neutron yield provides a direct measurement of ${ }^{235} \mathrm{U}$ mass. ${ }^{20-25}$ For the CWAM design, ${ }^{26,27}$ the expected minimum detectable ${ }^{235} \mathrm{U}$ mass will be in the range from 10 to $20 \mathrm{mg}$.

The ${ }^{238} \mathrm{U}$ mass will be determined from the promptto-delayed ratio measured during each assay. Figure 12 shows a normalized experimental prompt-to-delayed ratio plotted as a function of ${ }^{235} \mathrm{U}$ enrichment. The experimental data have been normalized to the expected CWAM 14-MeV and thermal neutron interrogation fluxes. The prompt-to-delayed ratio is a very sensitive function of ${ }^{235} \mathrm{U}$ enrichment in the expected GCEP 


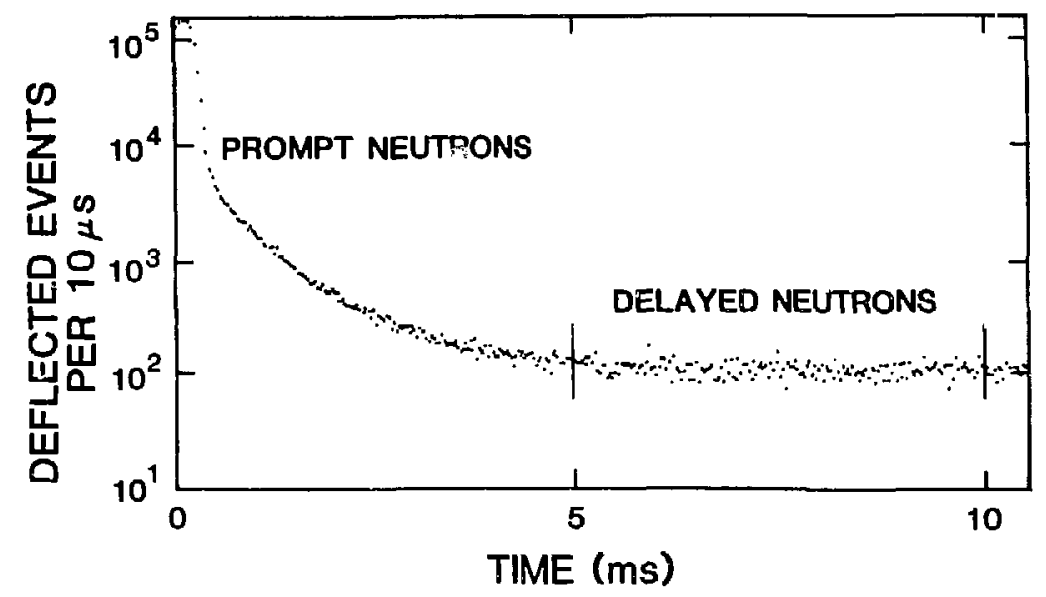

Fig. 11. Time multiscale spectra of a typical differential dieaway measurement of depleted uranium. The time region of 1 to $5 \mathrm{~ms}$ is produced primarily by ${ }^{235} \mathrm{U}(\mathrm{n}, \mathrm{f})$ prompt fission neutrons, and the region of 6 to $10 \mathrm{~ms}$ is produced primarily by the ${ }^{238} \mathrm{U} 14-\mathrm{MeV}$ fission delay of neutrons.

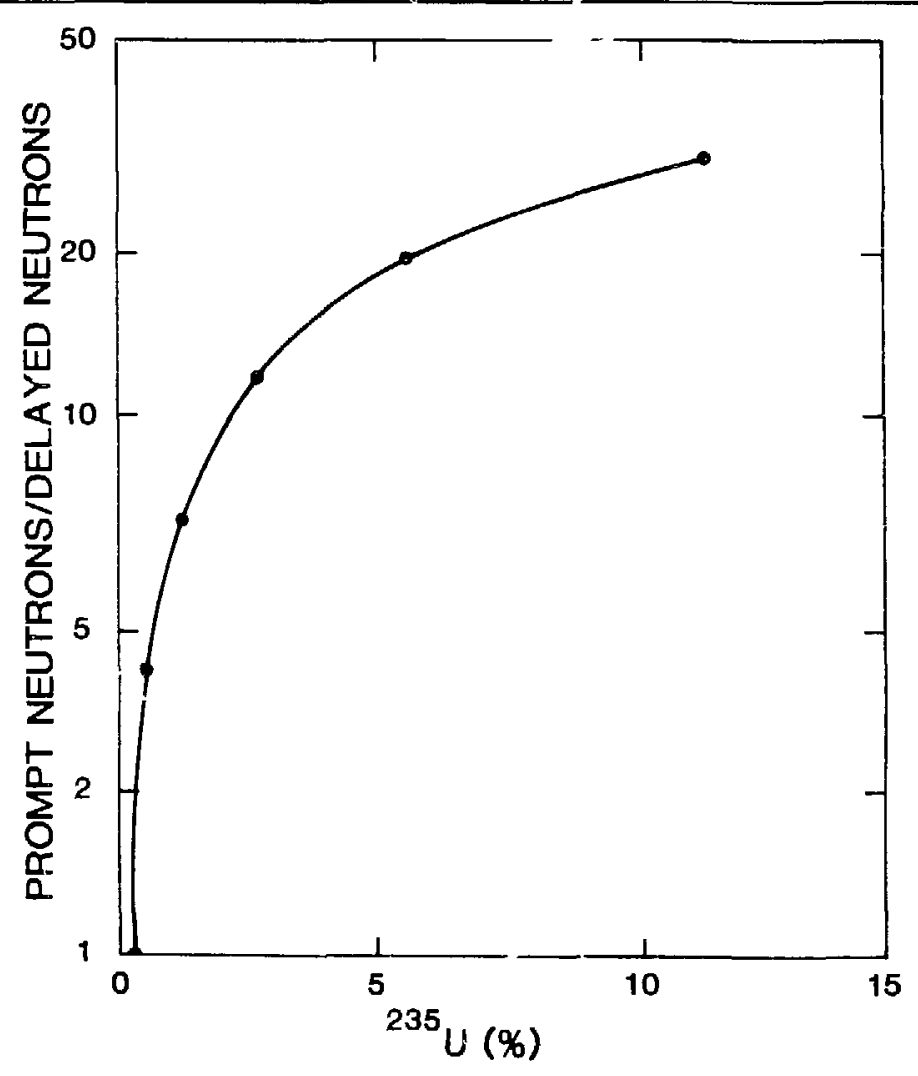

Fig. 12. Plot of the anticipated prompt-to-delayed ratio for the $\mathrm{CWAM}$ as a function of ${ }^{235} \mathrm{U}$ enrichment. 
operating range from 0.2 to $5.0 \%$. The minimum detectable ${ }^{238} \mathrm{U}$ mass in typical $208-\ell$ aluminum waste drums is expected to be about $500 \mathrm{~g}$.

Final assembly of the CWAM was under way at the end of 19.4. . Checkout and calibration measurements at Los Alamos are scheduled fe: the firct half of 1985 with delivery, setup, test, and evaluation at Portsmouth scheduled for the second half of 1985 .

\section{H. Richland/Fuel and Materials Examination Facility (FMEF)}

1. Secure Automated Fabrication (SAF) Line (R. G. Gutmacher, J. F. Hafe:, Q-4). We have carried out computer modeling and simulation of fuel-pin operaticus to assist Westinghouse Hanford Company in the design of the materials axcounting system for the SAF line at FMEF. In the fuel-pin operations, columins of mixed-oxide fuel pellets are formed and placed in cladding tubes that have the lower cold components and bottcm end caps already in place. The upper cold components are then loaded, and line end of the pin is decontaminated. The pins are evacuated, backfilled with pure helium, and transferred to Pulsed Magnetic Welding, where the tag-gas capsules and end caps are inserted into the pin and the end cap welded. After decontamination, the entire pin is checked by alpha monitoring to verify that there is no exterior contamination. The pins are then loaded into a shipping container where a helium leak test is performed.

We modeled evacıation and backfill cycles of 1,2 . and $4 \mathrm{~h}$. Although equipment failures could not be included because no estimates of failure rates and repair times wesc available, pin iejections at contamination monitoring points were incorporated. The simulation results (Table II) indicate that annual throughput is relatively insensitive to evacuation and backfill time. Bottlonecks in thi fuel-pin operations are related to the limited capacities of the fuel-pin transport ramps,

TABLE II. SAF Line Fuel-Pin Operations: Output vs Evacuation and Backfill Time"

\section{Evacuation and \\ Backfill Time}

(h)

Finished Pins/yr

$\begin{array}{ll}1 & 45430 \\ 2 & 45100 \\ 4 & 44550\end{array}$

"Model includes rejection mechanisins but not equipmen: failares. especially the lower ramp, which is filled close to capacity most $\mathrm{cf}$ the time, and to the time required for welding and extericr decontamination of a fuel pin. However, in all cases, the indicated yearly throughput is greater than 44500 fuel pins, which exceeds the $6000-\mathrm{kg}$ annual production requirement. Estimates of equipment failure rates and repair times that became availaile in 1984 will be incorporated in:o the computer simulation.

The SAF line powder and pellet operations underwent another major revision by Westinghouse Hanford Company design engineers during 1984. New process flow diagrams, a description of the new operating scenario, new estimates of equipment failure rates and repair times, and new information on measurements became available in November/December 1984. The information needed to assist Westinghouse Hanford Company in the design and evaluation of the materials accounting system is now at hand, and the project should be completed during 1985.

2. Measurement of Uranium/Plutonium Blending Retio (G. W. Nelson, S. - T. Hsue, T. E. Sampson, Q-1; R. G. Gutmacher, Q-4). Preparation of a batch of mixed oxides in the SAF line involves metering of the appropriate quantities of $\mathrm{UO}_{2}$, recycled mixed oxide, and $\mathrm{PuO}_{2}$ for a hali batch, using íced and weigh hoppers. The two half batches are combined $n$ a vee shell blender, where they are thoroughly mixed. Nieasurement of the uranium/plutonium ratio on the blended $(\mathrm{U}, \mathrm{Pu}) \mathrm{O}_{2}$ powder is required for both process control and maierials accounting to verify that the correct ratio was achieved and that the blend is homigeneous. Such measurements are conventionally made by taking samples of the blended powder and performing chemical analyses. To avoid sampling and to provide results more rapidly, thus minimizing production delays, a nondestructive method of analysis is desired. We have investigated the application of the "enrichment mu ter" principle to determination of the uran um/plutcnium blending ratio.

The enrichment meter principle, first discussed by Reilly, Walton, and Parker in $1970,{ }^{28}$ determines the ratio of ${ }^{235} \mathrm{U}$ to uranium by measuring the number of 185.7-keV gamma rays of ${ }^{235} \mathrm{U}$ that leave a thick homogeneolis sample of a uranium compound or metal. Because all uranium isotopes atteriuate the gamma rays identically, the cnrichment is directly proportional to the number of ${ }^{235} \mathrm{U}$ gamma rays. We have tested the extension of the principle to measurement of the uranium/plutonium ratio in well-characterized samples of homogeneous (U,Pu) $\mathrm{O}_{2}$ powders by determining the number of gamma rays from ${ }^{239} \mathrm{Pu}$ and ${ }^{241} \mathrm{Pu}$ that leave the sample. Because uranium and plutonium have different mass attenuation coefficients, the number of 
gamma rays from a plutonium isotope is not directly proportional to the mass fraction of that isotope. However, the uranium/plutonium mass ratio may be calculated using an algorithm that contains a calibration constant. This calibration constant must be determined for each gamma ray by measurements on a single reference material whose uranium/piutonium ratic is accurately known.

Our measurements were made on samples of (U,Pu) $\mathrm{O}_{2}$ powcier, supplied by Westinghouse rlanford Company, having a range in uranium/plutonium ratio from 1.4 to 6.0 . The powders were homogenized, sampled in triplicate for chemical and mass-spectrometric analyses, and repackaged into seven standards (Table III) prior to gamma-ray spectrometry. The powders were sealed in 3.25-in.-diam inner cans that were centered in 4.125-in.-diam outer cans. The thickness of the bottoms of the inner and outer cans was measured to the nearest $0.0003 \mathrm{~cm}$ prior to packaging the powders. Several gamma rays of ${ }^{239} \mathrm{Pu}$ and ${ }^{241} \mathrm{Pu}$ were measured; however, best results were obtained with the $375-\mathrm{keV}$ gamma ray of ${ }^{239} \mathrm{Pu}$ and the $208-\mathrm{keV}$ gamma ray of ${ }^{241} \mathrm{Pu}$. For measurements in a plant, it would be preferable to use the $375-\mathrm{keV}$ gamma ray because the fraction of ${ }^{239} \mathrm{Pu}$ will be known more accurately than the fraction of ${ }^{241} \mathrm{Pu}$.

Our measurements were made in the enrichmeni geometry-an upward-looking detector, an aluminum spacing tube that fitted over the detector and rested on the top of the detector flange, and a tungsten collimator. Rate-loss corrections were accomplished by monitoring the $88 . \mathrm{keV}$ peak from a ${ }^{109} \mathrm{Cd}$ source taped to the top of the detector. The photopeak areas were oniained with the GRPAUT program. ${ }^{29}$ The data were corrected for the thickness of the can bottoms, for the iron and americium content, and for moisture content. All of these corrections made minor contributions to the blending ratios for this set of standards. However, the correction for finite sample thickness even for these relatively large samples (minimum mass, $750 \mathrm{~g}$ ) was significant. For example, at $413 \mathrm{keV}$, this correction ranged from 0.2 to $3.6 \%$.

Standard HVA 5301 was choser as the standard to compute the calibration constants, because it had the largest total mass and thus the smallest correction factors for finite sample thickness. The peak areas of six gamma rays of ${ }^{239} \mathrm{Pu}$ and four gamma rays of ${ }^{241} \mathrm{Pu}$ were used to calculate the uranium/plutonium ratios of the other six samples as unknowns.

Table IV compares the uranium/plutonium mass ratios determined by the NDA technique $(375-\mathrm{keV}$ gamma rays of ${ }^{239} \mathrm{Pu}$ ) with those obtained by chemical analysis. The NDA results agree with the chemistry results within $0.6 \%$ (relative). For the chemical analysis, three samples, taken from the top, middle, and bottom of the container, were analyzed in duplicate. The following determinations were performed by Los Alamos Group CHM-1: total uranium, total plutonium, isotopic composition of plutonium and uranium, americium, iron, loss on ignition, and spectrographic analysis for other impurities.

The estimated uncertainties in the NDA results were obtained by propagation of the uncertainties in the peak areas given by the GRPAUT program. Each material was counted five times for $10000 \mathrm{~s}$ each time. The magnitudes of the uncertainties are consistent with counting statistics. Three of the powders were counted a second time about 20 days after the first count. The reproducibility of the measurements was found to be from 0.15 to $0.33 \%$ (relative), indicating that there was no significant "drift" of the instrumentation and that the decay corrections were adequate.

We have shown that the enrichment meter principle is applicable to the determination of uranium/plutonium mass ratios from 1.4 to 6.0 in mixed-oxide powders with good accuracy and precision. Th: techisique is suitable for measurements on blended powders in a vee shell or slab blender, as well as on powders in sealed cans. Application of the technique to

TABLE III. Properties of Mixed-Oxide Powder Standards

\begin{tabular}{|c|c|c|c|c|}
\hline \multirow[b]{2}{*}{$\begin{array}{l}\text { Standsrd } \\
\text { Number }\end{array}$} & \multirow[b]{2}{*}{$\begin{array}{c}\text { Mean Uranium/Plutonium } \\
\text { Mass Ratio }\end{array}$} & \multirow{2}{*}{$\begin{array}{c}\text { Mass } \\
\text { Powder } \\
\text { (g) }\end{array}$} & \multicolumn{2}{|c|}{ Thickness of Can Bottoms } \\
\hline & & & $\begin{array}{c}\text { Inner } \\
(\mathrm{cm})\end{array}$ & $\begin{array}{c}\text { Outer } \\
\text { (cm) }\end{array}$ \\
\hline HVA 5062 & 1.634 & 753.9 & 0.0236 & 0.0287 \\
\hline HVA 5065 & 1.442 & 884.4 & 0.0239 & 0.0293 \\
\hline HVA 5069 & 5.946 & 939.6 & 0.0239 & 0.0302 \\
\hline HVA 5175 & 3.487 & 1044.0 & 0.0239 & 0.0302 \\
\hline HVA 5256 & 2.806 & 1004.0 & 0.0234 & 0.0290 \\
\hline HVA 5301 & 2.199 & 1384.6 & 0.0234 & 0.0292 \\
\hline HVA 8971 & 2.649 & 1011.0 & 0.0234 & 0.0295 \\
\hline
\end{tabular}




\section{TABLE IV. Measurement of the Uranium/Plutonium Blend Ratio in Mixed- Oxide Powders}

\begin{tabular}{|c|c|c|c|c|}
\hline \multirow[t]{2}{*}{ Sample No. } & \multicolumn{2}{|c|}{ Enrichment Meter Principle } & \multicolumn{2}{|c|}{ Chemical Analysis } \\
\hline & $\overline{\mathbf{x}}$ & $\sigma$ & $\overline{\mathbf{x}}$ & $\sigma$ \\
\hline HVA 5062 & 1.633 & 0.002 & 1.634 & 0.006 \\
\hline HVA 5065 & 1.433 & 0.002 & 1.442 & 0.004 \\
\hline HVA 5069 & 5.997 & 0.007 & 5.946 & 0.005 \\
\hline HVA 5175 & 3.489 & 0.004 & 3.487 & 0.003 \\
\hline HVA 5256 & 2.805 & 0.003 & 2.806 & 0.007 \\
\hline HVA 5301" & 2.199 & 0.003 & 2.199 & 0.006 \\
\hline HVA 8971 & 2.627 & 0.003 & 2.649 & 0.009 \\
\hline
\end{tabular}

recycle Light-Water Reactor (LWR) mixed oxide would require validation of the principle at higher uranium/plutonium ratios.

\section{Richland/Hanford PUREX Rotary Calciner Holdup Monitor (T. W. Crane, Q-1)}

The neutron coincidence counter banks used for holdup monitors at the Rockwell Richland/Hanford PUREX plant saw service in the inventory exeicise at the close of this year. ${ }^{30,31}$ Rockwell personnel have calibrated the detectors and reported their results. ${ }^{32}$

Future holdup measurements will be complicated by the mixture of plutonium isotopics that can occur as the PLREX plant changes the type of plutonium material being processed. ${ }^{31}$ If a complete exchange of the holdup material occurs, then a recalibration wiil suffice. However, the more likely situation is a mixture of materials from two (or more) campaigns. Currently, Rockwell personnel are evaluating a gamma-ray-based system for measuring the isotopic composition of the holdup plutonium. A gamma-ray system was originally considered for the monitors, but unknown attenuation in the thick walls of the calciner and holdup plutonium would contribute inaccuracies to the measurements that could lead to a serious underestimation of the holdup.

J. Savannah R: jer/New Special Recovery (NSR) Facility (M. P. Baker, S. -T. Hsue, M. P. Kellogg, M. S. Krick, P. M. Rinard, T. E. Sampson, C. M. Schneider, S. M. Simmonds, J. K. Sprinkle, T. Van Lyssel, Q-1; A. L. Baker, W. C. Barnett, W. Ford, Q-4)

1. Introduction. The NSR facility under construction at the SRP is designed to recycle and recover offspecification plutonium, excess process waste, and pro- cess scrap and is located in a fifth- and sixth-level addition to an existing building whose lower levels contain a plutonium reprocessing canyon. The physical arrangement of the NSR is shown in Fig. 13.

Input materials scheduled for recovery will be brought from a storage vault to the Feed Assay Room where their total plutonium contents will be determined for input accountability purposes using a series of NDA measurements. Following the input accountability measurements, the materials will be transferred into the feed glove-box train for preparation before dissolution in one of two dissolver/anion-exchange systems. Following dissolution, solutions will be transferred directly to first-cycle canyon tanks or purified in anion-exchange coluinns and then transferred to second-cycle canyon tanks. Required NDA measurements of dissolver/anion-exchange cabinet solutions will be made on samples obtained from process vessels and trans ferred by conveyor to the Sample Assay Room.

Solid waste from the process will be transferred by conveyor to the waste-handling cabinet and assayed for plutonium content by NDA. The results of the measurement will determine whether the waste is recycled in the facility or sent to burnal. Liquid waste will be sampled, assayed for plutonium content by NDA in the Sample Assay Room, and transferred to canyon tanks. In addition, a sodium iodide gamma-ray detector array will be deployed at key points in the process. Measurements from this array will be used to determine holdup in process equipment, to set criticality alarm limits, and to monitor processing.

2. NDA Measurement System. We have been working with duPont personnel since October 1982 to defini an integrated system of modem, automated NDA instrumentation that will provide accountability and process monitoring information to the NSR facility operators. This integrated system design approach is 


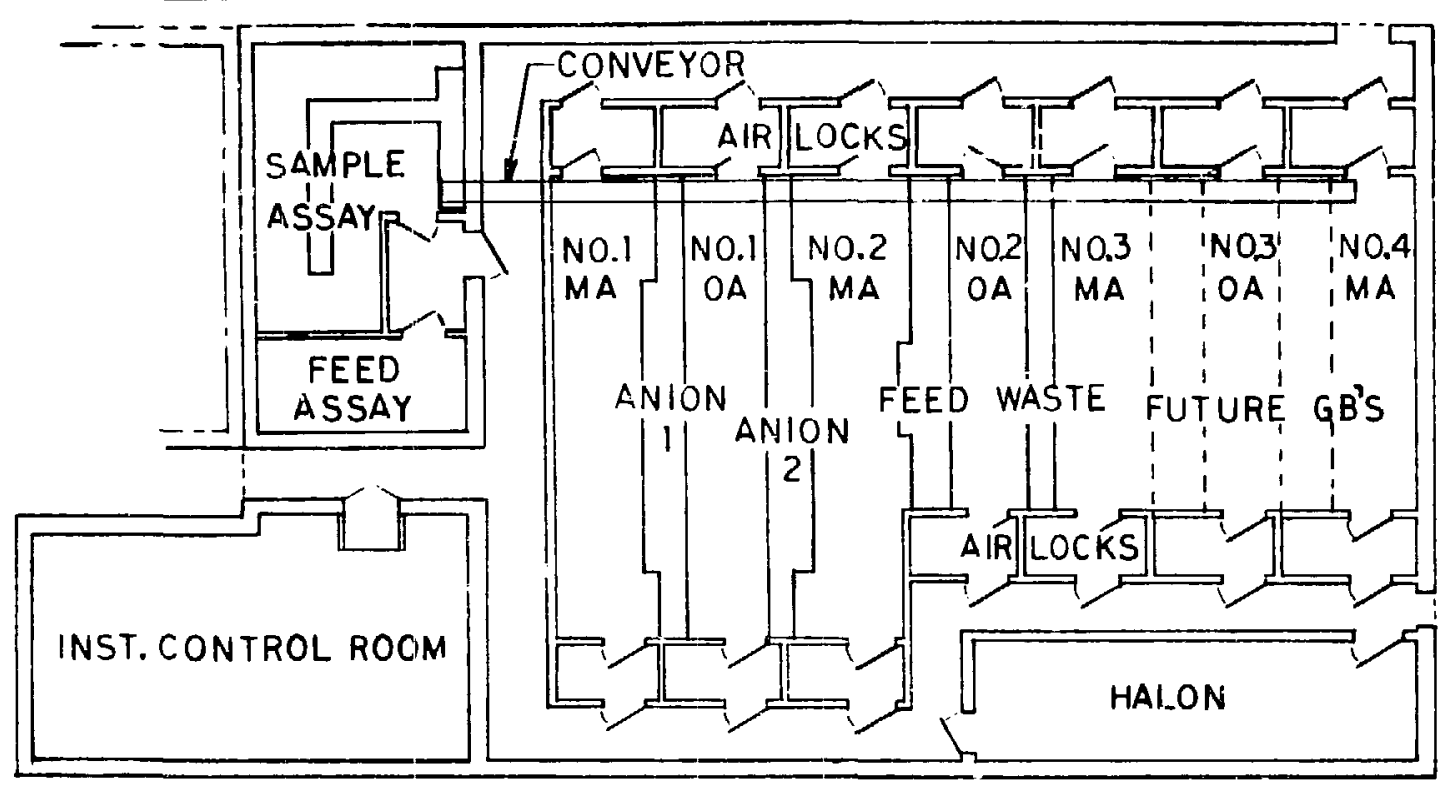

Fig. 13. Physical arrangement of the NSR facility.

necessary because only minimun routine chemical analysis is planned for materials passing through the facility. The NDA instrumentation is being developed and fabricated by a consortium including Los Alamos National Laboratory, Lawrence Livermore National Laboratory (LLNL), SRL, and Mound Laboratory. Los Alamos is system coordinator and will, with the assistance of the other Laboratories, combine the individual instruments into an integrated package. All NDA instrumentation will be shipped to Los Alamos for a 6month integrated tcsting period before system installation at Savanriah River.

A conceptual design study, ${ }^{33}$ completed in 1983 , proposed an integrated NDA measurements system. This proposal, with minor modifications, was generally accepted by all parties and resulted in the consensusintegrated system design shown in Fig. 14. In this system, ten individual NDA instruments report their results to a central instrument control computer (ICC). The ICC, in turn, is integrated into a facility computer network that includes other computers dedicated to process control and nuclear materials accounting functions. The three computers that make up this network have dedicated functions but exchange relevant information through a DECNET communications link to optimize the simultaneous performance of all functions.

Each NDA instrument that is part of the integrated system is microcomputer-based and thus capable of stand-alone operation if the central computer is out of service. This modular system design feature has also allowed each instrument supplier more freedom in indi- vidual instrument design. Nevertheless, certain hardware features, such as microcomputers, pulse processing modules, and multichannel analyzers are common throughout the system, and in almost every case at least two NDA measurement systems are controlled by a single Micro-PDP-11 computer.

in addition, there are many standard software features. The most important of these, from the point of view of faciiity operations, is the interface between the individual NDA instruments and the operator performing the assays. All instruments will be operated from dedicated microcomputer terminals and will have standardized operator/instrument dialogue. Another standard design feature is the communication between individual NDA instruments and the ICC. All such communications will be by means of serial lines using a standardized communications protocol. The MCP also is common to all instruments. Individual instrument MCP results are stored in the local microcomputer while the MCP results for all NDA instruments are archived in the ICC for system evaluation purposes. (Many of these features are also being incorporated into the design of NDA instruments for the Savannah River/HEU project see Part I, Sec. I, K.)

3. NDA Instrument Development. Individual NDA instruments are being developed and fabricated by four instrument suppliers. These instruments, their suppliers, the nature of the NDA measurement, and the location of the instrument in the facility are listed in Takle V. 


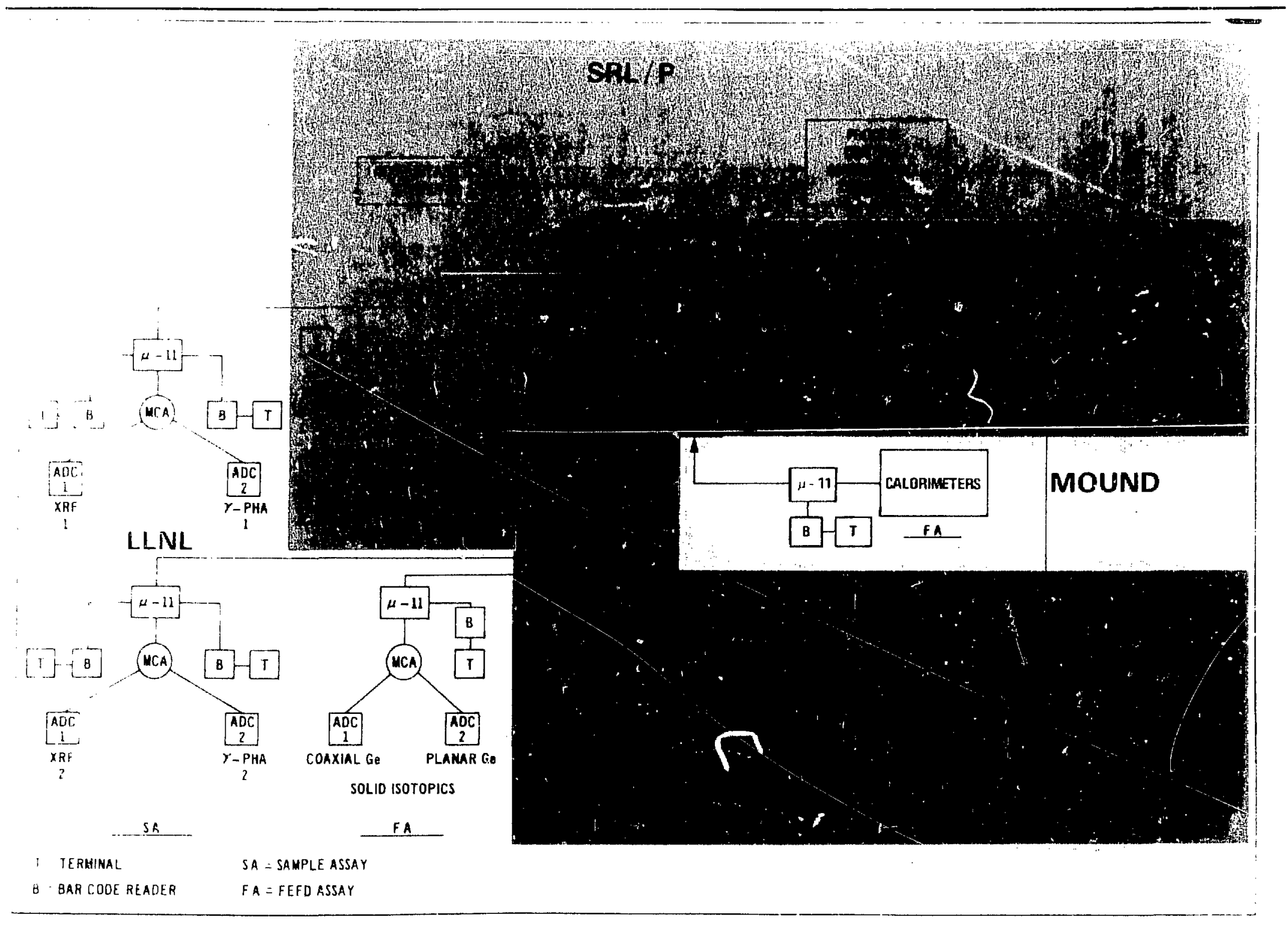


TABLE V. Individual NDA Instraments in the New Special Recovery Integrated System

\begin{tabular}{llll}
\hline \multicolumn{1}{c}{ Instrument } & Supplier & Measurement Type & Location \\
\hline & & & \\
Feed Coincidence Counter & Los Alamos & Effective ${ }^{200}$ Pu Mass & FAR \\
Calorimeter (4)" & Mound & Heat & FAR \\
Solids Isotopic Analyzer & LLNL & Pu Isotopic Frections & FAR \\
Turbidimeter & SRL & Suspended Solids & SAR \\
Densitometer & SRL & Solution Density & SAR \\
X-Ray Fluorescence (2) & LLNL & Pu Concentration & SAR \\
Gamma PHA (2)" & LLNL & Pu Concentration & SAR \\
LOSAI & Los Alamos & Pu Concentration (Low) & SAR \\
Waste Coincidence Counter & Los Alamos & Effective ${ }^{200}$ Pu Mass & Process Area \\
NaI Monitor Array & Los Alamos & 239Pu Mass & Process Area \\
\hline "Number of individual measurement units. & & \\
\hline \hline
\end{tabular}

Generally, the solids isotopic analyzer measurement will be used in conjunction with either the calorimeter or the feed coincider ce counter measurement to determine total plutonium mass of input materials in the feed assay room. In the Sample Assay Room (SAR), the integrity of samples is assured by first checking for suspended solids in the turbidimeter and then comparing the sample density, measured with the densitometer, to the measured density (Ruska) of the tank from which the sample was obtained. If these tests are successful, the plutonium concentration of the sample is then measured in either the $\mathrm{x}$-ray fluorescence, gamma PHA, or LOSAI analyzers.

Note that there are two $\mathrm{x}$-ray fluorescence and gamma PHA measurement systems. This instrument selection provides two types of redundancy. First, in normal operation, the two measurements are performed on duplicate samples to provide independent plutonium concentration values for comparison purposes. Second, if either instrument is out of service, there is a bac...p unit to take over the measurement function while the first instrument is repaired. These redundancy features are critical because these two measurements are part of the outpist accountability determinations for the facility.

The instruments being fabricated at Los Alamos and their status are described below.

a. Feed Coincidence Counter (FCC). The FCC is a passive neutron-well coincidence counter for the assay of the plutonium content of feed material to the NSR facility. Assays are to be performed to $0.5 \%(\mathrm{l} \sigma)$ precision and with 2-10\% accuracy, depending on the form and isotopic content of the plutonium in the feed material. A container of feed material will have up to $2.25 \mathrm{~kg}$ of plutonium.

A side view of the detector is shown in Fig. 15. The cylindrical detector consists of $24{ }^{3} \mathrm{He}$ proportional counters embedded in polyethylene and surrounded by

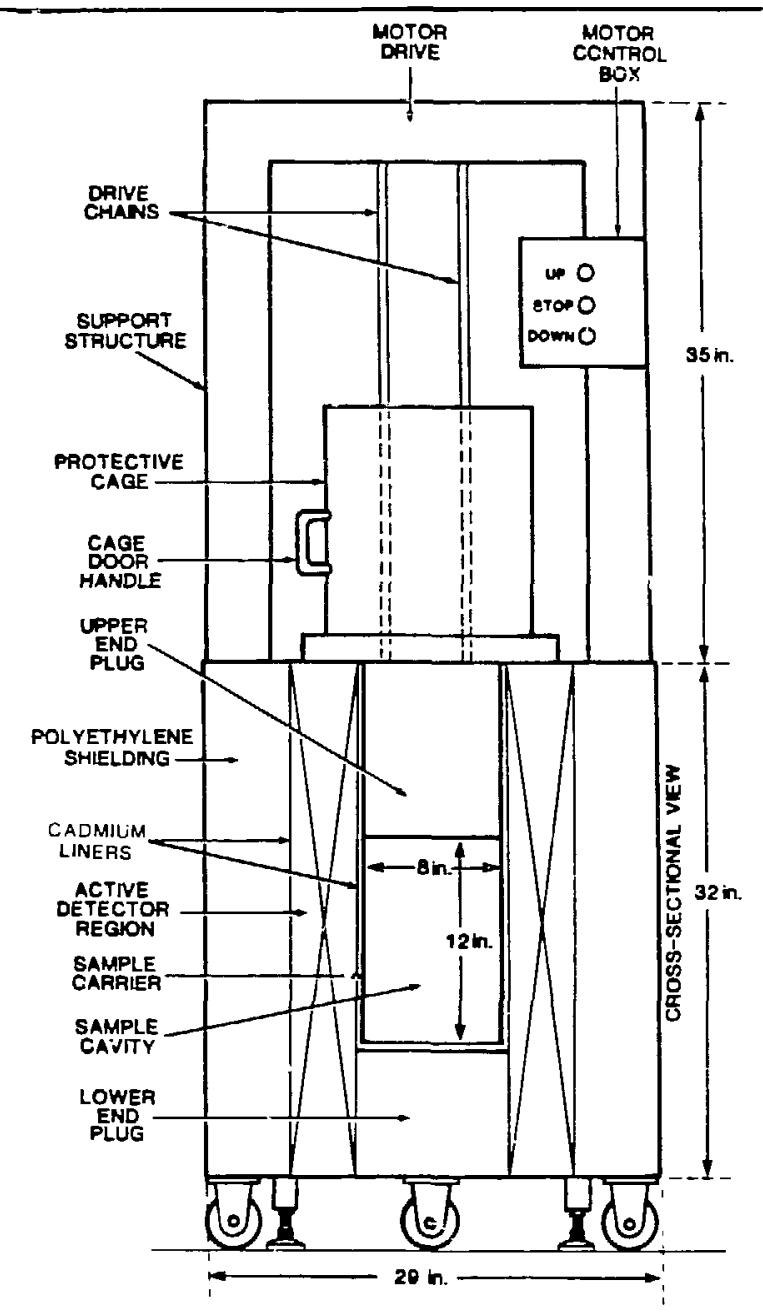

Fig. 15. Side view of the feed coincidence counter for determining plutonium content of input materials in the Feed Assay Room of the NSR facility. 
a poiyethylene shield. The sample well is $23 \mathrm{~cm}$ in diameter by $30 \mathrm{~cm}$ high. Containers of feed material are placed in a sample carrier by hand and then are lowered into the well by a motor-driven elevator. For safety, the elevator is surrounded by a cage that has a door interlocked with the motor controller.

Standard coincidence electronics with AMPTEK preamplifiers are used with the FCC. The AMPTEK circuit boards are in the detector high-voltage junction box, but the coincidence electronics are located in an adjacent Instrument Electronics Room (IER). The FCC uses six banks of detectors that can be intermixed in any combination into a single signal in the detector junction box using switches that control the individual banks. An LED panel, located at the detector, allows the six banks to be monitored independently.

The operator of the FCC controls the instrument using a terminal located near the detector in the FAR. This terminal is connected to a Micro-PDP-11 computer, located in the IER, which receives the neutron counting measurement data from the coincidence electronics and determines ${ }^{240} \mathrm{Pu}$ effective mass from stored calibration parameters.

The FCC fabrication is nearing completion, with testing scheduled to begin in February 1985.

b. Low-Concentration Plutonium Solution Assay Instrument (LOSAI). The LOSAI is designed to determine the plutonium concentration of solution samples that come primarily from the anion-exchange column effluent streams. Thus, these solutions typically contain less than $100 \mathrm{mg} / \mathrm{l}$ of plutonium and relatively large concentrations of ${ }^{241} \mathrm{Am}$ and ${ }^{237} \mathrm{U}$. The desired assay precision for a $35-\mathrm{ml}$ sample containing $20 \mathrm{mg} / \mathrm{l} \mathrm{Pu}$ is $25 \%(1 \sigma)$ in a 2000 -s counting interval. The corresponding assay accuracy desired is $5 \%$. Passive counting of 414-keV gamma rays from ${ }^{239} \mathrm{Pu}$ has been selected as the analysis method.

The design of the mechanical components to be attached to the SAR glove box is shown in Fig. 16. A 25\% germanium detector is closely coupled to a pancakeshaped sample container to optimize the detector counting rate and minimize the sample self-attenuation. A beam-tailoring assembly is used between the sample and detector to reduce the influence of ${ }^{241} \mathrm{Am}$ and ${ }^{237} \mathrm{U}$ gamma rays on the ${ }^{239} \mathrm{Pu}$ analysis. Lead shielding reduces the background from extraneous sources. A small plutonium source, mounted on a slide, can be positioned reproducibly in front of the detector for measurement control. The instrument is controlled by a terminal located near the measurement head in the SAR. This terminal is connected to the same Micro-PDP-11 as the FCC terminal (Fig. 14).

The software necessary to operate this instrument is under development and is expected to be ready for tests with plutonium solutions in February 1985. Five "clean" plutonium solution samples are being prepared

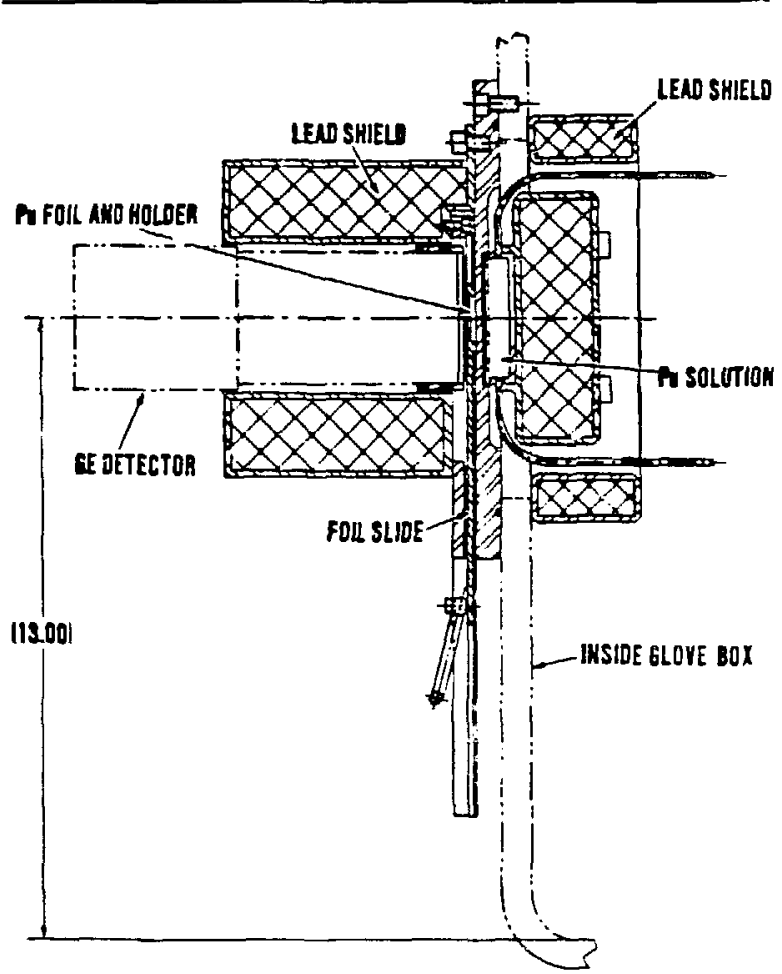

Fig. 16. Side view of LOSAI mechanical assembly.

to determine the instrument calibration as a function of plutonium concentration. In addition, several anionexchange effluent samples will be analyzed to evaluate the effects of other solution components on the calibration. All comr onents of the instrument have been fabricated and assembled. Testing is expected to be completed by March 1985.

c. Waste Coincidence Counter (WCC). The WCC is a passive neutron-well coincidence counter for the determination of the plutonium content in solid waste material intended for disposal. Plutonium contamination on the waste material is to be determined to within the greater of $25 \%$ or $1 \mathrm{~g}(1 \sigma)$. The detecter is designed to assay material lowered into a well extending below the floor of the waste cabinet.

A top view of the detector is shown in Fig. 17. The circle at the center of the drawing represents the well below the waste cabinet. The detector consists of four banks of ${ }^{3} \mathrm{He}$ proportional counters embedded in polyethylene. Shielding surrounds the active region of the detector to the extent allowed by the space available under the waste cabinet.

The coincidence-counting electronics are very similar to those used for the FCC. One special feature of the WCC, however, is that separate signals are sent from each of the four detector banks to the control room, 


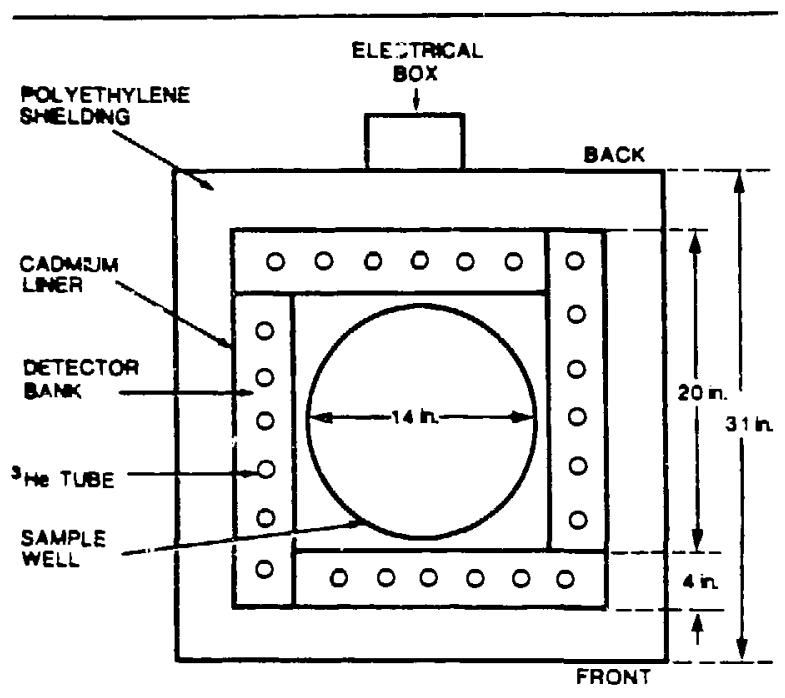

Fig. 17. Top view of the waste coincidence counter for determining plutonium content of solid waste in the wastehandling glove box of the NSR facility.

where the four signals can be monitored with a lightemitting diode (LED) display and intermixed in any combination into a single signal for the coincidence electronics. This feature allows a faulty detector bank to be identified and switched out of the system from the control room. The system is functional (with poorer performance characteristics) with fewer than four banks operating. Repairs, which are not easy to make under the waste cabinet, can then be scheduled for convenience.

The operator of the WCC controls the instrument using a terminal located near the detector in the process area. The terminal is connected to a Micro-PDP-11 computer located in the IER that receives the neutron counting data from the coincidence electronics and calculates ${ }^{240} \mathrm{Pu}$ effective mass from stored calibration constants. The sodium iodide (NaI) monitor array is also interfaced to this computer (Fig. 14).

Fabrication of the WCC is nearing completion. Tests will begin in February ! 985.

d. Sodium Iodide (NaI) Monitor Array. An arTyy of $13 \mathrm{NaI}$ detectors has been designed to determine holdup and provide process control and criticality information for various NSR process vessels. These vessels include tanks, anion-exchange columns, product transfer lines, and vent knockout pots. Plutonium contained in these vessels is determined by measuring the counting rates of the $400-k e V$ gamma-ray complex from ${ }^{239} \mathrm{Pu}$. The multichannel analysis fer all 13 monitors is performed by a single multichannel analyzer, under the control of a Micro-PDP-11 computer. Ratemeters provide hårdware process alarms that are independent of software alarms generated by the computer system. This computer also controls the WCC. These two instrument systems are considered to have process control as their major function and thus report their results to the process control system rather than the ICC. The eiectronics for the $\mathrm{NaI}$ monitor array (Fig. 18) will reside in the IER.

The $\mathrm{NaI}$ detectors used for tanks have similar shield/collimator arrangements (Fig. 19). Others require more slender casings for inserting into glove box penetrations. Anion-exchange columns, for example, are viewed with a $41-\mathrm{cm}-l$ ong $\mathrm{NaI}$ crystal for which a slotted collimator has been designed to provide uniform axial response to radiatio: originating along the column's length. For the product transfer lines, the monitors include ${ }^{137} \mathrm{Cs}$ transmission sources to allow corrections to be applied to the plutonium concentration measurements for bulk density changes in the fluid caused by entrained gas bubbles.

All detectors and electronic modules for the array have been received, and most of the collimator/shield assemblies have been fabricated. Software development and equipment testing are in progress. The array is expected to be ready for acceptance testing by May 1985.

4. Instrument Control Computer (ICC). As shown in Fig. 13, the ICC has three major functions. The first of these is to serve as a focal point and communications link for all the NDA measurements in the Feed Assay and Sample Assay Rooms. The second function is to communicate with the Process Controi Computer/Data Management Function and the F-Canyon Nuclear Materials Accounting Computer. The final major function is to gather and store all information necessary for performing the NSR accountability function. The ICC also schedules the assay of samples in the SAR by means of a display screen above the glove box and validates feed material cans as they enter and leave the FAR. We have written and distributed a functional description of the ICC that specifies the details of the system. ${ }^{34}$

The computer selected to perform these functions is a Digital Equipment Corporation VAX 11/750 with an RA81 fixed Winchester disk drive for on-line operations and in RL02 disk drive with removable disik packs for archiving data or transporting information between machines. We are using the VMS operating system and the DECNET package for communications with the other large computers in the network. Information is exchanged with the Micro-PDP-11-based NDA instruments over standard serial communications lines using a standard protocol. The ICC is installed at Los Alamos and currently is being used for software development.

We are testing the software packages that will provide the communications with the NDA instruments. The software packages to schedule samples and communicate with the Process Control and Nuciear 


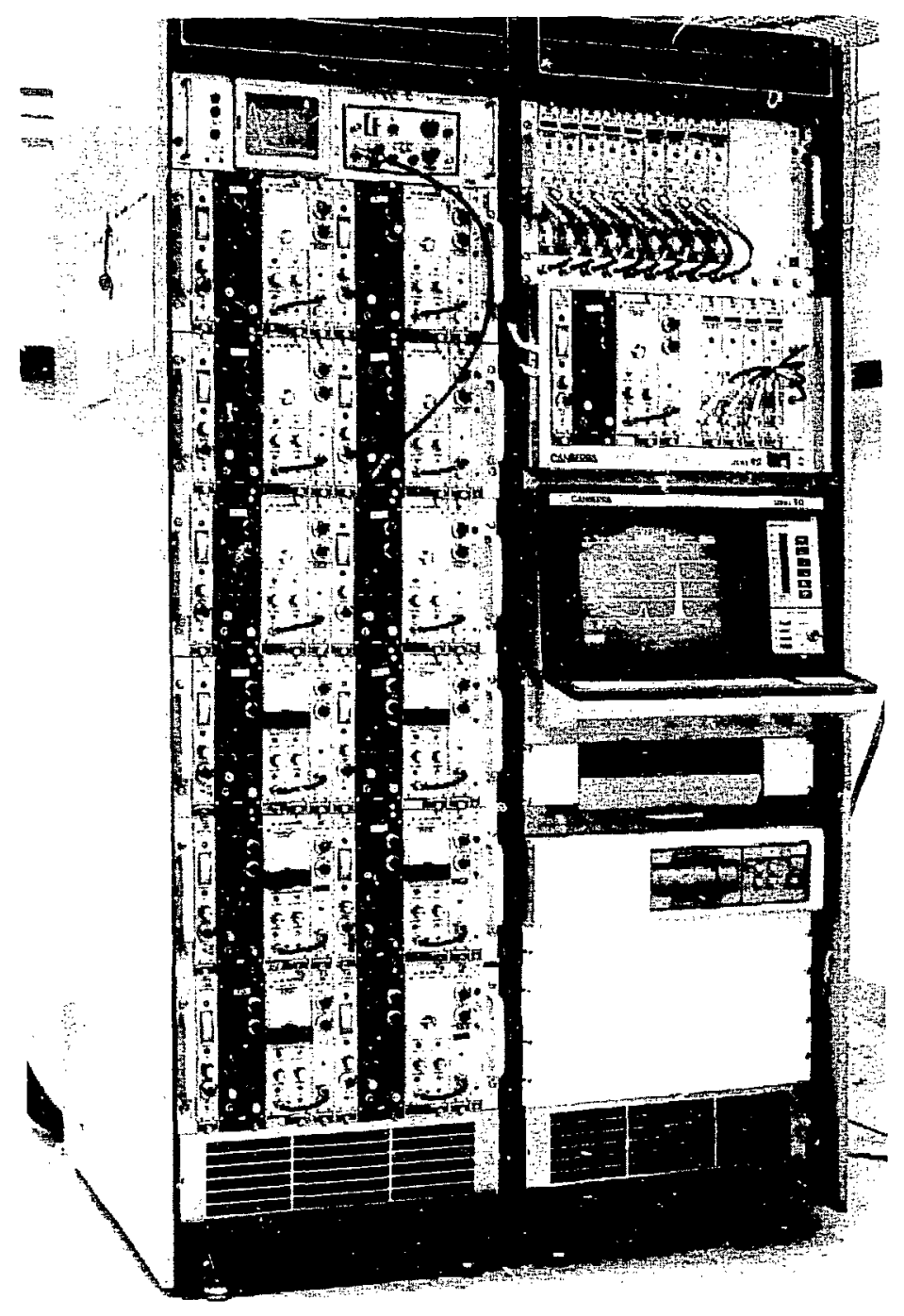

Fig. 18. Electronics instrumentation racks with multichannel analyzer and Micro-PDP-11 compliter for the sodium iodide monitor array.

Fig. 19. Sinield/collimator arrangement for sodium iodide monitor measulement of plutonium in tanks.

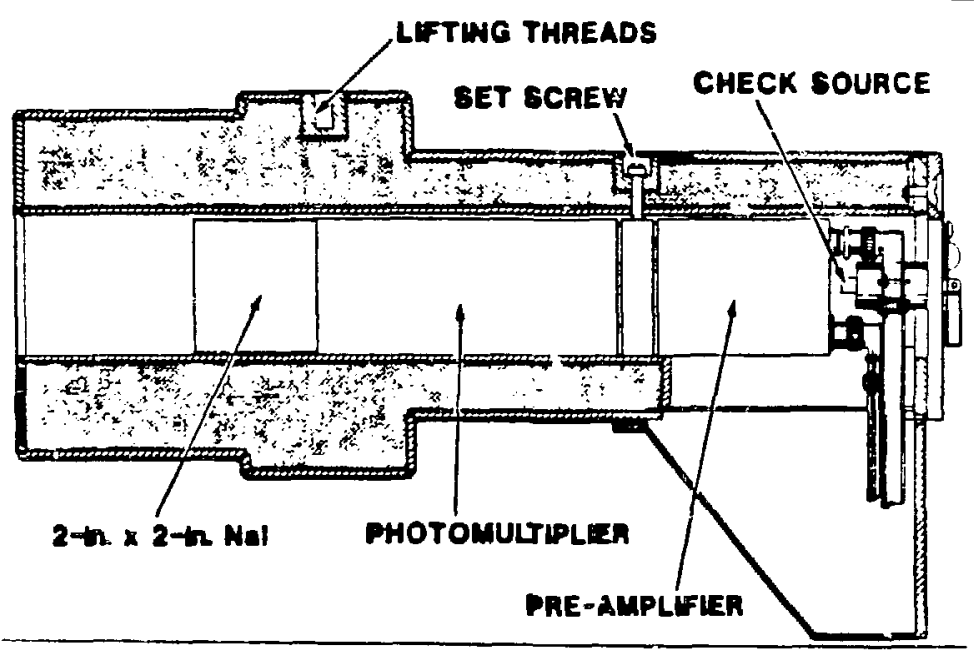


Materials Accounting Computers are under development. We aiso are designing a single database for the ICC that will serve the major functions of archiving all data received to establish a record of process transactions and to provide input to the NSR nuclear material accounting function.

5. System Integration and Future Plans. Following individual acceptance testing, all NDA instruments will be shipped to Los Alamos and assembled for acceptance testing of the integrated system. The primary purpose of this latter test, currently scheduled for September 1985 , is to assure the performance of the NDA instrument/ICC communications and the ICC software.

The 100-h acceptance test of the integrated system will be followed by an extensive training period provided by Los Alamos and the other contractors for SRP personnel. The purpose of this training is to instruct SRP operations and maintenance personnel in the principles and use of the equipment that makes up the integrated NDA system.

At the completio i of ihese training sessions, all equipment will remain in Los Alamos until the NSR facility construction schedule permits delivery of the integrated system to the construction site. At that time, Los Ala. mos and the other contractors will assist SRP peisonnel in installirg the integrated system. Following installation, consistent with the facility start-up schedule, Los Alamos will assist SRP in performing the initial calibration and check-out of a!l NDA instrumentation.

K. Savannah River/Highly Enriched Uranium (HEU) Assay Instrumentation (N. Ensslin, L. R. Cowder, E. L. Adams, J. Baca, C. Bjork, S. C. Bourret, P. R. Collinsworth, T. W. Crane, H. R. Dye, D. C. Garcia, D. L. Garcia, K. E. Kroncke, T. K. Li, G. O. Ortix, J. L. Parker, P. J. Polk, T. E. Sampson, C. M. Schneider, M. P. Kellogg, S. F. Nosterbuer, 5. M. Simmonds, J. E. Stewart, Q-1; N. J. Hoard, CHM-1)

1. Introduction. During the past year, work has continued at a rapid pace on the design, fabrication, and assembly of 10 nondestructive assay instruments for HEU measurements at Savannah River. Electrical and mechanical testing activities and the measurement of nuclear materials have begun on some of the instruments. In support of these activities, the fabrication of calibration standaris and the development of instrument software packages are under way. Over the next year, we will conduct a program of measurements of HEU samples with the goal of providing more accurate nondestructive assay instruments to Savannah River $^{2}$ and to other new facilities in the future. The present status of the instruments is summarized below. Delivery to Savannah River is scheduled for late 1985 and early 1986.

2. In-Line Californium Shufflers. We have completed the fabrication and assembly of two californium shufflers for the assay of high-density scrap and finished product. These shufflers will be installed below glove boxes in the new facility (Fig. 20). The colibration standards for these shufflers also have been fabricated and were recently measured for the first time in the High-Density Scrap Shuffler. The shuffler performed well during the measurement campaign and gave results for the delayed neutron response of a variety of simulated scrap materials. Future measurements will concentrate on maximizing delayed neutron response, improving assay reproducibility, and determining the sensitivity of the built-in correction monitors. The final software packages for the instrument control coriputer and the californium source motor microprocessor have been written and soon will be installed on both shufflers.

3. At-Line Solution Assay Instruments. We have completed the fabrication and assembly of four germanium-based gamma-ray detectors, two for highlevel solutions and two for low-level solutions. One high-level and one low-level detector have been connected to their computer and multichannel analyzer and are being tested for electronic stability and shutter operation. A set of solution standards ranging from 0.0001 to $500 \mathrm{~g} / \mathrm{l}$ has been prepared for initial sensitivity, precision, and vial-position measurements. Other goals and features of the planned measurement program are described in Ref. 35.

4. High-Density Waste Shuffler. This large californium shuffler was designed to accommodate 55gal. drums of high-density waste, as shown in Ref. 36, Fig. 18. Fabrication of all major parts has been completed, and a steel platform with a recess for the drum rotation mechanism has been erected. Assembly of this shuffler will take place in early 1985. A set of modular uranium standards that can be inserted into simulated waste matrices has been designed and will be fabricated at the same time.

5. Low-Density Waste Assay System. We have completed the fabrication and assembly of this system, which contains a large germanium detector that views rotating cartons of low-density waste in a far-field geometry. The duPont Company has provided an automatic carton ejection mechanism, which has been installed and works well. The software package for this system has been written, and the software, electionics, and mechanical features are being tested. Modular lowdensity waste standards have been designed for this system and will be fabricated soon. 


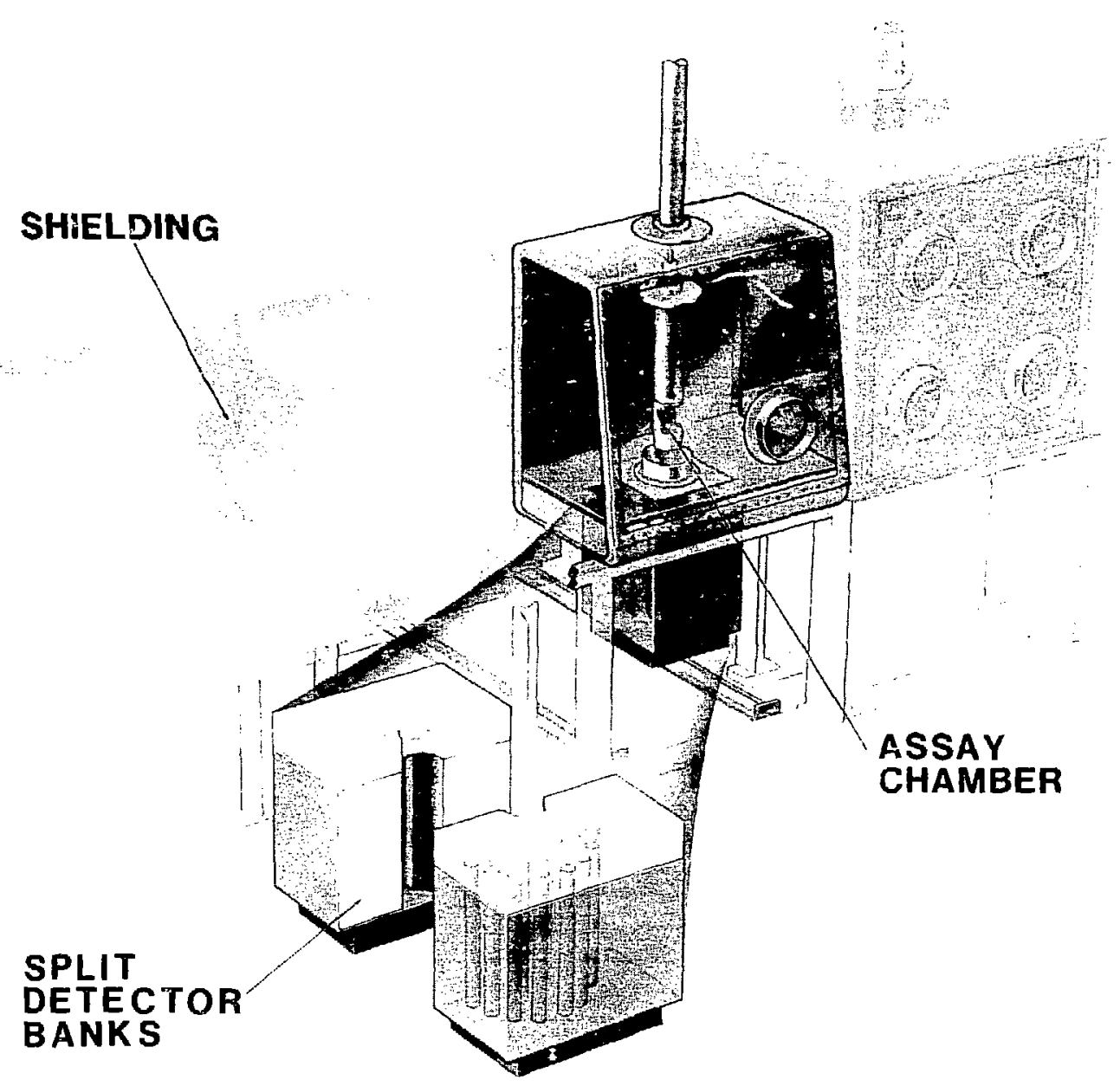

Fig. 20. In-line californium shuffler for the assay of highly enriched uranium as it will appear after installation at SRP.

6. Low-Density Scrap Assay System. Low-density scrap will be assayed by a high-resolution germanium detector using the segmented gamma-ray scanning technique. We have completed the design of a new segmented gamma-ray scanner with remotely movable detector and transmission source assemblies that can assay 10-10 38-cm-diam scrap containers. An assembly drawing is shown in Fig. 21 . The instrument will include a gear motor for horizontal motion, microprocessorcontrolled stepping motors for vertical scanning and sample rotation, and a variety of new sersors and assay diagnostics. Calibration standards are being fabricated by Los Alamos Group MST-6. Over the next year, laboratory measurements in support of this instrument will determine the appropriate attenuation correction factors as a function of transmission and study the usefulness of the $143 / 186 \mathrm{keV}$ peak ratio, the usefulness of the $x$-ray flag for clumping, ${ }^{37}$ and the capability for locating accumulations of uranium within the sample.

7. Receipts Assay Monitor. The ${ }^{235} \mathrm{U}$ content of incoming $\mathrm{UF}_{6}$ cylinders at Savannah River will be verified by a neutron coincidence counter. The design of this counter has been completed (Fig. 22). The counter is now being fabricated and, when completed and tested, will be calibrated and evaluated at the Portsmouth Gaseous Diffusion Plant, Piketon, Ohio. Of interest in the evaluation will be the operation and effectiveness of the computer-controlled removable carmium liner. This liner makes it possible to correct the assay, which is based on self-induced fissions within the $U_{6}$, for variations in material density. ${ }^{19}$ 


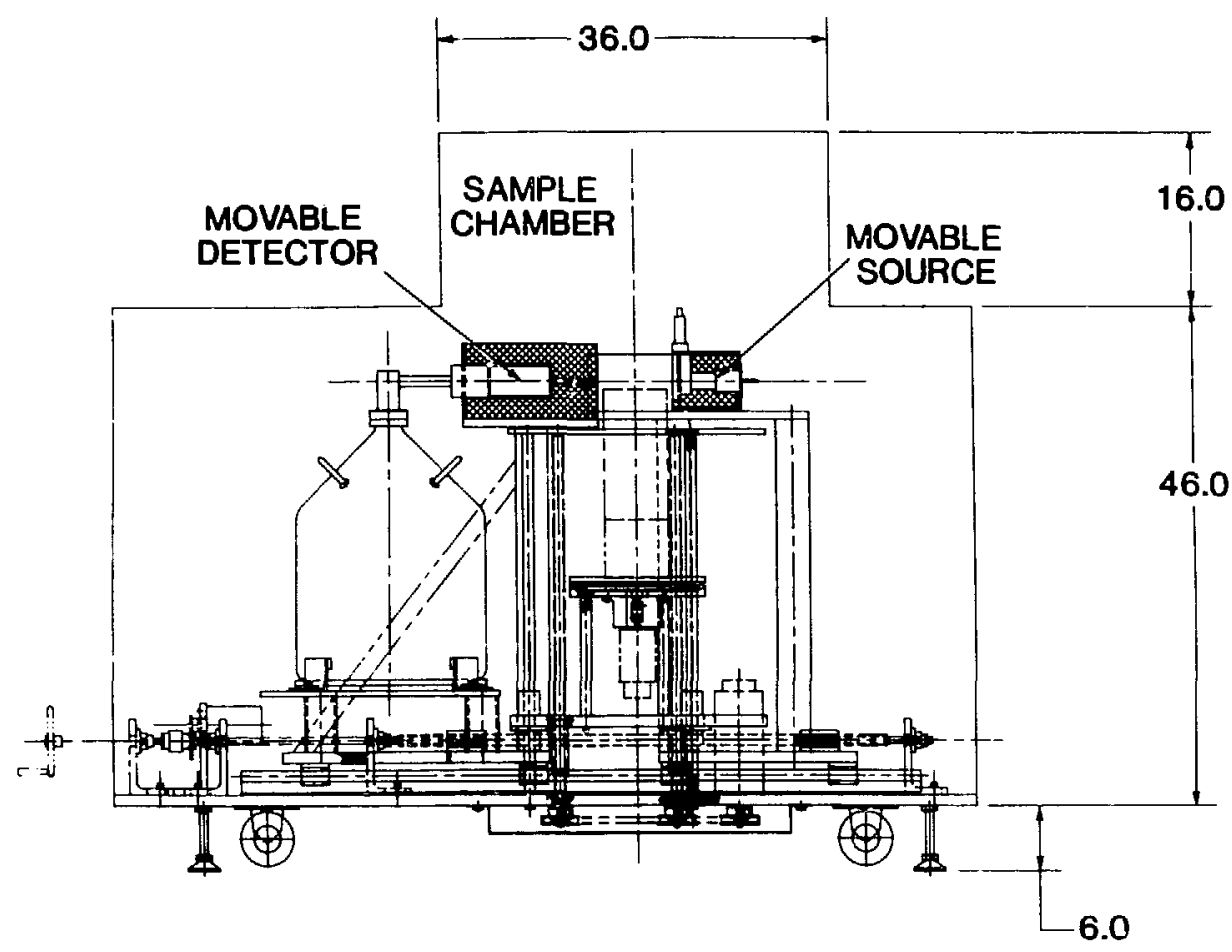

Fig. 21. Side view assembly drawing of the new segmented gamma scanner designed for the assay of low-density uranium scrap at SRP.

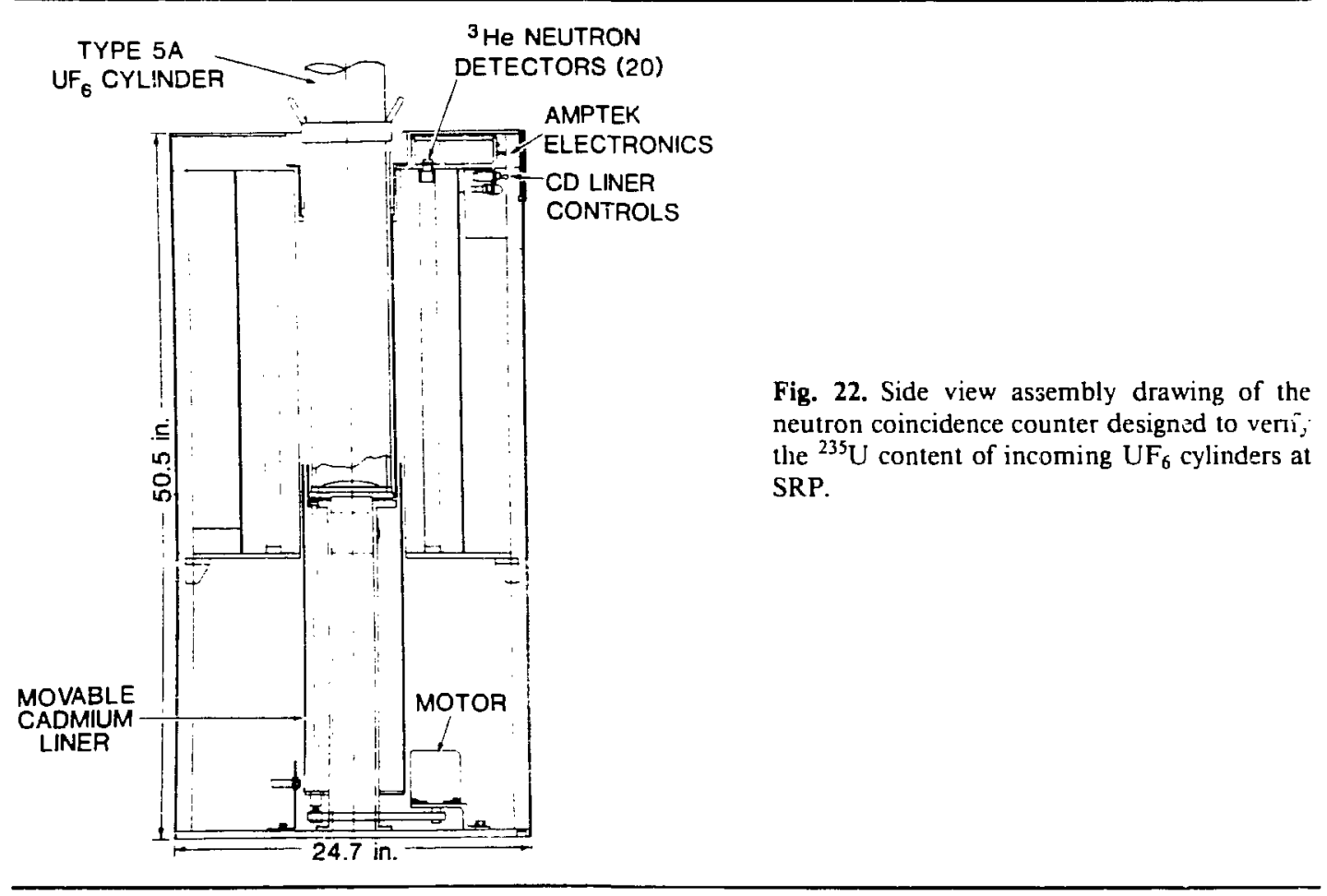




\section{Savannah River/Savannah River Plant (SRP)}

1. Variance Calculations for the Savannah River FBLine (D. Stirpe, Q-4). MACSYMA is an interactive, symbolic computer program capable of a variety of mathematical operations. It is especially useful for variance calculations because it allows for a definition of a variance function in terms of a list of arguments: the right side of the function definition shows how these arguments combine mathematically. Hence, the many variance expressions necessary to calculate the variance of different materials balance terms that appear in materials balance equations can be stored as functions. A numerical value of the function is returned when numerical values are assigned to the arguments in the function ciefinition.

MACSYMA was used to calculate the variance for the Savannah Fiver FB-line operating in steady-state batch mode. With the necessary process information and measurement-instrument standard deviations supplied, the variances of seven transfer terms and 17 inventory terms were calculated in little more than half an hour. The total variance obtained for the entire FB-line using MACSYMA (11.044 $\mathrm{kg}^{2}$ ) agreed closely with the value obtained earlier using the MEASIM code (11.064 kg $)$.

2. Plutonium Isotopics Assay for SRP/FB-Line (T. E. Sampson, S. -T. Hsue, Q-1). In FY 1981, a plutonium isotopic analysis instrument was installed for test and evaluation in the SRP FB line to measure scrap, waste, and FB-lire buttons, as well as incoming feed. ${ }^{38}$ The instrument performed without problems from the beginning, and test and evaluation were completed successfully in 1984.

In response to a DOE/OSS request in May 1984, Los Alamos has been assisting Savannah River in upgrading its F-Area scrap-measuring capability. Specifically, we have provided a dual-detector plutonium isotopics analysis system to replace the successfully tested siagledetector system. The dual-detector system was placed in routine operation on June $15,1984$.

\section{Ad Hoc Field Assistance}

1. DOE Albuquerque Operations Office; BSAM Evaluation (M. Hykel, Q-1). The DOE Albuquerque Operations Office (DOE/AL) has acquired a small, portable gamma-ray spectrometer, known as a ESAM, to perform verification measurements on uranium and plutonium during safeguards inspections. The BSAM is a stabilized $\mathrm{Nal}$ system with two single-chainnel analyzers and an HP.4lC calculator for data display and anaiysis. Los Alamos was asked to help test the instrument and to train DOE/AL personnel in its operation.
We first tested the instrumınt for stability. During operation with the internal battery, excessive noise appeared in the amplitier signal when the printer was in operaticn. Also, there was an occasional loss of stability during printer operation. The instrument was returned to the manufacturer for repair. After the instrument was repaired and returned to us, it was operated almost continuously for a month to test its stability. The problem with amplifier noise and loss of stabilization had been sorrected.

In Januzry 1984, DOE/AL personnel came to Los Alamos to be trained to operate the BSAM. They became familiar with the instrument controls, leisned to use calculation programs written at Los Alamos for ${ }^{235} \mathrm{U}$ enrichment measurements, and did some actual enrichment measurements.

In March 1984, the DOE/AL staff returned to Los Alamos to test the BSAM under in-plant conditions. We helped them use the instrument to perform uranium and plutonium verification measurements at several nuclear material storage areas. During these measurements, a small problem arose with the scaler/calculator readout and DOE/AL decided to return the instrument again to the manufacturer. Except for this problem, ihe exercises went very well, and the DOE/AL personnel were pleased with the performance of the BSAM.

2. Los Alamos Measurement Assistance (J. K. Sprinkle, Jr., E. L. Adams, T. W. Crane, R. Siebelist, S. M. Simmons, H. A. Smith, Q-1). We have continued our ongoing program of rapid responses to specific Los Alamos OS-2 and MST-Division requests for NDA measurement assistance. In at least 11 different exarcises, we have measured holdup in tanks and ductwork, assayed four barrels of heterogeneous scrap from General Atomic Corp., assayed nine barrels and three cans of contaminated waste from the Sigma Building at Los Alamos, and measured a total of 53 filters in five different measurement campaigns. Each of these activities was completed in a timely fashion. For example, one holdup exercise was initiated at the request of a Los Alamos health physics monitor who detected low levels of contamination in a duct that was in the process of being removed. The removal efforts ceased until we defined the locations of material and estimated the quantities involved. Many of the barrel and filter measurements are used to make discard/recovery decisions. Consequently, a quick response helps decrease requirements for temporary storage as well as provide a result for thc closing of a materials balance.

In addition, we moved the Random Driver/Uranium Solution Assay System (RD/USAS) from the recently decommissioned uranium recovery facility to the new location of uranium recovery efforts at Los Alamos. The USAS provides a quick and reliable assay of dirty, dilute 
uranium sc.utions that are occasionaliy generated as waste. The RD is used much more often to assay uranium-contaminated combustibles and to determine the shipper values for uranium oxide and graphite materials shipped from Los Alamos. The relocation of the instruments involved training new people in their use and maintenance, overseeing the disassembly and relocation, and supervising the recalibration efforts. The recalibration was not required because of the move but was necessitated by a switch to $2-\ell$ polyethylene bottles as the standard sample containers for umanium-bearing materials.

\section{Rocky Flats: Shipper-Receiver Confirmatory} Measurements (H. O. Menlove, Q-1). We are consulting with Rocky Flats and the SRP on the design of neutron coincidence box counters [Confirmatory Measurement Counters (CMCs)] for measurement of inhomogeneous buttons of plutonium and americium mixed with various salts. This material is to be transferred from Rocky Flats to the SRP for recovery. Current plans call for Rock $y$ Flats to fabricate two identical couriters-one to be used at Rocky Flats prior to shipment and the other at SRP following receipt of the material. Because the $(\alpha, n)$ rate from the material is extremely high, the new fast AMPTEK electronics package will be used for the counters. Although the identical counters should provide a "signature" of the material at both shipping and receiving points, it is hoped that a more quantitative assay also can be obtained for comparison with shipper's by-difference values and receiver's batch-recovery values. A Rocky Flats representative visited Los Alamos to discuss coincidence counter design, fast electronics implementation, and signature evaluation with Los Alamos personnel.

The first CMC has been completed and is located in the plutonium vault area at Rocky Flats. After alignment of the eight AMPTEK amplifier channels, measurements to determine the axial efficiency profile and the calibration for $\mathrm{PuO}_{2}$ powder ivere performed. Additional measurements to determine the counter deadtime and the calibration for fissile $\left({ }^{239} \mathrm{Pu}\right)$ content of scrub alloy will be uridertaken when the appropriate neutron sources and standards are available. Los Alamos will assist Rocky Flats and SRP in the calibration and impiementation of these new counters.

4. Kocky Flats: MC\&A System Consultatio:1 (K.K.S. Pillay, J. W. Tape, Q-4). The operations of the plutonium processing and metal production line in Building 371 at Rocky Flats have been indefinitely postponed after two campaigns. Materials accounting difficulties have been part of the problem with this facility. A major contributor to uncertainties in materials accounting is the very large residual inventories (holdup) possible in the nearlv 800 miles of process pipe lines, 10000 valves, and 300 storage tanks of various capacities. Rocky Flats requested Los Alamos expertise to evaluate and enhance safeguards capabilities for Building 371. Los Alamos personnel visited the site and are in consultation with Rocky Flats personnel on various aspects of safeguards systems evaluation. Our error analysis program EPIC is now being used by Rocky Flats personnel to develop inventory differences from materials acco:ıntability measurements done at Building 371 .

A formal, comprehensive program for future assistance and technology development has been proposed to the Office of Safeguards and Security for the DOE Rocky Flats Area Office.

5. Oak Riuge Y-12: Evaluation of the Los Alamos AWCC (P. A. Russe, H. O. Menlove, Q-1). The Los Alamos AWCC was shipued to $Y-12$ for a 2-month evaluation as a possible substitute for the $Y-12$ random driver. The greater stability of the AWCC would simplify the procedures for bulk assay of nuclear materials that are currently measured by the random driver. A second purpose of the evaluation was to determine whether the AWCC could replace the Y-12 plant laboratory measurements (primarily destructive analysis) for certain material categories and whether the counter could achieve $0.1 \%$ results for metal buttons. Installation and calibration of the AWCC were carried out by Los Alamos and Y-12 NMC and A personnel at the scrap recovery facility. The measurements for evaluatic ' of the counter were performed by the NMC and A Department at $\mathrm{Y}-12$.

The AWCC was used to measure more than 150 different materials in four categories: metal buttons (MBs), oxides (some with boron contamination), highdensity residues (HDRs), and $\mathrm{UF}_{4}$ or green salts (GSs). The reference values for these materials were de termined by sampling and destructive analysis in the plant laboratory (oxides and GSs), by weighing (MBs), and by the random driver (oxides and HDRs). Experiments also were conducted to evaluate corrections for differences in fill heights and densities within a material category.

Results obtained with the AWCC for all but the GSs are shown in Fig. 23. The decrease in specific response with increasing ${ }^{235} \mathrm{U}$ mass for the lower masses is the result of increasing self-shielding. The larger specific response for MBs is the result of increased multiplication for higher ${ }^{235} \mathrm{U}$ density. The data have not been corrected for variations in fill heighi and density. This accounts for some of the scatter about smooth behavior for a given material type. A separate calibration curve ( $\mathrm{g}$ ${ }^{235} \mathrm{U}$ vs response $\mathrm{R}$ ) for the AWCC is determined for each material category. The GS measurements were performed with the counter configured for passive assays (interrogation sources removed). In the self-interrogation mode, ${ }^{19}$ coincidences are induced by neutrons 


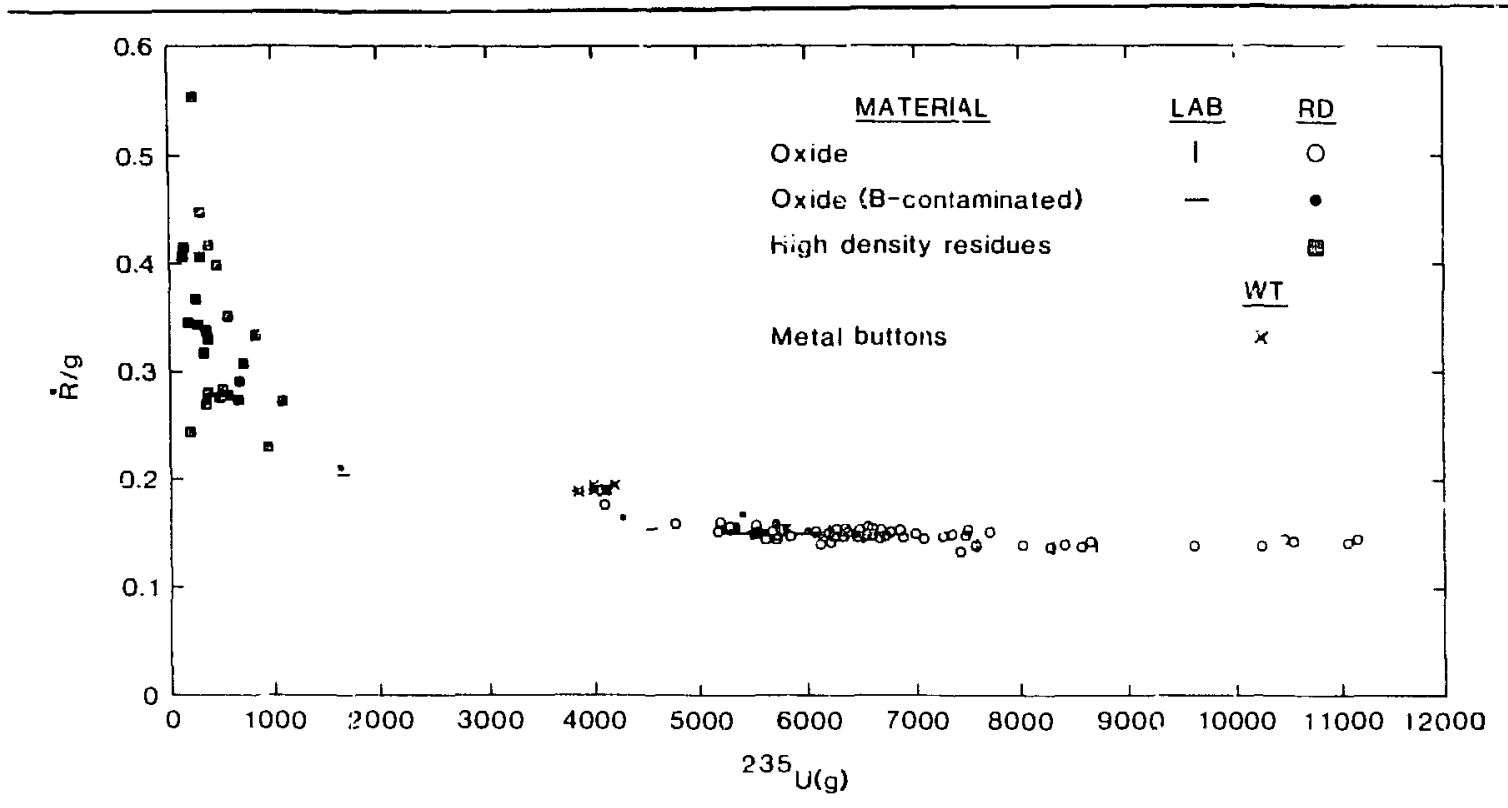

Fig. 23. Plot of the rate of real coincidences per gram of HEU vs the reference value for the HEU mass ior materials measured by the AliCC at Y-12 during the 2-month evaluation. The different symbols distinguish material categories and define the origin of the reference values. (The abbreviations L.AB, RD, and WT correspond to plant laboratory destructive analysis, random driver assay, and weighing, respectively.)

from $(\alpha, n)$ reactions. These results must be analyzed separately. All results are currently being analyzed at Los Alamos.

An Oak Ridge report ${ }^{39}$ on the evaluation of the $A W C C$ at $Y-12$ is now complete. The repor concludes that the AWCC can be considered as a replacement for the random driver for the assay of HDRs and oxides. The AWCC results $f(r$ the GSs are not sufficiently accuiate to consider the $A W C C$ as a replacement for sub- $0.5 \%$ analysis by the $\mathrm{Y}-12$ plant laboratory. The desired $0.1 \%$ results for the MBs also could not be achieved by the AWCC.

\section{SAFEGUARDS TECHNOLOGY TRAINING (C. Hatcher, H. Smith, Q-1; J. Malanify, Q-2; J. Markin, R Gutmacher, Q-4)}

As part of the DOE Saleguards Technology Training Program, four training courses were presented in 1984:

- Materials Accounting for Nuclear Safeguards (offered twice)

- Fundamentals of Nondestructive Assay of Nuclear Materia!

- Advanced Gamma-Ray Spectroscopy for Nuclear Materials Accountability

We also are developing a new course, "Attributes and Semiquantitative Measurements of Nuclear Materials." This course will cover gamma-ray and neutron meas- urement techniques for determining attributes of special nuclear materials and rapid measurement techniques applied to large inventories. Emplasis will be on the verification of the presence of nuclear materials, identification of the type of material. and estimation of the approximate amount of material present. Specific applications will include characterizing unlabeled samples, estimating plant holdup, identifying and quantifying waste, and monitoring vehicle and personnel portals. The first offering of this course is scheduled for mid-March, 1985.

The "Materials Accounting for Nuciear Safeguards" course was presented on April 9-12 and again on April 16-19 to accommodate the large student interest. It addressed methods for designing and implementing conventional and near-real-time accounting systems for safeguarding nuclear material. Lecture topics inciuded

- Fundamentals of Materiais Accounting

- The Structure of Safeguards Systems

- Measurement Technology

- Statistical Basis of Materials Accounting

- Decision Procedures for Materials Accounting

- Process Design and Sa feguards Systems

- Modeling and Simulation

- Materials Accounting Systems

- International Safeguards 
The course was enhanced from previous years by the presentation of four 1-1/2-h workshops on the afternoons of the second and third days. The workshop topics included (1) NDA and statistics, (2) automated chemical analysis, (3) real-time materials accounting simulator, and (4) practical considerations for safeguards systems designers. Each student participated in all four workshops and was provided an opportunity for extended "hands-on" experience with selected NDA instrumentation, destructive analysis instrumentation, materials accounting software, and systems design consultations.

The fundamentals course was presented October 1-5 and provided an introduction to the NDA of nuclear materials using both gamma-ray and neutron measurement techniques. Although designed primarily for professional-level scientists and engineers with little or no background in NDA, the course also proves useful to materials accounting supervisor, NRC inspeciors, and NDA technicians. Tropics included gamma-ray and neu tron interactions, uranium enrichment measurement, transmission-corrected gamma-ray assay, neutron singles counting, and neutron coincidence counting.

The advanced gamma-ray assay course was offered December 3-7 for scientists, engineers, and technicians desiring to become familiar with advanced NDA technioues typically used in in-plant instruments. The course emphasized the use of high-resolution gammaray spectroscopy systems using germanium detectors in applications such as uranium and plutonium isotopics measurements, segmented gamma scanning. absorp- tion-edge densitometry, and x-ray fluorescence. Because gamina-ray techniques are widely used for both portable and in-plant measurements, this course has been particularly useful to DOE facility operators and NRC and IAEA inspectors.

Table VI summarizes the training cours $s$ attendance for 1984. More than $80 \%$ of the students attending the 1984 courses were from DOE and its contractor organizations. We feel that this is an indication of the increased national attention to high-quality nuclear materials accounting and the trained personnel that it requires. Each training course presented in 1984 has been given several times in previous years, but the courses are updated each year to include the latest in measurement techniques, commercially available instruments, and materials accounting procedures.

The 1985 DOE Safeguards Technology Training Program Schedule includes the following five courses:

- Attributes and Semiquantitative Measurements of Nuclear Matcrials, March 1985

- Materials Accounting for Nuclear SafeÉuards, April 1985

- Neutron Assay of Nuclear Material, August 1985

- Fundamentals of NDA of Nuclear Material, October 1985

- Advanced Gamma-Ray Assay of Nuclear Material, December 1985.

TABLE VI. 1984 DOE Safeguards Technology Training Program Attendees

\begin{tabular}{|c|c|c|c|c|}
\hline \multirow[b]{2}{*}{ Facility } & \multicolumn{2}{|c|}{ Materials Accounting } & \multirow{2}{*}{$\begin{array}{c}\text { Fundamentals } \\
\text { of NDA } \\
\text { October 1-5 }\end{array}$} & \multirow{2}{*}{$\begin{array}{c}\text { Gamma-Ray } \\
\text { NDA } \\
\text { Dec. } 3-7\end{array}$} \\
\hline & April 9-12 & April 16-19 & & \\
\hline Argonne & 2 & 0 & 1 & 0 \\
\hline Babcock and Wilcox & $\mathbf{0}$ & $\mathbf{0}$ & 1 & 1 \\
\hline Battelle & 2 & 0 & 0 & 0 \\
\hline DOE & 6 & 1 & 3 & 1 \\
\hline duPont & 2 & 0 & 3 & 2 \\
\hline EG\&G & $\mathbf{0}$ & 2 & 2 & 2 \\
\hline G. A. Technologies & $\mathbf{0}$ & $\mathbf{0}$ & 1 & 1 \\
\hline Los Alamos & 3 & 7 & 7 & 4 \\
\hline LLNL & 1 & $\mathbf{0}$ & 3 & 1 \\
\hline Martin Marie ${ }^{-}$Oak Ridge) & 0 & 1 & 3 & $\mathbf{0}$ \\
\hline NFS, Erwin & $\mathbf{0}$ & $\mathbf{0}$ & 0 & 1 \\
\hline NRC & 1 & 3 & 1 & 1 \\
\hline Other & 1 & 2 & $\mathbf{0}$ & 1 \\
\hline Rockwell, Hanford & 2 & 1 & 5 & 3 \\
\hline Rockwell, Rocky Flats & 2 & 4 & 2 & 4 \\
\hline Westinghouse, Hanford & 1 & $\mathbf{0}$ & $\mathbf{0}$ & 0 \\
\hline $\mathbf{Y}-12$ & 1 & 0 & 0 & 0 \\
\hline Totals & 24 & 21 & 32 & 22 \\
\hline
\end{tabular}




\section{PART 2. SECURITY DEVELOPMENT AND SUPPORT}

\section{COMPUTER SECURITY}

\section{A. Center for Computer Security}

The Los Alamos computer security research and development program is intended to solve problems that arise in the DOE community and to aid in the identification and installation of the solutions. Los Alamos operates the DOE Center for Computer Security, which is designed to promote computer security research and development (R\&D), encourage computer security awareness, support computer security activities at DOE facilities, and act as an information clearinghouse for computer security projects.

1. CSSO Classes (D. G. Harder, Q-4; L. H. Baker, Q-DO/SG). The dramatically increasing number of secure computer systems within the Department o: Energy has resulted in a concomitant increase in the number of Computer System Security Officers (CSSOs). Over the last several years DOE has found the need to formalize the training available to these individuals. Because no commercially available training appeared appropriate for these people, a specialized class was developed by the DOE Center for Computer Security for recently appointed CSSOs. The course, which continues to evolve, is widely accepted, and attendance is usually overbooked.

During 1984, the course was taught at the Las Vegas Operations Office, the San Francisco Operations Office, the Oak Ridge Operations Office, and at DOE Headquarters (DOE/HQ). In each case, people attended from DOE and contractor organizations. Feedback from the first courses was used to modify later courses and resulted in the inclusion of information more specific to the CSSOs' needs.

In particular, later courses included additional basicr; in security and computer science and a more detailed discussion of threat and penetrations. Course feedback has been highly useful to the Center and to the DOE/HQ in determining what is well understood, and as a result, other DOE activities have been modified.

Instructors for the course come from the DOE Center for Computer Security (generally two people) and $\mathrm{DOE} / \mathrm{HQ}$ (generally one person). Usually, the DOE/HQ persor nel teach TEMPEST, TSCM, and DOE orders. This usually constitutes about one-third of the class. Center instructors teach the other two-thirds of the class and cover all other subjects.

3. Advice and Assistance (D. G. Harder, Q-4; L. H. Baker, Q-DO/SG). One of the primary functions of the DOE Center for Computer Security is to provide a source of advice and assistance to the DOE and to its contractors. This assistance can take several forms: simply answering questions over the telephone (which haprens at the Center about 6 to 10 times a day), sending people to DOE Operations Offices or contractor sites, or talking to people who come from these sites to Los Alamos for discussions with Center personnel.

In the last calendar year, advice and assistance in the form of computer security enhancement reviews (CSERs) have been carried on at eight sites: DOE/HQ, the Lawrence Livermore National Laboratory, the Richland Operations Office, the Nevada Operations Office, the Savannah River Operations Office, the Oak Ridge Operations Office, the Sandia National Laboratories/Albuquerque, and the Idaho Falls facilities. These CSERs are often used by the site to prepare for an I\&E team's visit.

CSER visits are different from other Center activities in that they are usually initiated by the site itself and not by $\mathrm{DOE} / \mathrm{HQ}$ or by the Center. In most cases, when the site is expecting an I\&E visit, the site's CSSO recognizes the need for an unbiased outside view of the site facilities. There is no written report from such a visit, and all information obtained is given only to the facility. This confidentiality has resulted in a significantly free exchange of ideas between the review team and site individuals. Feedback has been positive and indicates this exchange of information has helped to improve security of DOE sites.

Center personnel also participate in the vulnerability assessment (VA) activities conducted by the DOE Center for Operations Security. These VAs are initiated by $\mathrm{DOE} / \mathrm{HQ}$, but with the cooperation of the site. Center personnel serve as technicá: experts in computer or communications security.

It has become clear during CSERs and VAs that the blend of expertise and experience most useful in these kinds of visits is a fairly rare commodity. To increase the available expertise, we have asked people from other facilities to join in these visits, $b J$ th to provide us with their technical expertise and to provide them with the experience of being on the other side of such a review. Several people have been included in CSERs, and their activities are much appreciated. Of particular note are Ms. Shirley Baker of the Bendix, Kansas City facility, and Dr. Blaine Burnham and Mr. William Huntaman of Sandia National Lal oratory/AJbuquerque.

3. Center for Computer Security Newsletter (D. G. Harder, S. L. Hurdle, Q-4). Since its inception, the Center for Computer Security has prepared a newsletter to disseminate information of interest to the DOE computer security community. The mailing list for the 
newsletter has grown steadily and now exceeds a thousand addressees. Efforts to reduce the mailing list have shown that most of those on the list wish to continue to receive the newsletter. We consider this a compliment to the quality and quantity of information being distributed.

Late in 1984, the newsletter was modified to include a new format; tutorials on specific topics, such as partitioned computer networks; specific systems [such as the Honeywell secure communication processor (SCOMP)]; and a feature article in each issue on the computing environment at some site in the DOE complex. The newsletter should now be a much more immediately usable publication, rather than a historical or reseas ch-oriented document.

As an example of synergism in the DOE Center for Computer Security, the feedback obtained in the CSSO classes has significantly influenced the content of the newsletter.

4. Security Products Listing (S. J. Bogenholm, Q-4; Dennis Steinhauer, National Bureau of Standards). One item consistently requested by individuals in the DOE community has been a categorized and evaluated list of security products. Some lists are available commercially, but most are limited to a very small subset of the DOE interest, such as personal computers.

The Center has produced a draft of a comprehensive security products list. We have distributed the draft to selected individuals in the DOE community for comment and inclusion of additional items. We expect to keep this list current and to make it available to anyone in the DOE community who feels the need for such a document. Information about publication of the list will appear in computer security newsletters.

5. Security Education and Training Listing (M. Dresback, Q-4). As computer security has gained public recognition, the market for classes on the subject has grown, anc several individuals and organizations now provide computer security training. Although most of these classes are worthwhile, many of them are limited in scope, which limits their applicability to DOE programs.

The DOE Center for Computer Security is compiling a list of available computer security, education. and/or training classes with notations including comments of individuals in the DOE who have attended. We hope that this list will enable people to choose the most appropriate courses.

6. Support for Other Individuals (D. G. Harder, Q-4). The DOE Center for Computer Security has assisted several individuals either with salary support or with travel support over the last year. These individuals have had particular expertise needed by DOE, but the individuals' availability was constrained by their parent organizations.

One of these individuals was Air Force Major Mark Biladeau, a service academy research associate (SARA) employee of the Los Alamos National Laboratory during the summer of 1984. As a SARA, he provided a particular orientation to some of DOE's needs. More specifically, he developed some techniques for modeling computer networks and describing the interactions within computer networks. These techniques were fo'led into the wideband communication network (WBCN) and OPMODEL activities of the Center.

The DOE Center also can, in unusual circumstances, support the travel of particular individuals to particular functions. Two people from the National Bureau of Standards invited to give papers at the DOE Computer Security group meeting in April 1985 will have their travel expenses provided te: :low them to go. While the Center does not do this often, it can be done upon specific request from $\mathrm{DOE} / \mathrm{HQ}$ with the concuirence of Los Alamos line management.

7. Hard Disk Security Shield (D. G. Harder, Q-4). One of the major difficulities in using personal computers in a secure environment is the problem of nonvolatile storage. It usually is very difficult to lock a personal computer in a safe and equally difficult, in most cases, to remove the hard disk containing classified information from the computer. For this reason, many CSSOs and computer security operations managers (CSOMs) have expressed the need for a mechanical shield to protect hard disks on personal computers.

The DOE Center for Computer Security has pursued a contract for evaluation of available products, in case the Center has missed such products, and for the fabrication of prototypes of such a security shield for DOE. Delivery, in the late summer of 1985 , will consist of a report on shieid availability and, if appropriate, three prototypes.

After these shields are evaluated by DOE and the Center, construction plans will be made available to DOE facilities. While there is no commitment by the Center or by DOE for furt'ler purchase, experience suggests that commercial manufacturing may be the most effective way to produce such equipment.

8. Department of Defense (DoD)-Sponsored Computer Classes (J. W. Tape, D. G. Harder, Q-4). The DOE Center for Computer Security personnel attended several classes sponsored by the DoD and given by Rein Turn and Associates. These classes provide an overview for people just entering the computer security field and are especially useful for management personnel. 
The DoD Computer Center and the Natinnal Security Agency gave a second presentation of a "National Computer Security Course" (CY330). This course is designed for middle- and senior-level managers in the US government to inform thein of what is occurring in the DoD computer security community and in the US Government computer security arena. Two people from the DOE Center attended this course along with the program manager from $\mathrm{DOE} / \mathrm{HQ}$. One particularly interesting aspect of the course was the number of different perspectives on the computer security field that were presented.

9. Advice and Assistance Outside the DOE (D. G. Harder, Q-4; L. H. Baker, Q-DO/SG). Several DOE Center for Computer Security people have been asked to participate in activities outside DOE including in panel on protecting software and a computer techinology panel.

The Institute for Defense Analyses (IDA) convened a parel to study techniques availabie for protecting software from illicit copying (piracy) and, implicitly, diversion to foreign countries. Two Center personnel were among the 12 members of that panel. The resuits of the panel's deliberation were presented to the Secretary of Defense and are available from IDA.

One individual from the Center participated in the Director of Central Intelligence's computer security project as a member of the technology panel, which assessed available technologies ior improving the security level of intelligence community machines. The results of the panel's deliberations are available.

10. Other Support. As part of its support to $\mathrm{DOE} / \mathrm{HQ}$, the Center arranges for outside experts, on contract, to assist DOE I\&E teams. The Center provides a selection and a management role for these inclividuals. These consultants are among the few computer security experts in this country, and their availability, on short notice, is of particular benefit to the Center and to the DOE. The $y$ allow the Center to provide expert technical help to I \& $^{2} \mathrm{E}$ teams without directly involving Center nersonnel. As a matter of policy, the Center does not provide individuals to go with an I\&E team as technical experts because of our direct participation in pre-I\&E activities (the CSERs).

At the request of an individual from Sandia National Laboratories/Albuquerque, and DOE/HQ, the Center supported the travel of two individuals to a meeting at DOE/HQ on computer viruses. This topic is of increasing interest to DOE, despite its similarity to well-understood problems like Trojan horses, and was a matter of considerable interest in the meeting. Several people from the Center attended the meeting as well as surporting other ir. Jividuals there.
11. Management Support Tools (S. T. Smith, Q-4; J. J. Lim, Consultant). We have developed a framework for a knowledge-based expert system to perform vulnerability analyses for an environment that can be characterized as a set of definable safeguards protecting an application-specific set of generic targets from an application-specific set of generic threats. We have applied this methodology to the problem of computer security as a way of meeting, in part, the requirements in DOE Orders 1360.2 and 5636.4 to perform periodic risk analyses on computer systems that process classified, sensitive, or proprietary DOE data. The National Bureau of Standards is considering this methodoiogy as an alternative to FIPS-PUB 65, the present federal guideline for performing risk analyses on computer systems.

In the computer security application, the set of generic tilreats comprises natural hazards, direct human actions, and indirect human actions. Natural hazards include water, fire, power abnormalities; HVAC (heating, ventilating, and air conditioning) abnormalities; major hazards (such as floods, earthquakes, forest or brust: fires, and tornadoes); mairitenance and service errors; and housekeeping. Direct human actions require the presence of the adversary on the premises of the computer installation, while indirect human actions do not rixquire the adversary to be present. Examples of indirect human actions are wiretaps, dialups, data interceptions, masquerades as valid users. Trojan horses and so forth.

Generic targets for the computer security application are the physical plant, hardware, software, and documents. The physical plant includes the grounds and buildings where the computer is installed (as well as the actual room or rooms devoted to computer-related activity) and the personnel employed by the parent organization. The hardware encompasses not only the normal computer hardware but also power and HVAC and support equipment necessary to operate the computer installation and to carry out its daily business. Software is defined in the generic sense to be any information that is stored magnetically, whether it is within the computer's memory or on a portable magnetic storage device such as tapes or disks; data, programs, and operating systems are included in th: definition of software. Documents include such things as user's manuals, reports of results, program list: ngs, and dala listings (both papers containing data for input and listings of stored data and outpui listings).

The choice of the application-specific sets of generic threats is dictated by the kinds of safeguerds that musit be in place to protect the application-speci ic assets frorn the application-specific adversaries. If, for example, the targeted asset were a certain computer program stored in the computer's memory, with a backuy on magnetic tape, the safeguards required to protect that progran 
from damage or loss because of a fire or power abnormalities are different from the safeguards required to protect the same program from damage or theft by a human. By the same token, the safeguards required to protect the program from a human on the premises of the computer installation are different from the safeguards necessary to protect the same program from a human not on the premises.

Similarly, the choice of generic targets is applicationspecific. Certain kinds of safeguards are used to protect the physical plant (guns, guards, dogs, fences, physical identification, etc.), while other kinds of safeguards protect the hardware (property passes for removing hardware; standard operating procedures for maintenance, use, or service; etc.). Safeguards such as access lists and passwords are used to protect software. Documents are protected by distribution lists, proper filling procedures, and proper production procedures.

The vulneraibility assessment consists of an automated, interactive questionnaire in natural language implemented on a portable 16-bit microcomputer using commercially available standard software. It is the questicnnaire that models the safeguards system, extracting information about both the presence of, and the quality of, the set of safeguards specified for the application. This information is processed to give a qualitative picture of the level of safeguards at the installation, relative to the overall sensitivity of the work done there.

Future work will include extending the vulnerability assessment methodology, defining an application-specific set of outcorr.es, and creating a technique to measure the imfact of the outcome sel on the organization. These will be combined to produce a qualitative risk measure. Once the risk measure is established, a feedback mechanism will be devised to enable the organization to perform qualitative cost-benefit analyses to determine the relative worth of various schemes to enhance overall security.

This year our work has been presented at conferences in four countries (the United States, England, Canada, and Italy) as well as to many DOE organizations in Washington and throughout the field.

12. LAVA: An Automated Computer Security Vulnerability Assesisment Tool (S. T. Smith, Q-4; J. J. Lim, Consultant). During 1984 we presented overviews of our risk analysis framework methodology to numerous organizations throughout the federal government. We received a contract from the Nuclear Regi.latory Commission to implement a subset of the overall methodology to perform computer security vulncrability assessments. This implementation does not include assessing vulnerabilities on separate pieces of software and hardware, nor does it include the outcome scenarios or impact evaluation required for a full risk assessment.
We delivered our software package, "LAVA: Los Alamos Vulnerability Assessment," on September 27.

\section{B. Secure Computer Systems}

1. Secure Communication Processor (SCOMP) Operating System (R. C. Lindberg, E-8). The Honeywell SCOM/P, which is a modified Honeywell level 6/DPS-6 minicomputer, is a commercially available computer system designed around a securiiy kernel. The security kernel hardware is contained in a security protection module (SPM) that implements a four-ring (instruction execution domain) hardware environment to support the software capabilities. This system permits the simultaneous sharing of information among users with common interests, while denying access to that information by others without the "need to know." Also, potential users not having physical access rights are denied access to all computing resources. The Honeywell SCOMP is a Class AI secure operating system.

a. Hardware Descriprion. SCOMP satisfies the requirements of the reference monitor concept by providing complete mediation, isolation, and verification through interaction of hardware and software. The software first validates both the subject and the object by using the kernel's internal data structures and tables. It builds a data element, called a descriptor base root (DBR), for use by the hardware in the continued mediation of the desired access. The SPM mediates access to objects by using the information in the DBR. If the request is valid, the SPM maps the virtual request to a physical request and allows the desired action (read or write) to take place. If the request is invalid, a trap is generated and processed by the kernel.

Isolation of the security kernel is achieved through another hardware implementation, that of rings, or instruction execution domains. SCOMP uses four rings, with ring 0 (the most privileged ring) con taining most of the security kernel. Ring 1 also contains the security kernel; ring 2 contains the trusted software; and ring 3 (the "untrusted" ring) contains the user code. Controlled ring-crossing by less-privileged software allows performance of the various service functions (for example, read, write, or execute), while each request is simultaneously identified and validated.

Because each request for access is mediated by the hardware SPM, all input/output (I/O) can be placed outside the security kernel, thereby making the kernel quite small and compact. Also, new I/O capabilities can be added without modifying the security kernel, an obvious advantage.

b. Software Description. The SCOMP suftware consists of three major parts: the security kernel, the trusted software, and the SCOMP kernel interface package (SKIP). These elements provide for a user interface that 
allows the SCOMP to be used for development as well as for dedicated applications.

The security kernel is the heart of the SCOMP Trusted Operating Program (STOP). It functions primarily as the software portion of the reference monitor implementation by controlling access to objects in accordance with the imbedded security policy. Each object in the system (segments, devices, and processes) is uniquely identified by a 64-bit identifier that never changes during the lifetime of that object in the system. In addition, the kernel maintains both access and status information concerning an ohject, as well as ring brackets for potential subjects (owner, group, and other) that limit privileges required for access.

Trusted software is software that is relevant to security but which can selectively bypass the mandatory control mechanisms. Trusted software must be verified to ensure that it enforces the security policy so the system can operate reliably and consistently. Functions performed by trusted software must be correct because the system relies on them. For example, the editor that is used to build the user access database must be trusted (verified correct) because, if the database were not properly constructed, the log-in actions could not be assured.

Finally, the SKIP provides a filesystem, process control, and device $\mathrm{I} / \mathrm{O}$. The filesystem providied is hierarchical and multilevel. It comprises directories, tiles, and links. Access to any object is through Unix-like path names. The SKIP is protected through use of the SCOMP aing mechanism-only ring- 2 software is allowed to modify the filesystem structure.

For process control, the SKIP allows the user to create and delete processes, set priorities, and send and receive events, thereby providing an environment to build and manage applications software. The SKIP event mechanism is interrupt driven, and the user can provide handlers for different events as required. Events are queued so the user receives them in the order they occur. Because I/O devices are "owned" by a process and operate under interrupt control and because the security kernel does not support the I/O service function, users can process I/O through use of SKIP functions without violating security policy.

Other suppor processes provided include a Bournelike shell, which allows for a run-time environment; a $\mathrm{C}$ compiler; a user editor (ed); and a tape archiver (similar to tar). These tools, though minimal in both number and capabilities, allow a user to construct applications programs using SCOMP.

c. SCOMP At Los Alamos. In August 1982, Honeywell requested the DoD Computer Security Center to evaluate the SCOMP formally to determine whether the SCOMP is a class Al system. At approximately the same time, Honeywell worked with MITRE, the Naval Electronics Systems Command (Navelex), Los Alamos, and others to place SCOMP in different environments for user evaluation. Los Alamos received its first SCOMP in late 1982 and the second in early 1984.

The first SCOMP was a Honeywell Level 6 minicomputer, model 43, containing the SPM and Version 1.1 of the STOP software. Its early history was beset with both hardware and software problems that made the system unusable. Honeywell sent hardware design engineers to Los Alamos to correct the hardware problems and make the system work. Next, the software was inspected; documentation and software disagreed in most cases, and software performance was suspect. Some major flaws were discovered.

The hierarchical filesystem in SCOMP contains Unix-like discretionary access protections for all files. Because directories are considered to be files, they possess such protections. To access the contents of a direc. tory, "execute" privilege had to be given to subjects desiring such access. Certain files were piaced in that directory with different discretionary access privileges and attempts to read, alter, and delete those files were made. Direct attacks on the files themselves were properly thwared in accurdance with the mandatory and discretionary accesses assigned, but the directory itself could be deleted, thereby deleting all contents as well. This problem has been corrected by Honeywell.

No major security flaws could be found in the STOP code, but other problems in the user-operating envirenment were found and brought to the attention of Honeywell. Each time, Honeywell responded and corrected the problem; their support has been exemplary.

During this time, the DoD evaluation discovered more seriuus problems. Correction of those problems resulted in new releases of both the operating system software and the hardware SPM. Our SPMs were sent back to Honeywell for revision; when they were returned, the system again failed to work properly. Also, the software release had a major problem concerning synchronization that caused it to fail repeatedly. Honeywell again responded by sending both a hardware and a software team to Los Alamos to correct the problems, and both SCOMPs now perform correctly.

Because of the stringent security mechanisms designed into SCOMP, programming in a secure environment is difficult. To illustrate, the same diagnostic message is returned for a variety of "mistakes," for example "access denied." Several situations could cause this: the user does not have mandatory read or write permission or does not have discretionary access; the system program (editor or compiler) cannot read or write into a directory; or the device has not been assigned to the user. This lack of friendliness results fru.n attempting to avoid existence of covert channels through which very limited or no system information is given to the isce; thus preventing manipulation of system parameters. 
SCOMP is designed for highly sensitive applications where tight security must be maintained, and the software for such applications can be written for two environments-a "normal" environment, in which the user applications software resides in ring 3 ("untrusted") but which uses all the security features of SCOMP, and a "trusted" environment, in which the user applications software is built into SCOMP at ring 2 and normally is unavailable to other users. Because of the requirements of assurance and continuous protection in the security evaluation process, such code must be formally shown to be correct; that is, it must be submitted for formal evaluation as well, as it forms a change/addition/modification to STOP. Certifying trusted code by someone other than the manufacturer has not yet been addressed adequately.

We are investigating use of the SCOMP as a local area network (LAN) security controller. Functions for the controller will include user uuthentication, encryption key management, and auditing.

The DoD Center for Computer Security has completed its formal evaluation of SCOMP, and on December 24, 1984, the SCOMP was formally certified as meeting all the requirements for a Class Al system.

\section{Secure Computer Networks}

1. Link Access Control and Encryption System (E. Springer, E-8). We are developing necessary technologies for the secure protection of data communication networks. Data encryption equipment, using the Data Encryption Standard (DES) algorithm and calleci the Link Access Control and Encryption (Link ACE) systenl, protects unclassified sensitive data transmissions over unprotected lines between central computers and remote terminals.

The ACE system project was begun as an informal survey of DES devices available through the commercial markei. The DES algorithm, a mathematical operation for encrypting data, was developed by IBM researchers and approved in 1977 as the standard of the Federal Government by the National Bureau of Standards (NBS). At the time of the study, although there appeared to be an assortment of commercial companies competing for a position in the data link encryptor market, no commercial effort was directed at computer file encryption devices. As a result, the effort at the DOE Center for Computer Security at Los Alamos was initially directed at developing data file encryption devices to fill the void in the comniercial area. The Center developed a personnel acciss and data file encryption system known as the Transportable ACE system. We hoped conmercial organizations would perfect data link encryptor designs and lower the cost of such units through market expansion, but this did not happen.
Many commercial organizations dropped their link encryptor design efforts, enabling those remaining to increase the prices of their units because of weak market penetration. As a result, the Center developed a link encryptor, using the technology and hardware from the Transportable ACE system. The use of standard hardware has improved functionality and lowered cost to meet DOE requirements for unclassified sensitive data link encryption.

The Link ACE system is part of a continuing effort to produce a full range of computer and communication data-protection tools for the DOE. The Link ACE sys. tem has been installed in an operatiunal test-bed on the DOE's Central Personnel Clearance Index (CPCI) system. The CFCI system is a clearance information database network in Germantown, Mar.land, with remote terminal points at ten DOE area offices. Link ACE sysiem makes it possible to send unclassified sensitive data in a secure manner between the area offices and DOE/HQ using dial-up telephone communications. Remote Link ACE units are installed between terminals and dial-up modems at the area offices, and Master Link ACE units are instalied between the central computer and auto-answer modems ai the DOE/HQ computer facility. The Link ACE devices are used in physically protected areas, and personnel with access to these areas have a DOE "Q" clearance.

2. The New Link Ace II (E. Springer, E-8). The Center has developed an improved link encryptor, the Link ACE II, which will be used in the DOE/HQ CPCI system with the previously developed Lirk ACE. It also will be used in other sensitive, unclassified applications. This new link encryptor does the same function as the previously developed Link ACE, but tamper detection has been added for use in controlled areas with various access levels. The new unit is smaller, faster, and more cost effective than the earlier model.

Although the purpose of the Link ACE II project was to develop a pair of encryption units (one Master, one Remote) to protect unclassified sensitive data transmissions over data links between central computers and remote terminals, the Link ACE II units can be adapted easily to operate in other types of data links (between personal computers, in networks, between computers, and between networks). The Link ACE II is designed to fit on one printed circuit board, and the design logic is primarily CMOS except for the encryption chips. The DES chips used in the Link ACE II were approved by the NBS.

3. Trusted Interface for Local Area Networks (S. Mniszewski, R. Morel, E-8). Local area networks (LANs) are becoming increasingly popular in the work environment. A LAN lends itself well to applications such as office automation, electronic mail, distributed 
databases, process control, and any application that needs to share information and resources. At the same time, the need for computer security is present in all computing environments, government and industry. Data sccurity is necessary in the commercial world where day-to-day information, personnel information, and company secret data require iimited access. It is required in sensitive government applications to protect data stored in computers and to protect shared resources between UNCLASSIFIED, ADMINISTRATIVE, SECF.ET, and TOP SECRET computers. A cosily' solution is to have a separate, dedicated LAN for each security level. We are developing a multilevel secure LAN as a practical and less expensive solution.

Multilevel security for a LAN can be implemented in a number of ways. The approach we are using is to provide a trusted interface. Controlling access and protecting information on the network is the fundamental concern. Our network concepr has a centralized security controller for the LAN and individual node security devices to implement the security features. The centralized security controller, called the Trusted LAN Controller (TLC), will authenticate LAN users, authorize use of resources, manage encyryption keys, and audit security-relevant events. The node security device, which is called the Trusted LAN Interface (TLI), will handle end-to-end encryption and security-level confirmation.

a. Security Requirements. LAN security requirements comprise the protection of sensitive data from destruction, disclosure, and modification. Our system will protect sensitive data from passiv $\iota$ and aciive wiretapping, covert channels, destruction and modification, and disclosure if misrouted to improperly cleared users. Protection against security threats such as wiretapping and improper delivery will use data encryption. The covert channel threat can be minimized by limiting the number of repeated co .nmunication attempts. Auditing, encryption, and message authentication are useful in protecting against data destruction and modification.

The security perimeter for the LAN includes the TLC, the network transmission medium, and the TLI at each node. Because the computer attached to each node does not lie within the security perimeter, it does not have to he trusted. The TLI at each node handles the trusted communications within the LAN. When a node is established, the security level and capabilities must be declared and stored in the TLC authentication database. The TLC, in conjunction with the TLI, is then responsible for implementing the security for that node.

b. The Trusted Interface. Users must be authenticated to use the LAN when they log on at their home node. Whenever a user requests interaction with another node or necds the use of a resource, this communication must be authorized. Distribution of the master and session encryption keys to the node TLI units will be managed by the TLC. Communications between the node TLIs, as well as communications between the TLC and each TLI, will always be encrypted.

A LAN Security Manager must maintain the authentication and authorization information in the TLC. This individual also will be responsible for handling security infractions in real-time and for reviewing the audit trails for possible security problems.

c. Trusted LAN Controller. The TLC will handle authentication and authorization of LAN users. A database wrill be kept of users, with their classification levels, home nodes, and access rights. Every access to other LAN resources must be authorized by the TLC.

The TLC also does the encryption key management. Master keys will be distributed periodically to the TLIs. Session encryption keys are generated by the TLC, encrypted, and downloaded to the authe ized TLls. Session keys exist only for a given session and are destroyed at session termination.

The TLC will keep an audit trail of ail securityrelevant requests and events. Logged items include session start/stop times, LAN resource usage, security breaches, and access exceptions. The audit file is accessible only to the LAN Security Manager.

Security communications between the TLC and the TLIs will always be encrypted with the TLI's master key. Encrypted session keys will be sent to the TLls from the TLC when a connection has been authorized. The TLI will inforin the TLC when a session has ended, and the TLC will request that the session keys be zeroized. If inactivity occurs between session participants for longer than some chosen interval, the TLC will automatically terminate the session.

d. Trusted LAN Interface (TLI). The TLIs will perform session end-to-end encryption. Data will be buffered as necessary depending on transmission speeds. The Federal Government's DES will be provided in the test-bed if the LAN is located in a controlled area.

Each TLI will verify the security level of data coming into the node, as well as the source and destination security levels before passing data on to the destination node device. Integrity of information in the network must be preserved according to the Bell-LaPadula model. Depending on the simple security condition, access to information will be denied if the requesting user does not possess a security level at least as high as the LAN resource information. This condition is termed as "no read-up" and is related to the so-called *-property. According to the *-property, a user will not be allowed to write to an LAN resource unless the user possesses a security level equal to or lower than the LAN resource. This condition is stated as "no write-down."

The TLI will request authentication of a session connection to another LAN resource through the TLC. 
It will accept the session encryption keys and inform the TLC when a session is terminated. Erroneous access will be reported to the TLC.

e. Implementation. Our security enhancements will be incorporated into an Ethernet-type LAN with a bus topology using carrier sense multiple access with collision detection. A particular Ethernet implementation has not yet been chosen.

The TLC is planned to be a Honeywell SCOMP, the only Al-certified computer available today. We will take advantage of the built-in authentication, authorization, and auditing features.

The TLIs will be micro-based units similar to the Link ACE II encryption devices. DES encryption will be employed.

For testing, two personal computers, a Digital Equipment VAX/1 1-780, and another SCOMP will reside on the LAN as nodes at different security levels.

\section{Secure Computer Communications}

1. Wideband Communication Network (R. E. Lewis, Q-4). During 1984, the Center initiated an effort to develop a secure test-bed for the DOE wideband communication network (WBCN). This test-bed was designed to evaluate the security properties of the WBCN and similar networks (for example OPMODEL) and to provide a secure environment in which to test alternatives for WBCN implementations.

Because of his recognized expertise in secure communications, one of the Center's personnel was asked by DOE/HQ to lead a task force to develop a security plan for the WBCN and to assist in the development of a security plan for the Secure Albuqueique Operations Systems Architecture.

\section{OPERATIONS SECURITY (OPSEC) AND VUL- NERABILITY ASSESSMENTS (VAs) (T. D. Bearce, Q-4)}

This year saw significant growth in DOE-sponsored OPSEC activity with the establishment of the DOE Center for Operations Security at Los Alamos. Although the formal establishment date for the Center was October 1,1984 , the concept was approved in May, and significant effort was undertaken to have the Center operational at the beginning of FY 1985. The major functions of the Center are
- coordinate and establish fiscal year vulnerability assessment (VA) schedule

- coordinate, schejule, and conduct pre-VAs and VAs

- coordinate, schedule, and conduct OPSEC advice and training

- produce, publish, and distribute the DOE Security Operations Bulletin

- produce, coordinate, publish, and distribute OPSEC procedural guidance

- coordinate, schedule, and conduct the Annual OPSEC Workshop

As a part of the preparation for bringing the Center to an operational status, staffing levels for the Center were established and hiring actions were undertaken.

\section{A. Vulnerability Assessments}

Five vulnerability assessments were conducted during the year by Los Alamos and contractor personnel. Additional emphasis was placed on computer vulnerabilities by having computer specialists, from both Los $A$ lemos and contractors, assigned to the VA teams. The VAs conducted during this reporting periud were

Richland/Hanford Site March 12-30

(FY 1984)

Bendix, Kansas City May 8-23

(FY 1984)

L:wrence Livermore

National Lab.

July 17-Aug. 3

(FY 1984)

Sandia National

Laboratory, Alb.

Sept. 10-28

(FY 1984)

Nevada Operations

Office, NTS

Oct. 29-Nov. 16

(FY 1985)

All five VAs have been briefed at their respective locations, at the cognizant DOE Operations Office. and at DOE/HQ. Final copies of the Richland, Bendix, and Livermore reports have been sent to DOE for distribution. DOE authorization has been received for the Sandia report, and the Nevada final report is pending DOE approval.

The Center has coordinated and scheduled specific times and dates for the conduct of five of the six VAs (and pre-VAs) to be conducted during FY 1985. 


\section{B. Advice and Assistance}

During the reporting period, advice and assistance were provided to several DOE Operations Offices and $\mathrm{DOE} / \mathrm{HQ}$. Advice and assistance activities were

- April

Oak Ridge Operations

Office/Y-12-environmental issues

- May

Richland Operations

Office-classification issues for

N-Reactor

- June

Chicago Operations

Office-OPSEC programs for

unclassified contractors

- October

Nevada Operations Office-their OPSEC program and the in-house VA they conducted

Albuquerque Operations

Office-OPSEC at Sandia National

Laboratories, Albuquerque

- November Oak Ridge Operations

Office-OPSEC briefing maierial

The Rocky Flats Plant OPSEC

Coordinator visited the Los

Alamos OPSEC Center to discuss OPSEC.

The Mound Laboratories OPSEC Coordinator visited the Center to discuss Mound's OPSEC program and to invite Center participation in a Mound OPSEC seminar to be held in February 1985.

- December Oak Ridge Operations Office OPSEC Coordinator visited the Center to discuss their OPSEC program.

Discussions-with San Fraricisco Operations Office personnel for Center advice and assistance visits to California during early 1985

-with Savannah River Operations Office for the Center to visit them in January 1985 for advice and assistance on their OPSEC program -with DOE Headquarters for

Center support in the design and implementation of an OPSEC program for the DOE portion of a major national program

\section{Education and Training}

During May and June, in cooperation with Bendix, Kansas City, a classified training/education video tape on the conduct of a vulnerability assessment was completed. This tape has been used by the Center, $\mathrm{DOE} / \mathrm{HQ}$, and several DOE operations offices during briefings and OPSEC educational presentations and will be used as part of a three-day VA training course being developed by the Center.

We have developed an unclassified OPSEC briefing that consists of three parts: DOE OPSEC program overview, threat, and conduct of a VA. It will be distributed during 1985 .

The first draft fo: a three-day training course on how to conduct a VA was completed in December. The course will be refined, prepared for DOE approval, and distribu: ?d/piesented during 1985.

\section{DOE Security Operations Bulletin}

The DOE Security Operations Bulletin was reformatted by the Center, and the first Center-produced edition was distributed during November. The Bulletin is a classified publication and will include articles concerning OPSEC, counterintelligence, computer security. terrorism, document/information security, and other topics of interest to managers and security personnel.

\section{E. OPSEC Guidance}

OPSEC has distributed two published volumes during this reporting period.

\section{F. OPSEC Workshop}

Workshop proceedings are under way for a workshop held during this reporting period. 


\section{PART 3. SAFEGUARDS TECHNOLOGY DEVELOPMENT}

\section{EQUIPMENT DEVELOPMENT AND ENGI- NEERING}

\section{A. NDA Technology Development}

1. Flowing Fissile Assay System (L. G. Speir, E. L. Adams, J. E. Stewart, Q-1). We are developing a method to measure mass flow rates and ruclear materials concentrations in the solution streams of nuclear processing plants (Fig. 24). An assay is accomplished by pumping the solution through an irradiation chamber* where it is activated by a ${ }^{252} \mathrm{Cf}$ neutron source. The activated solution then flows through detectors that measure delayed neutrons and delayed gamma rays. The delayed-neutron signal is proportional to concentration, and the delayed-gamma-ray signals, measured at two different distances from the irradiation chamber, can be used to determine volumetric flow rate and concentration.

Uranium nitrate solutions, with a concentration of $300 \mathrm{~g} / \mathrm{l}$ and enriched to 0.19 and $17.43 \%$ in ${ }^{235} \mathrm{U}$, were measured during 1984. We expect to measure the $17.43 \%$-enriched uranium solution at several concentrations in 1985. The results of the measurements are shown in Figs. 25 and 26. A multiplication factor of 1.55 was observed between the 0.19 - and $17.43 \%$-enriched uranium solutions. This agrees with calculations that

-The irradiation chamber is in the international patent process. US Patent No. 4,464,330 was issued on August \%, 1984. use an "infinite," 1/2-in.-thick, 20\%-enriched uranium nitrate solution.

This technique for measuring flowing streams may also have application in uranium solution mining, oil shale recovery, coal slurry transportation, and any flowing process that can be induced to give a nuclear signature.

2. Surface Analysis of Plutonium Metal by EnergyDispersive X-Ray Fluorescence (M. C. Miller, T. K. Li, Q-1). We are helping Los Alamos group MST-13 personnel investigate the feasibility of a nondestructive assay method to determine whether low-Z elements are homogeneously distributed in plutonium metal. The low- $Z$ elements of interest are aluminum, calcium, magnesium, and zinc. They may compose $1 \%$ to $10 \%$ of the plutonium metal cylinder $(7.6 \mathrm{~cm}$ long by $3.8 \mathrm{~cm}$ in diameter). A possible solution is a scan surface analysis using energy-dispersive $x$-ray fluorescence.

This measurement poses special problems because of the low energy of the $x$ rays of interest (for example, the 1.3-keV $\mathrm{Mg} \mathrm{K} \alpha \mathrm{Al} \mathrm{K \alpha}$ and the 1.5-keV). Only about 3\% of the 1.3-keV $\mathrm{Mg} \mathrm{K \alpha} \times$ rays will be transmitted through $1 \mathrm{~cm}$ of air and a 1 -mil beryllium window. We have shown detection capability by fluorescing solid pieces of aluminum and magnesium (as well as other materials) using a KEVEX PXS 1 series portable $X$-ray source ( 25 $\mathrm{kV}, 2.0 \mathrm{~mA}$ maximum) and a KEVEX $30-\mathrm{mm}^{2} \mathrm{Si}(\mathrm{Li})$ detector with 1-mil beryllium window and resolution of $180 \mathrm{eV}$ at $5.9 \mathrm{keV}$. The measurements were conducted

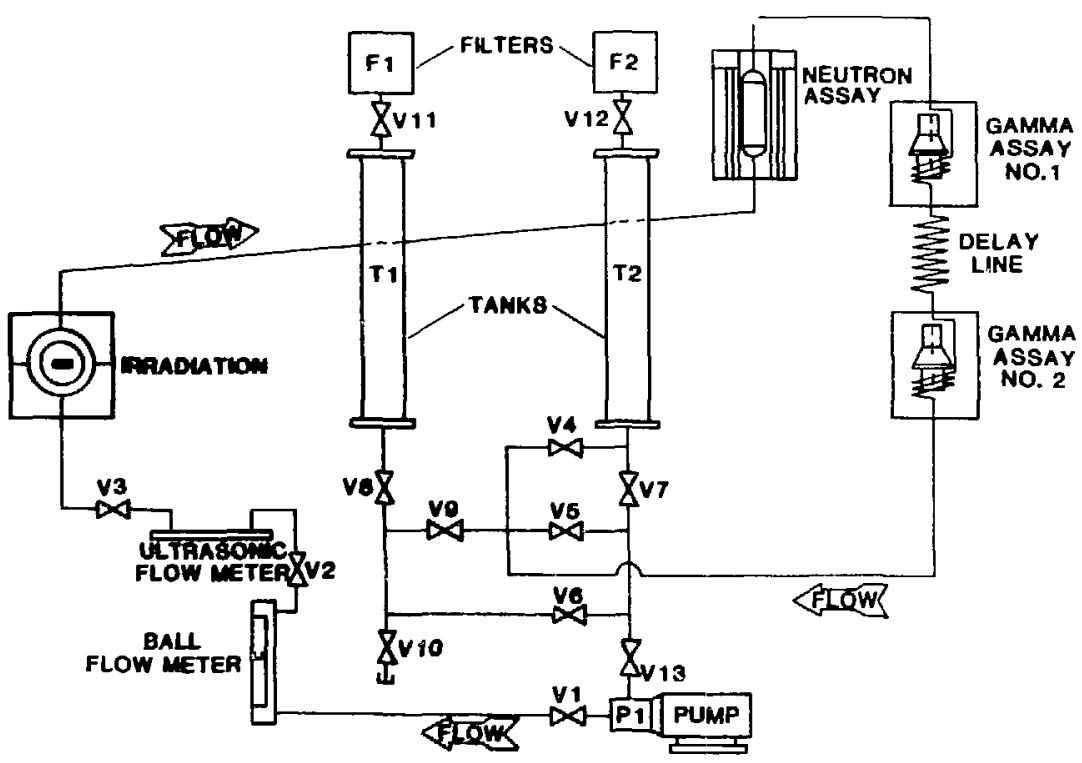

Fig. 24. Diagram of the flowing fissile assay system. 


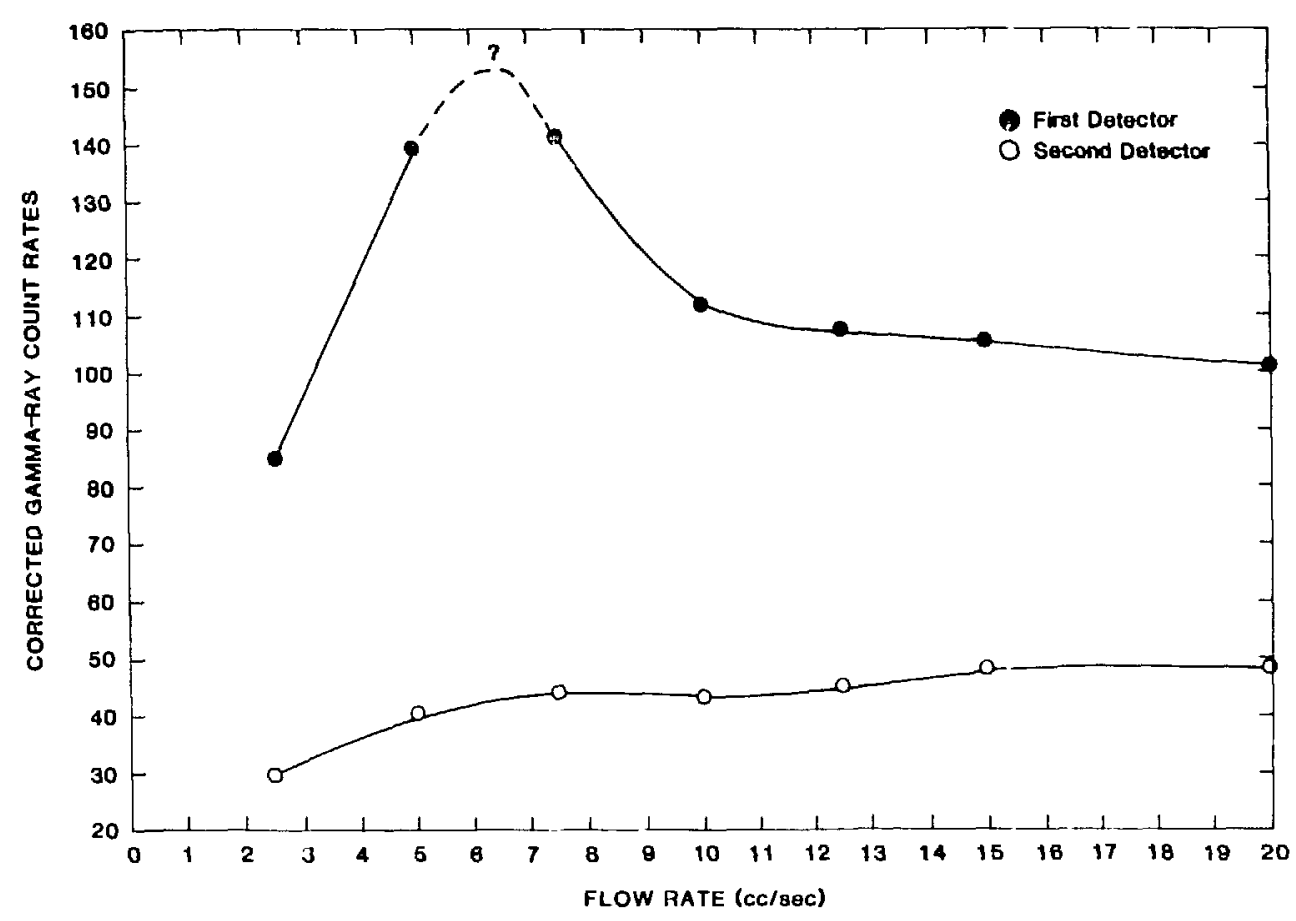

Fig. 25. Corrected gamma-ray count rates in detectors 1 and 2 (see. Fig. 24) as a function of flow rate for the $0.19 \%$-enriched uranium nitrate solution. Notice that here is an optimum fiow rate at which the count rate in the two detectors differs by a maximum amount.

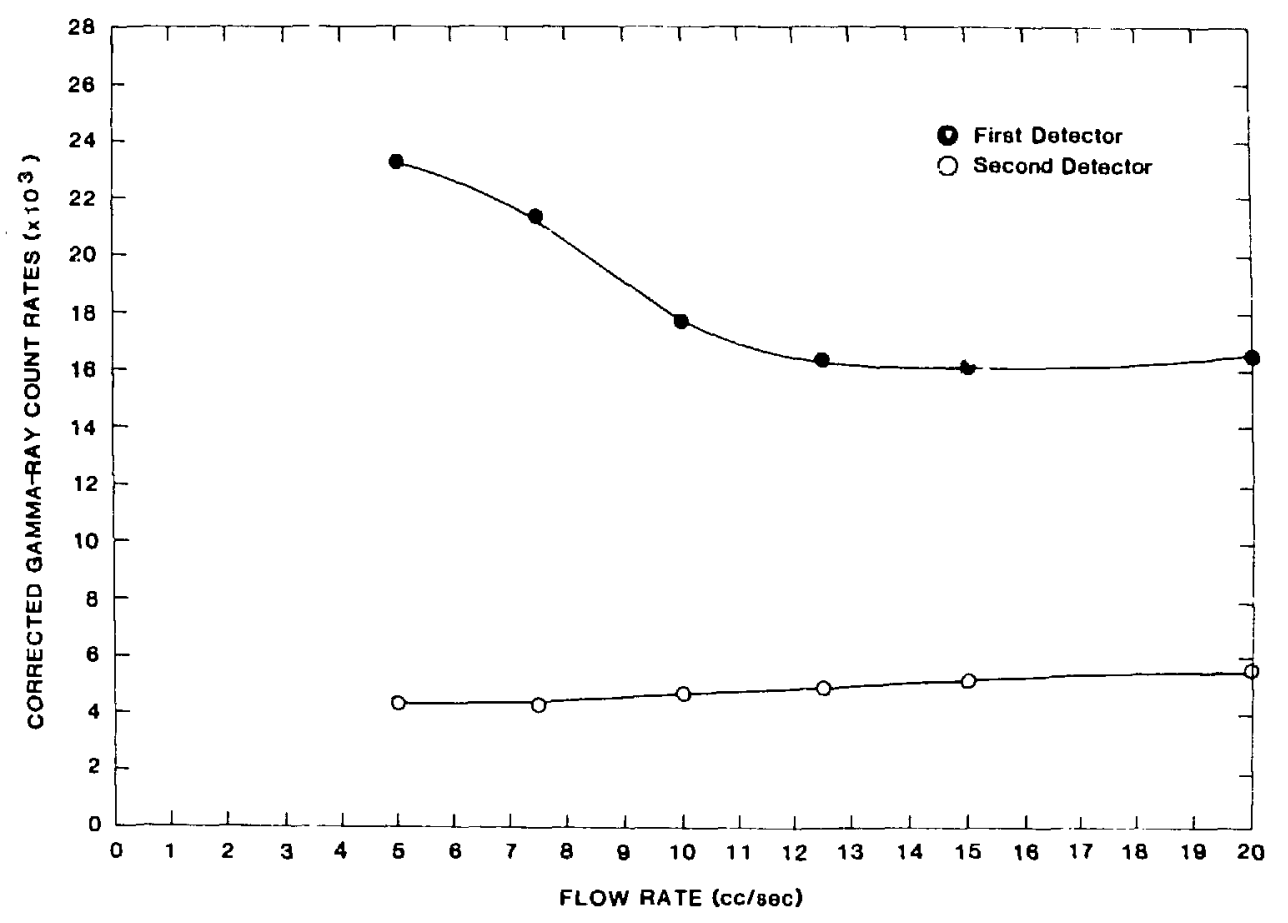

Fig. 26. Corrected gamma-ray count rates in detectors 1 and 2 (see Fig. 24) as a function of flow rate for the $0.19 \%$-enriched uranium nitrate solution. Notice that the optimum flow rate appears to be at a lower value than observed for the depleted uranium solution. 
in an air path with a "back-angle" type geometry. Figure 27 is a typical spectrum showing the resolution of the $\mathrm{K} \alpha$ lines of magnesium and aluminum along with other elemental lines. (Notice the presence of the $2.9-\mathrm{keV} \mathrm{Ar}$ $\mathrm{Ka}$ line, which is due to the air path.) This result is encouraging.

Further studies under way include

- conducting measurements in a nonair path, such as heliunı or a vacuum, with a detector that has better resolution and a thinner beryllium window and

- alternative excitation sources such as gamila rays or alpha particles that would provide a more compact setup and may be more compatible with glovebox operation.

3. A Compact Continuum $L_{111}$-Edge Densitometer (P. A. Russo, J. K. Sprinkle, Jr., M. L. Brooks, Q-1). We have designed a new $\mathrm{L}_{\mathrm{lll}}$-edge densitometer around a compact, commercial $\mathrm{x}$-ray generator weighing less than $5 \mathrm{~kg}$. Figure 28 is a scale drawing of the instrument showing the $\mathrm{x}$-ray generator, sample cell, collimation assembly, and detector. Figure 29 is a photograph of the equipment.

The direct-current generator $x$-ray spectrum was tailored to produce a continuum of $x$-ray energies from 14 to $20 \mathrm{keV}$. The $x$ rays were transmitted through $1-\mathrm{cm}-$ thick uranium reference solutions, and the measured trausmissions near the uranium $\mathrm{L}_{\mathrm{II}}$-absorption edge were used to compute the calibration constant, $-\Delta \mu X$, for the uranium concentration assay. Figure 30 shows the measured calibration constant as a function of the uraniu $\mathrm{n}$ reference concentration.

In the concentration range from 5 to $50 \mathrm{~g} / \ell$, the assay precision for 30 -min count times was $0.5 \%(1 \sigma)$ or better, and the flatness of the specific assay response was better than $0.5 \%(1 \sigma)$. Thus, the precision and acc'racy of this compact densitometer are equal to those demonstrated previ susly $y^{40-45}$ for the L-edge technique. The compact dimensions and optimized transmission geometry increase the practicality, versatility, and range of the L-edge applications.

A detailed report on the evaluation of this new compact instrument has been completed. ${ }^{46}$ We are expioring the use of new, commercial room-temperature solid state detectors to further simplify and comoact the equipment for L-edge measurements.

4. Discrete-Source $L_{m}$-Edge Densitometry (P. A. Russo, R. B. Strittmatter, M. L. Brooks, J. R. Wachter, Q-1). The in-plant applications of absorption-edge densitometry for routine assays of uranium or plutonium element concentrations have involved K-edge measurements only. ${ }^{41}$ The instruments use small, radioisotopic transmission sources of discrete gamma rays $(121.1 \mathrm{keV}$ from ${ }^{75} \mathrm{Se}, 122.1 \mathrm{keV}$ from ${ }^{57} \mathrm{Co}$, and 109.8 and 130.5 $\mathrm{keV}$ from ${ }^{169} \mathrm{Yb}$ ) to bracket the $\mathrm{K}$ edges of plutonium (at $121.8 \mathrm{keV}$ ) and uranium (at $115.6 \mathrm{keV}$ ). The compact configuration that can be achieved at the measurement station by using transmission sources of this type

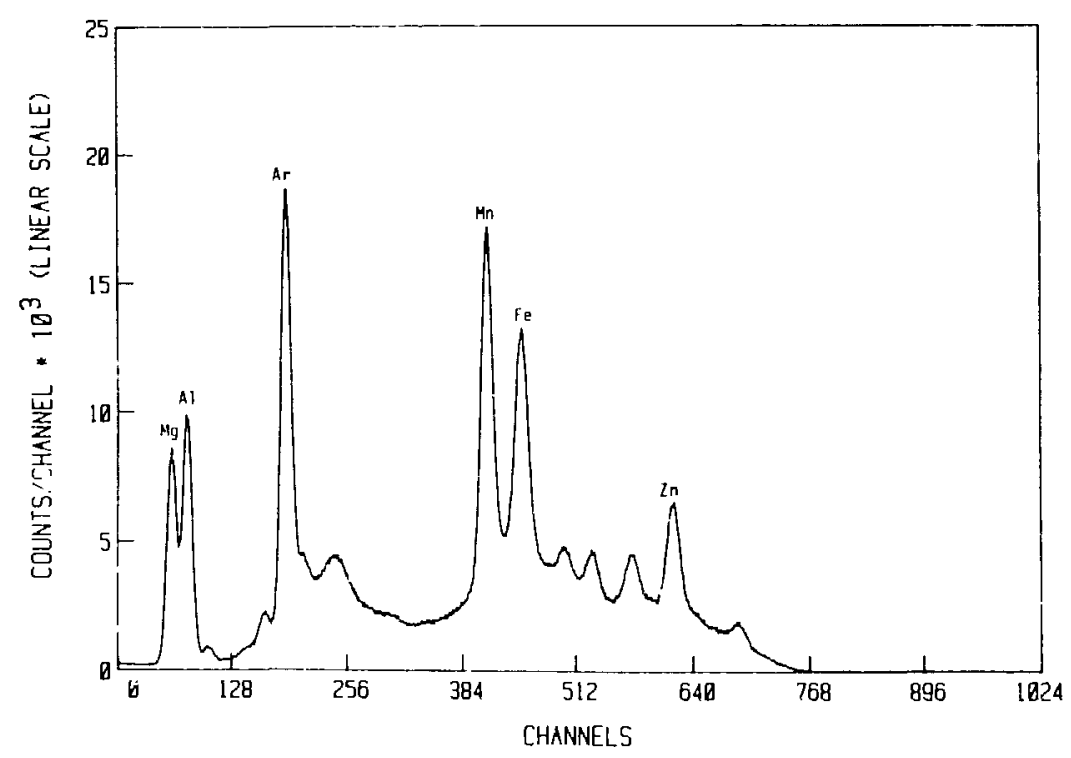

Fig. 27. Typical low-energy spectrum using an $\mathrm{x}$-ray generator and $\mathrm{Si}(\mathrm{Li})$ detector. Major peaks are (energies in kiloelectron volts): $\mathrm{Mg} \mathrm{Ka(1.3),} \mathrm{Al}$

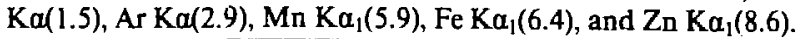




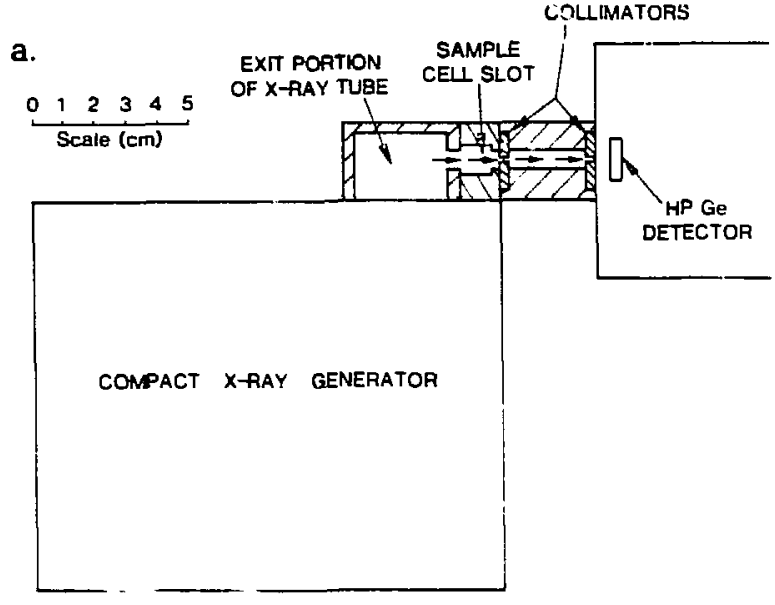

b.

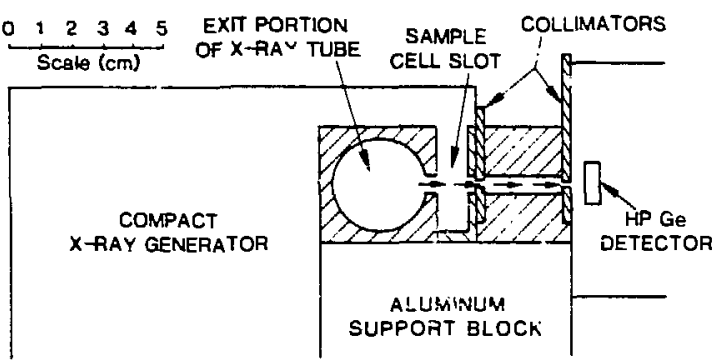

Fig. 28. Scale drawing of cruss-sectional views of the compact $\mathrm{L}_{\text {In }}$-edge densitometer. View (a) is a horizontal cross section through (and paraliel to) the collimated $x$-ray beam; view (b) is the analogous vertical cross sertion showing the $\mathbf{x}$-ray generator, sample cell slot, collimation, and detector. The cross-hatched material is brass. The horizontal arrows show the path of the x-ray beam.
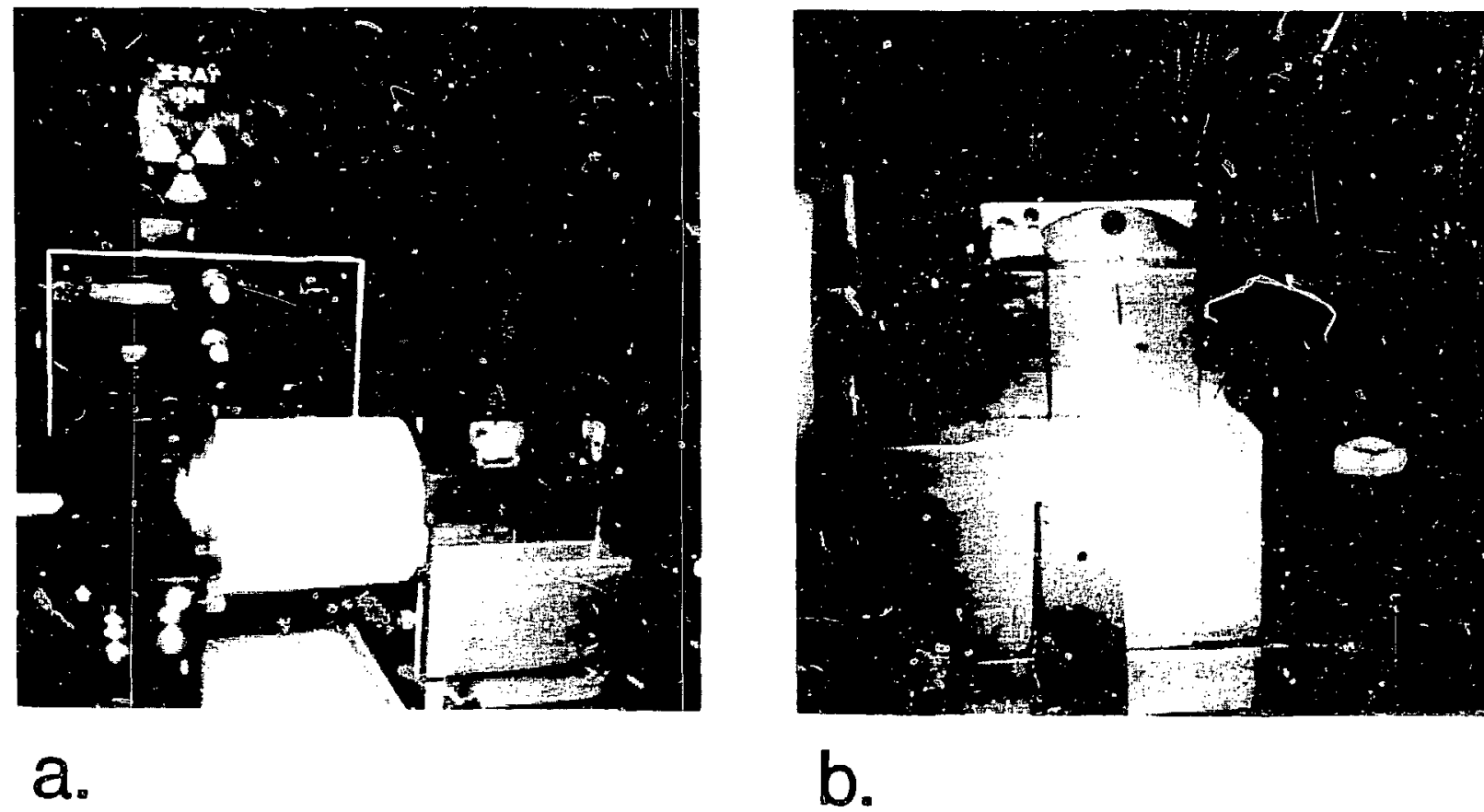

Fig. 29. Photueraph of the compact $\mathrm{L}_{\text {III }}$ edge densitometer. View (a) shows beam collimation hardware between the $\mathrm{x}$-ray generator and the detector, as well as the control box for the $\mathrm{x}$-ray generator; view (b) is a close-up of the beam colimation hardware with one of the 0.16 -crn-diam collimators and a sample cell in the foreground. 


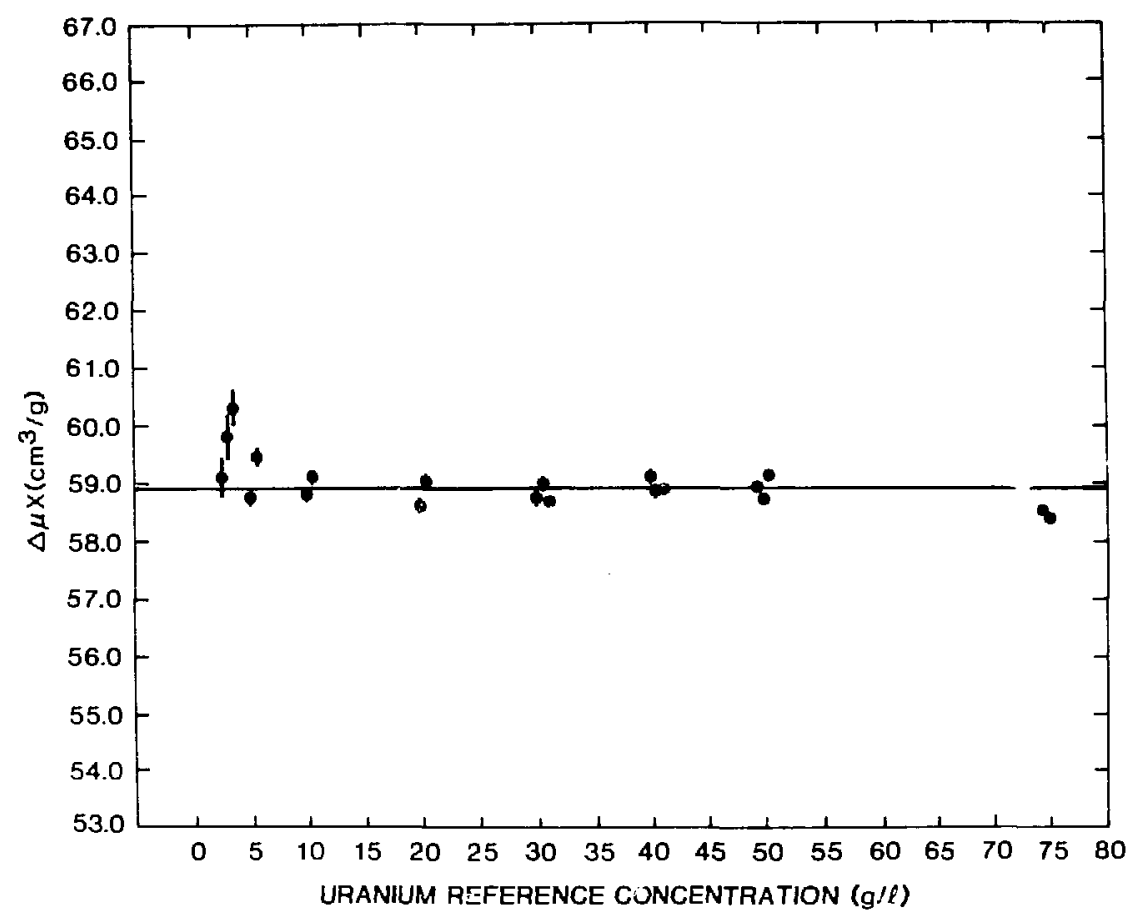

Fig. 30. A plot of $\Delta \mu \mathrm{X}$, the calibiation constant, calculated from the measured transmissions as a function of uranium reference solution concentration. Each horizontal grouping of points actually corresponds to a single reference solution concentration. Each individual point within a grouping is obtained with a different sample from the same reference solution stock. The error bars give the standard deviation in the data. The horizontal line is the weighted average of $\Delta \mu \mathrm{X}$ computed in the $5-$ to $50-\mathrm{g} / \mathrm{l}$ concentration range.

simplifies the shielding and instrument hardening requirements in areas where space is limited and atmospheres are corrosive.

The K-edge measurements give timely (30-min count periods) and precise $(0.5 \%$ or better) results for uranium or plutonium concentrations that exceed $50 \mathrm{~g} / \mathrm{l}$. However, to achieve this precision from the absorption-edge assay technique at lower concentrations, more sensitive measurements must be performed at the $\mathrm{L}_{111}$-absorption edge where the magnitude of the change in $\mu$ is nearly 10 times that at the $K$ edge.

Because there are no convenient radioisotopic sources that bracket the $\mathrm{L}_{\mathrm{III}}$-absorption edges, continuum (bremsstrahlung) sources, provided by $\mathrm{x}$-ray generators, have been used. ${ }^{41-44}$ The large size of this equipment and the possible additional maintenance requirements have made these instruments less acceptable to facility operators.

We have carried out experiments using secondary radioisotopic sources in an effort to diversify tise L-edge applications. The $22-\mathrm{keV}$ silver $\mathrm{x}$ rays emitted by' $\mathrm{a}^{102} \mathrm{Cd}$ radioisotopic source were used to fluoresce $K x$ rays from nonradioactive foils of niobium and molybdenum. These $x$ rays bracket the uranium $L_{1 I^{-}}$ absorption edge as shown in Table VII. The fluoresced $x$ rays were transmitted through reference solutions of uranium. The transmitted intensities were measured, and the $\mathrm{L}_{\mathrm{II}}$-edge assay results were evaluated.

Figure 31 shows the source-sample-detector geometries for the $\mathrm{L}_{\mathrm{W}}$-edge measurements. Spectra representative of the data used to analyze uranium solutions are shown in Fig. 32, where the dashed line represents the uranium $\mathrm{L}_{\mathrm{wr}}$-absorption edge. The upper figure shows the photopeaks of the molybdenum and niobium $\mathrm{K} x$ rays with no sample present, and tise lower figure shows the photopeaks after the $x$ rays passed througt a $20-\mathrm{g} / \mathrm{l}$ uranium solution.

The measured transmissions of the fluoresced $x$ rays through the uranium reference solutions were used to obtain the calibration constant, $-\Delta \mu_{\mathrm{u}} \mathrm{X}$, for the uranium $\mathrm{L}_{\mathrm{III}}$-edge assay. Figure 33 shows the calibration constant as a function of reference solution concentration obtained with three different reference solutions using different collimator diameters. These results were obtained using the measured transmissions of the $\mathrm{K}_{\alpha}$ and $K_{\beta}$ photopeaks of niobium at 16.6 and $18.7 \mathrm{keV}$, 


\section{TABLE VII. Data for Measurement Design}

\begin{tabular}{cccccc} 
& $\begin{array}{c}\text { Lin-Edge } \\
\text { Energy }\end{array}$ & & & \multicolumn{3}{c}{$\begin{array}{c}\text { L-X-Ray Peak Centroids } \\
\text { (keV) }\end{array}$} \\
Element & (keV) & Mixture & Foil & $\mathbf{K}_{\mathrm{a}}$ & $\mathbf{K}_{\boldsymbol{\beta}}$ \\
\hline & & & & & \\
Th & 16.30 & Th-U & Y & 14.9 & 16.7 \\
$\mathbf{U}$ & 17.17 & Th-U & Nb & 16.6 & 18.7 \\
$\mathbf{U}$ & 17.17 & U-Pu & $\mathbf{Z r}$ & 15.7 & 17.7 \\
Pu & 18.06 & U-Pu & Mo & 17.4 & 19.7 \\
\hline \hline
\end{tabular}

respectively. The average result of the plotted points is shown as a horizontal line. The relative standard deviation in the data used to compute the average is $1.3 \%$. This scatter is consistent with expected random uncertainties based on counting statistics. We are preparing a detailed report on these discrete $\mathrm{L}_{\mathrm{lII}}$-edge measurements.*

The results shown in Fig. 33 prove the principle of the secondary source $L_{\text {IIT-edge assay. Table VII suggests foils }}$ that can be used to analyze the elements thorium, uranium, and plutonium (which niay be present in

*M. L. Brooks, J. Wachter, P. A. Russo, and R. B. Strittmatter, "Discrete Source $\mathrm{L}_{111}$-Edge Measurements of SNM Concentration for Near-Real-Time Accounting." mixed solutions) by this assay method. The measurement design in each case is very simple.

The use of secondary discrete sources for the $\mathrm{L}_{\mathrm{III}}$-edge assays has, however, several disadvantages compared to the use of the $\mathrm{x}$-ray generator.

- The count rates with a reasonable primary source strength $\left(50 \mathrm{mCi}\right.$ of $\left.{ }^{109} \mathrm{Cd}\right)$ are 5 to 10 times less than optimum.

- Because the primary source strength is fixed, the useful concentration range that can be measured is reduced.

- The relatively large energy difference between the two photopeaks used for the assay introduces a

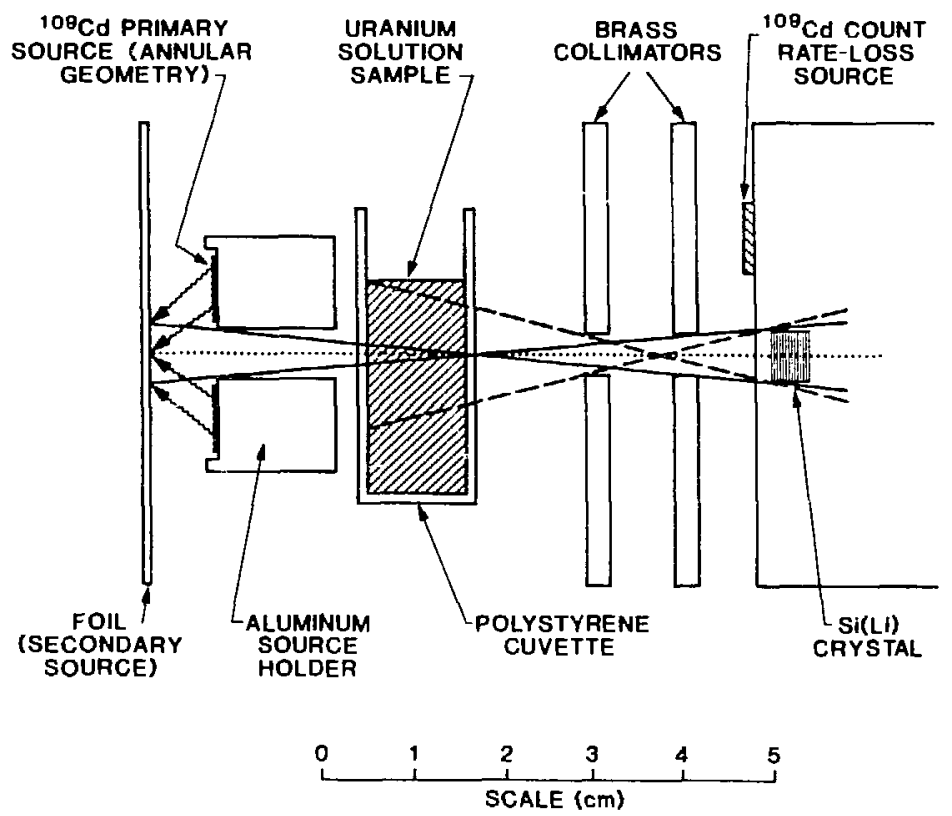

Fig. 31. Geometry of the discrute-source L-edge measurements. The dotted and solid lines from the foil to the detectoi show the minimum and maximum transmission path lengths respectively through the suliution. The dashed lines indicate the detection geometry. 

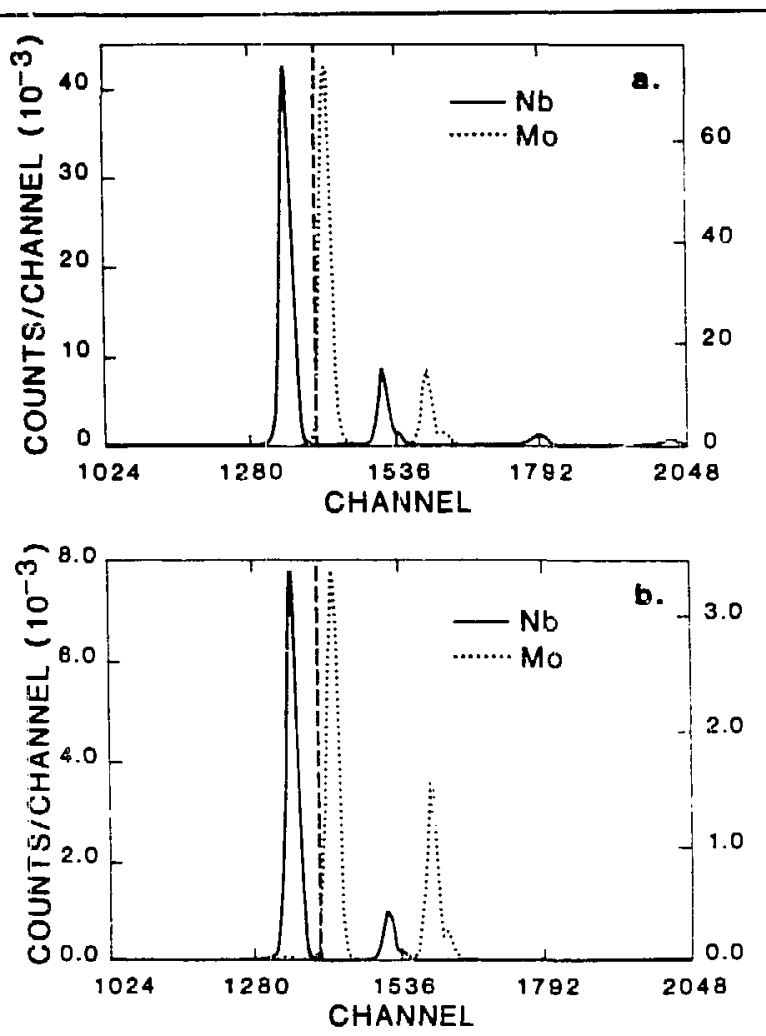

Fig. 32. The fluoresced $K_{a}$ and $K_{\beta}$ peaks of niobium and molybdenum (a) without a sample present and (b) after passing through a $20-\mathrm{g} / \mathrm{l}$ uranium solution. The dashed line is the uranium $L_{\pi I}$-absorption edge at $17.168 \mathrm{keV}$. The left vertical scale is for the niobium spectra and the right vertical scale is for the molybdenum spectra.
Fig. 33. Calibration constant, $-\Delta \mu_{u} x$, vs uranium concentration. The three gro"ps of points are eight data points obtained with the $19.98 \mathrm{~g} / \mathrm{l}$ uranium solution, eight points with the $39.83 \mathrm{~g} / \mathrm{l}$ solution, and one point with the $61.84 \mathrm{~g} / \ell$ solution. Each data point is the mean of two or three repeated 10 -min iuns. Each error bar gives the random uncertainty (one standard deviation) in the mean computed from counting statistics. The solid horizontal line is the unweighted average resuit: $0.0359 \pm 0.0001 \mathrm{~g} / \mathrm{l}$.

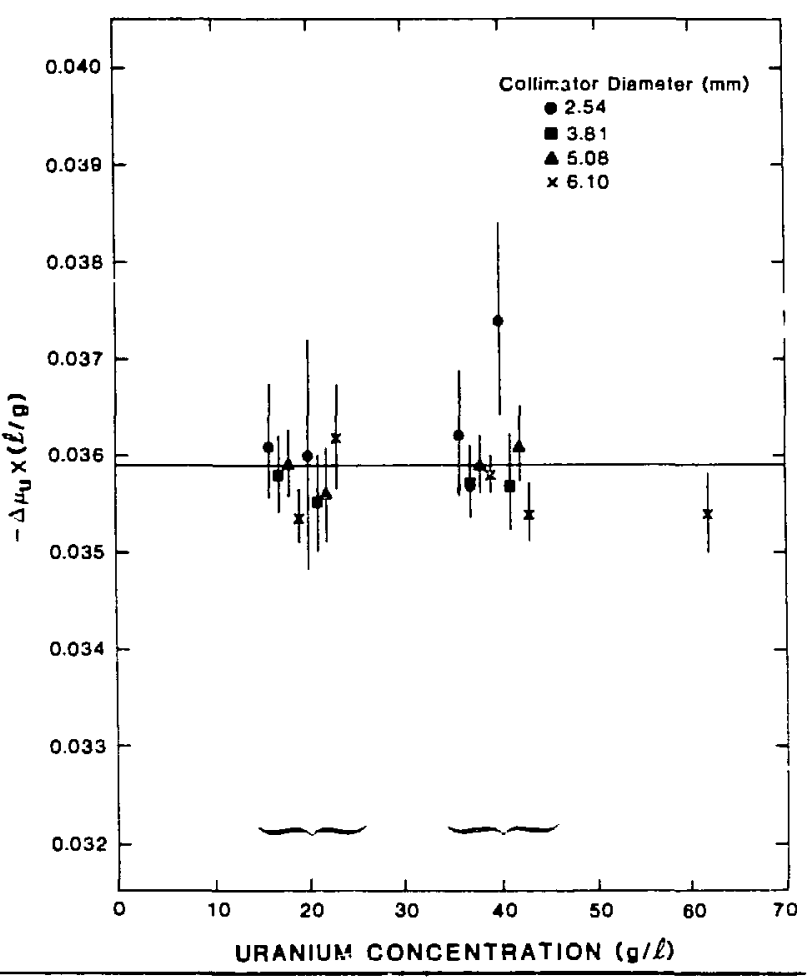


large matrix term into the assay. (This is avoided with the $\mathrm{x}$-ray generator continuum source by extrapolation of measured transmissions to the $\mathrm{L}_{11 r}$ absorption edge.)

Because of these disadvantages, we recommend that the compact $x$-ray generator ${ }^{4 i}$ be used, if possible, instead of secondary discrete $\mathrm{x}$-ray sources for $\mathrm{L}_{\mathrm{LI}}$-edge applications.

5. Test and Evaluation of TEWA System (\$. -T. Hsue, E. L. Sanford, Q-1; R. Dewberry, SRL). The test and evaluation (T\&E) of th $e$ Technique for Effluent Waste Assay $^{47}$ (TEWA) system was initiated at the request of the SRL as a part: of upgrading the FB line online analysis capability in the $F$ canyon. One type of solution generated is the $2 \mathrm{AW}$ waste stream from the second separation cycle. These solutions iypically contain low plutonium concentrations (up to $100 \mathrm{mg} / \mathrm{l}$ ) and relatively high americium concentrations (americium/plutonium ratios of up to 15\%). Two techniques have been selected for T\&E to select the appropriate method to assay these waste solutions: the OnLine Alpha Monitor (OLAM) and the TEWA.

TEWA is a continuation of our effort to develop assay techniques for waste solutions generated in plutonium processing plants. The first assay system of this type (LOSAI ${ }^{48}$ ) was installed at the recovery section of the Los Alamos Plutonium Facility in the fall of 1982 and has been in use ever since. Both the LOSAI and TEWA systems are based on the monitoring of the passive $L x$ rays to determine the plutonium concentration and/or americium concentration. The major improvement of the TEWA over the LOSAI system is the incorporation of the response function technique. The $\mathrm{L} x$-ray spectrum from this type of solution is rather complex; an example of the complexity of this region is indicated in Fig. 34, which shows the $L_{\beta}$ spectrum from $15 \mathrm{keV}$ to 18 $\mathrm{keV}$. There are a total of twenty $x$-ray peaks of various energies and intensities in this region. Also shown are the response functions for both the plutonium and americium components, each of which conisists of ten peaks. By means of least-square fitting to the spectral data, the two "heights" corresponding to the plutonium component and the americium compone it can be determined. The product of the plutonium "height" and the plutonium response function is proportional to the concr $^{r}$ :tration of plutonium in the solution. The data shuwn in Fig. 34 are from $\Rightarrow$ sample with an americium/plutonium ratio of 0.05 . As the americium fraction increases, the determination of the plutonium becomes increasingly difficult. Beyond a certain value of the americium/plutonium ratio, the determination of the plutonium is impossible without a chemical separation. The purpose of the current T\&E is to determine (1) the precision and the bias of this technique for plutonium and/or americium determination and (2) the maximum americium/plutonium ratio this technique can tolerate without a chemical separation.

The TEWA system was developed between March and October of 1983. The installation of the system occurred in the month of November. After the initial

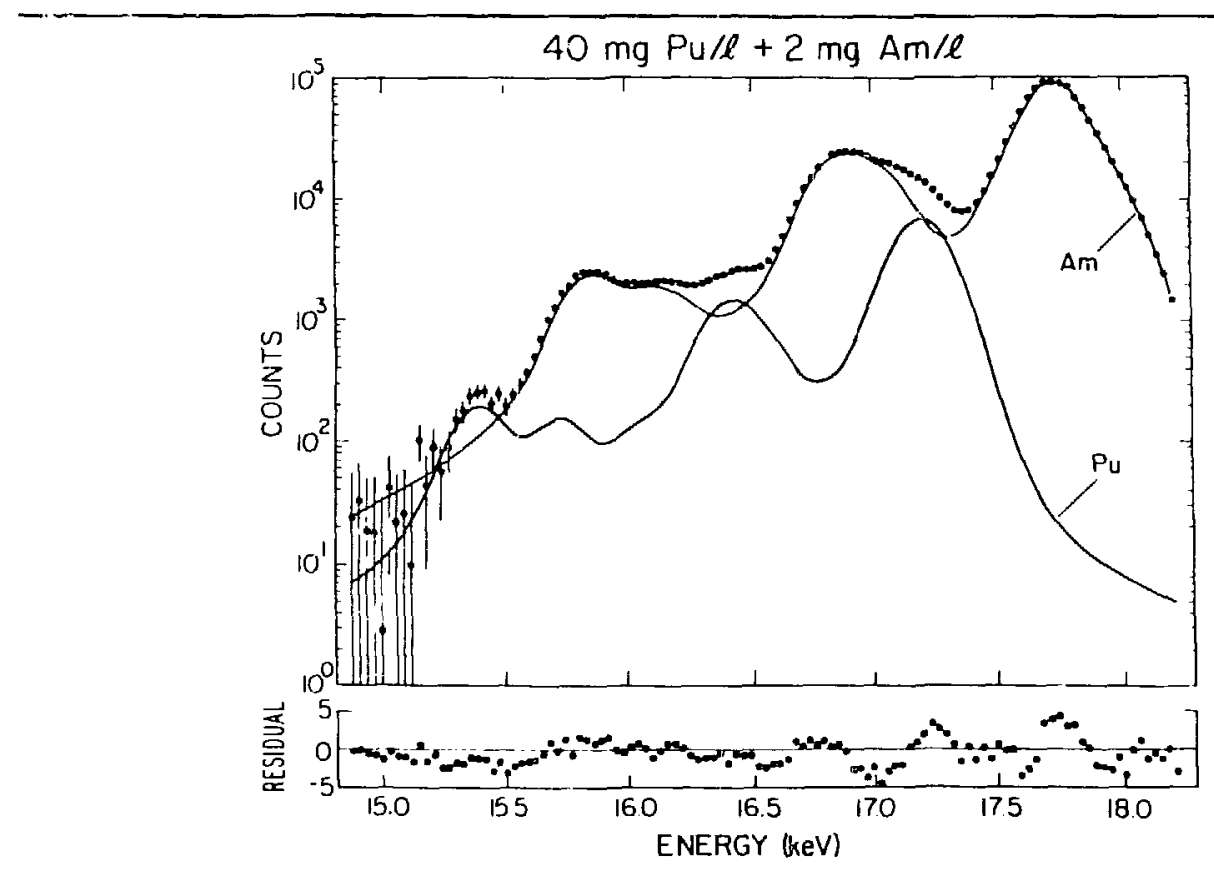

Fig. 34. $\mathrm{L}_{\beta} \mathrm{x}$-ray spectrum from an americium/plutonium mixed solution. 
installation and calib:ation, a set of 25 samples was prepared that ranged in americium/plutonium ratio from 0 to 0.3 and in plutonium concentrations from 5 to $100 \mathrm{mg} / \mathrm{R}$. All the samples were matrix matched to the $2 \mathrm{AW}$ solution of the $\mathrm{FB}$ line, and each sample contained $5 \mathrm{ml}$ of solution. Table VIII summarizes the measurement results and compares these samples. The chemical values were obtained by alpha counting with an accuracy of $10 \%$. The solutions were pipetted into small vials, and the vials were placed in the sample holder inside a glove box for assay. A Si(Li) detector viewed the sample from below the glove box through a 65 -mil-thick Lexan window. The typical assay time was $1000 \mathrm{~s}$. For the plutonium assay, the comparison ratios (NDA measurement divided by chemistry result) have an average of 0.992 with a standard deviation of $5.3 \%$ for the 25 samples. The TEWA system shows little or no bias in the plutonium determination. Variations in americium/plutonium ratios appear to have little effect on the plutonium determination. For the americium assay, the comparison ratios have an average value of 1.089 and a standard deviation of $7.1 \%$. The TEWA system seems to be biased high in the americium assay, but the bias could be removed by changing the calibra- t.on constants because there is no obvious dependence of the bias on americium concentration.

After these samples had been measured and studied, ve decided to investigate the sensitivity limit of the J'EWA system. For this purpose another set of 40 samples was prepared. The plutonium concentration of these samples ranged from $30 \mu \mathrm{g} / \mathrm{l}$ to $600 \mu \mathrm{g} / \mathrm{l}$ with a rninimum amount of americium. The measurement results of this set of samples are summarized in Table IX. The comparison ratios have a standard deviation of $16 \%$, and the calibration constant determined for this set of samples differs from that of the previ-us set by a factor of 2 . The reason for this difference is not understood. It is possible that the relative position between sample and detector has changed. It is also possible that for these relatively low-concentration samples the background continuum subtracted from the actual data to jenerate the net, or residual, counts (Fig. 34) takes on enhanced importance compared with that of a highconcentration sample. It is perhaps expecting too much for one calibration constant to be valid over four orders of magnitude in concentration. It is quite easy tc select the appropriate calibration constant from the software depending on the concentration range.

TABLE VII. TEWA Test and Evaluation at SRL High-Concentration Range

\begin{tabular}{|c|c|c|c|c|c|c|c|}
\hline Sample & Am/Pu Ratio & $\begin{array}{l}\text { Pu(Chem) } \\
(\mathrm{mg} / \mathrm{l})\end{array}$ & $\begin{array}{c}\operatorname{Pu}(\text { TEWA }) \\
(\mathbf{m g} / l)\end{array}$ & $\begin{array}{c}\text { Ratio } \\
\text { (TEWA/Chem) }\end{array}$ & Am(Chem) & Am(TEWA) & $\begin{array}{c}\text { Ratio } \\
\text { (TEWA/Chem) }\end{array}$ \\
\hline 1 & 0.000 & 5.0 & $5.12 \pm 0.09$ & 1.024 & 0.00 & $0.011 \pm 0.001$ & 0.000 \\
\hline 2 & 0.000 & 10.0 & $9.82 \pm 0.11$ & 0.982 & 0.00 & $0.006 \pm 0.001$ & 0.000 \\
\hline 3 & 0.000 & 30.0 & $29.47 \pm 0.19$ & 0.982 & 0.00 & $0.014 \pm 0.001$ & 0.000 \\
\hline 4 & 0.000 & 50.0 & $49.39 \pm 0.25$ & 0.988 & 0.00 & $0.026 \pm 0.001$ & 0.000 \\
\hline 5 & 0.000 & 100.0 & $99.42 \pm 0.35$ & 0.994 & 0.00 & $0.057 \pm 0.003$ & 0.000 \\
\hline 6 & 0.025 & 5.0 & $4.77 \pm 0.11$ & 0.954 & 0.12 & $0.130 \pm 0.001$ & 1.083 \\
\hline 7 & 0.025 & 10.0 & $9.67 \pm 0.16$ & 0.967 & 0.25 & $0.254 \pm 0.001$ & 1.016 \\
\hline 8 & 0.025 & 30.0 & $29.34 \pm 0.29$ & 0.978 & 0.75 & $0.828 \pm 0.004$ & 1.158 \\
\hline 9 & 0.025 & 50.0 & $49.11 \pm 0.38$ & 0.982 & 1.20 & $1.390 \pm 0.043$ & 1.158 \\
\hline 10 & 0.025 & 100.0 & $98.09 \pm 0.39$ & 0.981 & 2.50 & $2.810 \pm 0.023$ & 1.124 \\
\hline 11 & 0.050 & 5.0 & $4.85 \pm 0.13$ & 0.971 & 0.25 & $0.262 \pm 0.002$ & $1.04 B$ \\
\hline 12 & 0.050 & 10.0 & $10.5 \pm 0.14$ & 1.005 & 0.50 & $0.534 \pm 0.023$ & 1.068 \\
\hline 15 & 0.050 & 30.0 & $29.44 \pm 0.25$ & 0.981 & 1.50 & $1.695 \pm 0.021$ & 1.130 \\
\hline 14 & 0.050 & 50.0 & $49.75 \pm 0.48$ & 0.995 & 2.50 & $2.704 \pm 0.021$ & $1: 082$ \\
\hline 15 & 0.050 & 100.0 & $96.82 \pm 0.53$ & 0.968 & $5.0 \mathrm{~V}$ & $5.411 \pm 0.047$ & 1.082 \\
\hline 16 & 0.150 & 5.0 & $5.44 \pm 0.21$ & 1.088 & 0.75 & $0.800 \pm 0.018$ & 1.067 \\
\hline 17 & 0.150 & 10.0 & $10.24 \pm 0.30$ & $1.02 d$ & 1.59 & $1.601 \pm 0.028$ & 1.067 \\
\hline 18 & 0.150 & 30.0 & $28.27 \div 0.57$ & 0.942 & 4.50 & $5.048 \pm 0.005$ & 1.122 \\
\hline 19 & 0.150 & 50.0 & $46.15 \pm 0.80$ & 0.923 & 7.50 & $7.764 \pm 0.013$ & 1.035 \\
\hline 20 & 0.150 & 100.0 & $91.20 \pm 1.12$ & 0.912 & 15.00 & $15.226 \pm 0.036$ & 1.015 \\
\hline 21 & 0.300 & 5.0 & $5.25 \pm 0.20$ & 1.050 & 1.50 & $1.876 \pm 0.006$ & 1.251 \\
\hline 22 & 0.300 & 10.0 & $10.24 \pm 0.30$ & 1.024 & 3.00 & $3.592 \pm 0.005$ & 1.197 \\
\hline 23 & 0.300 & 40.0 & $37.54 \pm 0.83$ & 0.938 & 12.00 & $12.727 \pm 0.028$ & 1.061 \\
\hline 24 & 0.300 & 40.0 & $38.82 \pm 0.86$ & 0.971 & 12.00 & $13.049 \pm 0.064$ & 1.087 \\
\hline \multirow[t]{3}{*}{25} & 9.300 & 100.0 & $116.69 \pm 2.91$ & 1.167 & 30.00 & $27.682 \pm 0.033$ & 0.923 \\
\hline & & & av & 0.992 & & av & 1.089 \\
\hline & & & std dev & 0.053 & & std dev & 0.071 \\
\hline
\end{tabular}


TABLE IX. TEWA Test and Evaluation-low-Concentration Range

\begin{tabular}{|c|c|c|c|c|}
\hline Sample & $\begin{array}{c}\text { Pu(Chem) } \\
(\mu \mathbf{g} / l)\end{array}$ & $\begin{array}{c}\text { Pu(TEWA) } \\
(\mu \mathrm{g} / \ell)\end{array}$ & $\begin{array}{c}\text { Ratio } \\
\text { (TEWA/Chem) }\end{array}$ & $\begin{array}{c}\text { Count Time } \\
\text { (s) }\end{array}$ \\
\hline 1 & 29.0 & $24.5 \pm 6.1$ & 0.84 & 623 \\
\hline 2 & 29.0 & $33.0 \pm 2.8$ & 1.14 & 8500 \\
\hline 3 & 29.0 & $26.4 \pm 2.4$ & 0.91 & 8500 \\
\hline 4 & 29.0 & $33.9 \pm 2.8$ & 1.17 & 8500 \\
\hline 5 & 29.0 & $32.5 \pm 2.8$ & 1.12 & 8500 \\
\hline 6 & 29.0 & $39.6 \pm 2.8$ & 1.37 & 8500 \\
\hline 7 & 126.0 & $162.6 \pm 19.3$ & 1.25 & 644 \\
\hline 8 & 126.0 & $176.7 \pm 14.6$ & 1.40 & 1310 \\
\hline 9 & 126.0 & $165.1 \pm 7.0$ & 1.15 & 1310 \\
\hline 10 & 126.0 & $186.1 \pm 14.1$ & 1.48 & 1494 \\
\hline 11 & 253.0 & $232.8 \pm 16.5$ & 0.92 & 1428 \\
\hline 12 & 253.0 & $242.7 \pm 17.0$ & 0.96 & 1428 \\
\hline 13 & 253.0 & $225.3 \pm 16.5$ & 0.89 & 1428 \\
\hline 14 & 53.0 & $238.0 \pm 17.0$ & 0.94 & 1428 \\
\hline 15 & 253.0 & $201.7 \pm 15.6$ & 0.80 & 1428 \\
\hline 16 & 386.0 & $345.0 \pm 10.8$ & 0.89 & 4737 \\
\hline 17 & 386.0 & $335.1 \pm 10.8$ & 0.87 & 4737 \\
\hline 18 & 386.0 & $297.4 \pm 17.9$ & 0.77 & 1620 \\
\hline 19 & 386.0 & $327.5 \pm 10.8$ & 0.85 & 4737 \\
\hline 20 & 386.0 & $339.3 \pm 10.8$ & 0.88 & 4737 \\
\hline 21 & 386.0 & $267.6 \pm 36.3$ & 0.69 & 300 \\
\hline 22 & 471.0 & $486.3 \pm 23.6$ & 1.03 & 1394 \\
\hline 23 & 471.0 & $444.9 \pm 23.1$ & 0.94 & 1394 \\
\hline 24 & 471.0 & $440.6 \pm 23.6$ & 0.94 & 1394 \\
\hline 25 & 471.0 & $496.2 \pm 12.7$ & 1.05 & 5000 \\
\hline 26 & 505.0 & $486.8 \pm 11.8$ & 0.96 & 6118 \\
\hline 27 & 505.0 & $487.3 \pm 12.7$ & 0.96 & 5195 \\
\hline 28 & 505.0 & $484.4 \pm 26.4$ & 0.96 & 1178 \\
\hline 29 & 505.0 & $487.3 \pm 28.7$ & 0.96 & 1000 \\
\hline 30 & 565.0 & $533.0 \pm 30.2$ & 0.94 & 1000 \\
\hline 31 & 565.0 & $583.4 \pm 31.1$ & 1.03 & 1000 \\
\hline 32 & 565.0 & $526.4 \pm 29.7$ & 0.93 & 1000 \\
\hline 33 & 565.0 & $557.5 \pm 30.6$ & 0.99 & 1000 \\
\hline 34 & 565.0 & $598.5 \pm 31.6$ & 1.06 & 1000 \\
\hline 35 & 565.0 & $503.3 \pm 29.7$ & 0.89 & 1000 \\
\hline 36 & 565.0 & $589.1 \pm 30.6$ & 1.04 & 1000 \\
\hline 37 & 565.0 & $542.9 \pm 29.7$ & 0.96 & 1000 \\
\hline 38 & 565.0 & $541.0 \pm 30.2$ & 0.96 & 1000 \\
\hline 39 & 565.0 & $585.8 \pm 30.6$ & 1.04 & 1000 \\
\hline 40 & 565.0 & $562.7 \pm 17.9$ & 1.00 & 3000 \\
\hline \multirow[t]{3}{*}{41} & 0.0 & $1.9 \pm 1.9$ & & 55600 \\
\hline & & & 1.00 & \\
\hline & & std dev & 0.16 & \\
\hline
\end{tabular}

The T\&E of TEWA at SRL has given interesting results and has been rather successful. The TEWA system can assay without solutions having a maximum americicum/plutonium ratio of 0.30 without chemical separation. The sensitivity of TEWA is $30 \mu \mathrm{g} / \mathrm{l}$ for effluent solutions containing plutonium. The SRL has selected the TEWA as the technique for its canyon upgrade, and it should be useful for any plutonium recovery facility.

6. Test and Evaluation of Plutonium Solution Densitometer at SRP (H. Smith, Q-1). After r ompletion of 
the off-line tisting phase ${ }^{49}$ of the K-edge Plutonium Solution Densitometer in the SRP F-Area Analytical Labs in 198?, we installed the instrument in a bypass loop at the rolding tanks for the precipitator feed solution in the FB line. ${ }^{50}$ On-line assays of process solution were performed in 1982 and 1983 by SRP personnel and compared with destructive analysis. A report of these on-line results was prepared by SRP in 1984.* The test and evaluation exercise will be compl sted with a Los Alamos report on these same resuits.

7. Feasibility Study of Plutonium Isotopic Analysis of Resin Beads by Nondestructive Gamma-Ray Spactroscopy (T, K. Li, Q-1). We have developed a nondestructive gamma-ray technique ${ }^{51}$ to determine accurately plutonium isotopic ratios in a timely manner and in a wide range of masses, isotopic contents, and chemical forms. This technique, based on the highintensity, low-energy ( $36-68 \mathrm{keV}$ ) gamma rays, has demonstrated its sensitivity in measuring very small mass samples. Fc $\mathrm{r}$ example, within a 10 -min counting time, the measured precision ( $1 \mathrm{std} \mathrm{dev}$ ) for a sample of $15 \mathrm{mg}$ plutonium :reactor grade) is $1.48 \%$ for the ${ }^{238} \mathrm{Pu} /{ }^{239} \mathrm{Pu}$ ratio, $0.51 \%$ for the ${ }^{240} \mathrm{Pu} /{ }^{239} \mathrm{Pu}$ ratio, and $6.1 \%$ for the ${ }^{241} \mathrm{Pu} /{ }^{239} \mathrm{Pu}$ ratio. We have applied this technique in a study of the feasibility of plutoniurn isotopic analysis on resin beads.

Two sets of resin bead samples with completed mass spectrometu: analysis were provided by Joel A. Carter, Oak Ridge National Laboratory, and are described in Table X. Set I (samples 1 to 4) was prepared on November 15,198 , and Set II (samples 5 to 7 ) was prepared on May 14, 1934. Each sample consists of $\sim 10000$ beads loaded with an average of $9 \mu \mathrm{g}$ plutonium mass. issotopic compositio is varied irom 0.003 to $1.41 \%$ for ${ }^{238} \mathrm{Pu}$, from 57.53 to $97.47 \%$ for ${ }^{239} \mathrm{Pu}$, from 2.49 to $27.39 \%$ for ${ }^{240} \mathrm{Pu}$, and from 0.327 to $8.3 \%$ for ${ }^{241} \mathrm{Pu}$.

- For additio nal infornation, confer with Jack Parker, Savannah River Flant, Aiken, SC 29801 USA.
Table XI compares the preliminary gamma-ray spectroscopy results for a 4-h count time with mass spectrometry results. Uacertainties shown represent the estimated precision (I std dev) of gamma-ray spectroscopy as calculated from counting statistics, including uncertainiies from relative efficiencies. The average ratios of gamma-raj spectroscopy to mass spectrometry are 0.9942 for the ${ }^{236} \mathrm{Pu} /{ }^{239} \mathrm{Pu}$ ratio and 0.9953 for the ${ }^{240} \mathrm{Pu} /{ }^{239} \mathrm{Pu}$ ratio. These results show negligible bias when compared with mass spectrometry results. The $3.8 \%$ and $1.9 \%$ standard deviations of the ${ }^{238} \mathrm{Pu} /{ }^{239} \mathrm{Pu}$ and ${ }^{240} \mathrm{Pu} /{ }^{239} \mathrm{Pu}$ ratio, respectively, demonstrate the overall precision of measurements by low-energy gamma-ray spectroscopy in these wide ranges of plutonium isotopic distribution, within a 4-h cuunt time. Obviously, the precision obtained from the gamma-ray technique is affected by counting statistics of the fullenergy peaks, which is in turn a function of parameters such as sample mass, isotopic distribution, count time, and background. The mersured precision of seven resin bead samples from gamma-ray spectroscopy in 1-h and 4-h count times is listed in Table XII. These results demonstrate that this technique has many different applications to various types of materials in reprocessing plants. For example. sample 5 is typical of FFTF plutonium feed, and samples 6 and 7 are typical of plutonium from spent fuel in the LMFBR and LWR fuel cycles. These rapid and accurate nondestructive isotopic analyses on resin beads may provide useful information, for example, on burnup, accountability, and process monitoring. Furthermore, the simple operational features of automated nondestructive gamma-ray instruments may be of interest to process technicians for routing measurements in reprocessing facilities and to International Atomic Energy Agency inspectors.

8. Advances in High-Counting-Rate Electronics for Neutron Coincidence Counters (J. E. Swansen, H. O. Menlove, Q-1). Thermal-neutron counting systems utilizing polyethylene moderators and ${ }^{3} \mathrm{He}$ or $\mathrm{BF}_{3}$ gas-

TA BiLE X. Resin Bead Samples Plutonium Isotopic Compositions (at. \%)

\begin{tabular}{rlllll}
$\begin{array}{c}\text { Resin Bead } \\
\text { Sarnple }\end{array}$ & ${ }^{238} \mathrm{Pu}$ & ${ }^{279} \mathrm{Pu}$ & ${ }^{240} \mathrm{Pu}$ & ${ }^{241} \mathrm{Pu}$ & ${ }^{242} \mathrm{Pu}$ \\
\hline & & & & & \\
Set I 1 & $\mathbf{0 . 0 0 3}$ & 97.47 & 2.49 & 0.039 & 0.003 \\
2 & 0.017 & 81.04 & 18.90 & 0.032 & 0.006 \\
3 & 0.024 & 72.55 & 27.39 & 0.029 & 0.008 \\
${ }^{4}$ & 0.033 & 63.70 & 36.23 & 0.027 & 0.009 \\
Set II 5 & 0.055 & 87.02 & 11.70 & 1.022 & 0.206 \\
6 & 0.276 & 77.27 & 18.71 & 2.54 & 1.21 \\
7 & 1.41 & 57.53 & 27.37 & 8.30 & 5.39 \\
\hline \hline
\end{tabular}


TABLE XI. Comparison of Isotopic Ratios by Gamma-Ray Spectroscopy" with Mass Spectrometry

\begin{tabular}{|c|c|c|c|c|}
\hline & $\begin{array}{l}\text { Resin Bead } \\
\text { Sample }\end{array}$ & $\begin{array}{c}\text { Mass } \\
\text { Spectrometry }\end{array}$ & $\begin{array}{l}\text { Gamma-Ray } \\
\text { Spectroscopy }\end{array}$ & $\begin{array}{c}\text { Gamma-Ray Spectroscopy } \\
\text { Mass Spectrometry }\end{array}$ \\
\hline${ }^{238} \mathrm{Pu} /{ }^{239} \mathrm{Pu}$ & $\begin{array}{l}1 \\
2 \\
3 \\
4 \\
5 \\
6 \\
7\end{array}$ & $\begin{array}{l}3.05 \times 10^{-5} \\
2.08 \times 10^{-4} \\
3.28 \times 10^{-4} \\
5.13 \times 10^{-4} \\
6.29 \times 10^{-4} \\
3.56 \times 10^{-3} \\
2.44 \times 10^{-2}\end{array}$ & 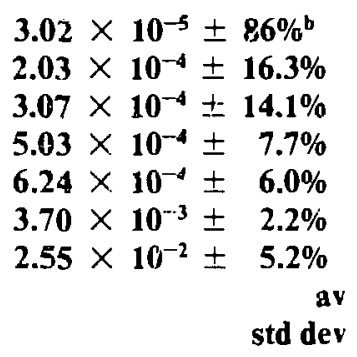 & $\begin{array}{l}0.9902 \\
0.976 \\
0.936 \\
0.9805 \\
0.9921 \\
1.0393 \\
1.0451 \\
0.9942 \\
0.0377\end{array}$ \\
\hline${ }^{240} \mathrm{Pu} /{ }^{239} \mathrm{Pu}$ & $\begin{array}{l}1 \\
2 \\
3 \\
4 \\
5 \\
6 \\
7\end{array}$ & $\begin{array}{l}0.6257 \\
0.234 \\
0.379 \\
0.571 \\
0.135 \\
0.243 \\
0.478\end{array}$ & $\begin{array}{l}0.0256 \pm \mathbf{6 . 6 \%} \\
0.229 \pm 2.1 \% \\
0.387 \pm 2.2 \% \\
0.563 \pm 2.0 \% \\
0.138 \pm 2.3 \% \\
0.238 \pm 2.0 \% \\
0.471 \pm 4.6 \% \\
\\
\end{array}$ & $\begin{array}{l}0.9961 \\
0.9786 \\
1.0211 \\
0.986 \\
1.0222 \\
0.9794 \\
0.9834 \\
0.9953 \\
0.0189\end{array}$ \\
\hline
\end{tabular}

4 h counting time.

${ }^{b}$ Uncertainties represent the estimated precision ( 1 std dev) as calculated from counting statistics, including uncertainties from re'ative eficiencies.

filled proportional counters have been limited in counting rate capability by the charge-collection time and the amplification circuitry. This resulted, in many cases, in large counting losses for materials with high nuclear material content and, in some cases, unreliable assays because of excessive counting rates. We have designed, fabricated, and tested a new detector system for thermal-nertron coincidence counting applications. The new ectronics system has a measured deadtime that is a factor of 4 lower than previous systems $\mathrm{s}^{52,53}$ and thus is capable of measuring samples of significantly larger mass. The counting rate capability of the new system is 1300000 counts/s with modifications to the shift-register hoard.

\begin{tabular}{|c|c|c|c|c|}
\hline \multirow{4}{*}{$\begin{array}{c}\text { Resin Bead } \\
\text { Sample }\end{array}$} & \multicolumn{4}{|c|}{ Relative Precision } \\
\hline & \multicolumn{2}{|c|}{ (1 std dev) in $1 \mathrm{~h}$} & \multicolumn{2}{|c|}{ ( 1 sțd dev) in $4 \mathrm{~h}$} \\
\hline & ${ }^{238} \mathrm{Pu}$ & ${ }^{240} \mathrm{Pu}$ & ${ }^{238} \mathbf{P u}$ & ${ }^{2.10} \mathrm{Pu}$ \\
\hline & ${ }^{239} \mathrm{Pu}$ & ${ }^{239} \mathrm{Pu}$ & ${ }^{239} \mathrm{Pu}$ & ${ }^{2,9} \mathrm{Pu}$ \\
\hline 1 & 75 & 14.8 & 30 & 6.6 \\
\hline 2 & 30 & 2.7 & 15 & 1.4 \\
\hline 3 & 27 & 5 & 13 & 2.5 \\
\hline 4 & 18 & 5 & 8.1 & 2.5 \\
\hline 5 & 11.2 & 5 & 6.3 & 2.5 \\
\hline 6 & 5.6 & 4.5 & 3.2 & 2.4 \\
\hline 7 & 8.8 & 7.5 & 4.2 & 4.0 \\
\hline
\end{tabular}


The new analog electronics system is based on the

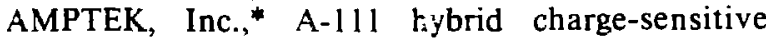
preamplifier/discriminator. Pulses resulting from neutron events are discriminated on the basis of pulse height from noise pulses and pulses resulting from gamma-ray events at the output of the amplifier. This approach eliminates the need for additional pulse-shaping circuitry, and when combined with a derandomizing buffer circuit, allows a maximum counting rate about four times higher than that previously attainable. This small amplifier/discriminator circuit is placed at the base of the ${ }^{3} \mathrm{He}$ proportional counter to entance the signal-to-noise ratio.

The basic approach of neutron time-correlation, or coincidence, counting has been used extensively ${ }^{5455}$ during the past decade for nuclear materials measurements and safeguards. The new instrument gives a significant improvement in counting rate capability, lower detector deadtime, counting stability, electrical noise resistance, and gamma-ray insensitivity. The following sections describe the detector design and performance characieristics.

*AMPTEK, Inc., 6 DeAngelo Drive, Bedford, MA 01730 USA. a. Detector Design. The detector unit consists of 18 ${ }^{3} \mathrm{He}$ tubes embedded in a cylindrical polyethylene body. Figure 35 shows a cross-sectional view of the detector, and Fig. 36 is a photograph of the complete system. The design of the system is similar to that of the high-level neutron coincidence counter (HLNCC), ${ }^{54}$ but the design has been modified to accommodate the new fast electronics and to achieve better performance characteristics. We refer to the new system as the HLNCC-II.

A primary design goal was to obtain a uniform, or flat, counting response profile over the height of the sample cavity while still keeping the system portable. This was achieved by placing polyethylene ring "shims" on the top and bottom of the detector to compensate for the end losses or leakage of neutrons out the ends. The additional polyethylene in the shims increases the counting efficiency. In addition to these outside rings, we designed the end plugs to increase the counting efficiency at each end of the detector. The polyethylene and aluminim $\mathrm{n}$ core in the end plugs gives a better response than either material alone. There is a cadmium liner in the sample cavity to prevent thermal neutrons from reflecting back into the sample and inducing additional fission reactions. This cadmium on the wall does not extend into the region of the end plugs, and thus the

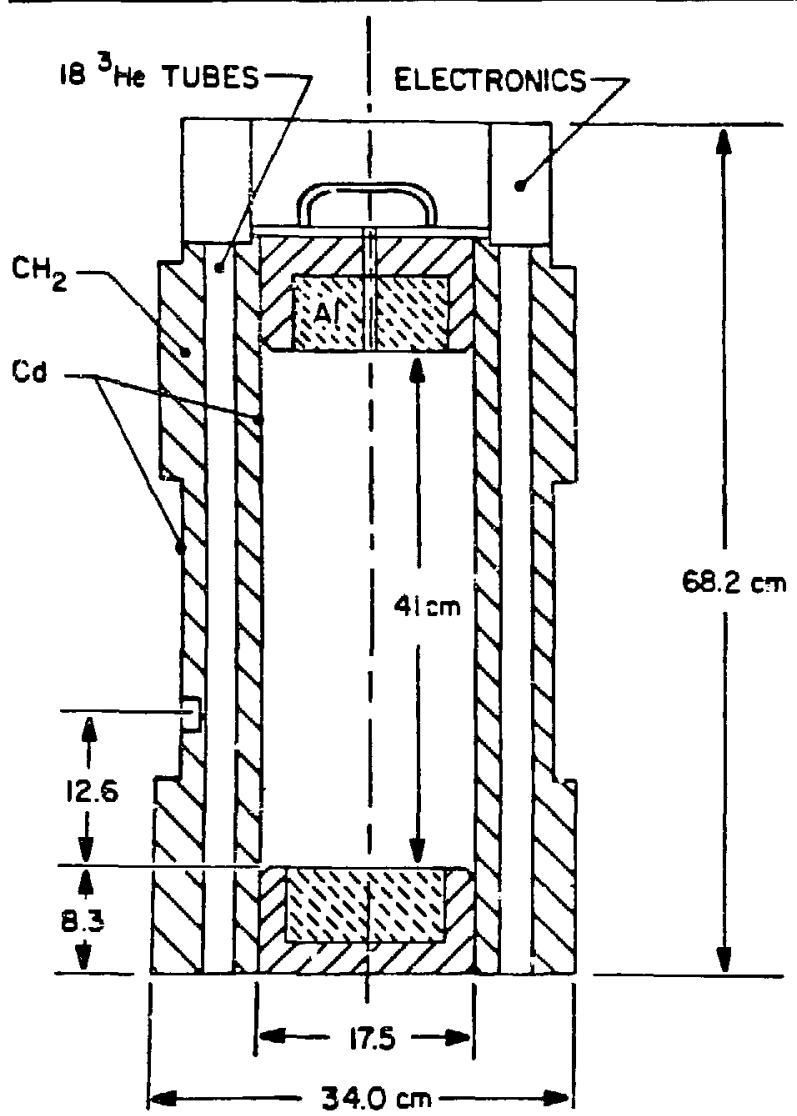

Fig. 35. Diagram of HLNCC-II used for the passive neutron coincidence counting of high-mass plutonium samples. 
polyethylene in the walls of the end plugs becomes an integral part of the ${ }^{3} \mathrm{He}$ tube moderator.

Measurements were performed to determine the optimum size of the polyethylene rings, or sleeves, and the end plugs. For the profile measurements, a ${ }^{252} \mathrm{Cf}$ neutron source was moved along the axis of the sainple cavity from the bottom plug to the top in increments of 2.54 $\mathrm{cm}$; both the totals rates and coincidence rates were recorded. The lengths of the external polyethylene sleeves were adjusted to obtain the longest uniform counting zone. The lengths of the end plugs also were adjusted to obtain the uniforr 1 profile shown in Fig. 37. This profile is flat to within 1\% for the totals rate and to within $2 \%$ for the coincidence rate over a distance of $30.5 \mathrm{~cm}$. The new system can accommodate a can up to $41 \mathrm{~cm}$ tall, which is $6 \mathrm{~cm}$ more than the cavity height of the HLNCC. Furthermore, the flat counting zone of the new system has been extended by a factor of abc: $t$ ? over that of the previous HLNCC.

The cadmium liner in the new system can be removed by pulling the aluminum-cadmium cylinder that lines the sample cavity. This makes it possible to apply the new neutron albedo inierrogation technique ${ }^{19}$ by reflecting thermal neutrons back into the plutonium. The increase in the measurcd coincidence response verifies that the appropriate amount 0 r issile material is in the sample.

b. Detector Electronics. The new electrunic system is based on the AMPTEK. A-111 hybrid charge-sensitive preamplifier/discriminator. One of these units can service up to about 12 detector tubes, but 6 units are used with the new system to share the counting load and reduce amplifier deadtime. Figure 38 shows the top view of the cylindrical thermal-neutron counter and the locations of six of these circuits. Three ${ }^{3} \mathrm{He}$ proportional tubes are connected in parallel to the input of each preamplifier/discriminator. In addition to the preamplifier, each board contains an OR circuit (a digital option provider) to combine the output of multiple boards and a light-emitting diode (LED) to signal the processing of an output pulse. This last feature is used to give a quick visual indication of the status of the

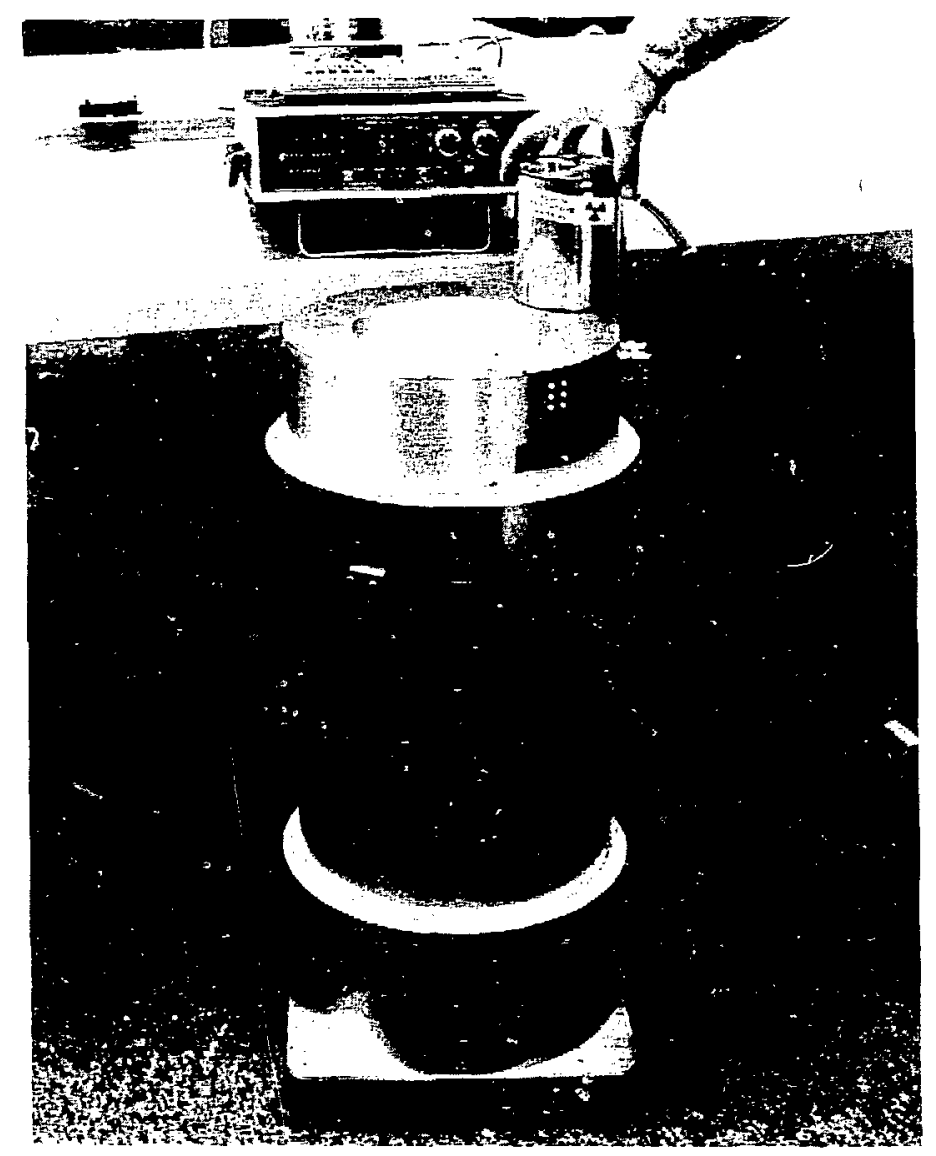

Fig. 36. Complete HLNCC-II system including detector head, shift-register coincidence electronics, and Hewlett Packard HP-97 progranmable calculator. 


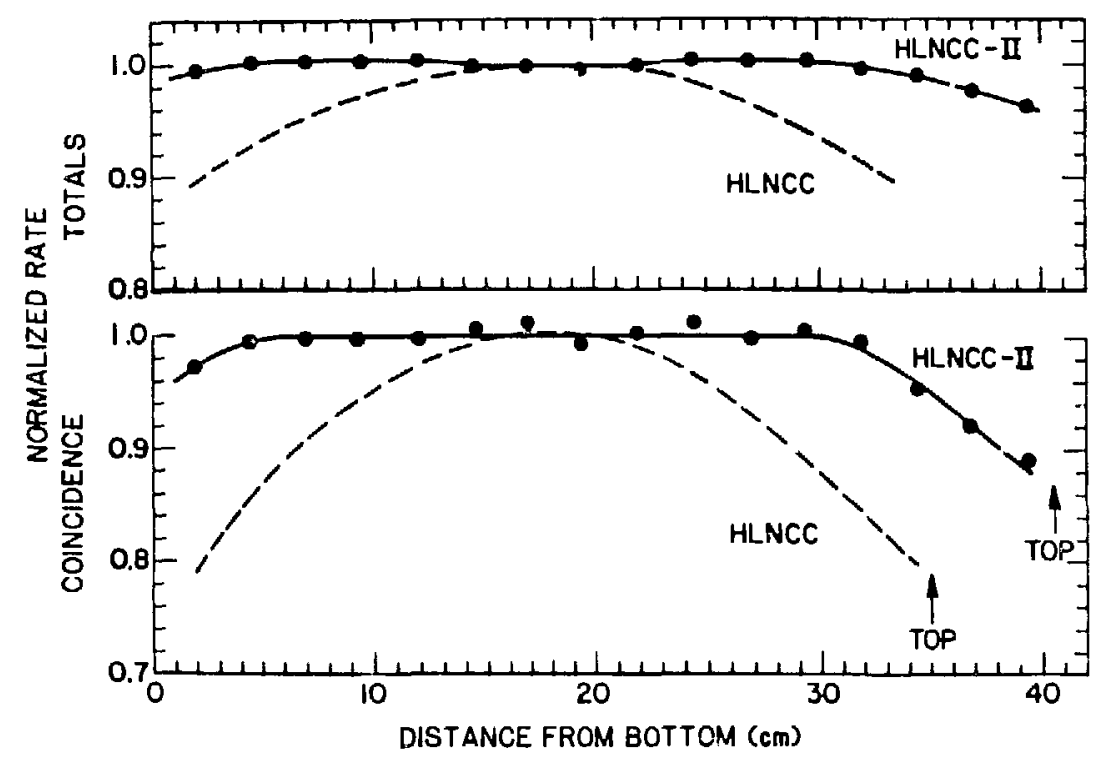

Fig. 37. Measured totals and coincidence response profiles, normalized to unity, for the HLNCC and HLNCC-II.

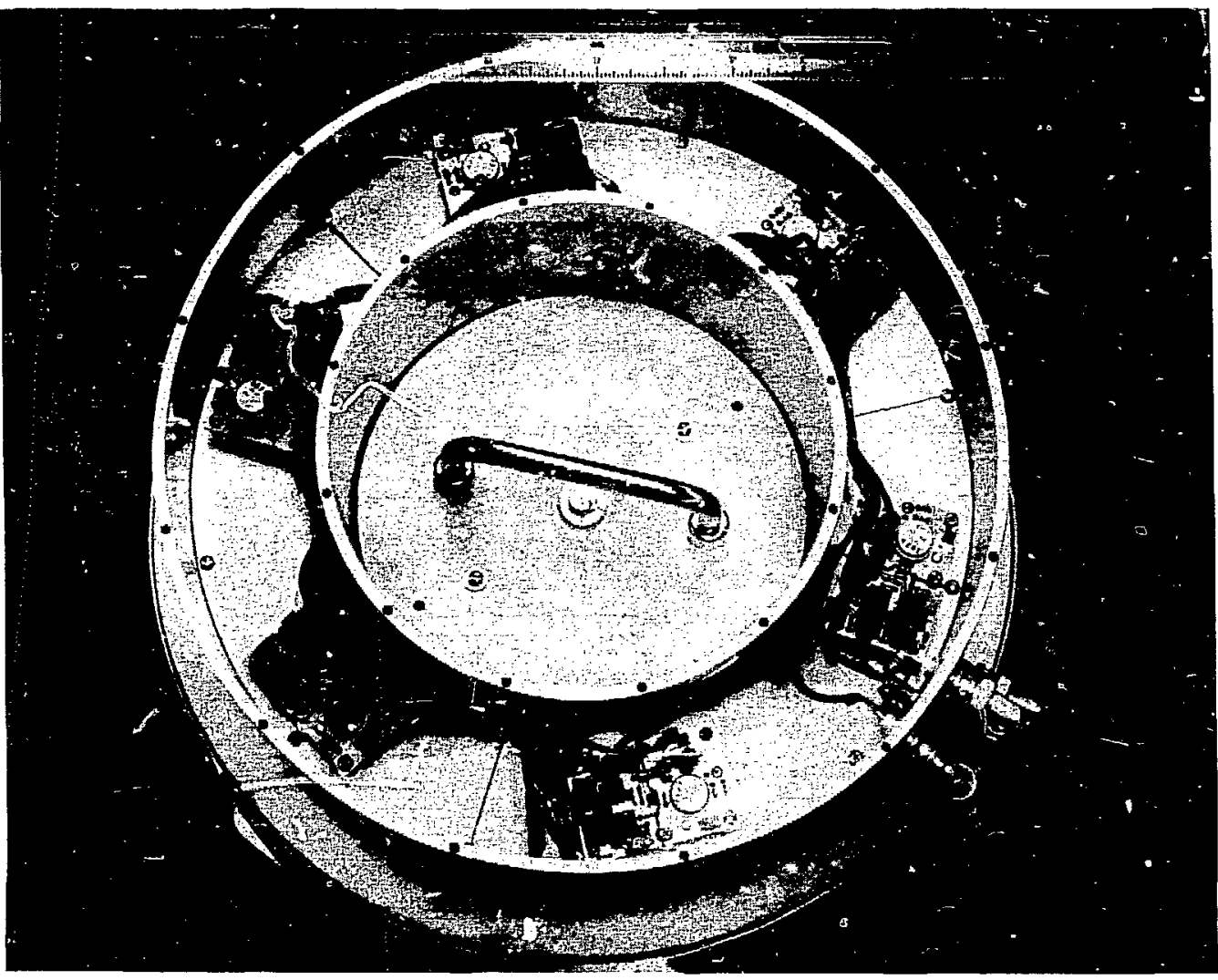

Fig. 38. Top view of the six AMPTEK-Lased amplifier/discriminator boards in the high-voltage junction box of the HLNCC-II. 
circuit where a dead unit gives no pulses and a noisy unit gives pulses with no sample present.

The output of the OR circuit is a 50-ns-wide logic pulse that is fed to the input of the shift-register board. ${ }^{56}$ The shift-register time-correlation logic system that we use with the detector is Model HEC-100 produced by IRT Corp.* (Fig. 36). This system has a modified shiftregister board with the addition of a derandomizing buffer vircuit ${ }^{57}$ to accommodate high counting rates and a 5-V power supply output for the AMPTEK preamplifier.

c. Counting Rate and Deadtime. Measurements were performed to establish the deadtime coefficient $\delta(T)$ and the maximum counting rate that can be achieved with the new HLNCC-II. The deadtime was measured by counting a ${ }^{252} \mathrm{Cf}$ source in the detector to establish the net coincidence rate $R_{0}$ (meas). Then AmLi $(\alpha, n)$ neutron sources were added to the sample cavity to drive up the totals rate and increase the deadtime. When the AmLi sources were removed from the counter, they were replaced by tungsten dummy sources (no AmLi) that had similar neutron absorption and scattering characteristics.

We define the following parameters:

$\mathbf{R}_{0}$ (meas) $=$ measured coincidence rate at the low level $T_{0}$ (meas) $=$ measured totals rate at the low level

$\mathrm{R}$ (meas) $=$ measure coincidence rate at the high level

$\mathrm{T}$ (meas) $=$ measured totals rate at the high level

$\mathbf{R}($ corr $)=\mathbf{R}$ (meas) $\mathrm{e}^{\delta(\mathrm{T}) \mathrm{T}}$

$\mathrm{T}($ corr $)=\mathrm{T}($ meas $) \mathrm{e}^{1 / 4 \mathrm{~s}(\mathrm{~T}) \mathrm{T}}$

To quantify any possible error in the deadtime correction, we looked a the difference in the coincidence rates, after deadtime correction, at the low and high counting rates. If the correc:ion is perfect, the difference is zero within the statistical precision. This difference is given by

per cent difference $=\frac{\mathbf{R}(\text { corr })-\mathbf{R}_{0}(\text { corr })}{\mathbf{R}_{0}(\text { corr })} \times 100$.

Previous measurements with the HLNCC had establised that the deadtime coefficient (in units of $\mu \mathrm{s}$ ) is approximately a linear function of $\mathrm{T}$ (meas) given by

$\delta(T)=[a+b T($ meas $)]$.

In the present work with the HLNCC-II. we have pushed the counting rate up to about 1300000 counts/s and found that the measured coincidence data are fit best with the following vaives for $a$ and $b$ :

$a=0.620$ and $b=0.200 \times 10^{-6}$

Using this value of $\delta(T)$, we have plotted the values of $\frac{\mathrm{R}(\operatorname{corr})-\mathrm{R}_{0}(\operatorname{corr})}{\mathrm{R}_{0}(\mathrm{corr})} \times 100$

as a function of $T$ (corr) in Fig. 39. The values of $R$ (corr) ranged from 9000 to 96000 counts/s. Within this range, the value of $R$ did not affect the percentage of the difference result. The data in Fig. 39 correspond to a piedelay of $4.5 \mu \mathrm{s}$. A longer predelay $(6.8 \mu \mathrm{s})$ eliminates this bias, but it also reduces the measured coincidence rate.

"IRT Corporation, P. O. Box 80817, San Diego, CA 92138 USA.

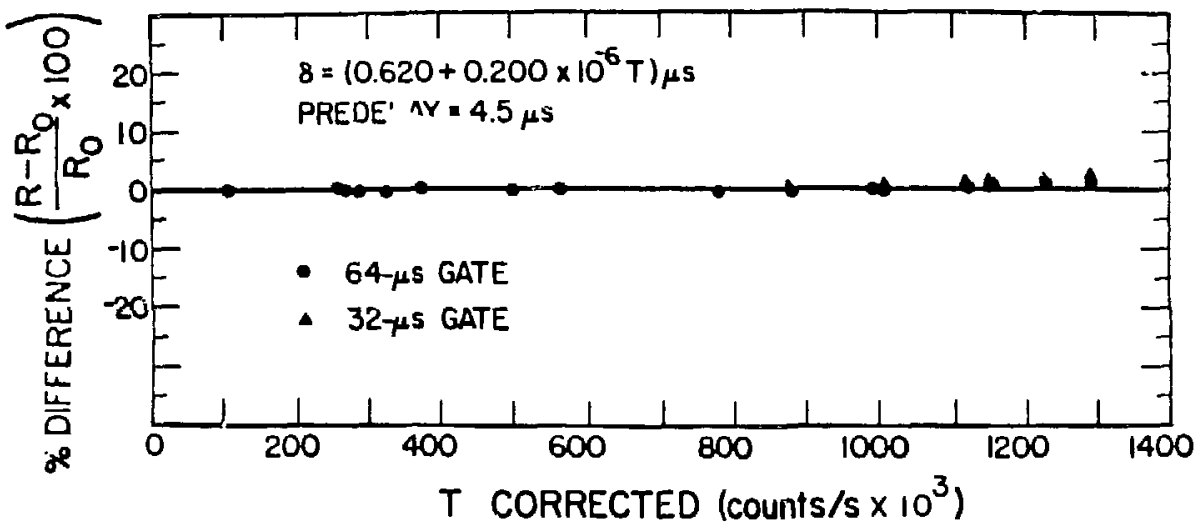

Fig. 39. Graph of deadtime correction error vs totals counting rate for timecorrelated counts in the HLNCC-II. 
a ounting Stability. We performed a series of measurements to determine the counting stability of the HLNCC-II. A constant, high-yield neutron source (AmLi, 432-yr half-life) was placed in the counter giving over 200000 counts/s. The system was run in the cyclic mode with 4000 - to 10000 -s data dumps for a 2-wk period. We determined the average totals ratu and the scatter about the mean. The observed standard deviation of individual runs about the mean was assumed to be the sum of the counting statistics term and the electronic stability term. The resulting electronic stabilit, was $0.002 \%$ ( 1 std dev). The measurements were performed in a laboratory with a very stable room temperature.

e. Gamma-Ray Sensitivity. The detecior (three tubes per preamplifier) was exposed to the righ-energy ${ }^{124} \mathrm{Sb}$ (about 1.6-MeV) gamma-ray flux, and no increase in counting rate from gamma pileup was observed for dose levels up to $1 \mathrm{R} / \mathrm{h}$. At dose levels above about $5 \mathrm{R} / \mathrm{h}$, the gamma pileup pushed above the discriminator level in the AMPTEK A-111. If a lower high-voltage setting is used, the yamma pileup drous below the discriminator threshold, but then we also lose part of the neutron signal.

f. Noise Sensitivity. The new HLNCC-II design with the AMPTEK circuit located directly above the ${ }^{3} \mathrm{He}$ tubes makes the system much less susceptible to raoiated noise pickup. The amplification package is completely enclosed by the aluminum junction box shown in Fig. 38, and the tubes are electrically isolated from the AMPTEK board by a grounding plane.

The new electronics design was measured to be much less sensitive to the radiative noise pickup than previous systems $^{5455}$ that had the preamplifiers external to the detector head.

g. Performance Paramcters. Because the new system was designed primarily for portable applications, it was necessary to minimize its size and weight. The ${ }^{3} \mathrm{He}$ tubes are identical to the tubes used in the standard HLNCC system. The key characteristics of the new HLNCC-II system are listed in Table XIII.

The neutron dieaway time $(\tau)$ is the mean time for a neutron to be slowed down and counted, to be absorbed, or to escape from the counter. A ${ }^{252} \mathrm{Cf}$ neutron source was measured in the center of the present detector with gate settings of 32 and $64 \mu \mathrm{s}$, and $\tau$ was calculated to be $43 \mu \mathrm{s}$.

The HLNCC-II system gives a convenient method for measuring the ${ }^{249} \mathrm{Pu}$-effective mass over a large range of sample sizes. Samples containing from less than a gram up to $10 \mathrm{~kg}$ of plutonium can be measured with the instrument. For the larger sample masses, a criticality evaluation must be made by the facility operator. For a i-kg sample of $\mathrm{PuO}_{2}\left(20 \%{ }^{240} \mathrm{Pu}\right)$, the statistical precision is $0.42 \%$ ( 1 RSD) for a 10 -min measurement.

In the future, the HLNCC-II will be evaluated for measuring additional types of plutonium including plu-

\section{TABLE XIII. Performance Parameters for the HLNCC-II}

\begin{tabular}{ll} 
Detector weight, kg & 43 \\
Outside diameter, cm & 34 \\
Sample-cavity diameter, cm & 17.5 \\
Sample-cavity height, cm & 41.0 \\
Absolute counting efficiency, \% & 17.5 \\
Neutron dieaway time, $\mu \mathrm{s}$ & 43 \\
Detector bias, V & 1680 \\
Coincidence gate time, $\mu \mathrm{s}$ & 64 \\
Flat counting zone & \\
(coincidence mode), cm & 30.5 \\
Maximum counting rate, $\mathrm{MHz}$ & 1.3 \\
PuO ${ }_{2}$ sample range, g & $10^{-1}-10^{4}$ \\
\hline
\end{tabular}

tonium metal plates and buttons, $\mathrm{PuF}^{4}$, mixed oxide (MOX), and scrap and waste. The system will be evaluated by the International Atomic Energy Agency inspectors for use in verifying plutionium samples in the field.

9. Cerenkov Glow Technique for Spent-Fuel Monitoring (N. Nicholson, Q-2). We have developed an instrument that allows the Cerenkov glow emitted from spent-fuel assemblies stored underwater to be viewed using a Cerenkov viewing device (CVD). The device is especially useful to IAEA inspectors requiring a rapid means of verifying the full inventory of a spent-fuel storage pond. An improved Cerenkov viewing device (ICVD) also has been developed that allows quantitative measurements of the intensity of the Cerenkov light in addition to the qualitative information obtained from a CVD. One drawback of the Cerenkov technique is that it usually requires that the spent-fuel storage area be darkened so that the low-intensity Cerenkov glow may be observed. Some IAEA member countries are concerned with having to reduce or extinguish normal lighting in the storage areas, and an effort is under way to provide an acceptable solution to this problem.

Several approaches have been taken, including the use of filters on both the lighting system and the input to the Cerenkov viewing device, the use of low-level oblique lighting, and the use of a pulsed light source in conjunction with a synchronized shutter on the CVD. Each potential solution has its advantages and disadvantages, and each impacts to some degree on the facility where the instrument is to be used.

The technique that appears to have the most promise of providing measurements as good as those obtained in total darkness is the strobed light approach. We have conducted a proof-of-principle experiment that demonstrates the feasibility of using a CVD or an ICVD in a normally lit room to view the very low-intensity 
Cerenkov glow from spent fuel as though the room lights were turned off. No loss of dynamic range is experienced in the ability to view very weak Cerenkov light sources as is experienced when using filters to block ambient room light but allow the Cerenkov light through. We are continuing our investigation of this approach and are pursuing the use of a bank of strobed lights sufficient to illuminate a very large area, such as a spent-fuel assembly storage bay. W'e plan to build a fieldable prototype system to be tested at a storage facility.

Other developments in improving the ICVD include a new battery charging system capable of recharging the 18-volt battery pack used to power the photometer section of the ICVD. The small, portable charger will allow extended use of the battery pack currently provided with the ICVD.

One disadvantage to using $.5 \mathrm{~mm}$ cameras to photograph the Cerenkov glow fror. spent fuel has been the time required to develop the film and obtain the slides and/or prints of the pictures. We have assembled a system that allows photos of the Cerenkov glow to be made into $35 \mathrm{~mm}$ slides or $3 \times 5$ color prints in just a few minutes after the film has been exposed. This assures the inspector that his pnotographs are of good quality before he concludes his inspection.

10. Thermal imaging (N. Nicholson, Q-2). We have used a thermal imager sensitive in the $1.2-$ to $6-\mu \mathrm{m}$ wavelength to determine the feasibility of using the infrared emissions from plutonium-bearing solutions and materials as an attribute measurement in a number of applications. The Secovision 220 thermal imager is a high-performance, completely poriable, thermoelectrically cooled thermal viewer. The viewer can oetect differences in temperature as small as 0.05 degrees Centigrade. Thermal imagery is provided on a l-in. cathode ray tube and viewed through a distortion-corrected eyepiece. The viewer is powerud by a rechargeable $\mathrm{NiCd}$ battery pack that provides $2.5 \mathrm{~h}$ of operation. The imager uses a high-efficiency thermoelectric cooler, which eliminates the need for liquid nitrogen or other cooling gases. Infrared energy, which is radiated by all objects at temperatures above $C$ $\mathrm{K}$, is passed through the entrance window and reflected off the scan mirror to the objective lens where it is focused into a linear array of 48 detector elements. The focused infrared energy causes the detector elements to generate a low-level voluage that is amplified and processed into a video signal and displayed in the cathode ray tube (CRT). The CRT is then viewed through an eyepiece. Figure 40 shows a block diagram of the Thermal Imager. The output connector provides raw data for processing the video interface that can provide black-and-white or color dispiays of the thermal imagery.

We used the thermal imager to observe a number of plutonium-bearing solutions, with concentrations ranging from $30 \mathrm{~g} / \mathrm{l}$ to $200 \mathrm{~g} / \mathrm{l}$. Thermal signals were observed from vials of solution containing $10 \mathrm{~m} \ell$ of solu-

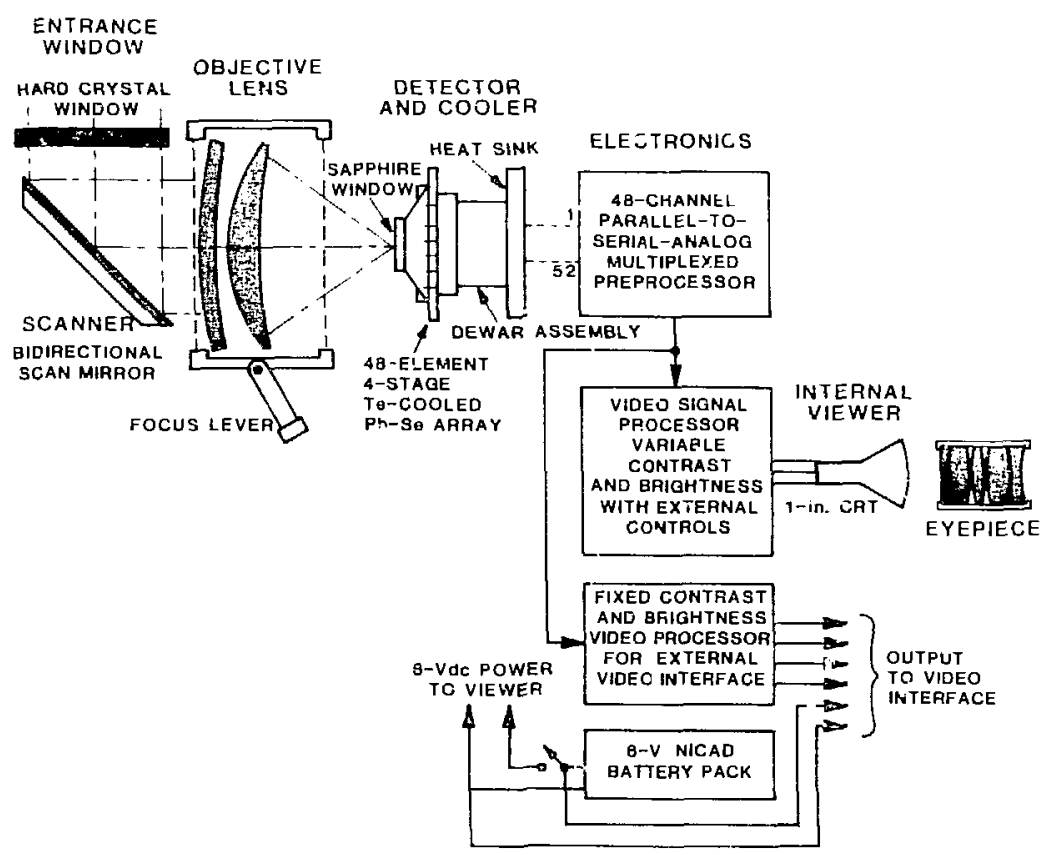

Fig. 40. Block diagram of the Thermal Imager. 
tion with concentrations of $100 \mathrm{~g} / \mathrm{l}$ and $200 \mathrm{~g} / \mathrm{l}$. Process line storage tanks containing solutions of $30 \mathrm{~g} / \mathrm{\ell}$ concentrations (observed empty, while filling, and then full) gave definite thermal signals above ambient. Although these initial results appear positive, they are not conclusive, and further measurements will be made to better judge the feasibility of this approach.

11. Neutron Monitoring During Conversion of $\mathrm{PuO}_{2}$ to $\mathrm{PuF}_{4}$ (G. W. Eccleston, M. P. Baker, P. A. Russo, Q-1; C. A. Ostenak, J. D. Williams, MST-13). The bomb reduction process for plutonium meial production was first demonstrated in 1944 at Los Alamos and remains essentially unchanged except for process scale. Plutoniun tetrafluoride $\left(\mathrm{PuF}_{4}\right)$ is prepared as feed for the reductiun process by the static-bed hydrofluorination of plutonium (IV) oxide $\left(\mathrm{PuO}_{2}\right)$ at $550^{\circ} \mathrm{C}$ in the presence of oxygen.

Initially, an empty hydrogen fluoride (HF) furnace is preheated to $200^{\circ} \mathrm{C}$. Following preheat, the caustic [potassium hydroxide (KOH)] scrubber system is turned on and the $\mathrm{PuO}_{2}$ feed powder, contained in a Hastelloy filter boat, is raised into the furnace by a hydraulic lift. The furnace is purged with argon and HF, and oxygen gas lines are slowly set to fixed-flow rates. A vacuum pulls the gases down through the $\mathrm{PuO}_{2}$ feed powder. The furnace temperature is increased to $550^{\circ} \mathrm{C}$, maintained at this temperature for $3 \mathrm{~h}$, and then shut off. After cooling to $300^{\circ} \mathrm{C}$, the HF source is shut off; at $270^{\circ} \mathrm{C}$, the $\mathrm{HF}$ and oxygen furnace valves are closed, a. $J$ the $\mathrm{PuF}_{4}$ is allowed to coul under vacuum. During this process. $\sim 95 \%$ of the $\mathrm{PuO}_{2}$ is normally converted to $\mathrm{PuF}_{4}$.
During the hydrofluorination process, the alpha-induced neutron rate increases as plutonium is converted from the oxide to the fluoriae, and we have made measurements to determine the feasibility of correlating neutron rates with oxide-to-fluoride conversion. Figure 41 shows neutron count rate as a function of time during the hydrofluorination process. The neutron rate rises rapidly while the furnace temperature is increased to $550^{\circ} \mathrm{C}$. During the 3-h baking period at $550^{\circ} \mathrm{C}$, the neutroin rate continues to increase although at a slower rate. Following furnace shutdown, the sample is still exposed to the HF gas, and the neutron rate continues to slowly increase. The data shown in Fig. 41 were collected from a $2.2-\mathrm{kg} \mathrm{PuO}_{2}$ production run that resulted in $\sim 95 \%$ conversion from the oxide to the fluoride.

The ability to monitor this process during ccnversion offers a number of potential benefits, including

- Enabling operators to maintain the $550^{\circ} \mathrm{C}$ furnace temperature until the conversion is complete. This ability would minimize reruns on batches that were not sufficiently converted during the 3 -h standard run time.

- Decreasing HF and $\mathrm{KOH}$ requirements as well as personnel radiation exposures by reducing the run time for batches that convert more quickly.

- Permitting various HF flow conditions and furnace temperatures to be studied to determine the optimal set of run parameters.

- Increasing metal yields and production throughput by ensuring adequate conversion and thereby decreasing nondiscardable, hard-to-measure slags.

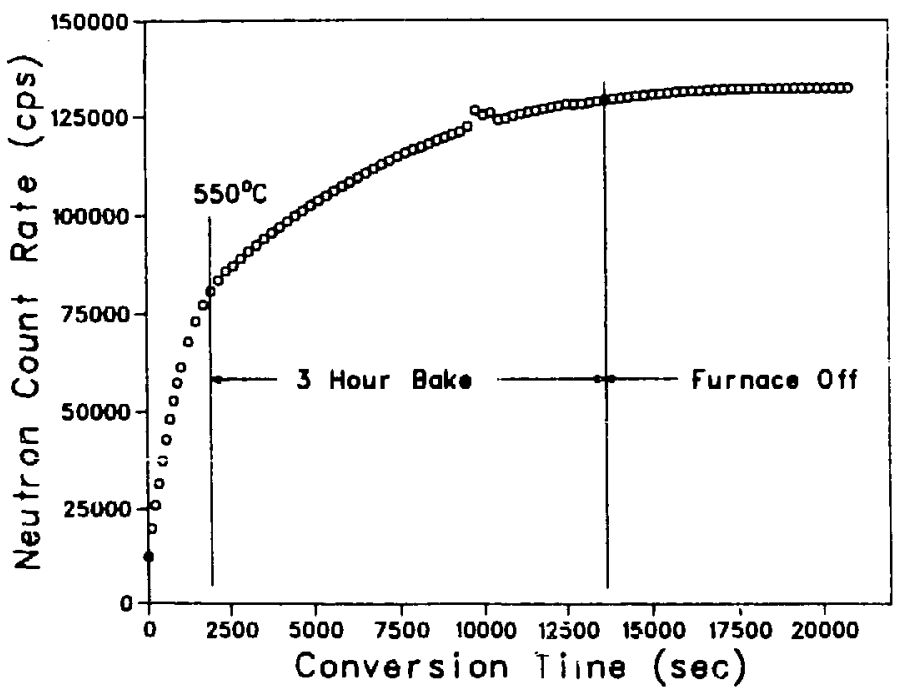

Fig. 41. Measuied neutron rate as $\mathrm{PuO}_{2}$ is converted to $\mathrm{PuF}_{4}$ in the hydrofluorination. 
The total neutron count rate measured during the conversion process is principally alph:-induced neutrons from $\mathrm{PuO}_{2}$ and $\mathrm{PuF}_{4}$. It is difficult to quantify the plutonium content in the hydrofluorinator based on totals measurements during the conversion process. However, the difference in the totals rate just before and immediately following runout of $\mathrm{PuF}_{4}$ may be used to give the weight of plutonium, as product, from the hydrofluorinator. Using the known weight of $\mathrm{PuO}_{2}$ initially loaded into the furnace may allow the holdup t.e be obtained by difference. In addition, monitoring the change in totals neutron rate for a large number of hydrofluorination runs will provide an indication of changes in furnace holdup.

12. Applications of NDA to Robotics Automation of the Process of Dirent Reduction of $\mathrm{PuO}_{2}$ (G. W. Eccleston, P. A. Russo, Q-1; R. F. Ford, D. W. Knobelock, MST-9; H. D. Ramsey, MST-13). A significant fraction of the plutonium oxide stream in the Los Alamos metal production process bypasses hydrofluorination (see Sec. 11, above) by direct conversion of the PuO to metal. The direct oxide reduction (DOR) takes place in a magnesium oxide crucible charged with about $700 \mathrm{~g}$ of $\mathrm{PuO}_{2}, 300 \mathrm{~g}$ of calcium metal, and $3500 \mathrm{~g} \mathrm{of} \mathrm{CaCl}_{2}$ in layers, bottom to top. The crucible, inserted in a can, is lowered into a furnace that extends down from the floor of the DOR glove box and is heated $10800^{\circ} \mathrm{C}$ over a 10 -h period. Stirring for 3 to $4 \mathrm{~min}$ after heating results in a temperature spike. After additional stirring and cooling, the crucible is removed from the furnace, the reacted charge is broken out, and the metal button at the bottom is split off from the solidified salt. The metal is subsequently electrorefined.

The time-consuming processes of breakout and splitting of the reacted charge expose personnel to high levels of radiation. Primarily for this reason. the use of robotics to automate the DOR procsss is being implemented. We are developing NDA technology for this application.

Implementation of robotics in the DOR process will require automatic monitoring of the process, detection of plutonium in salt and metallic forms. distinction between plutonium in the salt and metallic forms. and quantitative determinations of plutonium in the salt. We are exploring the use of NDA to address these requirements by mouting ${ }^{3} \mathrm{He}$ and $\mathrm{Nal}$ detectors at various locations on (or in) the DOR glove box to monitor the process and to assay and identify the process material. We are also testing techniques for manipulation of NDA detectors by robots inside the glove box.
Implementation of automation in a cold glove box is scheduled for FY 1987. Final implementation at the Los Alamos Plutonium Facility will follow.

13. Multifunction Electronics Controller Board (R. W. Slice, S. C. Bourret, P. R. Collinsworth, S. F. Klosterbuer, J. K. Halbig, Q-1). A new generation, multifunction board has been designed to be used as a smiart electronics controller. The board is built on a Digital Equipment Corporation (DEC) Q-bus dual form factor and can run in a Q-bus backplane or as a standalone controller. On the board is a Motorola 6809 central processing unit, $8 \mathrm{k}$ byies of random-access niemory, $16 \mathrm{k}$ bytes of erasable programmable read-only memory (EPROM), one RS-423/RS-422 serial line, two peripheral interface acapter parallel ports, one programmable clock, and five programmable array logic chips. The array logic chips allow any custom design necessary for an application.

The initial use for this board has been as the new SRP shuffler stepping motor controller. An intended application is as the new SRP segmented gamma scanner controller. Two of these boards, fabricated as prototypes, are currently running the two in-cabinet shufflers.

Software for this board can be written on a PDP-11 and either dowrioaded directly to the board or to an EPROM burner. The Motorola 6809 allows additional use of the Hewlett-Packard logic-state analyzer.

14. NDA Software Development (G. W. Eccleston, Q-1). Software developments during the past year have concentrated on DEC computers uncier the RT-II operating environment. on Motorola microprocessors where programs are self-contained in read-only memory (ROM), and on portable computers utilizing BASIC to control assay instrumentation. This assay equipment consists of the HLNCC. the portable multichannel analyzer (PMCA), and spent-fuel measurement instrumentation (ION). Descriptions of major areas of sofiware development effort are described under separate headings below.

a. GENERIC NDA Software (C. M. Schneider, S. -T. Hsue, T. E. Sampson, J. K. Sprinkle, S. M. Simmonds, $Q-1)$. Common to all NDA instrumentation in several of our projects is the DEC Micro-PDP-11 computer, which is being used for instrument control, to collect and analyze measurement data and to report assay results. Because the NDA instruments contain common operational features that are implemented with software, we have developed an instrument sofiware package (GENERIC) to be used on all the NDA 
systems. The code is written in FORTRAN IV under the RT-11 V5.1 operating system for most of the projects and is being converted to FORTRAN-77 under the RSX-11M V4.1 operating environment for one of them. Major features in the GENERIC software package consist of

- Similar operator menu on all instruments

- Automated measurement and analysis procedures

- Error checking and data diagnostics during operator interactions, instrument operation, and analysis of measurement diata

- Communications between the Micro-PDP-11 and a VAX computer

- Measurement control features

- Versatility allowing data to be archived and retrieved from disk for reanalysis and communications transmittal

- Parameter change features allowing modifications to system operation to be easily completed

- User-friendly operation that requires minimal operator input.

The user-friendly features and similar operator menu for all NDA instruments simplify operator training. Extensive error and diagnostic checks are incorporated into the software to detect problems and aid the facility in proper operation of the instrumentation. The communications feature allows the computer to cbtain sample identification and other information from a VAX computer and to transmit assay results to the VAX. This feature eases the requirement for the optrator to input information to the Micro-PDP-11 and to record the measurement results. GENERIC was designed to be versatile and to permit system parameters to be changed easily. The purpose is to enable the software package to be used both for physics tests by the instrument developer and for production assay measurements by a facility operator. Special features, such as control parameters, data structures, and analysis procedures, of each NDA system require that specialized software be added to the generic package. In addition, different requirements between projects may require some modifications to the generic package.

The generic package has been completed and is undergoing operational testing on two shufflers and a low-level solution assay instrument. The software has bern delivered to LLNL and Mound Laboratory for inclusion in their instruments that will be integrated with Los Alamos instruments on the NSR project at SRP. b. Compurer Communications (M. P. Kellosg, S. -T. Hswe, Q-1). A software protocol using the American Standard Code for Information Interchange (ASCII) characters has been developed to permit communications between a DEC Micro-PDP-11 computer using the RT.11 operating system and a DEC VAX computer running under the VMS operating system. The protocol is based on a communications package developed for the FAST facility delayed neutron interrogator project. ${ }^{\text {' }}$ The communication requires a master-slave relationship. The Micro-PDP-1I is the master, initiating all communications, and the VAX is a slave waiting for a message. Message transmission is followed by an acknowledgment indicating the information was correctly or incorrectly received; if incorrect, the message is retransmitted.

Hardware requires DL-11 serial line interfaces, and messages use only printable characters, which allows them to be sent directly to a printer for logging and debugging. The software contains error checking and has provisions for error recovery and message retransmission. In addition to parity checking on each character, error checking contains a byte count to check message length and a check sum to verify the longitudinal sum of message characters. Tests between a Micro-PDP-11 and VAX produced an effective data throughput of 450 characters per second over a serial line operating at 9600 bits per second.

Message content for communications has been defined and specified. The Micro-PDP-11 computers will obtain time synchronization and sample information from the VAX. Accountability, process control, and measurement control data will be transmitted to the VAX following completion of measurements. Status information will be transmitted when appropriate to inform the VAX of the instrument status. This information consists of

- Starting an assay, calibration, or measurement control test

- Collecting background data

- Suspended, ended, quit, terminated, or resumed an assay.

Currently, the communications software has been completed and tested and is being integrated into the generic softwaite package for final testing on the assay instruments. The software has been delivered to both Mound Laboratory and LLNL for use in their NSR instruments.

c. Extended Memory (XM), Multiterminal, and Program Overlays (M. P. Kellogg, C. M. Schneider, Q-1). The extended memory (XM) feature in the DEC Micro-PDP-1 1 computer is being used to run simultaneously the separate application programs that control two 
measurement stations, labeled D1 and D2 in Fig. 42. Each measurement station has a hardcopy terminal ( $\mathrm{T}$ ) and T2 in Fig. 42) dedicated to the application program. The multiterminal feature in RT-11 is implemented to assign private consoles to each application, which limits confusion because jobs need not share a terminal. The system console terminal is not assigned to the application programs to prevent operators from accessing the system. Using the assigned private terminals, the application programs can be used by operators. However, if the programs are exited, no access to system features is possible.

DEC PDP-11 computers have an architicture that provides ló-bit addressing, which allows the computer to directly address $32 \mathrm{~K}$ words (one $\mathrm{K}$ equals 1024 decimal). The highest $4 \mathrm{~K}$ words of address space, called the I/O page, sre reserved for device registers, general registers, and otuc: hardware connections to the computer. This limits the maximum memory address space for the software operating system and the application program to $28 \mathrm{~K}$ words. If the program exceeds the amount of memory available, it can be divided into overlay segments. During program execution, separatc and independent segments can take turns residing in the same place in physical memory. Software developed for NDA instrumentation typically exceeds the $28 \mathrm{~K}$-memory address limitations when loaded with the resident monitor. These programs must be extensively overlaid to circumvent the $28 \mathrm{~K}$-word limitation of physical memory.

Extended memory in the DEC PDP-11 series computers refers to physical memory above the $28 \mathrm{~K}$-word boundary that can be accessed only by using special hardware. Low memory is the physical memory between 0 and $28 \mathrm{~K}$ words that can be directly addressed by the computer. The Micro-PCP-11 Q-bus contains a 22bit address capability allowing $2048 \mathrm{~K}$ words to be ad- dr sssed using the hardware memory management unit. Extc?ded memory operation is necessary to load and run mutiple NDA programs that require extensive memory.

The X.M memory feature has been tested and $1 \mathrm{~s}$ in use to operate two NDA programs based on the setup in F.s. 42. Application of XM memory operation for the LLNiL. NSR assay systems was recently demonstrated, and several days were spent in training LLNL personnel on the method to build, link, and run their programs in the XM environment.

d. Multifunction Controller Board Software (S. F. Klosierbuer, Q-1). Software to operate the multifunction controller board (Part 3, Sec. I, A, 13) consists of a monitor program and a specialized program te operate and control hardware connected to the board. The software is written in M6809 assembly language and resides in PROM on the controller board. Currently, the board has been configured to operate the several delayed-neutron shuffler instruments.

Specialized software to control the shuffler comprises

- Software to control the hardware drivers that turn the metor power on/off and issue stepping motor pulses

- Communications software to receive commands and to send replies to the Micro-PDP-11 NDA computer

- Subroutines to provide a local menu enabling all hardware features of the controller board and shuffler to be exercised and tested in local mode.

The software on the multifunction controller board operates in a slave mode waiting for commands to be sent by the Micro-PDP-11 computer. Upon command receipt, the controller board performs the command and

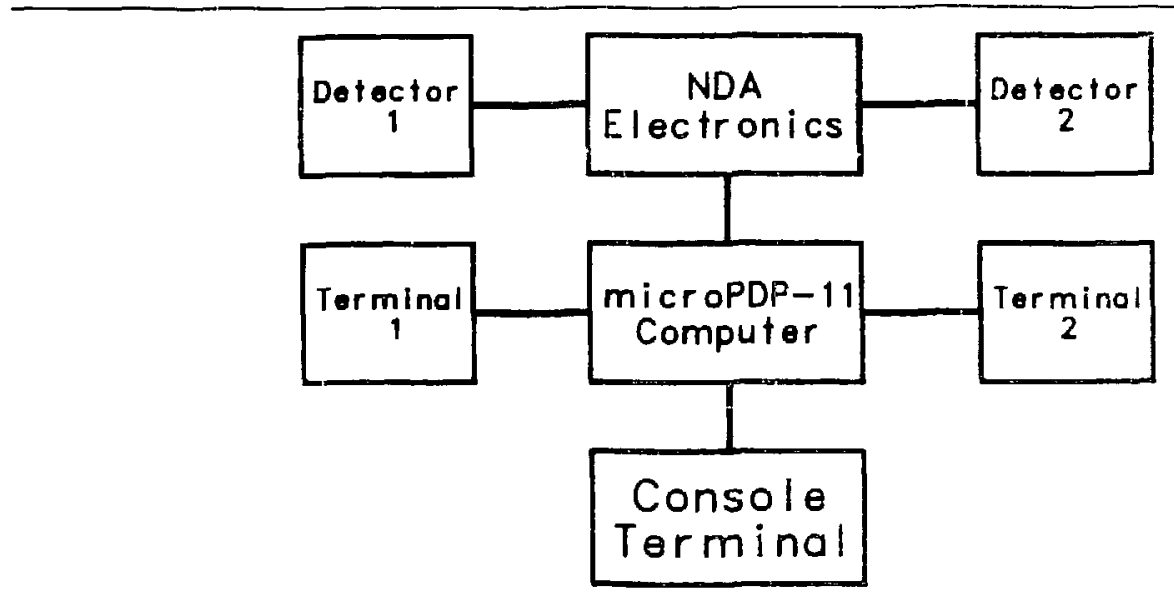

Fig. 42. Schematic of dual nondestructive assay (NDA) 5ystem controlled by one Micro-PDP-II computer. 
sends a complition response or error message to the Micro-PDP-11. In some specialized cases, the controller board will act on its own to return the shuffler's californium source to the storage position. This will occur, for example, if the sample access door is opened during an assay measurement.

We designed the multifunciion board to control a variety of dedicated hardware tasks. To use the board with other hardware requires changing the programmable logic array chips to modify the hardware driver functions, recoding the specialized local menu options in the M6809 ROM, and defining new commands required for computer communications. All these changes are straightforward and easily done. The basic structure of the software consisting of the communications and menu choices remains unchanged. The multifunction board will be modified soon to control the segmentedgamma-scanning NDA instruments.

e. Portable Multichannel Analyzer (PMCA) Software (S. f. Klosterbuer, $Q-1$ ). Applications software is being developed contirually to reside on ROMs in the Davidson 2056-4K PMCA. Recently, the program to determine the enrichment percentage of uranium powder with a NaI detector connected to the PMCA was modified to cnhance user interactions. Several features were added to the enrichment command:

\section{- A setup capability on entry to the command}

- The capability to read and write spectra to and from the PMCA tape within the command, which allows reanalysis of spectra

- Rearrangement of procedural steps in the command.

The IAEA has selected the Davidson 2056-4K PMCA for inspections, and the ROM containing the low-resolution enrichment program has been installed in the Agency units. In addition, a specialized user command for $\mathrm{UF}_{6}$ cylinder enrichment measurements was adapted to the PMCA and placed in a ROM. The portable $\mathrm{K}$-edge densitometer user program in the PMCA was modified to make minor corrections in the calculations. The PMCA and these user programs are finding increased application for both international and domestic safeguards activities.

f. BASIC Code for Portable Computers (R. A. Cameron, $S$. $F$. Klosterbuer, $Q-1)$. We are using the Epson HX-20 computer to control and operate the Davidson PMCA. ASCII character strings transmitted over a serial line simulate key pushes on the PMCA, and series of general purpose subroutines have been written in BASIC to control the PMCA and perform typical measurement procedures. This allows the measurement physicist to ensure that functions are operating properly and that desired and necessary features fit the applica- tion. The Epson computer permits the software development cycle to be shortened by using BASIC code that can be quickly and easily modified prior to the more difficult task of assembly language programming and PROM burning required for the PMCA.

The Epson subroutines permit the analyzer features to be set up through simulation of the SETUP and PRESET keys on the PMCA. The analyzer can be put into data acquisition mode through the ACQUIRE key simulation. Regions-of-interest (ROI) can be read into the Epson program for printout and calculations using the ROI, CALC, and I/O key simulations. Subroutines added to the Epson program include full-width-halfmaximum peak resolution calculations, centroid computations, and net areas using specified ROIs for background. This is an enhancement over the PMCA, which uses a set number of channels on either side of a peak for background subtraction.

The subroutines written for the Epson program constitute a general package that permits the PMCA to be set up externally, to acquire data, and to obtain peak areas for analysis. These subroutines can be linked in the order necessary for any particular measurement sequence. Some additional routines may be required to provide analysis of the samples being measured. BASIC permits program changes to be made easily and quickly and allows acditions or shanges in measurement procedures to be completed in a short time.

\section{B. Containment and Surveillance Technology Develop- ment}

1. SNM Monitor R\&D (P. E. Fehlau, Q-2). This project includes evaluation work on SNM monitoring methods ${ }^{58-59}$ and technical assistance to the users of such equipment. During 1984 we completed the Pajarito monitor, a pedestrian and vehicle monitor having high sensitivity for detecting enriched uranum, and began measuring its detection sensitivity. We also evaluated the new detection logic applied in the Pajarito monitor, a sequential probability ratio test, with Monte Carlo calculations and laboratory experiments. Other related evaluation activities were begun to measure the performance of new, commercially available, high-sensitivity pedestrian SNM portal monitors. New developments in monitoring tec'lnology during the period include a technique to identify body burdens of medical isotopes in individuals who alarm pedestrian radiation monitors. Assistance to users of radiation monitors during this period included observing SNM monitor use at eight DOE facilities, publishing a calibration manual $^{60}$ for one commercially available pedestrian monitor, and establishing more commonly available substitute test sources to replace plitonium standard test sources. 
a. Pajarito SNM Monitor. This highly sensitive pedestrian and vehicle SNM detection system (Fig. 43) monitors motor vehicles with overhead and underground plastic scintillation detectors and monitors pedestrians with large plastic scintillators that form a conventional pedestrian portal. We fully described the $\mathrm{Pa}$ jarito monitor and its vehicle-monitoring performance in a recent conference paper. ${ }^{58}$ Our goal for the vehicle monitor was to provide a uniform detection system in which vehicle structure could not supply shadow shielding to hide uranium inside a vehicle. We did this by placing detectors both below and above the vehicle being monitored and then separately anlayzing the signals from four small groups of detectors to optimize the detection sensitivity. We achieved a detection sensitivity for ur shielded, enriched uranium in medium-size vehicles that is much better than determined earlier for the best hand-held monitoring. Detection sensitivity for plutonium contained in medium-size vehicles also is impressive because it compares well with the detection sensitivity of pedestrian monitors.

Another improvement in the Pajarito vehicle monitor results from the application of a sequential monitoring scheme. The sequential procedure breaks the monitoring time into a sequence of subintervals after each of which all available data are tested. A decision (background intensity or significant intensity increase) is made as soon as possible instead of waiting until the end of a fixed monitoring time. As a result, waiting time in the monitor is considerably reduced. We applied sequential testing independently to each group of detectors with a four-channel monitor controller for which we investigated, by Monte Carlo simulation, the as-built performance and the effect of varying some of the operating parameters. The Monte Carlo computer code that we developed is described in a recent conference paper, ${ }^{61}$ and the simulation results are reviewed in Ref. 59. The most important calculation for the vehicle monitor is the average monitoring time (Fig. 44). The monitoring time varies with radiation intensity, taking less time when the radiation intensity is either near background or substantially above background. Near the threshold for detecting a significant intensity increase, the sequential method may, on the average, take as long as earlier, fixed-interval methods. However, for routine monitoring the radiation intensity usually is near background, and a substantially reduced monitoring time is needed even though detection sensitivity and false alarm probability are not degraded.

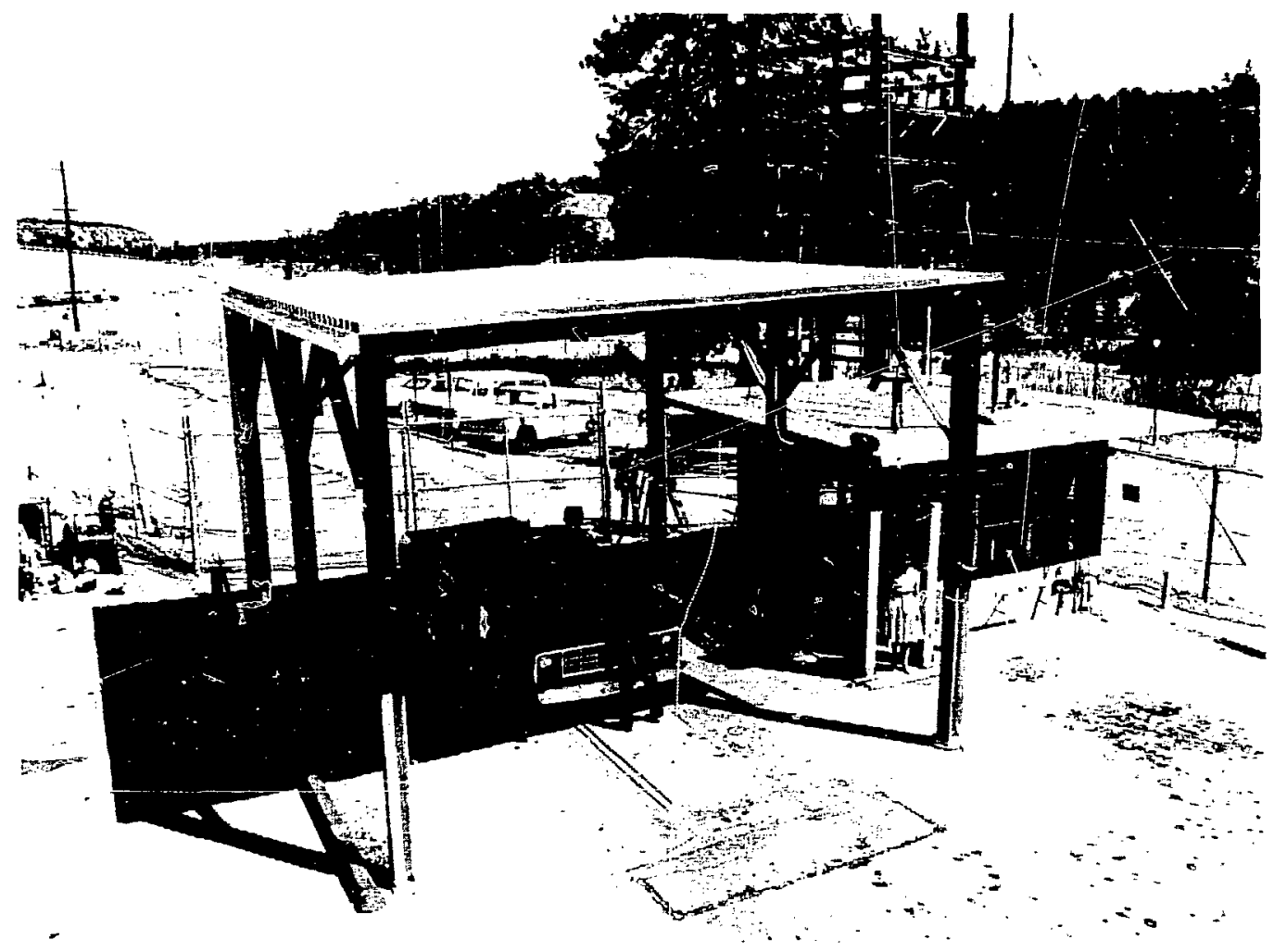

Fig. 43. The Pajarito monitor su:veys both pedestrians and motor vehicles for SNM as they depart Pajarito sile at Los Alamos. In this photograph, an incoming vehicle is being manually searched for contraband as it enters the site. 


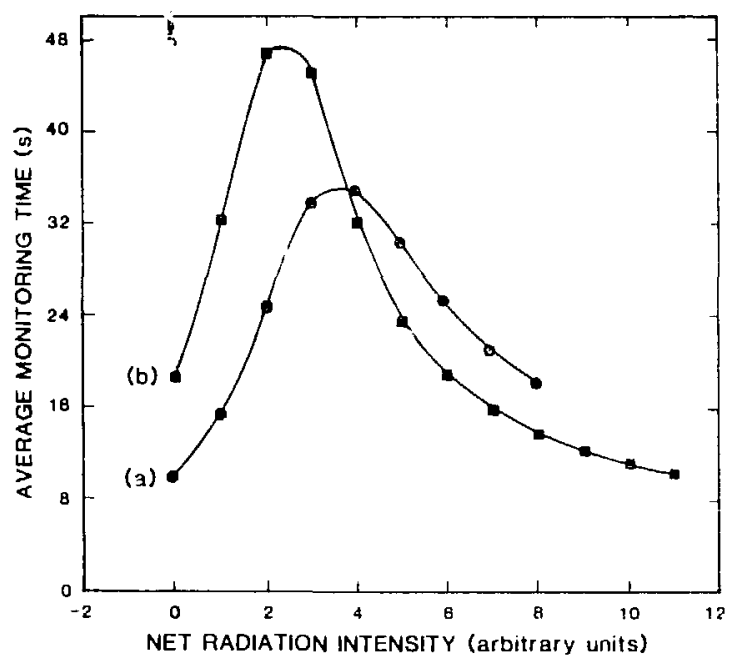

Fig. 44. The average monitoring time for the vehicle monitor depends on whether (a) a single channel or (b) all four channels must make the final decision. Background decisions require four judgments, and the result at background intensity appears at the left where the upper (four-channel) curve has a va!:, of about $18 \mathrm{~s}$. b. Commercial SNM Monitor Evaluation. In recent years, new radiation monitoring technology developed in DOE laboratories has been incorporated into commercial SNM monitors, and maniffacturers also have developed high-sensitivity radiation monitors for health physics applications. In most cases, standard tcst sources and standard testing environnents for the use of such equipment to detect SNM are not available to the manufacturers. User performance evaluation of such equipment seldom provides adequate information for others to determine whether to apply tine newly available equipment. To overcome the lack of useful performance data, we have, for some years, undertaken to evaluate new SNM monitoring equipment at the request of a manufacturer or user. We are currently evaluating a TSA Systems, Inc., PM-600P personnel monitor that was loaned to us by the Rocky Flats Plant. The PM-600P (Fig. 45) is a high-sensitivity pedestrian monitor that is finding application where 2- to $3-\mathrm{m}$ spacing between detector pillars is required. We are determining the false alarm probability for the monitor and will establish its detection sensitivity over a range of pillar spacing from 0.75 to $2.4 \mathrm{~m}$. We expect to evaluate another new monitor from IRT Corp. in the near future.

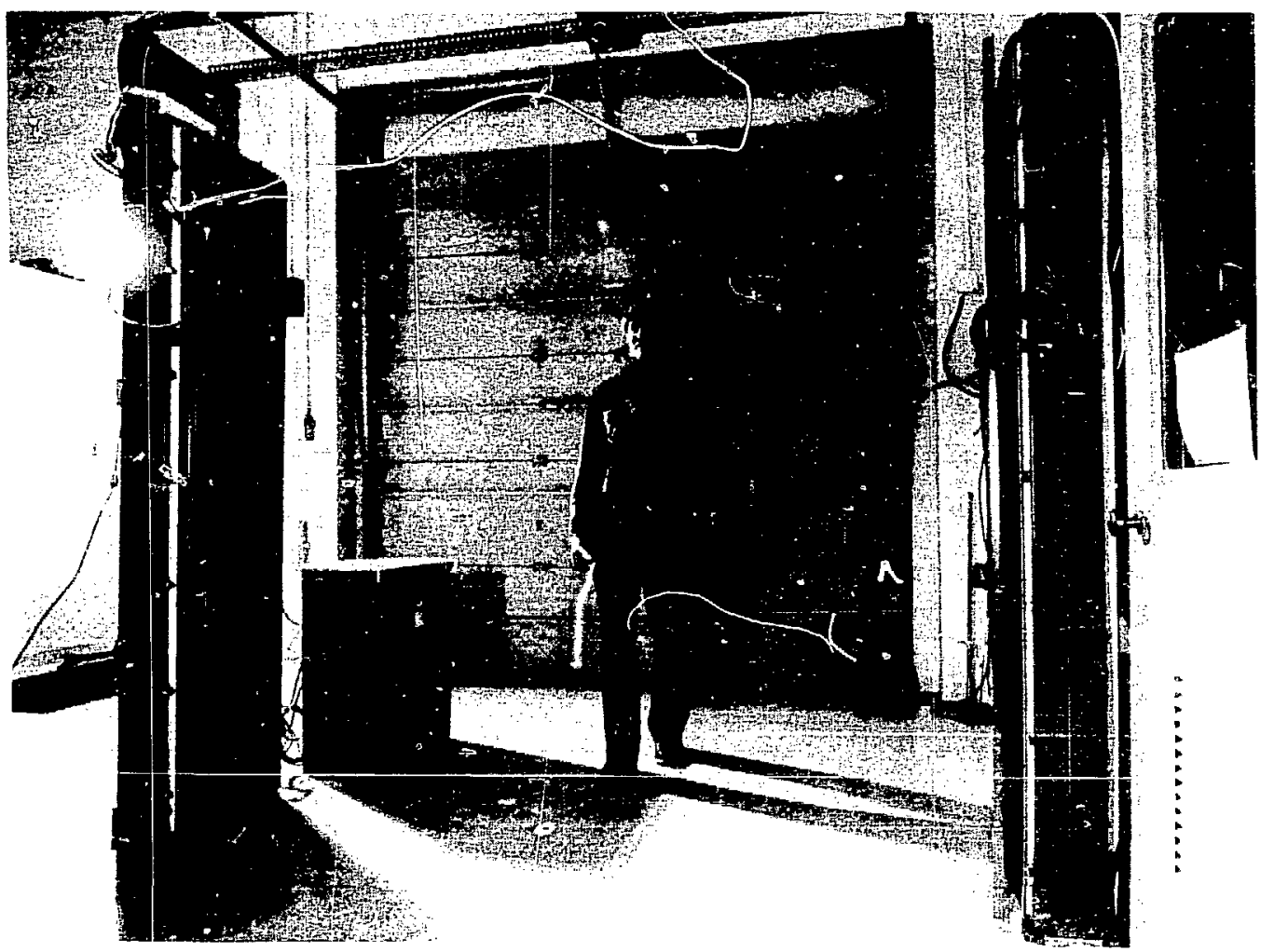

Fig. 45. The TSA Systems, Inc., PM-500P pedestrian monitor is being evaluated for use at pillar spacings as widc as $2.4 \mathrm{~m}$. False alarm probability testing is under way in this photograph. 
c. Radiation Source Verification and Identification. Whenever an SNM monitor is heard, the cause of the alarm should be identified. In many cases the individual or a health physics monitor can identify the source. In other cases, identification cannot be made without further investigation. There has long been a desire to develop simple, easily portable, automatic equipment to identify unknown radioactive materials. We have taken the first step towards automatic identification with a system to identify medical radioisotopes inside the human body.

The medical-isotope identification system (Fig. 46) identifies a radioisotope by collecting a gamma-ray energy spectrum with a $\mathrm{NaI}(\mathrm{Tl})$ detection system and multichannel analyzer. The stored results are sorted with a microprocessor using a mathematical technique that compares the results with standard spectra stored in the computer's memory as an isotope library. A figureof-merit for each comparison quantitatively estimates how well the results duplicate the shape of the stored spectrum. Limits on the figure-of-merit value eliminate dissimilar spectra from further consideration. Of the remaining spectra, the library spectrum having the best figure-of-merit is the most likely identification for the observed spectrum. Should no identification be made, the results are saved for later identification and addition to the library.

Operation of the system is sensitive enough to tell the difference between a bottle containing a medical isotope and the same isotope contained in the human body. The difference between the two spectra is downgraded radiation contributed by Compton scattering in the person's body. This sensitivity io scattered radiation prevents direct application of the technique to the automatic identification of SNM inside paclages where scattering may vary. We are now trying to calculate the Compten scattering contribution directly so that identification of sources inside different matrix materials may be possible without having to measure the individual library spectra.

d. SNM Monitors at DOE Facilities. During visits to SNM monitor users at Hanford, INEL, Goodyear Atomic, and Pantex, we encountered a need to develop more practical sources for gauging monitor performance, both on a daily basis and in quantitative evaluations. Another need is for better guidance on applying SNM monitors. Here the need is not only information on what is available but also on what constitutes an adequate monitor (one that detects the least amount of material possible with state-of-the-art monitors or simply one that detects a specific quantity of process material). A related matter is the purpose of recently installed metal detectors. There is a difference between suitable equipment for hand gun detection and for detecting lead shielding surrounding radioactive material, and often users are unaware of the difference or the specific purpose for installing their metal detectors. Finally, we developed a calibration manual for the National Nuclear Corp. (NNC) analog pedestrian SNM

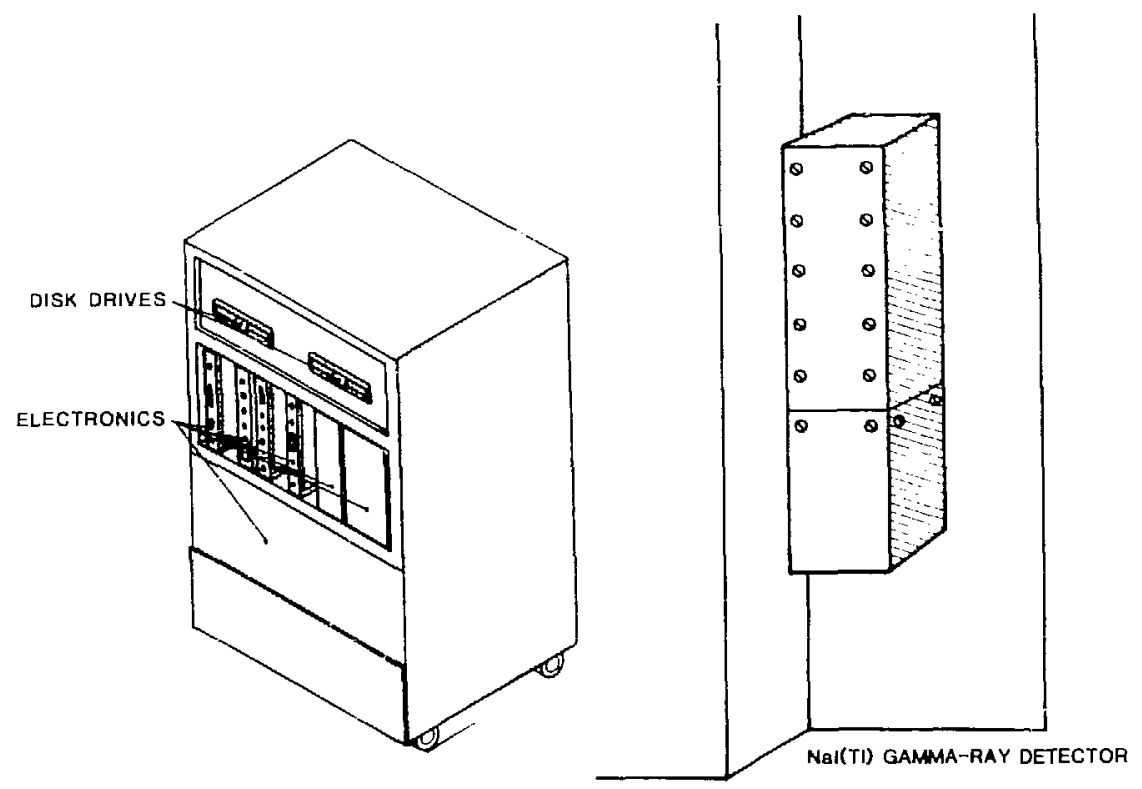

Fig. 46. The medical-isotope identification sysiem measures the energy spectrum of gamma radiation emerging from the body of a person who alarmed a peciestrian monitor. Automatic comparisons between observed and library spectra determine a best candidate for identification of the medical isotope. 
monitor and participated in trainiing maintenance technicians at the SRP to calibrate their NNC monitors.

The question of ground rules for applying SNM monitors and metal detectors, the appropriate test sources for verifying monitor performance, and the types of equipment for SNM and metal detection available commercially are being investigated with the goal to provide one or more SNM monitor applications guides for DOE facilities that must safeguard nuclear materials. This task will be completed during FY 1985 and includes a description of monitoring technology capabilities and limitations along with examples of specific application and practice and commercially available and well-developed in-house equipment.

2. Reactor Power Monitor (R. D. Hastings, K. V. Nixon, S. W. France, Q-2). The reactor power monitor attracted considerable attention and interest during 1984. After a successful demonstration and test at a power reactor site, the original instrument was returned to Los Alamos for examination and refurbishment.

We have been preparing a complete, up-to-date documentation package that will permit the International Atomic Energy Agency (IAEA) to acquire additional units. This documentation should be completed early in 1985, and the Agency has expressed interest in puchasing three new units from a commercial vendor.

The original instrument has recently undergone another successful test and demonstration. This experience involved installation at a research reactor site Such a facility involves a wider range of activitier, than a power reactor site. Aithough the instrument was not originally intended for such use. its operat: on is sufficiently flexible to have successfully monitored the operational history.

\section{Chemical and Isotope Analysis}

1. Automated Complexometric Titrator for Uranium (E. M. Hallen, D. D. Jackson, CHM-1). We have modified this automated instrument, which determines microgram amcunts of uranium in solution, to increase reliability by developing and incorporating a system for monitoring the liquid level in the sample cells to preclude overflow in case of a malfunction. A small infrared canner servcs both to detect the presence of a sample cell in correct position for the titration and to monitor the liquid lovel to prevent overflow. We also modified the control program to eliminate the possibility of transient electrical pulses causing erratic behavior.

We are evaluating the tolerance of the automated instrument for metal and nonmetal ions present in nuclear fuel-cycle materials and establishing tine measurement precision. After conclusion of the present tests, the instrument may be used for routize accountability measurements.
2. Laser-Excitation Fluorescence Uranium Analyzer (D. D. Jackson, CHM-1; W. M. Jones, CHM-2; J. N. Demas, Univ. of Virginia). We have developed a rapid and precise method for the determination of sub-partsper-million concentrations of uranium in solution. We have taken advantage of the long lifetime of uranyl fluorescence in solution in devising a phase-sensitive detection scheme to discriminate against scattered light and fluorescence from short-lived species. Phosphate, for example, strongly complexes uranyl and gives good fluorescence yields; phosphoric acid $I M$ was used for all the measurements. The excitation source is the acoustooptically modulated 458-nm line of an argon ion laser, and the fluorescence is measured with a monochromator, photomultiplier tube detector, and a dualchannel lock-in amplifier referenced to the modulation frequency. Detection limit (concentration at which signal minus background is twice the background) is about $5 \mathrm{ppb}$, and the signal is linear up to $100 \mathrm{ppm}$ uranyl concentration.

Uranyl fluorescence in solution is very sensitive to quenching by a variety of species that decrease the quantum yield by offering a mode of radiationless deactivation. Chemical methods of reducing quenching effects require considerable time and effort. By modulating the excitation source at a sufficiently high frequency, we can decrease the effect of quenching to a low level. We have investigated the effect of several strong quenchers including nitrate, chloride, iron, and chromium. As an example, by modulating at a frequency of $10 \mathrm{kHz}$, the quenching due to chloride can be reduced from a factor of 10 to a few per cent.

We are modifying the instrumentation to simplify the apparatus to reduce cosi and increase reliability. Fabrication of a system to replace the monochromator with an interference filter and photomultiplier detector is in progress.

3. Advanced Automated Controlled-Potential Coulometric Analyzer (R. M. Hollen, D. D. Jackson, CHM-1). We constructed a prototype automated instrument for the controlled-potential coulometric determination of plutonium in 1981 and prepared a report $^{62}$ that describes the automated instrument in detail, including the chemistry of the analytical procedure; a discussion of the mechanical, electrical, and control components and their operation; and test data showing precision capability. We are constructing an advanced automated instrument incorporating many improvements for increased accuracy and reliability. Design of the mechanicsi portion of the instrument is complete and a set of engineering drawings is available. Fabrication of the mechanical portion of the improved instrument is in progress.

A completely pneumatic system that is simpler and smaller than the pneumatic-hydraulic system on the 
original instrument, smoothly and with excellent reliabiiity drives syringes to deliver the various reagents and lifts the electrolysis cells in to position at the measurement station for the analysis. We developed a method of separating the pneumatic control system from the turntable sample transport and measurement station, making it possible to locate the pneumatic control system outside the glove box. This will save space in the glove box and simplify maintenance. The turntable sample transport system contains fewer componf.nts for increased reliability and is smaller to occupy less glove-box space. Improved sensors and interlocks are incorporated. A smail infrared scanner has replaced a mechanically activated switch to sense that an electrolysis cell has rotated into position at the measurement station and, therefore, reagent additions and the measurement can proceed. The scanner also monitors the liquid level to prevent overflow. A bar code system automatically reads the turntable position to aid in sample identification. We are designing an improved control system, based on an HP-85 programmable calculator and an HP-3497 data acouisition/control unit. The new control system will improve reliability and provide greater versatility with fewer components and decreased cost.

When it is completed, the instrument will be tested by comparing its assay results with highly precise measurements made manually by Los Alamos, analytical chemistry group. Use of the automated instrument for -lutonium assay for routine accountability measurements would decrease the total time and cost of the analysis and help eliminate analyst bias.

\section{Lasfr-Abetted Mass Spectrometer for Measuring} Uranium and Plutonium Isotopic Distributions (J. W. Early, CHM-1). The objective of this activity is the development of a mass spectrometer that will determine accurately the isotopic distribution of uranium and plutonium without need for prior chemical separations of these elements from the niany other elements present in nuclear fuel-cycle materials. This should result in considerable savings in time and cost of analysis. We are investigating a technique that uses resonant radiation pressure to photodeflect and separate impurity element masses that are isobaric with uranium or plutonium isotopes.

We developed an apparatus for the investigation of the basic properties of the photodeflection process. We selected barium for the initial experiments because of its simple atomic spectroscopy. A beam of neutral barium atoms was dzflected by interaction with the intense standing-wave light field of an intracavity, tunable dye laser beam. The mean angular deflection of about 0.5 degrees, measured using a movable slit in front of a quadrupole mass spectrometer, agrees well with predicted values. S. lectivity of the photodeflection tech- nique was demonstrated by complete separation of barium and strontium atoms from a mixed beam.

Additional experiments will evaluate the application of this technique to atoms of more complex spectroscopy, such as uranium and plutonium.

\section{Controlled-Potential Coulometric Determination} of Uranium (N. M. Saponara, D. D. Jackson, CHM-1). The method we developed for the controlledpotential coulometric determination of uranium at a solid platinum electrode ${ }^{63}$ features low milligram sensitivity, precision of $0.1 \%$ RSD at the 5-mg uranium level, high specificity, and long-term electrode stability, all of which should make it applicable in mainy areas for aicountability measurements. However, molybdenum, which is often present in nuclear fuel-cycle material, presents a troublesome, interfering action (the only one). None of the techniques we have investigated was successful in preventing the molybdenum interference. and we found no set of electrolysis conditions that would avoid the interference. We also investigated, without success, a separation step to remove molybdenum prior to the electrolysis. Extraction with $\alpha$ benzoin oxime in an organic solvent effectively removes the molybdenum, but electrolysis times are extended, probably due to traces of the organic solvent. We found no organic solvent in which the $a$-benzoin oxime was sufficiently soluble that did not cause electrode fculing and extend electrolysis times. The method is still applicable for uranium determination in material not containing molybdenum.

D. Standards Development: Consensus Standards Developmeni (R. G. Gutmacher, 2-4; C. W. Bjork, Q-1). Los Alamos safeguards personnel have participated in the standards writing activities of American Society for Testing and Materials (ASTM) Committee C-26 on the Nuclear Fuel Cycle. A "Standard Test Method for the Determination of Plutonium Isotopic Composition by Gamma-Ray Spectroscopy," developed by the Task Group on Plutonium Spectroscopy chaired by a Los Alamos representative, has passed committee and society ballots. The test method will appear in the 1985 Annual Bocts of ASTM Standards with the designation C1030. The r:ethod applies to the determination of isotopic abundances in plutonium oxide, mixed oxide, and piuionium metal.

Current activities of the task group include development of a standard test method for nondestrictive assay of special nuclear materials in low-density scrap and waste by segmented gamma-ray scanning. Future activities will be devoted to test methods for scrap and waste using neutron techniques. The determination of both plutunium and uranium will be addressed. 


\section{MC\&A TECHNOLOGY AND APPLICATIONS DEVELOPMENT}

A. Safeguards System Integration (J. T. Markin, Q-4). At the request of the DOE/Savannah River Operations Office, we are developing an approach to the conceptual design of an integrated safeguards system for the New Special Recovery process. This study will incorporate existing Savannah River plans for safeguards and, wherever possible, avoid creating additional requirements for personnel, equipment, or procedures.

A key aspect of an integrated safeguards system is information exchanges between facility and safeguards activities into a coordinated system for safeguards decision making. Integration of these information flows would be achieved by specifying

(1) all information sources having safeguards relevance including process monitoring measurements, process control information (such as valve settings), criticality sensor data, facility environmental data (such as air pressure in a glove box), as well as data generated by purcly safeguards activities (such as material measurements and confirmed authorization to enter an area);

(2) the format and content of the information;

(3) criteria for initiating transmission of the information to the safeguards system; and

(4) physical channels, administrative procedures, and a management structure for communicating the information.

Incorporating information from facility activities (such as process monitoring or health and safety) provides additional information that can indicate unauthorized personnel actions or detect loss of material. For example, a change in glove-box air pressure, decrease in a vessel's liquid level, or an alarm from an area radiatior monitor are all anomalies that could be indicators of material diversion. Future systems studies will emphasize the use of such facility-related information to complement the traditional safeguards sources of information.

\section{B. Advanced Materials Measurement and Accounting Systems}

1. Voice-Verification System (W. Ford, Q-4). We are continuing to develop a computerized voice-recognition system for application in a nuclear safeguards system where it is required to verify the identity of persorinel requesting access to nuclear material. System operation requires entry of an identification number (ID) through a device such as a badge reader. After the number is entered, the system loads the voice patterns associated with the entered ID into a voice-recognition board. The system then prompts the user to repeat a series of randomly selected words into a microphone. This prompting is done both on the display and via a voice synthesizer. At the end of the test, an accept/reject decision is .:-ade, and the system is readied for the next user. After five unsuccessful attempts using the same ID number, instructions are given to call for help.

Enrollment into the system is done by an operator and is controlled so that only authorized operators may enroll a person. In the simple demonstration system, the operator must know a password to call up the enrollment program. During enrollment the user is prompted, orally and visually, to repeat a series of 16 words for five passes. This ensures a good set of voicc patterns for that user. New users may find that the first set of voice patterns is no: satisfactory and will need to upgrade the patterns later. Normally the patterns remain good for months unless something happens to ine user's voice.

The system hardware comprises four main sections: the recognition section, the voice-synthesizer section, the microcomputer, and the operator/user interface. All components are readily available commercial items but were selected on the basis of the system as a whole rather than as individual components. The voice-recognition board is the heart of the system, so other components had to be compatible with available boards. Other considerations were the minimization of size and cost. A secondary consideration was easc of development and availability of development tools. Also considered was compatibility with possible host computer systems in existing security systems.

This system is being prepared for use by Sandia National Laboratories, Albuquerque, in a series of experiments, which will test and compare a variety of personnel identity-verification systems for access control. Results from these tests will provide guidance for modifying system design parameters to improve voice recognition under operating conditions.

2. Microcomputer-Based On-Line Distributed Processing for Nuclear Materials Accounting Systems (S. T. Smith, W. C. Barnett, Q-4; R. Bearse, Consultant). We have been investigating the use of microcomputers in a distributed-processing environment (DPE) for materials accounting applications. Materials accounting includes the nuclear material measurement, bookkeeping, and data analysis activi ies within and between materials balance areas used to generate and evaluate inventory and shipper-receiver differences. This is done either to identify a diversion of SNM or to verify that diversion has not occurred within regulatory limits. Accounting consists of three distinct operations: 
(1) maintaining book records of SNM amounts and locations, (2) physical measurement of these same SNM items, and (3) comparison of the book and measured inventories. Material control is taken to be that set of continuously applied procedures that protect against unauthorized use or diversion of SNM.

Materials accounting was originally done with hand receipts and ledgers: as was most bookkeeping in the world. Now, however, it is routine to capture information about the material being processed using a computer and to prepare inventories and reports on these data using the same computer. Data are entered into the computer either by the process operator himself or by trained clerks who obtain paper records from the process operators.

A distributed-processing environment is a network of computers or computer-based systems to accomplish what might otherwise be an involved and complicated procedure using a single computer (either with or without multiple data-eniry points, or terminals). Computers in an accountability environment are useful for data collection, database entry, database query, report generation, and various applications in problem solving. In a DPE, these features are enhanced by the capability to share resources with other processors; by this we mean that programs, databases (or parts thereof), and messages may be transferred over the network from processor to processor, and pristers, hard disks, and other peripherals can be shared. In addition, in a DPE, reliability is greatly increased compared with a central system, because individual parts can fail without disrupting the entire system. Other advantages of a DPE over a crntral system include local error checking, local security shecking, instrument interfacing, inírmation preprocessing, local databasing possibilities, and local trensaction recording and checking. Furthermore, one greai advantage of decentralization in processing is often overlcoked: it creates an environment that is conducive to user support.

Microcomputers, or personal computers (PCs), in a DPE, can do more than the independent processing iasks they usually perform; they can replace terminals in mainframe networks and can act as the parent processor in automated instrumentation networks. Using a PC as a terminal permits sharing the centrally stored data and powerful processing capabilities of a mainframe cornputer as well as freeing one from the processing slowdowns that are common in mainframe systems burdened by many tine-sharing users. In addition, the PC permits both thecking of errors in data input and the tracking of entire transactions for local areas within a materials balance area (MBA). Wher. the PC has one or more instrument interfaces associated with it, it becomes even mcre powerful, greatly reducing the opportunity for error in transmitting a measurement from the instrument to the database because the human interface has been transformed to an electronic interface.

We have begun to consider both the hardware and software required to sei up a DPE for a generic MC\&A system. We connected a 16 -bit microcomputer to instrumerts from which measurements were transmitted to a database operated by the microcomputer. To our knowledge, this is the first time that such a task has becn accomplished for a nuclear MC\&A system; we are preparing a rep $u r t$ that describes the system. ${ }^{*}$

Future work will include investigating various configurations of i:astrumented microcomputer networks to determine whether any contiguration has definite advantages over others for this application. We also shall evaluate various off-the-shelf software packages from the vast number available to determine whether both the databasing and the instrumentation interfacing can be accomplished with commercial software. If commercially available hardware and software can be used, the methodology will be readily transportable from one facility to another, rather than being facility-specific.

\section{MC\&A Technology Development}

1. Application of Artificial Intelligence (AI) Techniques. We are continuing to investigate and evaluate the application of state-of-the-art AI techniques to nuclear material: accountability.

a. A Computer Program for Symbolic Materials Balance Variance Calculation (C. A. Coulter, Q-4). Extant computer programs for the determination of materials balance (MB) variances require both that the user understand the use of statistics and that he do considerable "hand preprocessing" of measurement-uncertainty data before execution of the computer program. In addition, these programs usually produce only numerical results and have limited or no capabilities for determining the major contributions to the $\mathrm{MB}$ variancs. For these reasons, we decided to develop a variance-calculation program, written in LISP, that would require less expertise on the part of the user, simplify the data input process, produce brth symbolic and numerical results, and have a cap sbility for analysis of major variance contributions at the facility of interest. To enhance portability of the code pro Juced, we used a version of LISP available for the IBN PC and compatible com.uters.

A significant number of the procedures required for the variance-calculation program have already been written and tested. These include functions

\footnotetext{
*S. T. Smith, W. C. Barnett, R. Bearse, et al., "MicrocomputerBaced Eisi- buted Processing for Nuclear Materials Accounting Systems."
} 
- to accept and edit keyboard input,

- to convert character strings containing algebraic expressions into corresponding LISP lists (with error checking and error reporting for the algebraic expressions entered),

- to differentiate arbitrary combinations of rational and elementary functions of an independent variable,

- to manipulate and evaluate symbolic summations,

- to simplify algebraic expressions (by performing all arithmetic operations involving constants, collecting powers of each factor in a product/quotient, and collecting like terms in summations), and

- to convert LISP expressions into character strings displaying their equivalent algebraic representations.

These functions together with the functions to determine the total differential of a function of several variables (including indexed variables in summations) will form most of the tools needed for the symbolic evaluation of variances from $M B$ equations.

Recently a COMMON LISP interpreter for the IBM PC and compatible computers has become available, and a COiviMON LISP compiler is to be distributed by the same software producer within a few months. The part of the program already developed will be rewritten to follow COMMON LISP protocol, and future program development will all be carried out in this dialect. The final program will then not only be transportainis to other IBM PCs, but the source code can be transferred to a large number of other computers supporting this standard dialect of LISP

b. MACSYMA Applied to Variance Calculations (D. Stirpe, Q-4). MACSYMA is an interactive AI computer program capable of a variety of symbolic inathematical operations. We are using MACSYMA in two different ways to facilitate the calculation of variances of MR equations. The first approach is the more fundamental and requires that standard error-propagation formulas normally used to derive variance equations be programmed in MACSYMA läñguage. Because MACSYMA is rapable of many mathematical operations necessary to derive variance equations, it was thought that MACSYMA could be "taught" to derive the necessary variance equation for a particular $\mathrm{MB}$ equation. However, early efforts showed that this fundamental approach was going to be more difficult and time consuming than originally thought. A MACSYMA program to derive variance equations must include provisions for both variance and covariance relations for the many types of MB terms that can occur in an MB $\epsilon_{y}$ uation and mist also include provisions for treating additive, multiplicative, and mixed error models. Although some progress has been made in this approach, much more work is necessary.

The second approach toward facilitating variance calculations using MACSYMA simply recognizes that we have appiied materials accounting systems to a variety of nuclear facilities over the last few years; hence a lasge number of variance equations for different types of MB terms are already available. A MACSYMA file that contains about a dozen more commonly used variance and covariance equations was created for immediate use. We used this file recently to calculate the total variance of an MB system for the Savannah River FB line. The calculations for this facility were completed in little more than $0.5 \mathrm{~h}$, a very short time for an $\mathrm{MB}$ equation containing seven transfer terms and 17 inventory terms.

This approach proved so fruitful that we are now creating a MACSYMA file that may eventually contain as many as 100 variance equations. Also, these equations will be expressed in a form that considers process variability, which the earlier file does not. An obvious difficulty with such a large file of equations is that an individual performing the calculations must search through a long list to find the variance equations needed for a particular MB equation. Hence, a short MACSYMA program was written so the operator reed only list the MB terms that appear in a particular MB equation and enter the name of this list into two short functions; the appropriate variance and covariance expressions are then retumed for use in calculations.

\section{Statistical Methods for Materials Accounting}

a. Error Propagation/Inquiry Code (EPIC) ( $A$. Baker, $Q-4)$. We have developed a computer program called EPIC to calculate the variance of a materials balance closed about a materials balance area (MBA) in a processing plant operated under steady-state conditions. This code was designed for use in evaluating the significance of inventury differences in DOE nuclear plants. It rapidly estimates the variance of a materials balance using average plant operating data. The intent is to learn as much as possible about problem areas in a process with simple, straightforward calculations assuming a process is running in a steady-state mode. EPIC is designed to be used by plant personnel or others with little computer background. However, the user must be knowledgeable about measurement errors in the system being evaluated and have some klowledge of how measurement-error terms are combined in errorpropagation analyses. EPIC runs on any computer that accepts a standard form of the BASIC language. It is written in Microsoft BASIC, which is available on any $\mathrm{CP} / \mathrm{M}$ system or any MS-DOS system. The code was developed on a Hewlett-Packard Portable 110. The 
amount of memory necessary depends on the number of process units allowed for a process. The present version, which will handle 40 tanks and 20 input or output streams, requires $100 \mathrm{~K}$ bytes of memory.

Input to EPIC is inventory and transfer information about a process in the form of measurement values and their associated errors. These measurements reflect both process unit inventuries such as inventories in tanks and transfers of material into and out of the MBA. The beginning inverttory in a process unit is expected to be the same as the ending inventory. The errors required are the total correlated error and the total random error asscciated with each measurement value. Both relative (per cent) and absolute ( 1 std dev) errors can be accommociated. EPIC uses a set of eight equations to calculate the varianca for each measurement point. After a!l of these variances are calculated. the total variance for the MBA is calculaied using a simple algebraic sum of variances.

This program is being distributed to a lirnited number of users for testing in the field, comments aboui the ease of use, and suggestions for improvement and additions. We have written a first draî of a user's manual, which is being distributed a!ong with the program.

b. Improved Sample-Size Determination for Attribuses and Variables Sampling (A. S. Goldman, Q-4; R. R. Picard, $S-1)$. Verification of a declared inventory or materials balance often requires that independent measurements be made on a large number of items. The number of item, randomly selected for verification of declared values can be obtained by using a two-level attributes/variables strategy. This two-level strategy offers the advantages that the attributes measurement, whirh is intended to detect la:ge falsifications, can be relatively inprecise and can ie performed quickly on a large number of items. The variables measurement, which is designed to detect small falsifications and must therefore be more precise and time consuming, need only be performed on a relatively small number of items. Two recent papers ${ }^{64,65}$ have addressed the problem of deriving sample-size relaticns. but the relations obtained are based on conservative. limiting approximations. We have addressed this poblem by using computer simulations in which such approximations are not riecessary.

To formulate the proutem for computer simulation, the overall nondetection probability (NDP) of falsifications (items with incorrect declared values) is expressed as the sum of six components. Only three of these components are mujur contributors to tile NDP: (1) the probability that no falsified items appear in the attributes and variables samples, (2) the probability that falsinied items appear in the attributes sample, but the attributes measurements do not alarm, and no falsified items appear in the variables sample, and (3) the probability that falsified items appear in both samples, but neither the attributes nor the variables measurements alarm. No approximation to the hypergeometric density function, which appears in each of these probabilities, is made. In addition, the simulation treats the realistic case where both the attributes and variables instruments have random and correlated measurementerror components. Finally, the attributes and variables false alarm probabilites (FAPs) are determined. Results of the simulation are presented in plots of NDP and FAP as functions of the magnitude of the falsification, with the attributes and variables sample sizes and the random and correlated measurement-error standard deviations of the attributes and variables measurement instruments $t$-eated as parameters.

We simulat.d several problems, incluciing the one solved by Sanbe $m$ in Ref. 64, which we used to test the simulation pı acedure. In this problem, Sanborn makes two conservative, limiting assumptions.

- The attributes measurement error is en:irely correlated; there is no random component.

- The variables measurement is exact.

The simulated results agree with those obtained by Sariborn; that is, for NDP less than or equal to 0.10 [or a detection probability (DP) greater than or equal to 0.90 ], the attributes sample size is 47 and the rariabies sample size is 8 . However, because the attributes $F A P=0.023$, one additional item must be remeasured at the variables level. Hence, the averige inumber of meastrements is $47+9=56$.

This problem was formulated more sualistically by allowing for error in the variables measurement and, in addition, allowing for both random and correlated error components in both measurements. Hence, we assumed

- the same total attributes measurement variance as before, but distributed with an $80 \%$ random error conponent and a $20 \%$ correlated component. and

- a total variables measurement relative standard deviation of $2 \%$, also distributed with $80 \%$ of the variance random and $20 \%$ correlated.

For falsification per item in the range $0.080 \mathrm{~kg}$ to 2.0 $\mathrm{kg}$, the NDP was less than 0.10 for an attributes sample size of 41 and a variables sample size of 5 . The attributes $\mathrm{FAP}=0.023$, so one additional variabies measisrement usually is required. Hence, the averagi number of measurements required is $41+6=47$, somewhat less than the more conservative results above. More importantly, the number of variables measurements, which can be time consuming and expensive, dropped to two-thirds of the more conservative value obtained above. 
Note that for both measurement instruments, the correlated error standard deviation was assumed as onehalf of the random error standard deviation. When we assumed that the correlated error component of the variables instrument was only one-eighth of the random error component, we were able to reduce the variables sample size to four items while maintaining the NDP equal to or less than 0.10 . The total number of measurements is then $41+5=46$, and the number of variables measurements (five) dropped to almost half of the conservative value obtained in Ref. 64.

3. Headquarters Initiative: Shipper-Receiver Differences (C. A. Coulter, Q-4). DOE orders specify that when Category I or Il quantities of unirradiated SNM are transferred from one facility to another, the receiver must (under most circumstances) obtain an independent measurement of the amount of material transferred within 10 calendar days of receipt of the material. This requirement frequently has not been met in practice. The DOE Office of Safeguards and Security requested that we analyze safeguards requiremicnts for the transfer of Category I and II quantities of plutonium in desirable forms (for example, relativeiy pure metal and oxide) and determine whether alternative safeguards requirements taking greater account of inaterial control procedures might provide the same or a greater level of detection for the loss of material in transit. Consequently, we investigated the flow of material from the end of processing at one facility through the transfer stage to a second facility and the introduction of the material into the process at the receiving facility. We concluded that diversion of Category I and II quantities of plutonium in desirable forms can be detected with high probability by NDA fingerprint measurements performed by shipper and receiver without the need for a receiver's accounting measurement before the material is required for processing purposes and that it is acceptable from the safeguards viewpoint to close out DOE/NRC Form 741 for a transfer on the basis of such fingerprint measurements. Consequently, we recommended that the regulations governing shipper-receiver measurements for unirradiated Category I and II quantities of plutonium in desirable forms be amended to incorporate the following requirements.

1. The receiver may elect (a) to perform his accounting measurement on the material receives within 10 calendar days of receipt or (b) to arrange with the shipper for a sel of NDA fingerprint measurements to be made on the material by both shipper and receiver, with the shipper's NDA fingerprint measurements preferably performed immediately after the material is canned (or otherwise packaged) and the receiver's confirmatory NDA fingerprint measurements performed on the material within 10 calendar days of his receipt of the material.
2. When procedure $1(b)$ is $e^{\prime}$ ected, the shipper and receiver must select a set of ivDA measurements for which raw measurement results are technically so difficult to imitate with bogus material or bogus items that such a substitution scenario is not credible. The weight and total and coincidence neutron count rates for the material are recommended as possible fingerprint measurements. The shipper and receiver must perform the same types of measurements (for example, weights of individual cans, neutron coun $\downarrow$ rates for items in shipping containers) and must exchange calibration samples and calculate the accuracy of raw measurement values for the NDA measurements selected.

3. If procedure $I(a)$ is selected, the statistical significance of shipper-receiver differences in measured amounts of material transferred must be determined. If procedure $I(b)$ is selected, the statistical significance of shipper-receiver differences in NDA fingerprint measurement values is to be determinud. (A statistical procedure for determining significance is to be recommended later.) In either case, differences determined to be statistically siznificant at a level stipulated by regulation musı be investigated-and, if possibie, resolved-according to current regulatory requirements.

4. When the shipper-receiver differences determined by either procedure I(a) or procedure 1(b) are found to be not statistically significant at the stipulated level or are resolved, the DOE/NRC Form 741 for the shipment is closed, indicating that all transferred items have been received intact.

5. When procedure l(b) is used to accept the shipment, the receiver shall carry the maierial received on his books at shipper's value pending his accounting measurement. After the accounting measurement has been obtained, the receiver shall correct his book value for the material to the value obtained by his accounting measurement and shall reporn the corrected value to the appropriate DOE office. The difference between shipper's anc' receiver's accounting values shall not be allocated to either shipper or receiver.

6. The receiver shall calrulate the cumulative sum of differences in shipper's anc' receiver's accounting measurements for material transferred and shall examine the statistical significance of this difference by means of an accepted sequential testing procedure. (A specific procedure is to be recommended later.) If the test indicates that a significant difference exists at a level stipulated by regulation, the appropriate DOE office shall be notified and an investigation of the difference initiated according to current regulatory requirements. The purpose of the investigation shall $k=$ to determine the cause of the difference and take corrective action to reduce future shipper-receiver differences, not to amend previously recorded shipper and recei ver measurement values. 
PART 4. INTERNATIONAL SUPPORT

\section{ENRICHMENT PLANT SAFEGUARDS}

\section{A. Portsmouth Gas Centrifuge Enrichment Plant (GCEP)}

Los Alamos activities in the US Enrichment Plant Safeguards program for international safeguards are focused on the development of technologies for effective international safeguards of gas centrifuge enrichment plants, specifically the Portsmouth GCEP. Included in these activities is the development of the limited-frequency-unannounced-access strategy (LFUA), the integrated data acquisition system, the in-line e rrichment monitor, and area neutron-monitoring technology. ${ }^{66}$

The International Atomic Energy Agency (IAEA) is currently negotiating Facility Attachments for centrifuge enrichment facilities in the United Kingdom. the iNetherlands, Japan, and the United States. A primary condition for the success of these negotiations is the development and acceptance of a measurement technique for use during LFUA inspections. Los Alamos has provided an international lead in developi ${ }^{-} z$ and demonstrating an integrated passive/active gamma-ray measurement technology for LFUA inspections and has been instrumental in gaining international acceptance of the measure nent methods.

Maintaining effective safeguards for high-throughput enrichment plants could seriously affect limited inspectorate personnel resources and could pose an unacceptable burden on the operations of a full-scale commercial enrichment plant. Improving inspector efficiency and reducing the impact on the facility operator have been the goals of the integrated data acquisition system (IDAS), an at-site computer for dedicated use by the IAEA inspector, and the in-line enrichment monitor. This equipment has been developed and tested during a single-site system-level test of the safeguards equipment developed at Los Alamos and Sandia National Laboratories (SNL) for future implementation at the Portsmouth GCEP. Delivery of this equipment to Portsmouth was originally scheduled for December :984. However, t-cause of schedule uncertainties for the GCEP constru ion related to the DOE enrichment process selection, completion and installation of the international safeguards system have been deferred.

An important aspect in the development of equipment for international safeguards is the review and acceptance of the technologies by the international community and the i.AEA. To this end Los Alamos participated in a series of bilateral discussions with the United Kingdom and with the IAE $f_{s}$, presented or contributed to five papers available to the international safeguards community, ${ }^{6.71}$ ard participated in the
IAEA Topical Meeting on Safeguards Measurements in the Cascade Area: of Centrifuge Uraniu..t Enrichment Plants, Vienna, November 19-2i, 1984.

1. Limited-Frequency-Unannounced-Access Inspection Strategy (J. C. Pratt, D. A. Close, Q-2). This development activity will provide the IAEA with a technique and portable instrumentation for verifying that the uranium gas inside enrichment-plant pipes is not above $20 \%$ enrichment. The IAEA inspectors can use the equipment to verify declared operation of cascade header pipes inside the cascade halls.

Development has been divided into three parts. The first is the study of gamma-ray emissions, both passive and stimulated, from low-pressure uranium gas, such as we expect to find in enrichment plant process pipes. The second is the application of these observations to create an enrichment measurement method. The third part is development of an automated portable enrichment verification technique based on the enrichment measurement method.

Three observations summarize this work. First, the passive gamma-ray output of process pipes is complicated by emissions of depcsits on the pipe walls. Second, measurement of the enrichment of the $U F_{6}$ gas in process (ignoring wall deposits) has been demonstrated in the laboratory. Third. the measurement is complicated and the statistical uncertainties from reasonable acquisition times are relatively large. Application of the enrichment measurement method as a verification technique for enrichment plant safeguards is suggested, but its complexity requires automation of the measurement process for the instrument to be useful for in-plant verification.

We will continue to investigate the gamma-ray emissions to confirm these observations and conclusions. Examination of potential complications from normal process activities will shape the details for application of the laboratory technique to the process plant measurements. Development of the equipment of a portable automated verification techrique will continue.

a. Passive Observation of Low-Pressure Uranium $G$ us. Several papers at the 1984 European Safeguards and Research Development Association (ESARDA) Meeting ${ }^{68,72,73}$ by researchers in the Federal Republic of Germany, the United Kingdom, and the United States, as weell as earlier publications from the vetherlands, ${ }^{74}$ reported that gas inside process pipes is accompanied by varying amounts of uranıum deposit on the walls of the pipes. US studies have investigated potential methods by which these de $\bar{p}$ ssits occur. ${ }^{68}$ One method in particular, the inleakage of air carrying water vapor, which interacts with the gaseous $U_{6}$, suggests that there 
is no limit to the amount of deposit that can occur. In addition, deposited uranium and gas-phase uranium both decay to gamma-emitting daughters. These daughters, because of their finite half-lives, may not be in equilibrium with the process uranium in the pipes. Figure 47 shows the results of a computer simulation of the time behavior of the gamma-ray count rates from potential enrichment indicators. The simulated behavior assumes a history of ordinary operation interspersed with three periods of special conditions: increased deposit formation, pipe evacuation, and production of $20 \%$ enriched uranium at reduced pressure. Clcarly, this ratio cannot be used as a reliable measure of enrichment.

Furthermore, the daughters from gas-phase uranium decay are transported from the gas to the pipe walls and may deposit in a nonuniform fashion that depends on pipe geometry. An example of this nonuniform deposit was measured at the Centrifuge Production Demonstration Facility in a $30-\mathrm{m}$ straight pipe followed by a vertical bend (Fig. 48). Behavior of the gamma-ray count rates from ${ }^{235} \mathrm{U}$ and the daughters of ${ }^{238} \mathrm{U}$ in the vicinity of this bend demonstrates that the measuring points must be carefully selected for any verification technique that uses the daughter gamma-ray count rates as an indication of ${ }^{238} \mathrm{U}$ amount.

In spite of these concerns, the ratio of ${ }^{235} U$ count rates to those from ${ }^{238} \mathrm{U}$ daughters can be stable as illustrated in Fig. 49, which shows the results of measurements on a pipe in the Centrifuge Test Facility after the facility was shut down. Again, however, this stable relationship can be upset in at least the two ways discussed, and the measurenitnt poirts will have to be chosen carefully for the technique to work.

b. Uranium Enrichment Measurement. Uranium enrichment is the fraction (usually expressed as a percentage) of ${ }^{235} \mathrm{U}$ in a uranium sample. It is therefore a ratio of two quantities, ${ }^{235} \mathrm{U}$ and total uranium. In our proposed technique, the denominator (total uranium) of the enrichment calculation is obtained by $\mathrm{x}$-ray fluorescence (XRF) of uranium in the gas phase following active interrogation with a ${ }^{57} \mathrm{Co}$ source. Both the interrogation source and the detector are collimated to limit the region interrogated and observed to one near the center of the pipe. This limits the measurement to the gas inside the pipe and ignores deposits on the walls. Such measurement of the total gas-phase uranium appears highly reliable in the laboratory.

In addition, because the $185.7-\mathrm{keV}$ gamma rays from ${ }^{235} \mathrm{U}$ remain visible above the energy of the $122-\mathrm{keV}$ excitation source used in XRF measurement, data from this measurement can be combined with data from the passive measurement to give the amount of ${ }^{235} \mathrm{U}$. The narrowly collimated detector counts 185.7 from both deposit and gas during the fluorescence measurements, but $t^{t}$ relative amounts counted from these two sources are different from passive measurement. The geometrical acceptance for the narrow collimator used

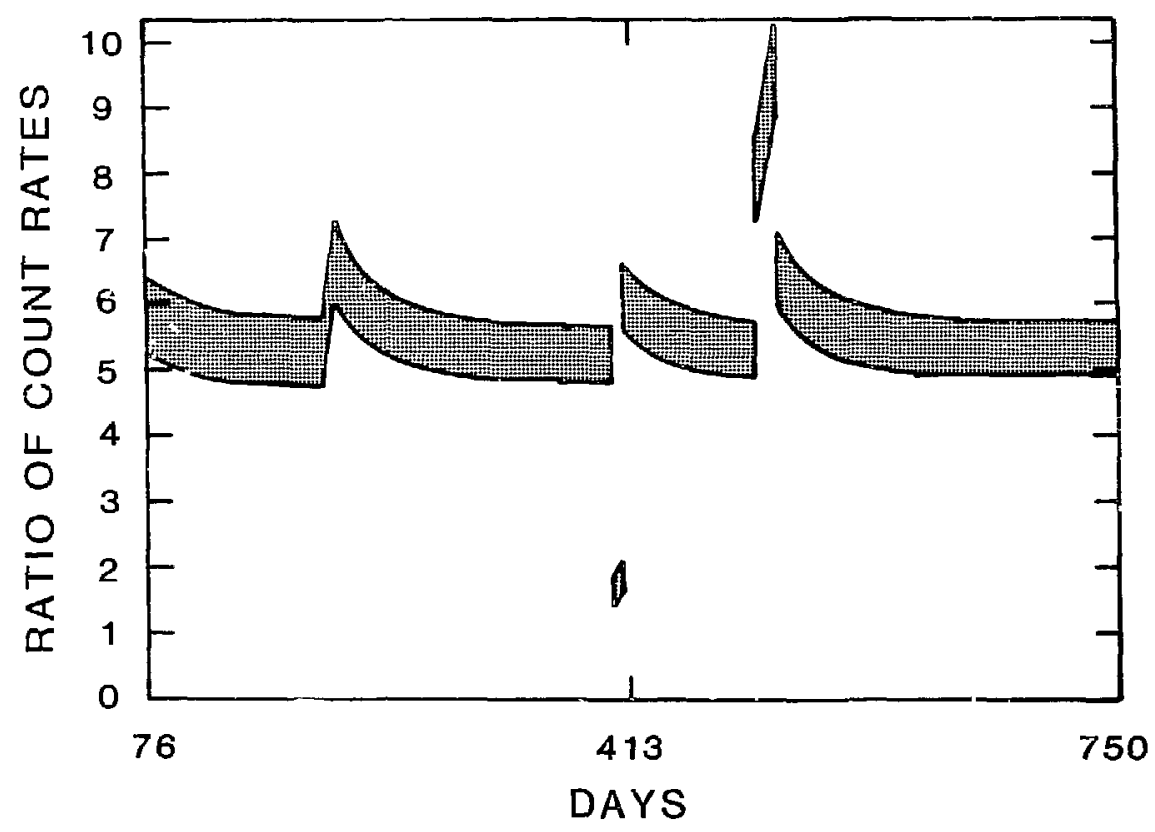

Fig. 47. Computer model of the relative behavior of $185.7-\mathrm{keV}\left({ }^{235} \mathrm{U}\right)$ and $63.3-\mathrm{keV}$ $\left({ }^{234} \mathrm{Th}\right)$ count rates, for normal operation with episodes of a sudden deposit of uranium, vacuum for 1 week, and $H E U$ production at reduced pressure. 

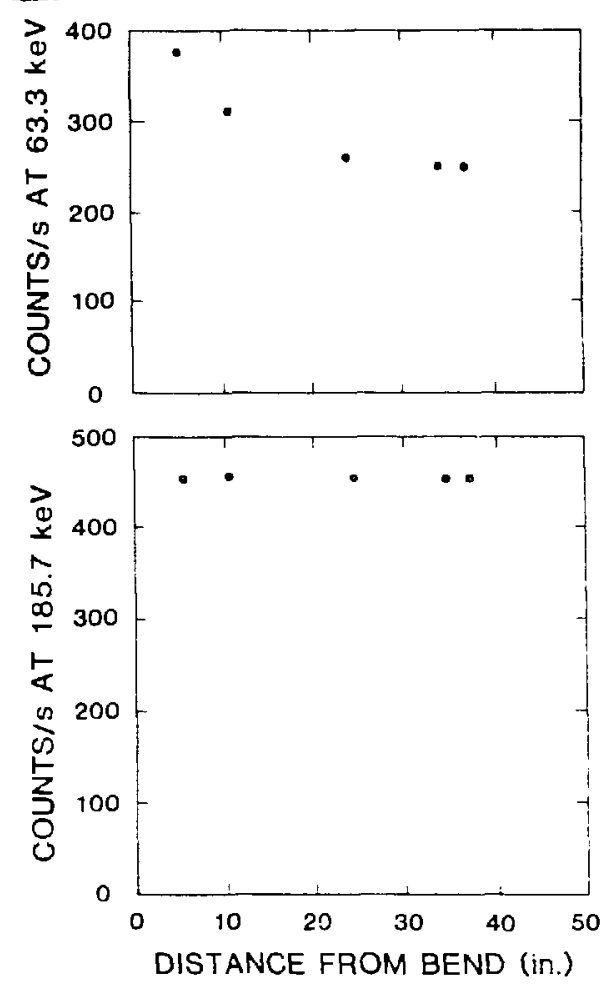

Fig. 48. The Oak Ridge Centrifuge Production Demonstration Facility product pipe has a long straight section $(\sim 30 \mathrm{~m}$ long: followed by a bend. The figure shows the $63.3-\mathrm{keV}\left({ }^{234} \mathrm{Th}\right)$ and $185.7-\mathrm{keV}\left({ }^{235} \mathrm{U}\right)$ photopeak count rates as a function of position after the bend. The units shown are arbitrary.

Fig. 49. The Oak Ridge Centrifuge Test Facility product pipe deposit photopeak count rates for $185.7 \mathrm{keV}\left({ }^{235} \mathrm{U}\right), 63.3 \mathrm{keV}$ $\left({ }^{234} \mathrm{Th}\right)$, and $92.4 \mathrm{keV}\left({ }^{234} \mathrm{Th}\right)$. Units showis are counts per second. Error bars of approximately $5 \%$ are omitted for clarity.
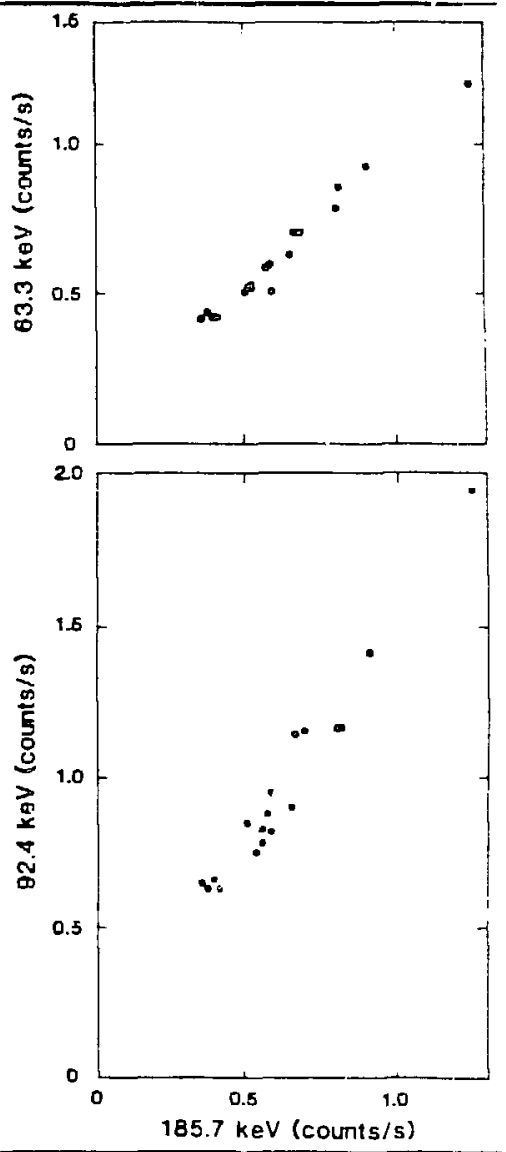
in the XRF measurement for both gaseous and deposited ${ }^{235} \mathrm{U}$ are smaller than those of the open collimator used in the passive measurements, and the relative gas/deposit acceptances of the two collimators differ by a factor of about 2. A series of laboratory measurements (acquisition of specira with each coilimator geometry on deposit-bearing pipes with and without gas) completely determinies these purely geometrical acceptance factors, which, in turn, p:ovide the crefficients in the equations.

$$
M !=A(1,1) * G+\hat{\wedge}(1,2) * D
$$

and

$$
M 2=A(2,1) * G+A(2,2) * D,
$$

where $\mathrm{Ml}$ is the measured 185.7 rate in the passive measurement; $\mathrm{M} 2$, the measured 185.7 rate in the active measurement: $G$, the quantity of ${ }^{235} \mathrm{U}$ in gas phase; $\mathrm{D}$. the quantity of ${ }^{235} U$ in wall deposit; and $A(i, j)$, the $2 \times 2$ matrix of geometrical acceptance. These equations are solved for the deposit and gas concentrations.

The ${ }^{235} \mathrm{U}$ signal from the gas, obtained by this twocollimator technique, forms the numerator of the enrichment calculation. Measurement of the gamma rays of the ${ }^{238} \mathrm{U}$ daughters is not required. While the geometry for both the passive and active measurements must be carefully controlled to allow this interpretation, no other assumptions are required and the ratio nature of the calculation means that an automated measurement process can determine the enrichmeat without explicit knowledge of the pressure. c. Uranium Enrichn ent Verification. The proposed uranium-enrichment verification procedure thus comprises two measurement steps and a complex decisionmaking process. The first step is a comparison of the passive gamma-ray count rates observed for ${ }^{235} \mathrm{U}$ and the thorium daughter of ${ }^{238} U$ with the rates expected for the type of pipe being measured. The result of this comparison is an estimate of the quantity of "excess" ${ }^{235} \mathrm{U}$ present; that is, the ${ }^{235} \mathrm{U}$ signal above that expected from the historical data preserved in the inspector's database. If this pipe measurement shows no significant ${ }^{235} \mathrm{U}$ signal above that observed in such pipes in the past and if the inspector is willing to assume that the amount of uranium under observation is the same as that of past measurements (that is, the gas pressure is the normal operating pressure), he can conclude that the enrichment is the plant's normal operating enrichment and that the plant is operating as declared. The required passive measurements and data comparison takc: only a few minutes to complete and may be sufficient for a decision.

If, however, the passive measurements indicate excess ${ }^{235} \mathrm{U}$ or are inconclusive, the inspector is obligated to make the XRF measurements (the second step of the verification procedure). These measurements can require several tens of minutes that will permit a decision between confirmed plant operation as declared and undeclared HEU production.

We are developing equipment (Fig. 50) to make this a practical technique for in-plant verification of deciared operation. The portable multichannel analyzer/computer contains an automated process to

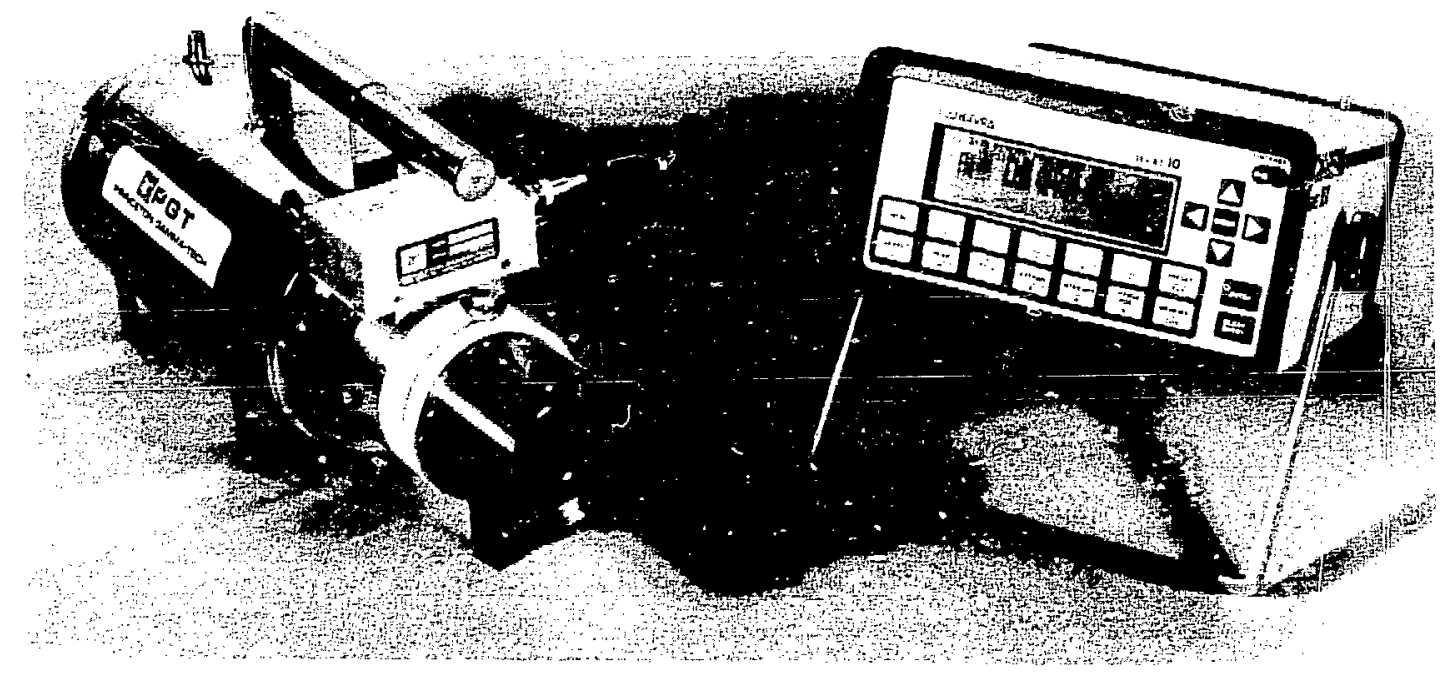

Fig. 50. Detector and portable computer for uranium-enrichment verification. 
assist the IAEA inspector in making a decision in the complex two-step procedure. The equipment assumes the responsibility for

- data acquisition of high-resolution spectra,

- computation of the count rates for specified photopeaks,

- comparison of current and historic data using a Sequential Probability Ratio Test (SPRT),

- iteration as necessary,

- data acquisition of high-resolution spectra oh tained from XRF measurements,

- computation of the count rates for specified photopeaks,

- calculation of the enrichment of the process gas and its estimated uncertainty.

- iteration, as necessarz, in an SPRT until a decision is reached,

- recording the measurement's location and results, and

- graphic presentation (without actual numerical values) of the data and results in each step of the process, alluwing the inspector to monitor the procedure and independently evaluate the application of the process to the data.
An option to stop the verification procedure is offered if the first decision process finds the ${ }^{235} U$ signal to be consistent with the historical record, allowing the inspector to make either a short confirmatory measurement or the complete verification mensurement.

2. IAEA Inspector's Computer System (A. L. Baker, w. C. Barnett, T. A. Kelley, R. R. Picard, R. B. Strittmatter, W. J. Whitty, Q-4; J. K. Sprinkle, Jr., Q-1). The IDAS is an automated data acquisition and data management system designed for at-site use by the IAEA inspector in performing lis inspection activities. ${ }^{66,67}$ The IDAS has been designed to provide (1) data acquisition and data management functions for an in-line enrichment monitoring system, (2) an interface between the facility operator's declared nuclear materials accountability data and the IAEA inspectnr. and (3) support for the LFUA strategy inspections. A schematic of the information flow to and from the IDAS is shown in Fig. 51, and Fig. 52 shows the DEC VAX/11-730 during the single-site test at Los Alamos. The computer system includes a removable $10-\mathrm{MB}$ RL02 disk pack, a fixed 80-MB RA80 disk, and a magnetic tape drive.

The IDAS computer receives enrichment data from nrichment monitor processor (EMP), stores it. ex. nnes it for potential anomalies, and produces reports upon inquiry by the inspector. The EMP ideveloped by SNL) serves as the front-end processor for the IDAS by collecti..g and authenticating data from up

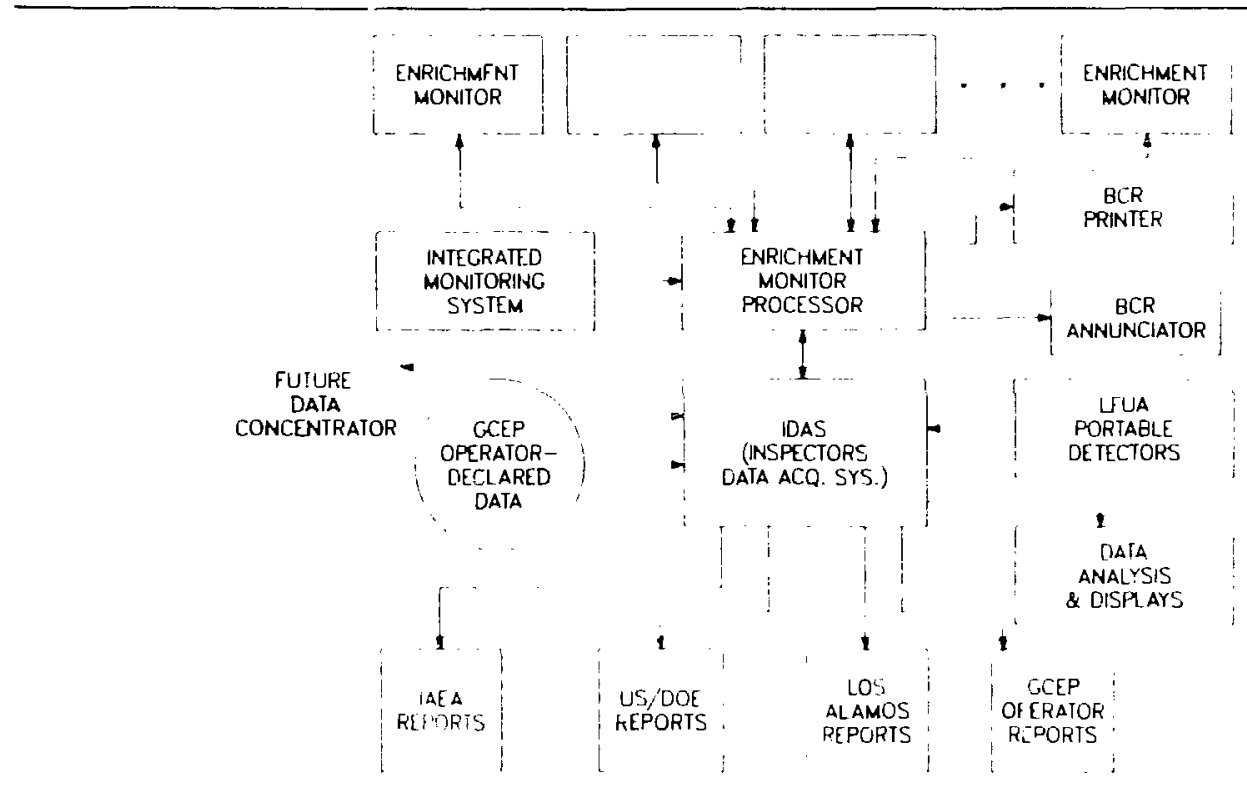

Fig. 51. Information flow to and from the inspector's Integrated Data Acquis1tion System (IDAS), Br "'Building Control Room), GCEP (Gas Centrifuge Enrichment Plant). IAEA (International Alomic Energy Agency), and LFIIA (limited-frequency-unannounced-access) strategy. 


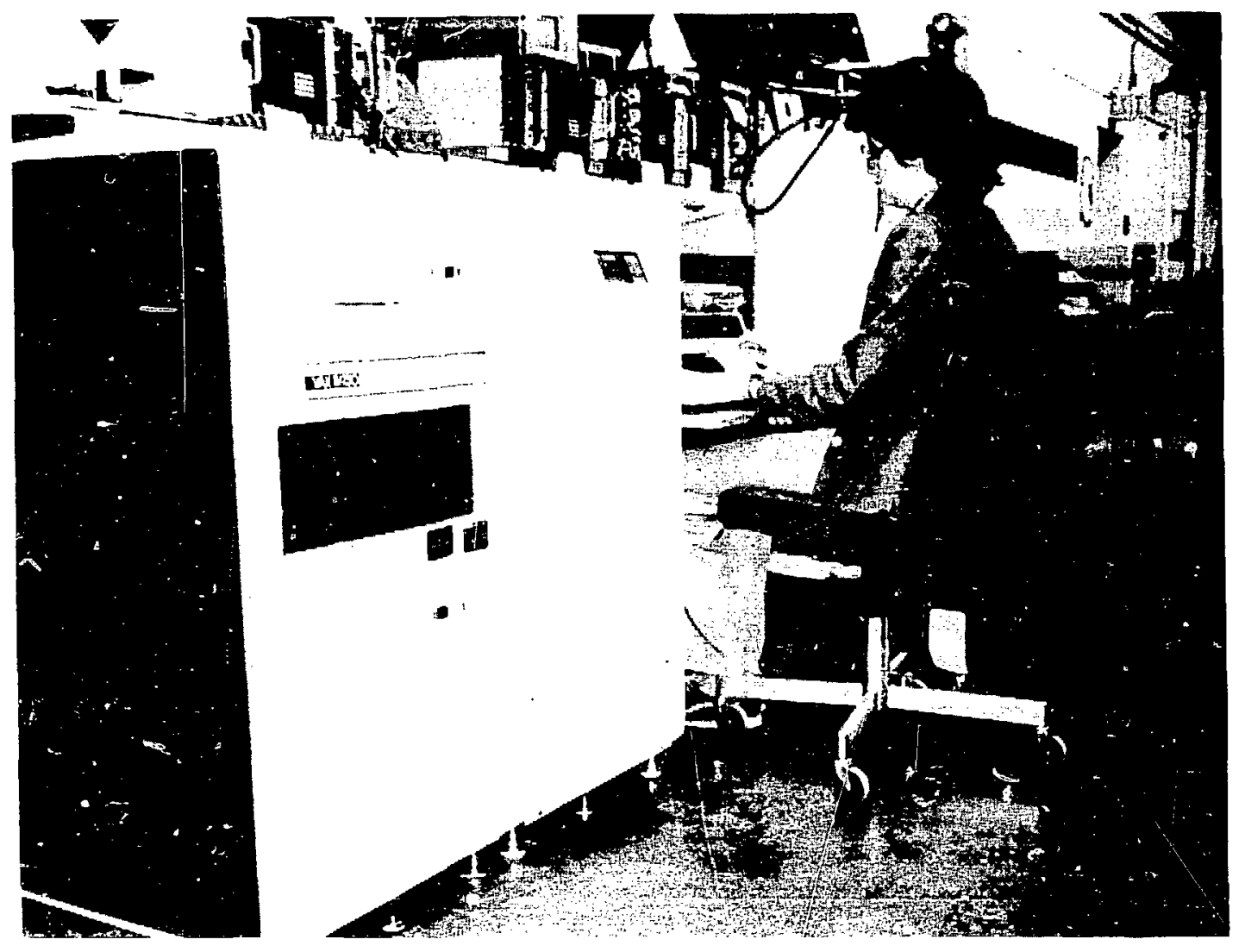

Fig. 52. The Integrated Data Acquisition System shown in operation during single-site testing at Los Alamos. The Digilal Equipment Corporation (DEC) VAX/11-730 computer system that includes a removable I0-MB RL02 disk pack. a fixed 80 -MB R480 disk, and a magnetic tape drive is shown.

to eight enrichment monitors, receiving tamper and intrusion alarm rate data, transferring the data to the IDAS, and providing a redundant data storage capability. Examination of potential anomalies in the enrichment data uses a sequential testing procedure that is designed to provide a timely indication if the enrichment diverges from a prescribed range of acceptable values. Means and standard deviations of data satisfying measurement control criteria arc computed for inspection periods specified by the inspector. and a summary report is produced.

The IDAS provides the primary data interface between the facility operator and the IAEA inspector during a safeguards inspection. The GCEP operator's declared nuclear materials accountability data can be input to the II) $4 \mathrm{~S}$ by magnetic tape for comparison and evaluation.

The IDAS can receive datis stored on digital data tapes generated by the portable multichannel analyzer used in the gamma-ray based LFUA strategy measure- ments. This capability is being used to establish a database of gamma-ray spectra being collected at GCEP cascade header pipes. A peak-st ipping software package has been installed and will be used to perform detailed analysis of the spectra. Specifications for LFUA data analysis of the data base are currently being developed and will be incorporated into the IDAS software.

We have completed the IDAS software design, coding, and testing for all data acquisition interfaces for the enrichment monitoring system, the operator's declared data, and the LFUA data. These interfaces and data management functions were tested extensively during a single-site test of the safeguards equipment developed for installation at the Portsmouth GCEP.

Remaining activities include specifying and impleme ing data analysis functions for the LFUA and the (,erator's declared cata and interacting with representatives of the IAEA regarding the sysiem design and implemencation. 
3. In-Line Enrichment Monitor (J. K. Sprinkle, Jr., D. L. Garcia, R. Siebelist, L. A. Stovall, Q-1; R. B. Strittmattei, (-4; P.. R. Picard, S-1). The in-line enrichment monitor technology provides the capability for continuous measurement of the $\mathrm{UF}_{6}$ feed, product, and tails streams enrichments. ${ }^{66.67}$ The automated acquisition, storage, analysis, and reporting of data can proceed in an unattended mode. Figure 53 shows a cutaway view of the enrichment monitor. During the period December 1983 to September 1984, a prototype enrichment monitor installed in a $U_{6}$ test loop at the Oak Ridge GDP underwent extensive testing of measurement performance, as well as testing specific to the GCEP installation. During these tests $\mathrm{UF}_{6}$ with enrichments ranging from $0.2 \%$ to $3.0 \%$ was measured at various gas pressures.

Analysis of the enrichment monitor data using standard test procedures supported the assumptions of independent and normally distributed measurement errors. ${ }^{70}$ Most of the random variability over the longest time period of constant enrichment and pressure $(\sim 1$ week) was a consequence of counting statistics. Longterm correlated errors can be inferred from the series of different measurements of $0.2 \%$ to $3.0 \%$ assay $\mathrm{UF}_{6}$. Based on those measurements, the tag mass spectrometry assay and sample mass spectrometry assay agreed by better than $0.5 \%$, the weighted average relative bias was $-0.3 \%$, and the unweighted relative bias

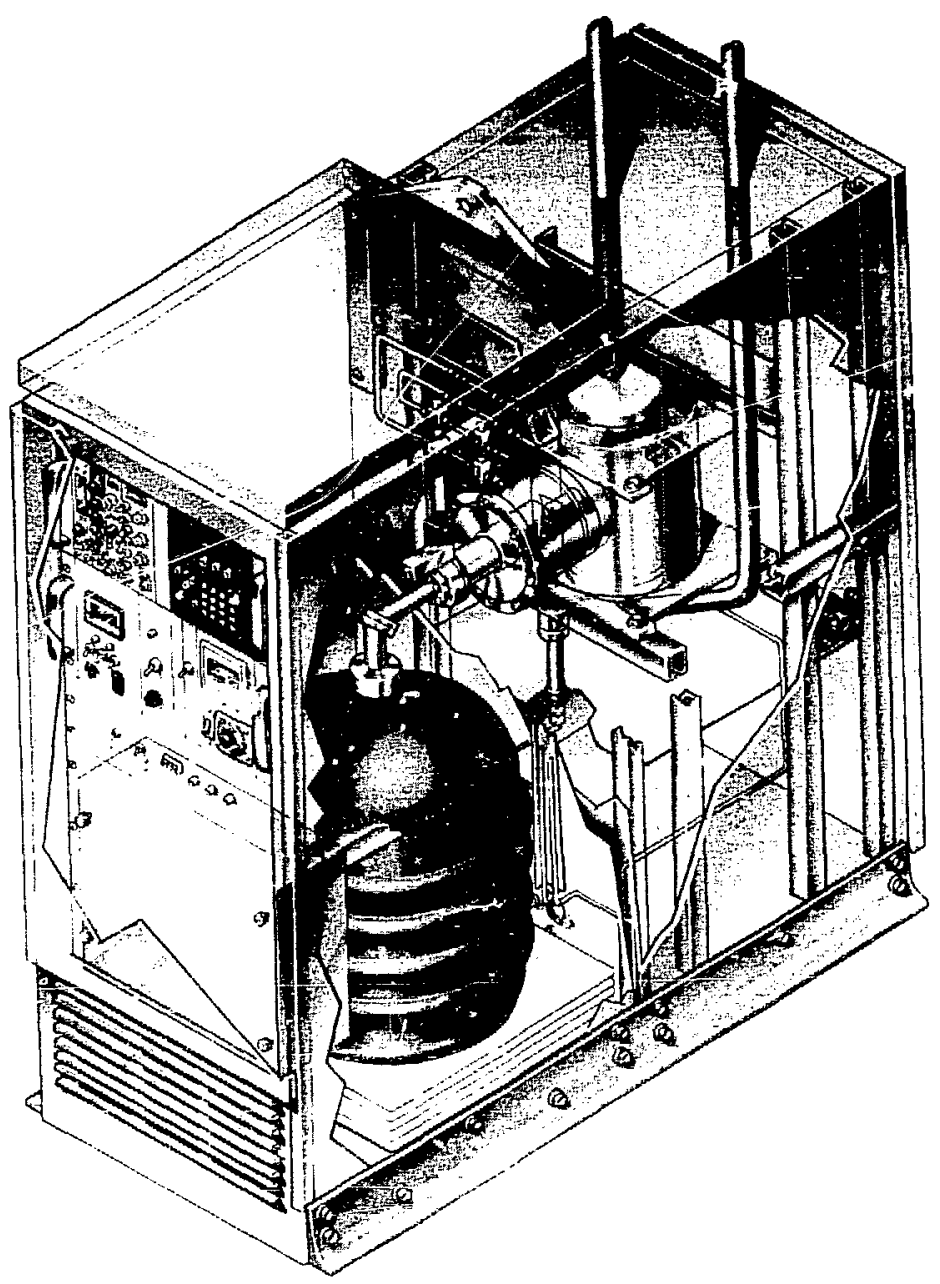

Fig. 53. The in-line enrichment monitor. The front cabinet houses the detector and electronics, and the rear cabinet houses the heated $U \bar{r}_{\mathrm{b}}$ chamber and its associated hardware. 
was $-0.55 \%$. Figure 54 shows the difference percentage between the sample mass spectrometry results and the monitor results. Based on counting statistics, the initial calibration was precise to $0.2 \%$ relative ( $1 \mathrm{std} \mathrm{dev}$ ).

Statistical testing techniques that can be automated are needed to interpret the large amounts of data generated by instruments that continuously measure process streams. A combination of such statistical testing tech. niques and measurement control procedures provides a basis by which the validity of the assay procedures can be authenticated. However, these techniques typically require the comparison of values with values associated with a properly operating instrument. The results of statistical tests applied to the data were presented at the ESARDA/INMM Joint Specialist Meeting on "Error Propagation in NDA Measurements for Safeglards," Ispra, Italy, September 12-14, 1984.

The single-site test of the international safeguards equipment developed for the Portsmouth GCEP provided system level testing of the equipment developed at Los Alamos and SNL. The test pe-formec at Los Alamos with the cooperation of personnel from: Sandia National Laboratory included four enrichment monitor programmable data acquisition and control modules, the integrated monitoring system II, the enrichment monitor processor, the limited-frequency-unannounced-access data cassette interface, the Gcodyear
Atomic Corporation data tape interface, and the integrated data acquisition system. The operational experience ciuring the 2 months of testing demonstrated the proper functioning of all system components and interfaces.

4. IAEA Detection Sensitivity and Attributes/Variables Sample Sizes (D. Stirpe, Q-4). Independent LAEA verification of the operator's materials balance drawn about the major streams at the Portsmouth GCEP and the associated detection sensitivity, obtained by calculating $\sigma_{\text {MUF-D, }}$, have been extensively discussed. ${ }^{75,76}$ The researchers suggest that the IAEA use a relatively imprecise (attributes) measurement to detect gross falsifications and then calculate the fractional numbers of feed, product, and tails cylinders that should be sampled for remeasurement [at the Seibersdorf Analytical Laboratory (SAL)] at a more precise (variables) level. The detection sensitivity given in the references is based on the assumption that the SAL is capable of operator-quality measurements of the ${ }^{235} \mathrm{U}$ concentration. More recent i.iformation ${ }^{77}$ indicates that the Thermal Ionization Mass Spectrometer at the SAL can make ${ }^{235} \mathrm{U}$ concentration measurements only to about $2 \%$, which is considerably larger than assumed in the cited references. Hence, the detection sensitivity

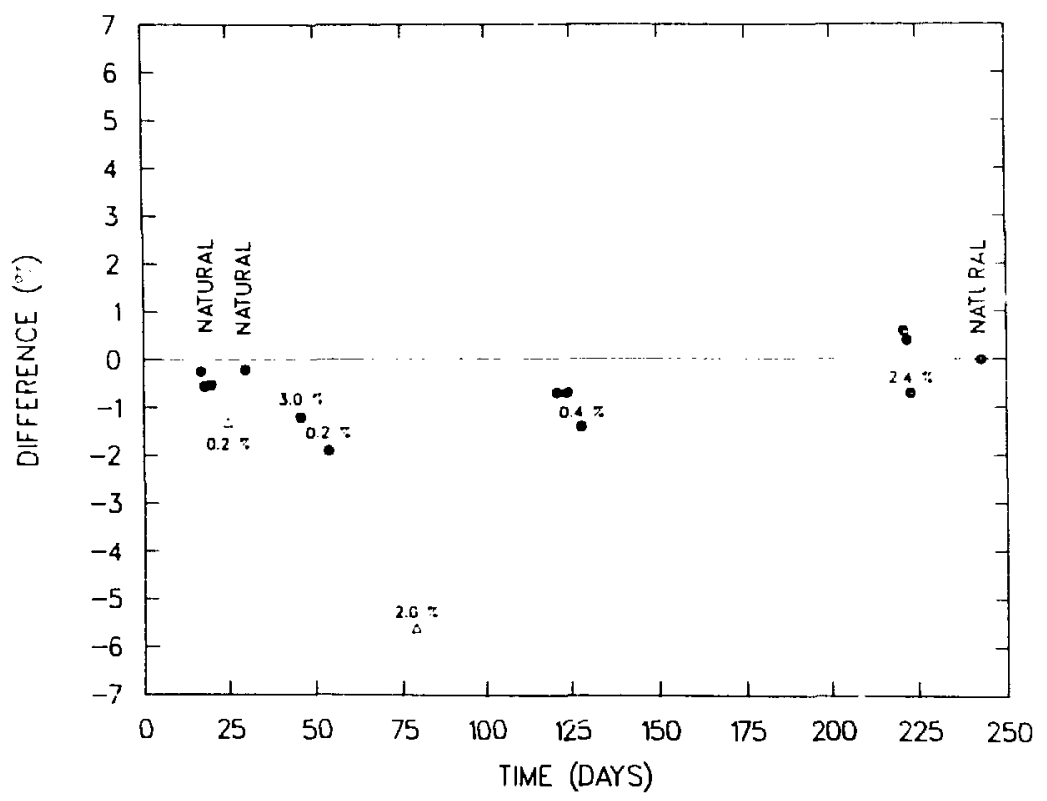

Fig. 5M. The percentage difference between the mass spectrometry and the enrichment monitor results. The data represented by circles were based on comparisons with sample mass spectrometry assays. The data represented by triangles were compared only with a tag assay or a purge gas assay because of difficulties in obtaining a mass spectrometry sample representative of the messured gas. For the data point obtained on day 80 , the tag mass spectrometry assay and a mass spectrometry assay of the purge gas differed by $\sim 5 \%$. 
quoted there is very optimistic $\left(31 \mathrm{~kg}{ }^{235} \mathrm{U}\right.$ for an 1100 MTSWU/yr facility, with a detection probablity of $90 \%$ and a false alarm probablity of 5\%). Using the more recent information about the SAL's mass spectrometer measurtment capabilities, we calculated the detection sensitivity as $345 \mathrm{~kg}^{235} \mathrm{U}$, more than 10 times larger than earlier values.

It is also suggested ${ }^{76}$ that the IAEA use an in-line enrichment monitor (Part 4, Sec. I, A, 3, above) as an attributes instrument in the feed, product. and tails streams. The measurement-error standard deviation of this enrichment monitor is in the range from 1.5 to $3 \%$. depending on the ${ }^{235} \mathrm{U}$ fraction, so the number of feed, product, and tails samples to be sent to the SAL for variables measurement is 7,5 , and 4 . respectively (out of 193 feed, 43 product, and 135 tails cylinders for an 1100-MTSWU/yr facility).

Because the measurement uncertainties of the Laboratory's in-line enrichment monitor and the SAL's mass spectrometer are very nearly the same, we proposcd that the in-line monitor be used as both an attributes and variables instrument in each stream. In this case. the detection sensitivity becomes $202 \mathrm{~kg}{ }^{235} \mathrm{U}$ and no samples need be sent to the SAL for remeasurement, except at the IAEA's discretion. The dettction sensitivity of $202 \mathrm{~kg}{ }^{235} \mathrm{U}$ still does not meet the IAEA's detection goal quantity ( $75 \mathrm{~kg}$ of contained ${ }^{235} \mathrm{U}$ ), but it is less than twothirds of the value calculated above, using the SAL's more realistic measurement capabilities.

5. Neutron Energy Responsc of an Area Neutron Monitor (J. E. Stewart, S. M. Simmonds, Q-1). Reference 78 describes a strategy for continuous IA.EA inspections at centrifuge enrichment plants. It is based on an array of fixed-position collimated-slni neutron detectors.

The prototype detector contains $11{ }^{3} \mathrm{He}$ proportional couniers each with a fill pressure of $4 \mathrm{~atm}$ and a $50.8-\mathrm{cm}$ active length. The 11 counters are surrounded by a polyethylene slab $61 \mathrm{~cm}$ long, $30.4 \mathrm{~cm}$ wide, ard $10.2 \mathrm{~cm}$ high. The detector core is surrounded by a cadmium layer $0.8 \mathrm{~mm}$ thick. In the collimated mode, all sides of the detector core except the open face are covered with polyethylene shielding blocks; the open face is covered with a $1.3-\mathrm{cm}(0.5-i n$.$) polyethylene facing.$

We designed the monitor to have a neutron energy response similar to the neutron energy emission spectrum from HEU production in centrifuge cascades and to minimize response to low-energy neutrons from primary cosmic-ray events in the atmosphere and at the Earth's surface. The design was gu: Jed by measurements using monoenergetic neutrons produced by a 3.75-MeV Van de Graaff accelerator. In addition, we made absolute detector efficiency measurements with a ${ }^{252} \mathrm{Cf}$ isotopic neutron source that emits a broad spectrum of neutron energies.
Using the general-purpose Monte Carlo code MCNP, ${ }^{79}$ we performed calculations to duplicate the neutronics of the energy response measurements. Measured and calculated efficiencies are shown in Fig. 55. Figure 56 shows similar data, but for a $2.5-\mathrm{cm}$ (1-in.) polyethylene sheet (filter) on the detector front face. The agreement between measured and calculated data is excellent. Most differences are within the $1 \sigma$ error bars associated with the measurements and calculations. Figure 57 shows calculated neutron energy response for three filter thicknesses. The effect of the filter is clearly shown.

This study demonstrates the utility of the MCNP code for detailed detector energy calibrations and the accuracy that is possible over a large range of neutron energies. Results of the study can be used directly for designing other, similar detectors.

\section{B. Compact ${ }^{252} \mathrm{Cf}$ Shuffler for $\mathrm{UF}_{6}$ Measurements} (H. O. Menlove, J. E. Stewart, E. L. Adams, Q-1)

For the verification of the uranium enrichment and inventory in an enrichment facility, it is necessary to sample various containers and parts of the process equipment. It is costly and time consuming to send the associated $U_{6}$ samples to the laboratory for chemical analyses.

We have developed a technique for NDA measurements in the plani on small $U_{6}$ samples. Typical samples are small metal cylinders or Teflon tubes that contain about $10 \mathrm{~g}$ of $\mathrm{UF}_{6}$. Because the $\mathrm{UF}_{6}$ is distributed nonuniformly in the container, gamma-ray assay is difficult; an active, neutron assay is required.

The ${ }^{252} \mathrm{Cf}$ shuffler method uses a neutron source to irradiate the fissionable material repetitively, and the delayed neutrons from induced fissions are counted when the source is withdrawn from the sample position. The inst:ument measures the ${ }^{237} \mathrm{U}$ mass in the sample, and the enrichment is inferred from the weight of the sample. In fact, what is measured are the grams of ${ }^{235} \mathrm{U}$ per gram of samp.e, which, for uniform samples, can be combined with the weight of the large container to get the total ${ }^{235} \mathrm{U}$ mass, independent of the chemical composition and purity.

Figure 58 shows the instrument's neutron shield and detector. The detector is an inventory sample coincidence counter (INVS), ${ }^{80}$ which was developed for IAEA inspectors to measure small plutoniun samples. This counter rormally operates with the shift-register coincidence electronics $^{52}$ to measure the spontaneous fission rate from $\mathrm{PuO}_{2}$ powder. pcllets, and nitrate. When the passive coincidence system is combined with the ${ }^{252} \mathrm{Cf}$ active-assay shuffler, it can be used for uranium assay as well as for mix d oxide (MOX) and plulcnium. 
COLLILATED SLAB NEUTRON DETECTOR

OETECTION EFFICIENCY WITH HALF INCH POLYETHYLENE FILTER

(NORMALLY INCIDENT NEUTRONS)

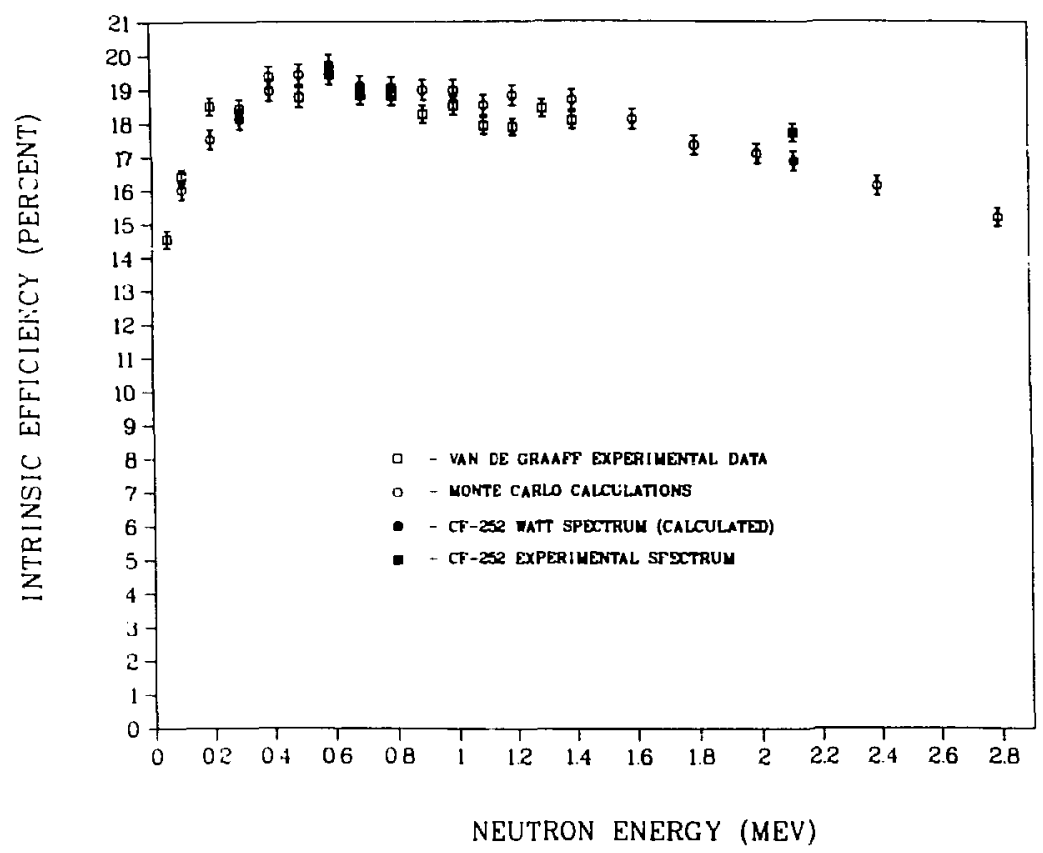

Fig. 55. Collimated-slab neutron detector detection efficiency with $1.25-\mathrm{cm}(1 / 2-i n$.) polyethylene filter (normally incident neutrons).

COLLIMATED SLAB NEUTRON DETECTOR

DETECTION EFFICIENCY WITH ONE INCH POTECTHYLENE FILTER
(NORMALLY INCIDENT NEUTRONS)

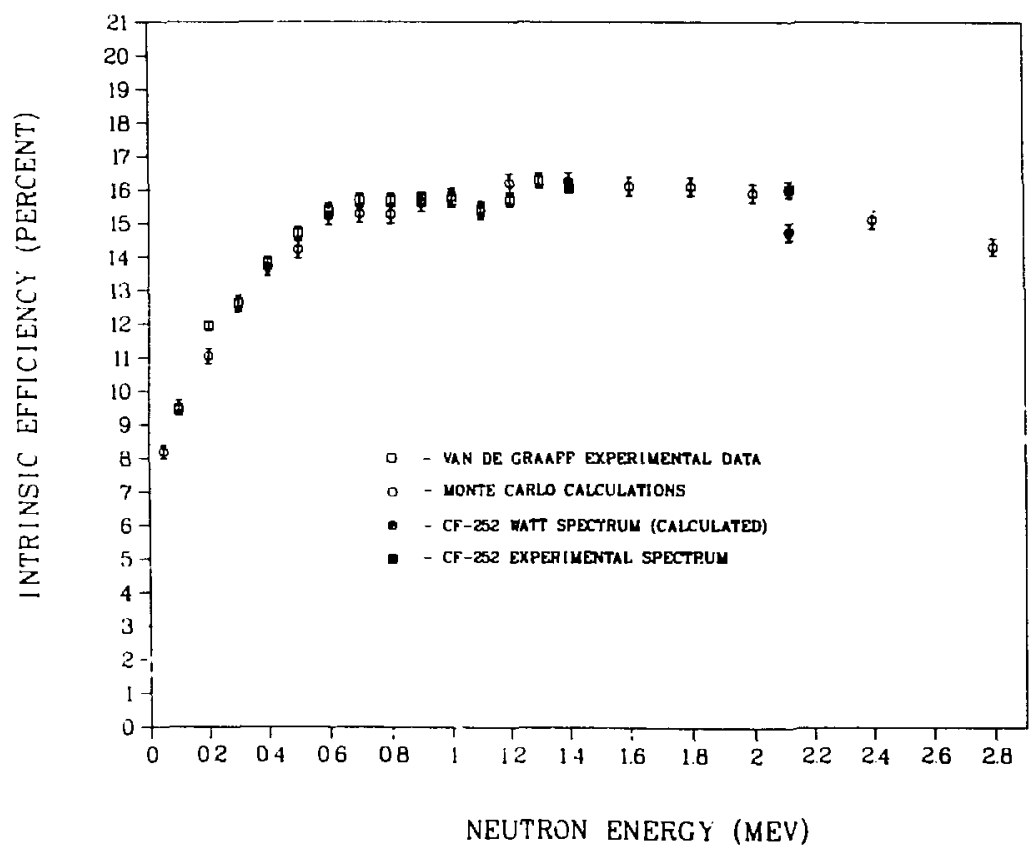

Fig. 56. Collimated-slab neutron detector detection efficiency with $2.5-\mathrm{cm}$ (1-in.) polyethylene filtcr (normally incident neutrons). 
COLLIMATED SLAB NFITEN DETECTOR

DETECTION EFFICIENCY

(NORMALLY INCIDENT NEUTRONS)

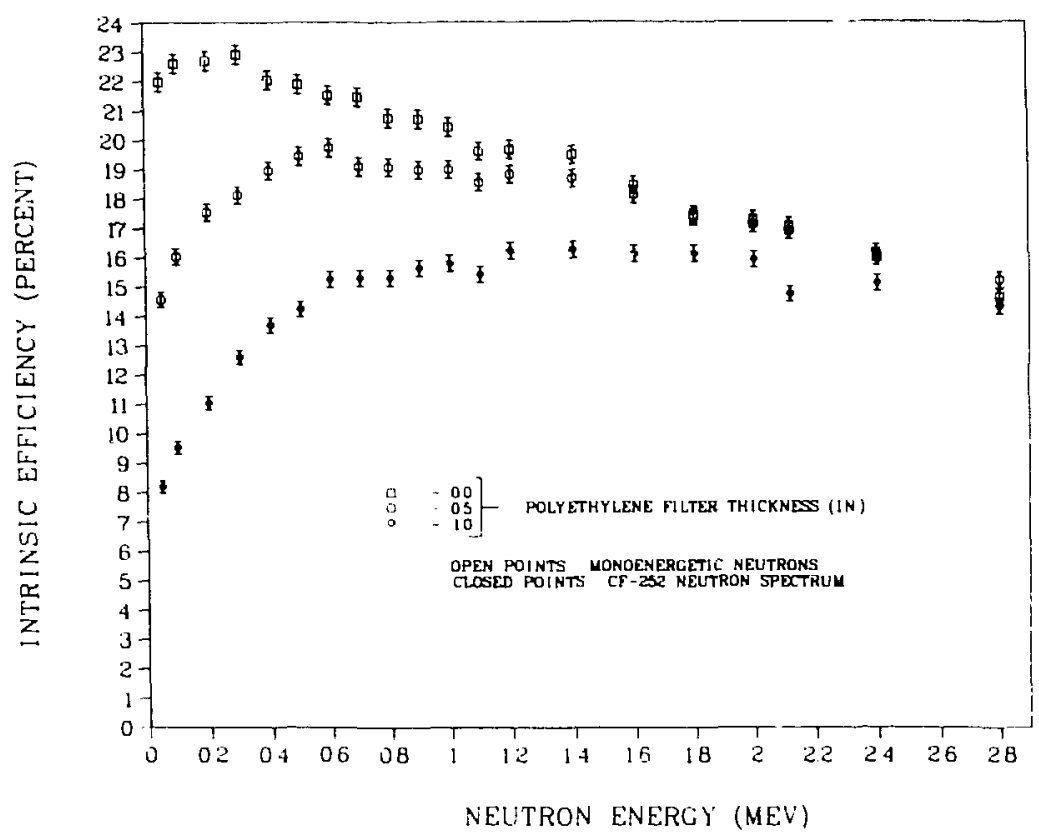

Fig. 57. Collimated-slab neutron detector detection efficiency with polyethylene filters of certain thicknesses (normally incident neutrons).

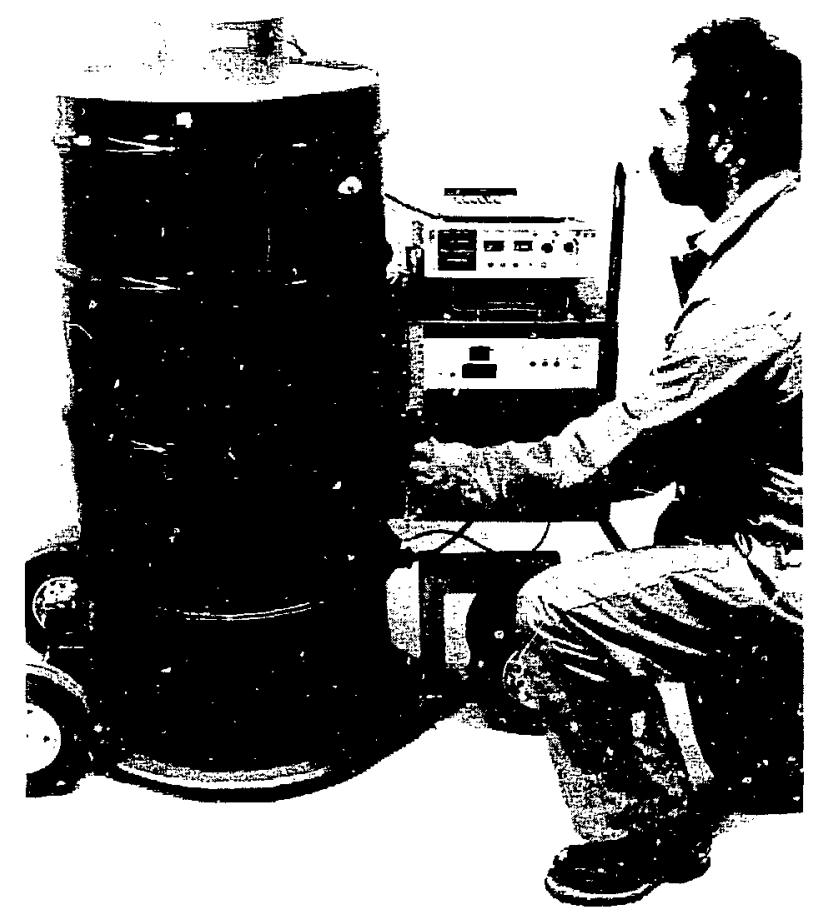

Fig. 58. Transportable ${ }^{252} \mathrm{Cf}$ shuffler system including the source and shield, detector head, and electronics. 
We achieved the compact design of the present shuffler by using a small ${ }^{252} \mathrm{Cf}$ thermal neutron source (about $8 \times 10^{6} \mathrm{n} / \mathrm{s}$ ), a high-efficiency detector (about 37\%), and close source-sample coupling. The unit was designed to measure subgram quantities of ${ }^{235} \mathrm{U}$ in the form of lowenriched $\mathrm{UF}_{6}, \mathrm{UO}_{2}$, or uranyl nitrate. The relatively low intensity of the ${ }^{252} \mathrm{Cf}$ source allows handling for brief periods with little or no shielding. When the ${ }^{252} \mathrm{CF}$ snurce is in the barrel (Fig. 58), the radiation dosc is negiigible.

The system weighs $280 \mathrm{~kg}$, and the INVS detector head and HEC -100 electronics can be decoupled from the system for separate use.

Table XIV gives the performance characteristics for low-enrichment $U_{6}$ samples. For the evaluation of the assay accuracy, Martin Marietta prepared a set of 10 pinch-tube $U F_{6}$ standards and shipped them to Los Alamos. These standards are described in Table XV. The tag ${ }^{235} \mathrm{U}$ mass assumed a uranium fraction in the $\mathrm{UF}_{6}$ of 0.67 . Because initial measurements with ihe compact shuffler indicated a substantial contaminant in the $\mathrm{UF}_{6}$, we performed ${ }^{235} \mathrm{U}$ assays using the Van de Gr:aff NDA fast neutron system. The Van de Graaff as jay values are listed in the last column of Table XV. We can't determine the accuracy of the NDA measurements until chemical analysis is completed to measure the uranium mass in the $\mathrm{UF}_{6}$ samples.

In addition to tile assay of enrichment plant $\mathrm{UF}_{6}$ product samples, the shuffler also may have application in reprocessing plants to measure highly radioactive samples from process points prior to the final product stage.

\section{TABLE XIV. Performance Characteristics of the}

Compact Shuffler

\section{${ }^{252} \mathrm{Cr}$ Source Yield \\ Source Background Rate \\ ${ }^{235}$ U Signal Rate \\ Sensitivity Level ${ }^{b}$}

'The signal rate is for a thermal-neutron interrogation, and becsuse the duty cycle is $50 \%(10 \mathrm{~s}-10 \mathrm{~s})$, the elapsed time is approximately double the counting time.

'The sensitivity level is defined as the net signal being $s$ 's of the background level for a 1000-s count.

\section{REPROCESSING PLANT SAFEGUARDS}

A. Dounreay Shuffler (G. Eccleston, Hi. O. Menlove, S. Klosterbuer, T. Van Lyssel, Q-1)

A delaved-neutron shuffler a.ssay system was installed and calibrated at the Dounreay, Scotland, fuel reprocessing plant during the psriod September 10-17, 1984. We developed the shuffier under a joint program with the United Kingdom. It is used to assay leached hulls th:at cor:tain plutonium (typically 1 to $20 \mathrm{~g}$ ) and uowls that contain cent ifuge sludge produced from reprocessed P:ototype Fast Reactor (PFR) fuel. Tr e next PFR reprocessing campaign is sclıeduled to begin in January 1985 and extend into March. During this sampaigu, the shuffler will rneasure approximately 200 leached-hull samples.

\begin{tabular}{|c|c|c|c|c|c|}
\hline \multirow[b]{2}{*}{ Tube } & \multirow[b]{2}{*}{ Enrichment \% } & \multicolumn{4}{|c|}{ Weight (g) } \\
\hline & & Gross & Net & $239 i^{12}$ & ${ }^{235} \mathbf{U}^{b}$ \\
\hline \multirow[t]{2}{*}{$\mathbf{A}$} & 0.31350 & 15.2 & 7.54 & 0.0158 & 0.0154 \\
\hline & 0.31350 & 19.5 & 11.86 & 0.0249 & 0.0320 \\
\hline \multirow[t]{2}{*}{ B } & 0.71098 & 11.4 & 3.94 & 0.0118 & 0.0265 \\
\hline & 0.71098 & 18.5 & 10.70 & 0.0510 & 0.0585 \\
\hline \multirow[t]{2}{*}{ C } & 1.04516 & 14.3 & 6.24 & 0.0437 & 0.0330 \\
\hline & 1.04516 & 20.6 & 12.46 & 0.0872 & 0.0847 \\
\hline \multirow[t]{2}{*}{$D$} & 1.96184 & 14.5 & 6.68 & 0.0878 & 0.0650 \\
\hline & 1.96184 & 19.1 & 11.43 & 0.1502 & 0.1348 \\
\hline \multirow[t]{2}{*}{$\mathbf{E}$} & 3.02758 & 15.0 & 6.67 & $0 . .354$ & 0.0997 \\
\hline & 3.02758 & 19.1 & 11.39 & 0.2310 & 0.2090 \\
\hline
\end{tabular}


During September, tne mechanical and electronic components of the shuffler were installed and tested, and the existing $\mathrm{BF}_{3}$ detectors were removed from the hot cell and replaced with nine ${ }^{3} \mathrm{He}$ neutron detectors. The amplifier analog electronics were modified by Harwell to operate these helium counters. A series of tests demonstrated proper detector operation under the intense gamma-ray backgrounds produced in the hot cell from spent fuel. Following iustrument installaticn, check-out, and detector testing a ${ }^{252} \mathrm{Cf}$ neutron source was inserted into tine shuffler. This source, obtained from SRL, had a neutron emission rate of $6.7 \times 10^{9} \mathrm{n} / \mathrm{s}$ on the date of installation.

The shufier control module, developed by Los Alamos, contains a Motorola 6809 microprocessor with interface electronics that moves the californium neutron source in the shuffler and communicates with the facility's PET computer. The PET rontrols the assay procedure and communicates with the shuffler module by sending commands to the microprocessor, which is a slave to the PET. The microprocessor software provides signals to a stepping motor that moves and positions the californiun source tor sample irradiation and subsequent delayed-neutron counting. For precise assay the software mist: $i$ :-ove the source rapidly and position it accurately. The software is written in assembly language and is contained in a programmable read only memory (PROM); in addition to the shuffler control code, the program also contains error-checking diagnortics to flag and report problems. Communication with the PET computer is accomplished using the date input/output lines of the Harwell MOUSF. module. We developed, documented, anri delivered a PET diagnostic program for the shuffler.

A preliminary calibration (Fig. 59) of the shuffler was obtained using 12 plutonium stancic: ds (Tables XVI and XVII) developed by Dounreay. Calibration measurements were made with the sample roughly positioned at one location near the center of the assay region. Final calibration requires a 10-segment scanning measurement, wnich will be accomplished when a new crane is mounted in the hot cell. For the preliı. "nary measurements, the standards were combine'd to form loadings between 10 and $50 \mathrm{~g}$ of plutonium. The measurement data are listed in Table XVIII.

Measurements made with no plutonium present gave a delayed-neutron rate of 13 counts/s. This background cor sesponded to roughly $2.5 \mathrm{~g}$ of plutonium at the center of the measurement well and limits the ability of the instrument to measure very low loadings of plutonium. The previous DT-generator system also had a residu. delayed-neutron background of similar magnitude. The preliminary measurements show the shuffler will detect plutonium at the $0.5 \mathrm{-g}$ level with precisions of $5 \%$ or better. After the crane is installed, better sample positioning and scanning of the full bask:t may produce a lower detection limit.

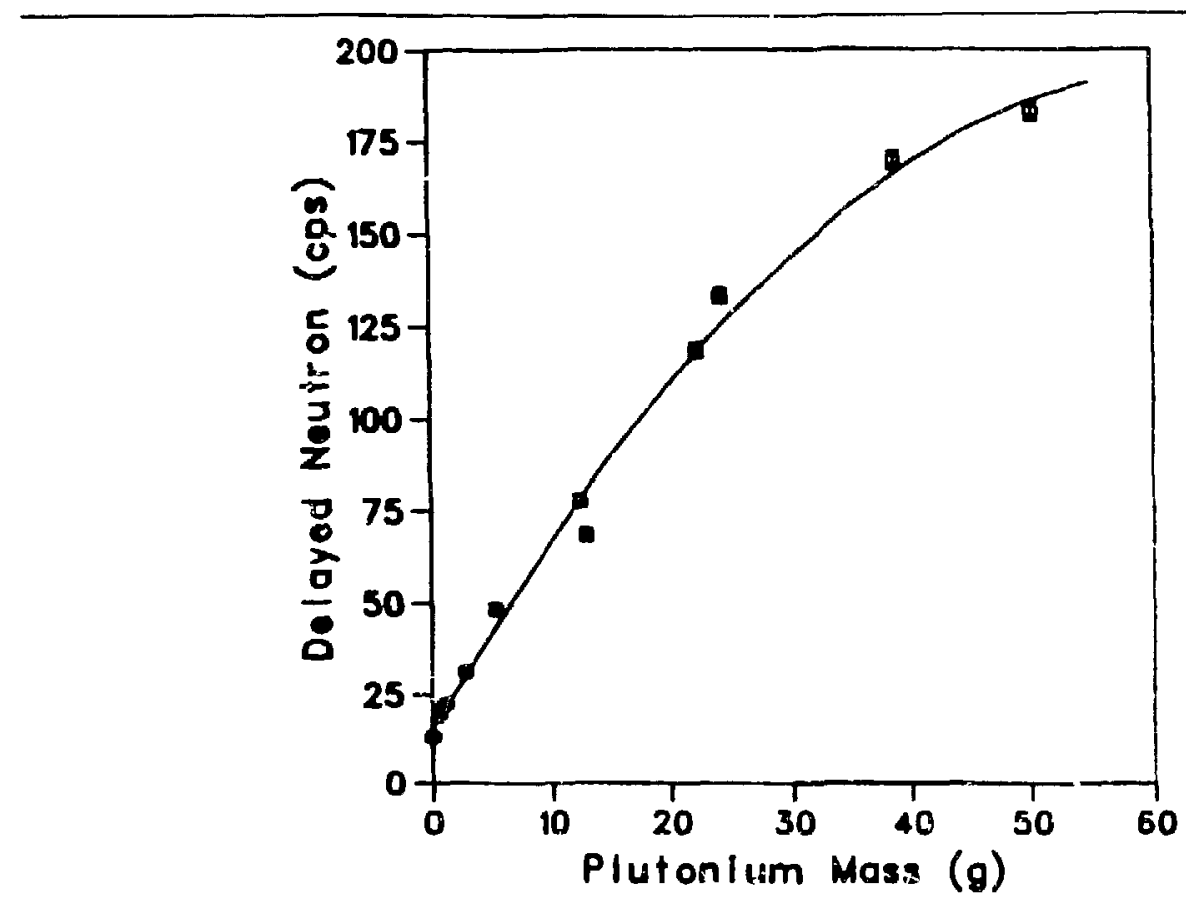

Fig. 59. Duunreay chuffler siandards measured at a fixed position in the assay well. 


\begin{tabular}{|c|c|c|c|}
\hline TABLE XVI. & \multicolumn{3}{|c|}{$\begin{array}{l}\text { Dounreay Plutonium Leached-Hull Stan- } \\
\text { dards }\end{array}$} \\
\hline $\begin{array}{l}\text { Sample } \\
\text { No. }\end{array}$ & $\mathrm{PuO}_{2}+\mathrm{UO}_{2}{ }^{\mathrm{n}}$ & $\begin{array}{c}\text { Total } \\
\text { Plutonium } \\
\text { (g) }\end{array}$ & $\begin{array}{c}{ }^{299} \mathrm{Pu} \\
(\mathrm{g})\end{array}$ \\
\hline 1 & 1.977 & 0.527 & 0.417 \\
\hline 2 & 3.906 & 1.041 & 0.825 \\
\hline 3 & 10.272 & 2.737 & 2.169 \\
\hline 4 & 19.836 & 5.286 & 4.190 \\
\hline 5 & 27.640 & 7.366 & 5.838 \\
\hline 6 & 37.044 & 9.872 & 7.824 \\
\hline 7 & 46.993 & 12.524 & 9.926 \\
\hline 8 & 28.454 & 7.583 & 6.016 \\
\hline 9 & 54.203 & 14.445 & 11.449 \\
\hline 10 & 48.964 & 13.049 & 10.342 \\
\hline 11 & 43.354 & 11.554 & 9.157 \\
\hline 12 & 42.379 & 11.294 & 8.951 \\
\hline
\end{tabular}

'The $\mathrm{UO}_{2}$ consists of natural uranium.

\begin{tabular}{cc}
\hline \hline $\begin{array}{c}\text { TABLE XVII. Isotopic Composition of Plutonium } \\
\text { Standards }\end{array}$ \\
\hline \\
Plutonium & $\begin{array}{c}\text { Isotope } \\
(\%)\end{array}$ \\
\hline & \\
${ }^{239} \mathrm{Pu}$ & 79.257 \\
${ }^{240} \mathrm{Pu}$ & 18.394 \\
${ }^{211} \mathrm{Pu}$ & 1.819 \\
${ }^{242} \mathrm{Pu}$ & 0.53 \\
\hline
\end{tabular}

\begin{tabular}{|c|c|c|c|}
\hline \multicolumn{4}{|c|}{ TABLE XVIII. Dounreay Shuffler Calibration Data } \\
\hline Sumple No. & $\begin{array}{c}\text { Pu Mass } \\
\text { (g) }\end{array}$ & $\begin{array}{c}\text { Passive } \\
\text { Neutrons } \\
\text { (counts/s) }\end{array}$ & $\begin{array}{l}\text { Delayed } \\
\text { Neutrons } \\
\text { (counts/s) }\end{array}$ \\
\hline none & $\mathbf{0}$ & $72.4 \pm 0.7$ & $13.04 \pm 1.03$ \\
\hline 1 & 0.527 & 74.88 & $19.21 \pm 1.06$ \\
\hline 2 & 1.041 & 78.75 & $22.19 \pm 1.09$ \\
\hline 3 & 2.737 & 91.62 & $31.20 \pm 1.20$ \\
\hline 4 & 5.286 & 109.7 & $48.41 \pm 1.34$ \\
\hline 7 & 12.524 & 164.8 & $77.71 \pm 1.64$ \\
\hline 10 & 13.049 & 172.2 & $68.63 \pm 1.66$ \\
\hline $6 \div 7$ & 22.396 & 227.6 & $118.6 \pm 1.96$ \\
\hline $10+12$ & 24.343 & 247.8 & $133.3 \pm 2.90$ \\
\hline $9+10+12$ & 38.788 & 335.6 & $169.9 \pm 2.37$ \\
\hline $9+10+11+12$ & 50.342 & 382.47 & $183.2 \pm 2.51$ \\
\hline
\end{tabular}


Measurements with large quantities of plutonium in the 25- to 50-g range were obtained by stacking combinations of samples $9,10,11$, and 12 . The delayedneutron count rates for these measurements are lower than will be observed when scanring the sample. The effect is caused by geometric stacking. where sume of the plutorium is out of the sensitive region of the measurement well.

\section{B. Compact K-Edge Densitometer (L. R. Cowder, S. F Klosterbuer, R. H. Augustson, Q-1)}

The compact K-edge densitometer (tested in Vienna during the fall of 1983) was modified according to IAEA recommendations, and a second unit was built and delivered to the agency. Improvements were made to the MCA software, which will be tested by the IAEA in 1985.

The IAEA is negotiating with facilities for realistic field testing of the device. In the meantime. the EURATOM inspectorate has expressed interest in testing the compact unit at some of their plants.

\section{Tokai-Mura K-Edge Densitometer Software Lpdate} (J. K. Sprinkle, S. -T. Hsue, P. A. Ruso, R. H. Augustson, Q-1)

As part of the US support program to the IAEA. we are updating the Tokai-Mura densitometer scftware. The Japanese have purchased new computer hardware and have changed operating systems. As we modify the software to accommodate these changes. we will streamline the program's operation and install additional analysis capability that will make the instrument less sensitive to matrix variations in the samples. We are also trying to convince the facility personnel and the IAEA to modify the assay station to accept parallelsided cells. This modification would eliminate the instrument's sensitivity to sample positioning.

\section{INTERNATIONAL TECHNICAL. EXCHANGES}

For more than a decade. the US safeguards R\&D programs have arranged technical exchanges with similar programs in other countries. Such exchanges improve safeguards technology for all participants. For example, Los Alamos has been active in developing instrumentation such as the Uranium Neutron Coincidence Collar (UNCC). while the EURATOM organization has access to light-water fuel fabrication facilities and reactors. The technical exchange program brings the Los Alames instruments to EURATOM fa- cilities collecting in-field measurement data, offering valuable operating experience. Other exchange activities compare two instruments or measurement techniques developed at different laboratories. By comparing results obtained on the same set of materials during the same measurement campaign, instrument developers learn he to improve the accuracy, reliability, and operational eas. of their systems. During the past year. Los Alamos has worked with the IAEA, EURATCM (both the Luxembourg inspectorate and Ispra laboratory). the British Nuclear MateriaIs Accounting and Control Team, the Netherlands ECN. and the Finnish Nuclear Inspectorate.

\section{A. Program of Technical Assistance to IAEA Safe- guards (POTAS)}

1. Overview (R. H. Augustson, Q-1). The largest technical exchange activity is conducted with the IAEA and sponsored by POTAS. The 1984 POTAS activities focused for the most part on following through to field implementation work done during 1983. Los Alamos was responsible for 18 tasks covering instrument development, field exercises, training, and quality assurance.

In the area of instrument development, Los Alamos assisted in carrying four instruments into the commercialization phase. The IAEA placed orders for a number of nigh-level neutron coincidence counters, Mod II, to be delivered in early 1985. Los Alamos prepared the specification package and is performing the acceptance tests. The IAEA chose a commercial, portable multichannel analyzer and ordered 15 units. Once again, Los Alamos performed the acceptance tests. We have developed and prepared specifications for the commercialization of the ION-1 electronics package for spent-fuel measurements and for a reactor power monitor that will monitor reactor operating history. These two units will be ready for commercial procurement during 1985. In addition to these activities, work continued on K-edge densitometry, calibration of instruments, and direct support of IAEA inspector measurements.

Field exercises were again an imporant activity during 1984. A second physical inventory verification (PIV) exercise was held at the Westinghouse Hanford Engineering Laboratory with two inspection teams (four IAEA staff each) performing the verification. This exercise included a more extensive calibration effort and the use of calorimetry for calibration and ancimaly resolution. The use of gamma-ray spectrometry for determination of plutonium isotopics was expanded in this second exercise. PIV exercises for a light-water power reactor and a highly enriched uranium fabrication facility were developed in 1984 and will be given in 1985. 
Training for new inspectors continues to be an area of immediate direct benefit to the IAEA. This year we upgraded the curriculum and worked toward a better integration of the material taught in Vienna and in Los Alamos. Two courses were given during 1984, and the consensus is that integration is leading to an improved course.

This year Los Alamos participated in helping the IAEA to develop quality assurance procedures in the areas of inspection planning and optical surveillance (Part 4, Sec. III, A, 2, below). Reports outlining the procedures have been written. We foresee activity in implementing these procedures during 1985 .

2. Quality Assurance for Inspection Plamaing (J. T. Markin, Q-4). Each year the IAEA publishes a Safeguards Implementation Report (SIR) that is a statement about the status of safeguards at over 400 nuclear facilities. The SIR conclusions are based on information gathered by Agency inspectors through inspection activities, such as verifying consistency of facility operating and accounting records and verification through independent measurements of inventories and inventory changes. Accomplishment of these inspections is a complex process carried out by the three Operarions Divisions of the IAEA through an inspection planning process that coordinates limited personnel and equipment to attain the Agency's inspection goals.

Under a POTAS task entitled "Quality Assurance for the Inspection Planning Process." we have characterized the planning process as it is currently practiced at the Agency and suggested methods for monitoring and maintaining its quality. Our description of planning includes administrative drtails (such as arranging for visas, telexes, and travei), technical aspects (such as compiling information about the facility, determining sample sizes, and sclecting measurement equipment), and management functions (such as briefings before and after an inspection and maintaining the Computerized Inspection Report system).

Our suggestions for a quality assurance program for inspection planning consist of (1) specifying the administrative and technical aspects of inspection planning for each facility type, (2) documenting these procedures in a written standard, (3) monitoring the planning process for conformance to the standard, and (4) taking action to correct deficiencies with respect to the planning standard. Wherever possible. we incorporate existing Agency planning procedures inio the quality assurance program. For example, existing pre- and postinspection briefings in which section heads review the inspection plan and its implementation could form the basis for monitoring conformance to a planning standard.

Principal recommendations for implementing quality assurance procedures within the Operations Divisions are to develop, with operations personnel, a detailed written standard that describes administrative, technical, and management aspects of inspection planning and to identify key attributes of planning that should be monitored as indicators of planning quality.

Benefits from applying quality assurance principles to planning are (1) uniformity of inspection planning despite differences in inspectors and facility conditions, (2) a framework for incorporating innovations in inspection technology and in nuclear processing technology into planning, and (3) increased inspection efficiency by lowering the incidence of incomplete inspection activities that become follow-up actions for the next inspection.

B. Commission of the European Communities, Joint Research Centre (JRC), Ispra, Italy

1. Intercomparison of the Active Well Coincidence Counter and PHONID-II (H. O. Menlove, M. S. Krick, R. Cameron, Q-1). In recent years, both the $A W C C^{18}$ and the PHONID-II ${ }^{81}$ have been used for the nondestructive assay of ${ }^{235} \mathrm{U}$. The purpose of the present effort was to compare the two NDA instruments for a wide variety of nuclear material categories. To this end, the AWCC (Serial No. 003) was shipped from Los Alamos to the NUKEM fuel fabrication plant in Hanau, Germany, where the PHONID-II has been in use for several years. In addition to the intercomparison, useful calibration information was obtained for both instruments.

The experimental work was performed during the period October 1-5, 1984, by a joint team from EURATOM-Luxembourg, JRC-Ispra, Los Alamos, and the IAEA. A large variety of HEU samples provided by the facility operator included HEU metal pieces, disks, uranium-aluminum plates (bildchen), $\mathrm{U}_{3} \mathrm{O}_{8}$ powder, (uranium/thorium) coated particles, and $\mathrm{UF}_{4}$ salt. These material types are typical of material under inspector verification. The mass of the samples ranged from a few grams to about $5 \mathrm{~kg}$ of ${ }^{235} \mathrm{U}$.

The experimental comparison of the AWCC and the PHONID-II included an evaluation of counting rates, sensitivity, accuracy, linearity, stability, and matrix effects. Table XIX gives the specifications for both the PHONID-II and the AWCC showing the major physical diserences in the two systems. The weight and size of the AWCC are considerably less than for the PHONIDII.

a. PHONID-II Results. When the results for all of the sample categories are plotted on the same graph, we can see the relationship between the different material types. Figure 60 (upper graph) shows this data for the PHONID-II. Materials with the lowest ${ }^{235} \mathrm{U}$ density ( $\rho 235$ ) values [(uranium-aluminum) bildchen and $U_{4}$ ] give the highest response, and the HEU metals have the lowest response because of the high p235 value. For 


\begin{tabular}{lll}
\hline \hline TABLE XIX. PHONID-II and AWCC System Speciîications \\
\hline & PHONID-II & AWCC \\
\hline & & \\
Neutron sources, two & Sb-Be & AmLi \\
Total Source Strength & $\sim 7 \times 107$ & $\sim 8 \times 104$ \\
Interrogation Energy & Fast neutron & Fast neutron \\
Detector Type & ${ }^{4}$ He tubes & ${ }^{3}$ He tubes \\
Countiog & Fast neutrons & Thermalized neutrons \\
Response signal & Singles count & Slow coincidence \\
& & (autocorrelation) \\
Coincidence Gate & None & $64 \mu \mathrm{s}$ \\
Body Weight & $>2000$ kg & 125 kg \\
Electronics & NIM bin plus minicomputer & HLNCC package plus \\
& & minicomputer \\
\hline \hline
\end{tabular}

Fig. 60. The measured response from the PHONID-II (upper graph) and AWCC (lower graph) for all of the material types used in the comparison.
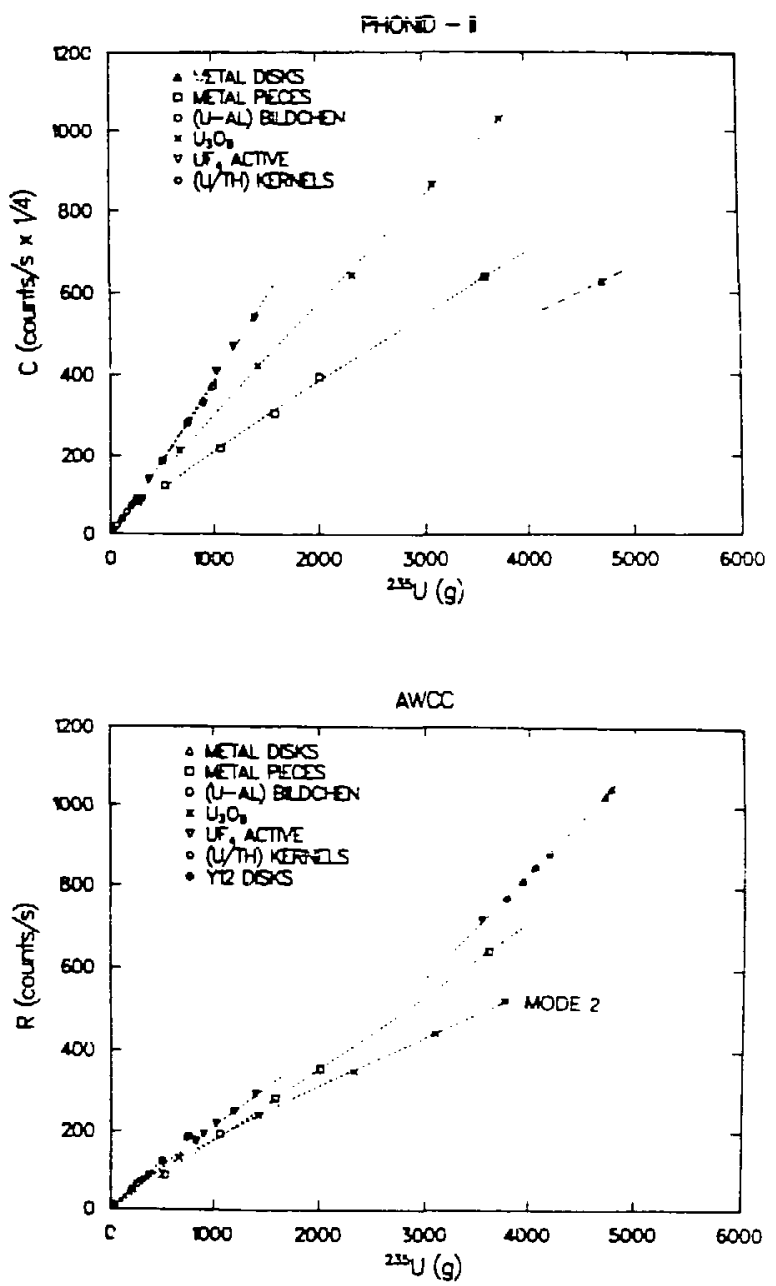
bildchen, $p 235$ is about $0.3 \mathrm{~g}^{235} \mathrm{U} / \mathrm{cm}^{3}$, whereas for the HEU metal disk 2235 is about $17.7 \mathrm{~g}{ }^{235} \mathrm{U} / \mathrm{cm}^{3}$. Thus, there is much more neutron self-shielding in the metal than in the (uranium-aluminum) plates. The lower graph of Fig. 60 shows the same samples measured with the AWCC.

A more sensitive way to examine the linearity of the response is to plot counts per gram vs grams (Fig. 61). When the data are presented this way, we can readiiy see that the thin-sample response is about 0.4 counts $/ \mathrm{g}{ }^{235} \mathrm{U}$ as compared with the HEU metal disk at 0.133 counts/g. The lower graph in Fig. 61 shows the same data for the AWCC.

The response (counts per gram) for the (uranium/thorium) kernels drops rapidly as a function of ${ }^{235} \mathrm{U}$ mass for the PHONID-Il. This might be caused by the geometric change in the (uranium/thorium) kernels. That is, for low-mass samples, the sample shape is a flat pancake with very little self-shielding, whereas, for full containers. the sample shape is a cylinder with
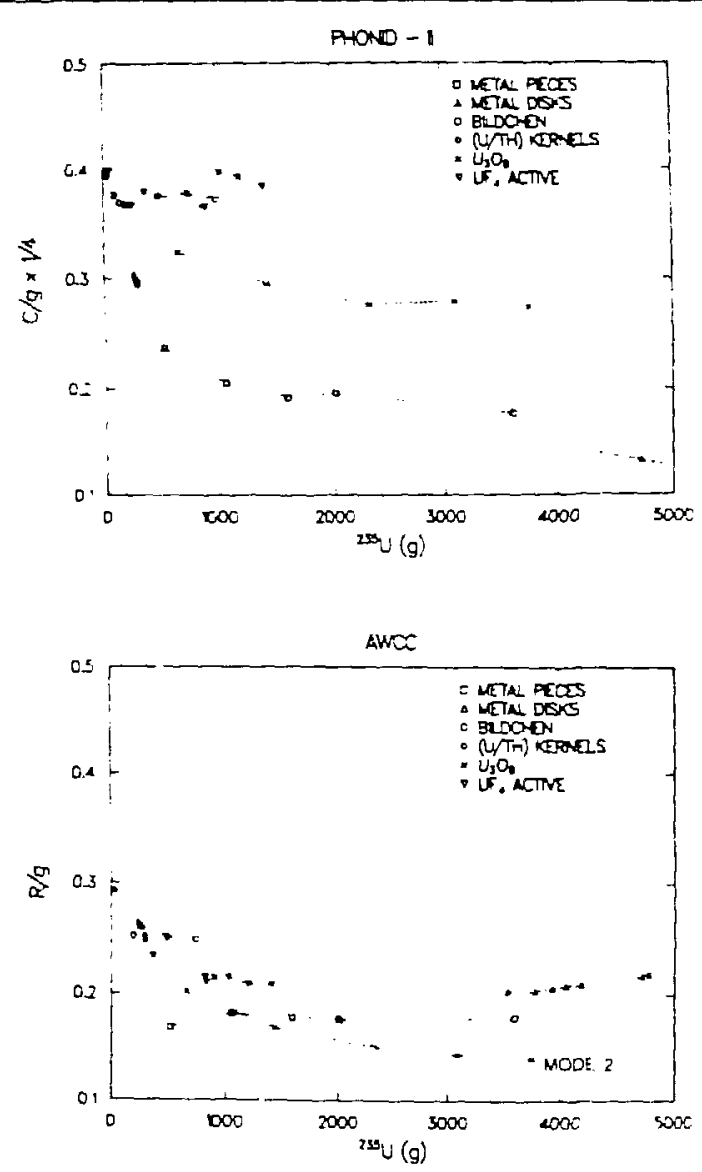

Fig. 61. The response per gram vs grams for the PHONID-II (upper graph) and AWCC (lower graph) for the different materials. height approximately equal to diameter, which gives the maximum self-shielding per gram of material. In addition, the thorium/uranium ratio (10/1) in the kernels will give a rapid increase in thorium coritent for the full cans. Inelastic scattering in the thorium will reduce the energy of the induced-fission spectrum neutrons in transit to the detectors, anc' the lower-energy neutrons will drop below the threshold of the ${ }^{4} \mathrm{He}$ detectors.

The dip in the bildchen curve at about $300 \mathrm{~g}$ is probably a geometry vs efficiency effect as the height of the bildchen stack increased. The sample is very uniform, so there is negligible sample-to-sample scatter.

The HEU metal pieces have a higher response than the metal disk because of the lower $\rho 235$ value for the loosely packed pieces (that is, less self-shielding). Even the lowest loading (that is, a single layer of pieces) exhibits a considerable amount of self-shielding.

b. AWCC Results. Figure 60 (lower graph) shows the composite data for all of the samples measured in the AWCC. The data for the HEU metal disks fall above the other data because of the fast-neutron multiplication in the metal disks. The nonlinearity in the $\mathrm{U}_{3} \mathrm{O}_{8}$ powder curve is caused more by geometric effects than by neutron self-shielding. In comparing the AWCC results with the PHONID-II results, we see that the spread in the data is less for the AWCC.

To give a more sensitive illustration of the selfshielding, we have plotted response per gram (R/g) vs grams in Fig. 61. The "thin-sample" response with mininum self-shielding is 0.29 counts/s $\mathrm{g}{ }^{235} \mathrm{U}$ for the small (uranium/thorium) kernel sample. This response also is boosted slightly by the graphite matrix in the particle coatings. The minimum response is for the smaliesi can of metal pieces where $\mathrm{R} / \mathrm{g}$ is 0.17 . The spread in the data is a factor of 1.7 , which is significantly less than the factor of 3 spread for the PHONID-II data. The reason for this reduction in the data spread is the compensation between the neutron multiplication and self-shielding. This effect can be seen clearly for the HEU metal disk data that fall above the metal pieces and continue to increase with increasing mass.

c. Summary. Both the PHONID-II and the AWCC can be used to verify the ${ }^{235} U$ content in the materials used for this comparison. In the low-mass range, the PHONID-11 has the advantage of better sensitivity and shorter counting times. For high-mass and high-density samples, the AWCC has the advantage of being less subject to errors from inhomogeneities and self-shielding. The weight and neutron-source characteristics of the AWCC make it more suitable for portable applications. Both instruments can give satisfactory verification information if properly used by the inspectors.

2. ESARDA/INMM Conference on NDA Statistical Problems (J. T. Markin, Q-4). One member of the Safeguards Systems Group (Q-4) attended the 
ESARDA/INMM Joint Specialist Meeting on NDA Statistical Probleıns at Ispra, Italy, and presented a paper coauthored by two members of the Advanced Technology Group (Q-2) on the application of sequential statistical methods to portal monitoring. This meeting was intended to create a dialogue among designers of NDA instruments and statisticians with the goal of improving both NDA instrument performance and th: interpretation of NDA measurement data. Topics presented at the meeting included statistical analysis of NDA data to detect instrument malfunction or materials accounting anomalies, error models of instruments, mathematical methods for improving instrument design, and estimation of calibration relationships.

\section{US-European Economic Community (EEC) Tech- nical Exchange Program}

1. Test and Evaluation of Spent-Fuel Equipment (S. F. Klosterbuer, G. E. Bosier, Q-1). In November 1983. the staff members participated in spent-fuel measurement exercises at two facilities in Germany. These exercises were arranged by the Directorate of EURATOM Safeguards antached to the EEC. Los Alamos was invited to participate in these exercises through bilateral agreements between the US Government ar. EURATOM. The purpose of the exercises was to demonstrate the use of the $10 \mathrm{~N}-1 /$ fork equipment for measuring spent-fuel assemblies in reactor storage ponds. Equipment used in the exercises was then loaned tu EURATOM for a 6-month evaluation period. Because commercial versions of the ION-1 and fork are still not available, the loan period has since been extended for an additional year.

Since these exercises, the equipment has been used by EURATOM several times and results of the measurements have been used in actual inspection reports. However, because mosi of the data are regarded is safeguards confidential. Los Alamos has not been directly involved in the data analysis. From information we have received it appears that the results have been reasonably good and that EURA TOM is planning to use the equipment "routinely," which, in this case, implies that the equipment can be used as the need arises. It does not mean that the equipment would be used at every inspection in all facilities that have spent-fuel assemblies.

From a Los Alamos perspective, the interactions with EURATOM have been most helpful and favorable. The EURATOM usage was the first time that the same ION-1/fork measurement system has been used in several facilities. Over the past few years, the spent-fuel measurement equipment has been evolving into the present system, and as a result. equipment used at previous exercises has inevitably beer different. From the EURATOM experiences we have had an opportunity to see how stable the equipment is and how well the fork can be repeatedly decontaminated. Problems that have occurred so far have been minor. For example, some of the rechargeable batteries had to be replaced. Also, there have been some occasions where the $10 N-1 /$ fork data appear to be inconsistent with other available data. So far we have not been able to explain these inconsistencies, but we are looking closely at in-house equipment for similar effects.

Gencrally, the equipment has been easily decontaminated. Because the equipment is shipped between facilities that can accept radioactive materials, the equipment is cleaned to saisfy shipping requirements for radioactive materials. Shipping requirements are quite stringent so that the fork poses no health hazard, but the cleanup effort is considerably reduced. There do not appear to be any signs of radiation damage to the fork because of the repeated usage. This was one of the questions that have been raised about repeated applications of the same equipment.

The EURATOM use of this equipment also has helped in the effort to get approval by facility operators to use the equipment. Because of the impact this equipment has on a facility, there has been some reluctance by the operators to allow the equipment to be used in their facilities. EURATOM personnel have negotiated with utilities in various regions of Germany and have obtained some approval to use the equipment. Such agreements can now be used as models in negotiations with other facilities and also can be used by the IAEA in its attem ${ }_{\mathrm{i}}$ its $(i)$ negotiate the use of the cquipment.

2. Field Exereises at Belgonucleaire, Nukem, and Riso (H. O. Menlove, J. E. Foley, M. S. Krick, Q-1). The following exercises were part of the US-EEC Technical Exchange Program and had participation by staff from EURATOM-Luxembourg, Los Alamos, the IAEA, JRC-Ispra, and the local facilities.

a. Belgonucleaire Fuel Fabrication Plant, Dessel, Belgium. The purpose of this exercise was to demonstrate and calibrate the upgrade $d$ version of the highlevel neutron coincidence counter (HLNCC-II) using the high-burnup samples availatle at Belgonucleaire. Absolute calibrations were obtained with large plutonium samples using the new Ensslin-Boehnel multiplication correction procedure. The HLNCC-II was left with the EURATOM inspectorate for additional field evaluation during the next 6 months.

b. Nukem, Hanau, FRG. EURATOM staff have been using the PHONID system (an Sb-Be photoneutron system) for the past several years at Nukem. but they desire a portable system such as the AWCC that can be used in other facilities. In this exercise the AWCC was demonstrated, calibrated, and 
compared to the PHONID system for a variety of uranium fuel materials (see Part 4, Sec. III, B, 1, above).

c. Danish Atomic Energy Commission Research Establishment, Riso, Denmark. The AWCC was shipped from Nukem to Riso (1) to calibrate the counter for the verification of cylindrical MTR-type fuel assemblies and (2) to demonstrate the AWCC to Riso personnel and two inspectors from the EURATOM Inspectorate, Luxembourg, who had not been present at the Nukem exercise. This was the first AWCC calibration for cylindrical MTR-type assemblies.

The AWCC was left with the EURATOM inspectorate for additional field evaluation during the next 6 months.

\section{IAEA Advisory/Working Groups}

1. Quality of NDA Data (R. H. Augustson, Q-1). One staff memher attended the Advisory Group Meeting on Evaluation of the Quality of Safeguards Nondestructive Measurement Data held in Vienna on November 19-23, 1984. This meeting focused on the current status of IAEA NDA measurements, methods for transmitting field data to the agency, and the statistical analysis of these field data. A paper coauthored with Mr. W. Strohm (Mound Laboratories) described the physical inventory verification exercise held at the Hanford Engineering Development Laboratory in September 1984.*

2. Reprocessing Working Group (S. -T. Hsue, Q-1; R. Gutmacher, J. T. Markin, R. Picard, Q-4). The IAEA is planning a consultants' working group on reprocessing facilities to develop an international safeguards approach for such facilities. In preparation for this meeting, the IAEA is preparing a working paper on the safeguards technology to be available to inspectors. At the request of the IAEA, we have written four sections for the working paper on the subjects:

- Equipment Calibration Statistics. A description of how to develop and monitor calibration equations for measurement instruments

- Sequential Material Unaccounted For (MUF) Evaluation. A survey of the sequential statistical methods that are relevant to timely detection of material loss

\footnotetext{
* Analysis of NDA Data from Simulated Physical Inventory Verification Exercise at a Mixed-Oxide Fuel Fabrication Facility," Los Alamos National Laboratory document LAUR-84-3617.
}

- Random and Systematic Measurement Uncertainties. A tutorial on the development of error models for measurement processes

- Plutonium and Uranium Analytical Measurements. A survey of analytical measurement methods having application in reprocessing facilities.

E. ESARDA (H. O. Menlove, L. R. Cowder, T. D. Reilly, Q-1; J. T. Markin, S. T. Smith, R. B. Strittmatter, Q-4)

Los Alamos continues to maintain close contact with the ESARDA organization through attendance at meetings and participation in working groups. One staff member attended a Specialists' Meeting on Neutron Coincidence Counting held at Harwell, United Kingdom, during May. The subject of main interest was neutron multiplication and how to correct for it.

Los Alamos had three participants in the Sixth Annual ESARDA Symposium held in Venice during May. Each presented a paper. ${ }^{82-84}$

Three staff members presented papers at a Specialists' Meeting on Statistical Analysis of NDA data held in the Ispra JRC in September. ${ }^{59,70,85}$

These interactions within ESARDA are valuable to keep us in contact with the R\&D community not only in Europe but Japan as well.

F. Brazil Bilateral Safeguards Exchange (H. O. Menlove, J. E. Foley, M. S. Krick, Q-1)

The first phase of the US-Brazil bilateral safeguards technical exchange took place during the week of October $15-19,1984$. The interaction is being coordinated by DOE, the Office of Safeguards and Security, and the National Nuclear Energy Commission (CNEN) in Brazil. The initial focus of the exchange is an in-plant evaluation of the neutron coincidence collar and associated training. The Los Alamos collar will be evaluated by the CNEN for verification of fresh LightWater Reactor (LWR) fuel assemblies at the Resende Fuel Fabrication Plant, which is operated by Nuclebras for the production of Pressurized-Water Reactor (PWR) fuel assemblies.

Los Alamos staff presented a 2-day training program on NDA techniques for safeguarding LWR fabrication facilities to eight staff members of CNEN and Nuclebras. Detailed instructions were given on neutron coincidence counting and the shift-register electronics.

The CNEN has recently completed a new safeguards laboratory building dedicated to both destructive analy- 
sis and NDA. This was the site for our training activities during the visit. The CNEN plans to use this laboratory to perform a parallel analysis of any samples taken by IAEA inspectors.

We visited the Resende Fuel Fabrication Plant to discuss the in-plant measurement program and to determine the measurement location for the neutron collar.

A follow-up visit took place in December 1984 to install the neutron collar and to initiate the measurement program for the 40 PWR assemblies in storage at the Resende plant. The staff of CNEN was very cooperative during the visit, and Rex Alves, the CNEN Director, stated his interest in and support of the bilateral interaction. There is a possibility for future cooperation in the areas of training, uranium enrichment measurements, spent-fuel verification, and strengthening of this new safeguards laboratory in Brazil.

IV. FUEL-CYCLE SAFEGUARDS (J. T. Markin, $H$. S. Vaccaro, Q-4; W. H. Chambers, Consultant)

Current IAEA practice for assigning inspection effort allocates essentially the same resources to facilities of the same type. An alternative to this facility-based allocation scheme, now under investigation by the IAEA, considers the characteristics of the State's fuel cycle (such as the State's accounting system and the presence or absence of particular facilities including reprocessing or enrichment plants) in assigning inspection resources to a particular facility. As an adjunct to analyses of such fuel-cycle-based allocation schemes, we have developed a meth $\sim d$ for assigning inspection effort across multiple fuel cycles so that a measure of inspection performance is maximized, subject to inspection resource constraints.

Agency safeguards approaches that are the basis of inspection planning are derived from analyses of rredible scenarios for diverting material and the anomalies generated by these diversion-related actions. For each scenario weighting factors are assigned to reflect the relative importance of the scenario considering the attractiveness of the material involved and the technical complexity of implementing the scenario. Also, each pair of inspection activities and scenarios is assigned a subjective probability that the scenario is detected given the application of the inspection activity.

We have formulated a global resource allocation problem in which inspection activities are assigned across multiple fuel cycles with multiple facilities so that a performance measure reflecting the inspection effectiveness for all fuel cycles is optimized. ${ }^{84}$ Our solution method is a dynamic programming algorithm that requires as input the total resources available for inspec-

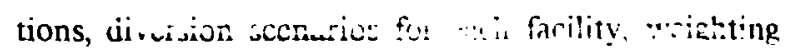
factors for each scenario, a list of potential inspection activities for each facility with detection probabilities for each scenario and the cost of the activity, weighting factors reflecting the relative safeguards importance of each facility, and a performance measure that incorporates the detection probabilities and the weighting factors. Program output consists of the optimal choice of inspection activizies for each facility, the value of the performance measure, and the total cost of the global inspection plan. This optimization method will be applied in future studies of fuel-cycle-based inspection planning, to determine optimal allocations where the complexity of the planning decisions requires a computerized optimization algorithm.

\section{INTERNATIONAL TPAINING COURSES ON IMPLEMENTATION OF STATE SYSTEMS OF ACCOUNTING FOR AND CONTROL OF NU- CLEAR MATERIAL (E. A. Hskkila, Q-DO/SG; T. D. Reilly, Q-1)}

The International Training Course on Implementation of State Systems of Accounting for and Control of Nuclear Material (SSAC) is sponsored by the US DOE and the IAEA to provide information on nuclear material accounting and control to safeguards personnel from the member states of the IAEA. The cuurse is mandated by the Nuclear Nonproliferation Act of 1978 (NNPA). It is a 3-week course conducted partly in Santa $\mathrm{Fe}$ and Los Alamos, New Mexico, and partly at a commercial US nuclear facility. Alternate sessions emphasize safeguards at item-accounting and bulk-accounting facilities. Most of the 25 to 30 participants come from countries that are beginning to develop a nuclear energy program. Instructors come from the IAEA, DOE, NRC, Los Alamos, and US and foreign nuclear facilities and control authorities.

The fourth SSAC course was presented October 17 through November 4, 1983, in Sinta Fe, Los Alamos. and Richland, Washington. It emphasized safeguards techniques at bulk-accounting facilities. The LWR fuel fabrication plant operated by the EXXON Nuclear Company hosted the facility portion of the course. ${ }^{86}$

Preparations were begun in 1984 for the fifth SSAC course, which will be presented June 3 through 21, 1985 . The course syllabus was developed and finalized, lecturers were selected and invited to participate, and the field-trip arrangements were begun. The course will emphasize item-accounting facilities, and attendees will visit the San Onofre Nuclear Generating Station operated by the Southern California Edison Company in San Clemente, California. 


\section{PART 5. RELATED SAFEGUARDS PROJECTS}

In this section, we highlight safeguards work that is related to our DOE/OSS programs but that is sponsored by others.

\section{US NUCLEAR REGULATORY PROJECTS}

\author{
A. Sequential Statistical Tests for Safeguards (A. S.
} Goldman, Q-4)

The NRC has proposed a set of regulations known as Material Control and Accounting Reform Amendments. We have completed a study that provides statistical testing procedures that will enable a licensee to comply with Section 70.83(b)(2) of the Amendments. These test procedures address the problem of detecting protracted materials los 3 s for at single materials control unit (MCU) and include modified versions of Page's and power-one procedures.

Sequential tests typically assume that independent observations are taken at successive time intervals until a decision is reached concerning loss of mate rials. For materials accounting applications, we must adapt thcse tests to dependent data nver a specified accounting period. A decision must then be made within the given time frame.

The suggested steps in making a decision for using either Pagc's or power-orıe procedures include (1) determining correct decision boundaries, (2) transforming the dependent cumulative sums of inventory differences (IDs) into independent standardized statistics. (3) calculating the test statistic, (4) comparing the test statistic with the boundary, and (5) making a decision that there is a significant loss when the test statistic falls outside the boundary or there is zero loss otherwise.

To conform with the regulations, decision boundaries were established for a 60-day inventory period using a computer simuiation. Data were generated from simulated measurement data from a $\mathrm{MCU}$ in a $\mathrm{UF}_{6}$-to- $\mathrm{U}_{3} \mathrm{O}_{8}$ conversion process as described in Ref. 87 . The MEASIM progran was used to simulate process variation and holdup.

Four different loss strategies were used in comparing the sequential test procedures: protracted losses over a long period of time (days 11-60), protracted losses near the beginning of the period (days 6-30), protracted losses at the end of the period (days 31-60), and a sequence of six abrupt losses every tenth day (days 10,20,30,40, 50, $60)$.

The criteria for selecting a "best" test for a given loss strategy were (1) the test statistic should have the highest detection probability and (2) the test statistic should be able to detect protracted losses in the shortest time from the onset of loss.

Test recommendations based on loss scenarios and criteria are

\begin{tabular}{lcl}
$\begin{array}{l}\text { Loss Scenario } \\
\text { (Constani Loss) } \\
\text { (days) }\end{array}$ & $\begin{array}{c}\text { Shortest Average } \\
\text { Detection Time } \\
\text { From Onset } \\
\text { of Loss }\end{array}$ & $\begin{array}{c}\text { Highes. } \\
\text { Detection } \\
\text { Probability }\end{array}$ \\
\hline $6-30$ & $\begin{array}{l}\text { Page's } \\
11-60\end{array}$ & $\begin{array}{l}\text { Power-one } \\
31-60\end{array}$ \\
$\begin{array}{l}\text { Page's } \\
\text { Page's }\end{array}$ & $\begin{array}{l}\text { Power-one } \\
\text { Page's }\end{array}$ \\
\hline $0,30,40,50,60$ & Page's & Page's
\end{tabular}

Principal conclusions with respect to testing procedures that meet the Reform Amendment requirements for protracted losses are

- No single test procedure is best for both criteria and all diversion scenarios.

- Page's test gives most timely detection.

- The power-one test is more sensitive for protracted losses early in the 60-day accounting period, whereas Page's test is more sensitive near the end.

- For the process model given in the study and a 5\% false alarm probability in each 60-day period, as low as reasonably achievable amounts (ALARA) of material to be detected with $90 \%$ probability are given as follows:

Loss Scenario

(Constant Loss)

ALARA

(days)

$(\mathrm{kg})$

6-30

6.9

$11-60$

9.3

$31-60$

4.6

$10,20,30,40,50,60$

6.5

- If holdup and process variation are not included in the materials balance model bui are present in the process, then, assuming steady-state conditions, false alarms can increase from $5 \%$ to $\sim 10 \%$. 
B. Estimation Methods for the Process Holdup of Special Nuclear Materials (K. K. S. Pillay, Q-4; R. R. Picard, S-1)

In 1981, the NRC sponsored a research study in support of the proposed MC\&.A Reform Amendments to refocus resources away from periodic physical inventories to a more timely detection of SNM losses. This project was successfully completed during 1984 , and a final project report was issued in June $1984{ }^{88}$ The primary objective of this investigation was to explore the possibilities of developing statistical estimation models for the holdup of SNM at processing facilities.

1. Use of Historical Data. The task of gathering holdup information and developing holdup estimators for specific processes underwent several stages. Historical records from HEU processing facilities, which were gathered as part of periodic inventory development, were first considered as an available source of long-term holdup data. However, the large measurement errors and incomplete recording of many relevant factors made this source of information of limited value to statistical model development. The next step in gathering good-quality holdup data was through carefully designed measurements of SNM holdup at two of the materials processing facilities of Los Alamos. Selected measurements conducted over a period of one year showed that cerain equipment. such as air filters and calciners, lends itself to good-quality holdup measurements and model development. The value of these models was further confirmed when controlled experiments were performed involving high-quality data collection using radioactive tracers.

2. Controlled Experiments. Controlled experiments were designed to measure uranium holdup accumulated during dust-generating operations of fuel fabrication, feed dissolution processes, ammonium diuranate (ADU) precipitation and calcination, pulse column operation, and the circulation of uranyl solutions through pipes and pipe fittings. Total throughput of uranium through these experimental facilities ranged from $50 \mathrm{~kg}$ to about $50 \mathrm{Mt}$. The quality of measured holdup data obtained from these controlled experiments was improved by at least an order of magnitude through the use of carefully selected radioactive tracers and specially designed calibration standards. Tracers, at concentration levels of about one part-per-billion, were homogeneously incorporated in to the process materials. Considerable attention was given to the fabrication of instrument calibration standards compatible with the equipment measured and the aistribution of holdup therein. These standards also helped improve the quality of holdup data from noninvasive, nondestructive assays using gamma-ray spectrometry.
3. Modeling Approaches. The modeling of holdup as a function of time and space was used to meet the requirements for different equipment. The models required a variety of techniques, including multiple regression, Kalman filtering, and response surface methodology. Application of these techniques was relatively straightforward, as was error propagation for modelbased estimates. In most cases, the results demonstrated the value of statistical models developed from highquality measurements for the estimation of present and future residual holdup. In addition, many advantages and limitations of estimation models developed from a variety of data gathering approaches were also identified.

4. Conclusions. There are many difficulties associated with the measurement and the development of reliable estimates of the holdup of SNM in large processing facilities. Materials accumulating on the interior surfaces, cracks, pores, and zones of poor circulation of process equipment are not easily measured by conventional methods. This examination of statistical models for holdup prediction demonstrated that, in many cases, modeling can be used to develop estimates of the residual inventories of SNM. The value of the statistical model, however, depends strongly on the quality of holdup data used in the model's development. If process operating conditions are subject to frequent changes or holdup measurement errors are very large, it is unrealistic to expect holdup models to be very useful. On the other hand, if the process is stable and the holdup data gathered are of good quality, holdup models can be very valuable for making present and .uture estimates of holdup.

This investigation also showed that several factors such as the layout of pipes, corrosion of construction materials, and the concentration of solutions affect the holdup of materials and that in many cases, the holdup of SNM is not simply a function of the material throughput.

The major findings of this in vestigation are

- Measurement of the residual holdup of SNM at large processing facilities is a difficult problem and will remain so because of the inherent limitations of plant layout and NDA techniques.

- There are several approaches to improving the quality of measurements: better instrumentation. better calibration standards, and the application of carefully chosen secondary measurement techniques.

- Statistical estimation models can be useful in materials accounting; however, process operations, variability of process conditions, and quality of 
measuremenis affect the value of model-based estimates.

- Significant improvements to holdup measurements and data collection for holdup estimation can be achieved if these problems are addressed during the design stages of a plant and the necessary features are incorporated.

\section{Passive Nondestructive Assay Reference Manual (N. Ensslin, D. Reilly, Q-1)}

Los Alamos is tasked by the US NRC to produce a general reference manual on passive nondestructivc assay of nuclear materials. The book will be part of a four-volume series on safeguards measurements commissioned by the NRC. The volumes already in print are Active Nondestructive Assay of Nuclear Material by T. Gozani and Handbook of Nuclear Safeguards Measurement Methods by D. Rogers. A handbook of statistical methods for safeguards also is being written.

The major sections of our volume cover gamma-ray assay techniques, neutron assay techniques, calorimetry, and applications. The applications section includes chapters on perimeter and personnel monitors, spent-fuel assay, attribute measurements, and an applications guide. The present outline calls for 24 chapters and several appendices.

The manual is progressing well, although it is behind the schedule set in the summer of 1982. The final text will be ready for photocomposition by the fall of 1985 and should be in print by late 1986 .

The book will be a general reference for newcomers to safeguards, nuclear facility accountability personnel, and NDA instrument developirs. It will be used extensively in the Nuclear Safeguards Training Program at Los Alamos and should replace the existing reference manual. ${ }^{89}$

\section{THE ATOMIC SPECTRUM OF PLUTONIUM (R. G. Gutmacher, Q-4)}

A monograph entitled "The Atomic Spectrum of Plutonium" was issued as Argonne National Laboratory report ANL-83-9.5 in August 1984. The 612 pages of the monograph contain 30799 atomic emission lines of neutral and singly-ionized plutonium, their wavelengths, energy level classification, isotope shifts, and other spectroscopic data. Also given are tables of $\mathrm{Pu} \mathrm{I}$ and Pu II energy levels, with their isotope shifts and Jand g-values. These data are basic and essential for plutonium spectroscopy, resonance ionization mass spectrometry, and other safeguards analytical techniques for plutonium. A companion paper "Term Anal- ysis of the Spectrum of Neutral Plutonium (Pu l)" will be submitted for pubication.

\section{SP-100 SAFEGUARDS ISSUES (K. K. S. Pillay, H. S. Vaccaro, Q-4)}

The SP-100 program is a joint effort of DARPA-SDI, DOE, and NASA to develop a 100-kWe class space reactor. Present reactor design concepts propose to use more than 100 kilograms of highly enriched uranium as the fuel material. This quantity of special nuclear material (SNM) is a safeguards concern. The issues surrounding this concern are being examined systematically in the context of the overall program goals and current international policies. During 1984, the SP-100 program achieved the goal of identifying surety (safety \& safeguards) issues and is now in the process of developing plans for resolving these issues.

The objective of the safeguards study is to develop criteria for minimizing potentials for loss and/or diversion of SNM during various phases of the mission. The ascent and reentry phases as well as operation of the reactor in low earth orbit are recognized to have significant safeguards problems. Some of the key parameters that would impact nuclear material safeguards (such as reentry dispersion, footprints of dispersed fuel material, recoverability and convertibility of SNM, and number of significant quantities of SNM) have been highlighted for all the participants of the SP-100 program for their consideration during the de $\%$ copment of various phases of this long-term project.

The Los Alamos Safeguards Systemis Group recently propesed a set of quantified objectives for SP-1Ci' safeguards. In the absence of existing guidelines for spacebased nu:-lear facilities, these proposals are based on the IAEA's goals for inspection of land-based nuclear facilities but have been judiciously adapted for the SP-100 $r_{1}$ ogram. The proposed objectives are (1) the risks of exposing a significant quantity of SNM from SP-100 for diversion should be kept as low as reasonably achievable without jeopardizing mission performance and (2) the risks should not in any event exceed $0.6 \%$ per year. These safeguards objectives result in preferences for fuel dispersion during the reentry of SP-100. The preferred degree of breakup is to subgram-sized particles or no breakup at all. In the absence of complete breakup. the dispersion over as small an area as possible is preferred, but debris footprints up to a few hundred miles are acceptable. Preference for dipersion was established with the aid of a Monte Carlo simulation model to examine the risk of diversion under various scenarios for footprint size, diverter states, cooperation among diverters, and fuel quantity. The model developed at Los Alamos may be applicable to future megawatt versions of SP-100. 
IV. TRU WASTE SYSTEMS SIMULATION (E. A. Kern, Q-4)

This task was intiated in 1983 for the primary purpose of developing a cimputf $r$ code (i) simulate the flow of defense, contact-handled TRU waste from storage and generating sites to the WIPP repository. We developed the TRUSIM code to satisfy this objective. Application of the TRUSIM code made it possible to calculate important system design parameters such as transportation resource requirements and WIPP backlogs. A major limitation of the 1983 TRUSIM code was its dependence on another code, MPLAN, which was developed by the S. M. Stoller Corp. for shipping rate schedules. Our goals in 1984 were to (1) restrun MPLAN to provide more flexibility for waste workoff strategies and to allow for direct comp:ter linkage to TRUSIM, (2) increase the flexibility of TRUSIM for different operating scenarios, (3) incorporate a menudriven input capability for TRUSIM, (4) improve the graphical output capabilities of both MPLAN and TRUSIM, (5) validate and verify MPLAN and TRUSIM, and (6) convert both codes to the IBM PC and transfer the codes to Transuranic Waste Systems Office.

Because MPLAN had reached a point where additional capabilities would be difficult to implement as a result of the complex algebraic equations used, we rebuilt MPLAN using the SLAM II simulation language. This allowed much greater flexibility for network operating scenarios and provided for a direct computer linkup with the TRUSIM code. In addition, we expanded the graphical and tabular outpits of MPI $4 N$ to generate directly report- and presentation-quality graphs and tables.

We also modified TRUSIM to provide greater flexibility for different operating scenarios and developed a menu-driven inpul package to provide a high degree of user-friendliness. The tabular and graphical output capabilities were improved, and the inputs to the code were made more realistic.

Close coordination with waste generation and storage sites and the WIPP project office was one of the primary goals of the task. At a validation and verification meeting held in Denver in March 1984, most of the major sites and WIPP were represented. We presented a detailed status report on MPLAN and TR.USIM. Nearly all the recommendations and suggestions made at that meeting were eventually incorporated into the MPLAN and TRUSiM cojes.

A Systems Simulation Workshop was held in conjunction with the TRU Update Meeting \#8 in Albuquerque. MPLAN and TRUSIM were accessed and run via a 1200-baud tclephone hookup to the Q-4 VAX in
Los Alamos. A large screen frojector was used to demonstrate the graphical output capabilities of the two codes.

The MPLAN and TRUSIM codes were converted to the IBM PC and transferred to TWSO. Since the SLAAM II simulation language was not available for the PC, it was necessary to restructure the codes using the SIMAN simulation language before transfer to the IBM PC could be accomplished.

V. SUPPORT TO SRP/HB-LINE SODIUM IODIDE MONITOR ARRAY (M. P. Baker, S. -T. Hsue, J. Leavitt, ‘. Rinard, S. Simmonds, T. Van -

We are collaborating with the duPont Company on a sodium iodide ( $\mathrm{NaI}$ ), gamma-ray detector array for the HB-Line ${ }^{239} \mathrm{Pu}$ enhancement project at the SRP. The array will provide information for acrountability on holdud, for process control, and for criticality safety. The requirements of the project are very similar to those of the NaI array for the New Special Recuvery facility (Pan ', Section V). Although the HB-Line system is suppor ted entirely by the construction project, system performance will benefit greatly from the experience gained on the NSR NaI array. In fact, to meet the stringent delivery schedule (September 1985), the ground rule was adopted that the two Nal arrays would be as similar as possible.

Following discussions with processing and engineering personnel in Savannah River in September, we issued a conceptual design study ${ }^{\%}$ that outlined our proposals for deploying the NaI monitoring array, costs associated with performing the work, and the delivery schedule. Concepts presented in the report have been largely accepted by duPont, and we are proceeding with mechanical design of the collimator/shieiding assemblies. Applications that must be addressed include process tanks, anion exchange columns, raffinate streams, product transfer lines, and holding tanks, as well as portable measurements.

VI. TECHNICAL ASSISTANCE FOR THE LOS ALAMOS NATIONAL LABORATORY PLUTONIUM FACILITY (H. Smith, Q-1)

The Los Alamos Safeguards Groups are receiving ar increasing number of requests and funding for technical assistance in process control and instrumentation and in materials accounting and rondestructive assay measurements at the Los Alamos Plutonium Facility (TA-55). 
A. Caustic Waste Tank Mtasurement Instrument (L. A. Stovall, L. C. Osborn, Q-1; T. W. Kreider, E. A. Thomas, E-2)

In April 1984, Safeguards Group Q-1 was asked to provide a liquid-level measurement instrument for use by the Los Alamos Nuclear Materials Process Technology Group (MST-12) on their new caustic wastc collection tank system being built at TA-55 with a hydrostatic level measurcment principle. ${ }^{91}$ It was agreed that the new instrumentation would be based on zarlier work and would be produced as a package with commercially availabie hardware, complete with design and fabrication drawings for a finished product suitable for use in a päoduction facility.

The hydrostatic metho of liquid-level determination uses a sensitive pressure transducer to masure the pressure 1 ex dired to blow bubbles into the liquid from the tip of a long tube extending to the bottom $m_{\perp}$ of the tank. The transducer provides an electrical signal that can be plocessed and displayad to the operator as "liquid height" or "liquid volume."

An identical measurement is made with a second, shorter tube, and the difference between the two pressures is proportional to the liquid density. Our design allows both measurements to be made with the same transducer and plumbing. Either mass or dessity is available to the operator by activation of a controipanel switch.

The new design is simple, and the instrument is easy to fabricate and maintain in i-idusurial applications. It uses commercial electronics, with only the control-panel switches and readodts needing custcm installation. Detailed fabrication drawings were prepared, and eight instruments were fabricated. The drawings are now available to anyone interested in the liquid-level measuring devic $\%$. Operation and maintenance manuais are cun antly being preparer. Figure ó 2 show, the transducer package with a view of the internal construction.
Fig. 62. (a) Complete package and (b) internal view of the transducer and plumbing circuit for the hydrostatic liquid level and density gauge. The four external connections shown provide flowing nitrogen to the system. access to the long and short bubbler tubes. and a path to room (reference) pressure.

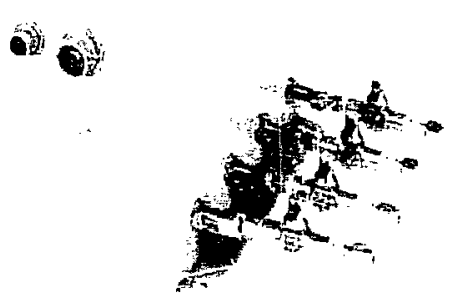

(a)

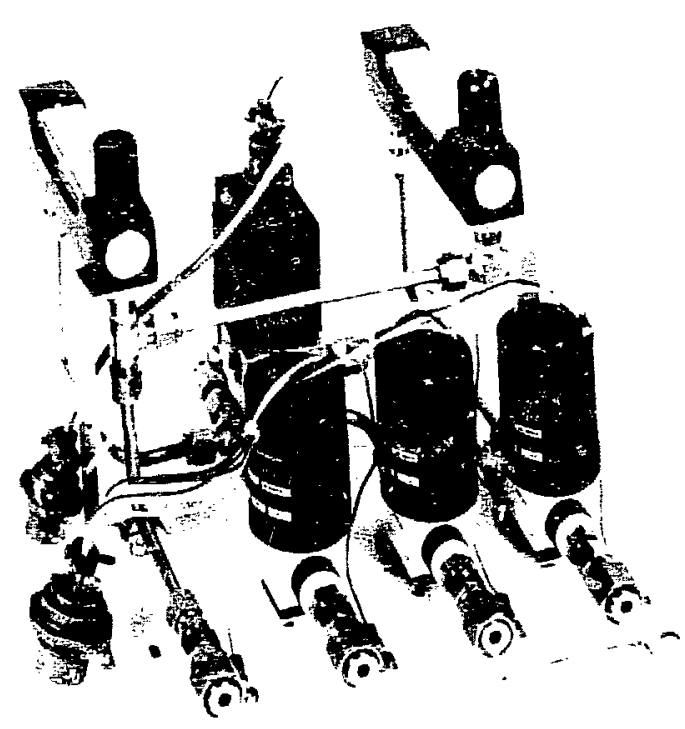

(b) 
Six of these instruments have been installed on new caustic waste collection tanks at TA-55. The control panel for the six-tank system is currently being built by the Los Alamos Electronics Fabrication Group. Laboratory bench tests of all of the completed units indicate that they will perform satisfactorily with an accuracy of better than $1 \%$ of total tank volume and density. Final testing and calibration of the system will take place when the tanks and control panel are installed in 1985 .

B. Segmented Gamma Ssanner for TA-55 (C. Bjork, T. Dye, J. Baca, G. G. Ortiz, D. C. Garcia, F. A. Daral, G Walton, 2-1)

Mechanical assembiy was completed for ar in-line segmented gamma-ray scanner (SGS) to be used at TA-55 to measure the ${ }^{239} \mathrm{Pu}$ content of process scrap. The sample to be measured remains in containment and is place 1 on a tumtable and lowered into a recessed well attachel to the bottom of a dedicated glove box. The vertical scan of the sample is accomplished by a stepping-motor drive that moves the entire detector and transmission source assembly under computer conirol. The sample container is rotated during assdy by magnetic ccupling through the stainless steei well wall.

Testing and installation of the SGS unit are expected to be completers during 1985 .

\section{Add-On NDA Training (H. Smith, Staff, Q-1)}

At the request of the Los Alamos Nuclear Materials Management Group (MST-10), we presented supplementary lectures and laboratory sessions on techniques of neutron and gamma-ray assay of plutonium samples, following the October DOE course, "Fundamentals of Nondestructive Assay of Nuclear Material." These sessions took place over a period of 4 days during which the classes were presented twice, each time to one-half of the personnel in MST-10. A similar follow-on course on advanced gamma-ray NDA techniques was provide $d$ to this group after our DOE course on "Advanced Gamma-Ray Spectroscopy for Nuclear Materials Accounting" in December.

D. Model of the Los Alamos Plutonium Facility (C. A. Coulter, K. E. Thomas, Q-4)

The Safeguards Systems Group (O-4) is assisting the Nuclear Materials Process Technology Group (MST-12) in developing a process modei for TA-55 to aid scheduling and process sptimization. Work on the modeling effort to date has hid three facets.

- We used the simulation language SIMAN to construct a rough preliminary model of the Plutonium Facility using c entinuous-flow approximations and average processing rates to provide a check for results obtained from the planned more-detailed model.

- With the help of MST-12 personnel, considerable progress has been made in compiling the detailed process information iequired for the complete SIMAN model that is to be constructed.

- As a side issue to the primary modeling effort, Q-4 personnel aided MST-12 and MST-13 in calculat.. ing information required for a complex-wide model being prepared exterually to describe all DOE plutonium processing facilities at a gross, average-flow level.

E. Database Design and Applications Support for Los Alarsos Plutonium Facility (W. J. Whitty, ?-4)

As part of the direct support to TA-55, Group Q-4 is automating some of the MST-12 monthly reporting functions. Because we do not presently have access to an appropriate classified computer, we are using unrestricted PF/LASS inventory data, which is similar to MASS data. We restructured this data to provide a "development aid" for database applications and report generation with MASS data when classified computing facilities are available.

The database management system (DBMS) selected for this effort was INGRES (Interactive Graphics and Retrieval System), which is a commercially available product from Relational Technology, Inc. (RTI). INGRES is a relational DBMS having the advantages of simplicity of database design and restructuring, data independence, and easy ad hoc query capability. It is a de facto Laboratory standaro with over 40 licenses and 350 INGRES trained employees.

Report generation is the initial step of the database work. MST Division also has requiremicnts for improving process control to increase throughput. The ready access of timely inforination on process functions through ad hoc queries to the database will greatly enhance MST's ability to run TA-55 processes efficienuly. 


\section{PUBLICATIONS/PRESENTATIONS-ABSTRACTS}

1. W. Alston, R. Augustson, W. DeMerschman, J. Merrill, and D. Reilly, "Alsalysis of NDA Data from Simulated Physical Inventory Verification Exercise at Mixed-Oxide Fuel Fabrication Facility," ESARDA/INMM Joint Specialist Meeting on "Error Propagation in NDA Measurements for Safeguards," Ispra, Italy, September 12-14, 1984.

Under the auspices of the US Program of Technical Support to IAEA Safeguards, selected United States nuclear facilities are madis available to the IAEA to conduct simulated physiral inventory verifications (PIV). These exercises simulate, insofar as possible, all the activities of an actual PIV including resords audit, item verification, sampling of nucleas material inventory, verification measurements (both destructive and nondestructive), and data analysis.

The first exercise was held November 8-18, 1983, at the mixed-oxide (MOX) fuel fabrication facility of the Westinghouse Hanford Engineering Development Laboratory (HEDL) in Richland, Washington. Eight IAEA in spectors, functioning as two independent inspection teams, went to HEDL to verify an exercise inventory containing approximately $88 \mathrm{~kg}$ of plutonium in materials ranging from $\mathrm{PuO}_{2}$ powder feed to finished MOX fuel assemblies for the Fast Flux Tesi Facility reactor. For the verification measurements they, used a series of neutroncoincidence and gamma-ray spectroscopy instruments designed to measure the variety of nuclear material in the inventory.

Many measurements were made during the course of this exercise. This paper will discuss the statistical treatment of the measurement data with the specific goal of answering the crucial question, "based on the measured sample of the inventory iterns, is the operator's material balance statement correct?" Measurement data and analysis results from the exercise will be presented and discussed.

2. R. H. Augustson and W. W. Strohm, "Analysis of NDA Data from Simulated Physical Inventory Verification Exercise at a Mixed-Oxide Fuel Fabrication Facility," presentation for the Advisory Group Meeting on Quality of NDA Data, International Atomic Energy Agency, Vienna, Austria, November 1984.

No abstract available.
3. M. P. Baker, "An Integrated Nondestructive Assay System for a New Plutonium Scrap Recovery Facility," ESARDA 7th Symposium on Safeguards and Nuclear Material Managenient, Liege, Belgium, May 21-23, 1985 (Abstract andi Summary, Los Aiamos National Laboratory document LAUR-84-3432).

A consortium of iaboratories is collaborating with the Savannah River Plant to develop an integrated system of state-of-the-an nondestructive assay (NDA) instrumentation to provide nuclear materials accounting and process control information for a new plutonium scrap recovery facility. individual microcomputer-based instruments report assay. esults to an Instrument Control Computer (ICC). The ICC, in turn, is part of a larger computer network that includes computers that perform process control and nuclear materials accounting functions. Integrated system design cousiderations, integral testing, and individual instrument measurement functiors are discussed.

4. G. E. Bosler, G. W. Ecrleston, J. K. Halbig, S. -T. Hsue, and H. O. Menlove, "Developed Measurement Techniques Useful to Spent-Fuel Management," Ametican Nuclear Society 1984 Annual Meetir.g, New Orleans, LA, June 3-8, 1984.

No abstract available

5. L. R. Cowder, S. F. Klosterbuer, R. H. Augustson, A. Emailpour, R. Hawkins, and E. Kuhn, "Á Compact K-Edge Densitometer," European Safeguards Research and Development Association (ESARDA), 6th Symposium on Safeguards and Nuclear Material Management, Venice, Italy, May 14-18, 1984.

Los Alamos Nationai Laboratory has designed, built, and is currently testing a compact $\mathrm{K}$-edge densitometer for use by International Atomic Energy Agency (IAEA) inspectors. The unit, which can easily be moved from ore location to another within a facilii, , is positioned outside a glove box with the body of the instrument inserted into the glove. A fixture inside the glove box fits around the body and positions a sample holder. A hand-held high-purity germanium detector powered by a battery pack and a Davidson portable multichannel analyzer (MCA) is used to measure the transmission through plutonium nitrate solutions at $E_{Y}=121.1$ and $122.2 \mathrm{keV}$. 
The Davidson MCA is programmed to lead the user through the measurement procedure and perform all the data analyses. The insirument is currently installed at the Safeguards Analytical Laboratory, where IAEA personnel are evaluating its accuracy, ease of operation, and safety.

6. T. W. Crane, "Detectability Limits and Precision for Shufflers," Los Alamos National Laboratory report LA-I0158 (August 1984).

The mathematical formulae for the detectability limit and precision of nondestructive assay (NDA) instruments have been developed. Definitions are given and references to previous discussions on the subject are cited. The examples are limited to ${ }^{252} \mathrm{Cf}$ Shuifflers; however, the formalism applies to all NDA instruments. The detectability limit for the Liquid-Sample Shuffler test bed is quoted at $4.2 \mathrm{mg} / \ell$ of ${ }^{235} \mathrm{U}$ when all the statistical precision effects are included for an $8-\mu \mathrm{g}{ }^{252} \mathrm{C}$ f source and a measurement time of 5 min is used.

7. G. W. Eccleston, J. E. Foley, M. Krick, H. O. Menlove, P. Goris, and A. Ramalho, "Coincidence Measurements of FFTF Breeder Fuel Subassemblies," Los Alamos National Laboratory report LA-9902-MS (ISPO-199) (April 1984).

A prototype coincidence counter developed to assay fast breeder reartor fuel was used to measure four fist-flux test facility subassemblies at the Hanford Engineering Development Laboratory in Richland, Washington. Plutonium conrents in the four subassemblies ranged between 7.4 and $9.7 \mathrm{~kg}$ with corresponding ${ }^{240} \mathrm{Pu}$-effective contents between 0.9 and $1.2 \mathrm{~kg}$. Large count rates were observed from the measurements. and plots of the data showed significant multiplication in the fuel. The measured data were corrected for deadtime and multiplication effects using established formulas. These corrections require accurate knowledge of the plutonium isotopics and ${ }^{241} \mathrm{Am}$ content in the fuel. Multiplication-corrected coincidence count rates agreed with the expected count rates based on spontaneous fission-neutron emission rates. These measurements indicate that breeder fuel subassemblies with ${ }^{240} \mathrm{Pu}$-effective contents up to $1.2 \mathrm{~kg}$ can be nondestructively assayed using the shift-register electronics with the prototype counters. Measurements using the standard Los Alamos National Laboratory shift-register coincidence electronics unit can produce an assay value accurate to $\pm 1 \%$ in $1000 \mathrm{~s}$. The uncertainty results from counting statistics and deadtimecorrection errors.

8. J. E. Foley, "The Role of Los Alamos in the US Program of Technical Assistance to IAEA Safeguards," talk presented to the Latin American Chapter of the American Nuclear Society, Rio de Janeiro, Firazil, October 16, 1984.

Management techniques that have been used effectively to implement science and engineering in hoth US and international nuclear facilities will be discussed. Particular attention will be given to methods and techniques used by our group (Q-1) to implement the use of nuclear safeguards assay equipment at the IAEA in Vienna, Austria. Both "bottom up" and "top down" implementation paths will be discussed, along with the importance of follow through and trainirig.

9. J. E. Foley, "Implementing Science and Engineering: Managing to Get Someining Done," informal lecture given to the Engineering Club at $F t$. I_ewis College, Durango, CO, October 11, 1984.

The purpose, goals, and accomplishments of the US Program of Technical Assistance to IAEA Safeguards will be described. Particular attention will be given to the research and development, implementation, and training activities of Los Alamos in the program. The active assay: instrument that is teing demonstrated by Los Alamos at the Resende LEU fuel fabricatiın facility in Erazil will be discussed in de'ail.

10. J. K. Halbig, G. E. Bosler, J. R. Phillips, and P. M. Rinard, "A System for Measuring TRU Materials in a Three-Mile Island Demineralizer," American Nuclear Society 1984 Annual Meeting, New Orleans, LA, June 3-8, 1984.

No abstract available.

11. S. -T. Hsue and M. P. Baker, "Nondestructive Assay System Development for a Plutonium Scrap Rer:overy Facility," invited paper presented at the 1984 Nuclear Science Symposium, Orlando, FL. October 31-November 2,1984; to be published in the Proceedings of the Institute of Electrical and Electronics Engineers.

A plutonium scrap recovery facility is being constructed at the Savannah River Plant (SRP). The safeguards groups of the Los Alamos $\mathrm{Na}$ tional Laboratury have been working since the carly design stage of the facility with SRF and 
other national laboratories to develop a state-ofih ${ }^{3}$-ari assay system for this new facility. Not only will the most current assay techniques be incorporated into the system, but also the various nondestructive assay (NDA) instruments are to be integrated with an Instrument Control Computer (ICC). This undertaking is both challenging and ambitious; an entire assay system of this type has never been done before in a working facility. This paper will describe, in particular, the effort of the Los Alamos Safeguards Assay Group in this endeavor. Our effort in this project can be roughly divided into three phases: NDA developinent, system integration, and integral testing.

12. T. K. Li, "Plutonium Isotopic Measurement by Nondestructive Gamma-Ray Spectroscopy," International Chemical Congress of Pacific Basin Societies-PAC CHEM '84, Honolulu. HI. December 16-21, 1984 (Abstract, Los Alamos National Laboratory document LA-UR-84-[385).

We have initiated a study of the feasibility of plutorium isotopic analysis on resin beads by employing nondestructive gamma-ray spectroscopy. Seven resin bead samples were measured, with each sample having an average o: $9 \mu \mathrm{g}$ of plutonium over a wide range of isotopic compositions. Preliminary gamma-ray spectroscopy results, obtained from 4-h c ounting time measurements, were compared with mass spectrometry results. The average ratios of gamma-ray spectroscopy to mass spectrometry were $0.9942 \pm 0.0377$ for ${ }^{238} \mathrm{Pu} /{ }^{239} \mathrm{Pu}$ and 0.9953 \pm 0.0189 for ${ }^{240} \mathrm{Pu} /{ }^{239} \mathrm{Pu}$. These rapid, automated, and accurate nondestructive isotopic analyses of resin beads may have very useful application for process control and accountability. as well as for International Atomic Energy Agency inspectors.

13. H. O. Menlove, E. L. Adams, and O. R. Holbrooks, "Pluionium Nitra:e Botile Counter Manual," Los Alamos National Laboratory report LA-10009-M (March 1984).

A neutron coincidence counter has been $d$ sigred for plutonium nitrate assay in large storage bottles. This assay system can be used in the reprocessing plant or in the nitrate-to-oxide conversion facility. The system is based on the family of neutron detectors similar to the highlevel neutron coincidence counter. This manual describes the system ano gives performance and calibration parameters for typical applications.
14. H. O. Menlove, G. W. Eccleston, J. E. Swansen, P. Goris, R. Abedin-Zadeh, and A. Ramalho, "Universal Fast Breeder Reactor Subassembly Counter Manual," Los Alamos National Laboratory report LA-10226-M (ISPO-215) (August 1984).

A neutron coincidence cour $r_{\mathrm{L}}$ er has been designed for the measurement of fust breeder reactor fuel assemtilies. This assay system can accommodate the full range of geometries and masses found in fast breeder subassemblies under IAEA safeguards. The system's high-performance capability accommodates high plutonium loadings of up to $16 \mathrm{~kg}$. This manual describes the system and its operation and gives performance and calibration parameters for typical applications.

15. J. L. Parker, "The Üse of Calibration Standards and the Correction ior Sample Self-Attenuation in Gamma-Ray Nondestructive Assay," Los Alamos National Laboratory report LA-10045 (August 1984).

The efficient use of appropriate calibration standards and the correction for the attenuation of the gamma rays within an assay sample by the sample itself are two important and closely related subjects in gamma-ray nondestructive assay. Much research relating to those subjects has been dore in the Nuclear Safeguards Research and Tevelopment program at the Los Alamos National Laboratory since 1970. This report brings together most of the significant results of that research. Also discussed are the nature of appropriate calibration standards and the necessary conditions on the composition, size, and shape of the samples to allow accurate assays. Procedures for determining the correction for the sample self-attenuation are described at length including both general principles and several specific useful cases. The most useful concept is that knowing the linear attenuation coefficient of the sample (which can usually be determined) and the size and shape of the sample and its position relative to the detector permits the computation of the correction factor for the self-attenuation. A major objective of the report is to explain how the procedures for determining the self-attenuation correction factor can be applied so that calibration standards can be entirely appropriate without being particularly similar, either physically or chemically, to the items to be assayed. This would minimize the set of standards required to assay items with a wide range of size, shape, and chemical composition. 
16. Phillip M. Rinard, "Neutron Measurements in Borated Water for PWR Fuel Inspections," Los Alamos National Laboratory report LA-10068-MS (June 1984).

A "fork" detector has been developed for use in the international effort to safeguard irradiated fuel assemblies. To improve interpretation of data from a fork, the following three facets of the detector's neutron counting response have been examined using a tank of borated water and a pressurized-water reactor fresh-fuel assembly:

(1) The detector's sensitivity to neutrons initiated at different positions within the assembly was measured and this sensitivity can be used to generate total responses to assemblies with uniform or nonuniform irradiation.

(2) Using fissior chambers with and without cadmium wrappings provided ratios of count rates that can give an independent estimate of the boron conceñisation in the water. The precision of a boron determination can be estimated from these measureInents.

3) The water temperature was raised, causing small but possibly important effects on the count rates.

These facets of the fork detector's neutron response were studied at boron concentrations ranging from 0 to ahout 3500 part s per million (pnm), in steps of about $500 \mathrm{ppm}$.

17. R. B. Strittmatter, R. R. Picard, J. K. Sprinkle, Jr., and J. R. Tarrant, "Data Evaluation of a Gas-Phase UF 6 Enrichment Monitor," talk presented at the ESARDA/INMM Joint Specialist Meeting on "Error Propagation in NLA Measurements for Safeguards," Ispra, Italy, September 12-14, 1984.

We have developed a gas-phase $U_{6}$ enrichment monitor for use by the International Atomic Energy Agency at the Portsmouth Gas Centrifuge Enrichment Plant. The enrichment monituring system provides a method for effective nuclear materials accountability verification while reducing the effort for both the facility operator and the inspector. The effectiveness of the system is critically dependent on understanding the measurement precision and bias as it applies to the verification of operator-declared data.

The gas-phase enrichment is determined by combining measurement of ${ }^{235} U$ and the total uranium concentrations using high resolution gammd-ray spectroscopy schniques. The ${ }^{235} \mathrm{U}$ concentration is determined from a measurement of the 185.7-keV gamma rays emitted from the decay of ${ }^{235} \mathrm{U}$, and the toial uranium concentration is determined by measuring the transmission through the $U \mathrm{~F}_{6}$ gas of $60-\mathrm{keV}$ gamma rays from an external ${ }^{241} \mathrm{Am}$ source. Two in-line gas-phase $U_{6}$ enrichment monitors have been installed at the Oak Ridge Gaseous Diffusion Plant (ORGDP), one in the Paducah-product feed station and one in a $U_{6}$ test loop that can be operated with a range of $U_{6}$ enrichments, pressures, and flow rates. Statistical techniques have been applied to data obtained from enrichment monitors installed at the ORGDP to evaluate the sources of bias in the measurement. The use of measurement control data and the use of statistical tests on the large data base available to the inspector in verifying declared data are discussed.

18. J. E. Swansen, "Deadtime Reduction in Thermal Neutron Coincidence Counter," Los Alamos National Laboratory report LA-9936-MS (March 1984).

Two areas for reducing coincidence deadtime havc been investigated, analog and digital. The analog work includes use of a commercially available hybrid preamplifier discriminator useful to at least $150 \mathrm{kpps} / \mathrm{channel}$ with present detectors and added circuitry for combining multiple channels.

The digital work includes reducing $O R$ gate deadtime and the introduction of a derandomizing buffer at the input of the shift-register section. Providing benefits to $1 \mathrm{Mpps}$, the combined efforts of this work have reduced the sixchannel coincidence deaudtime from $\sim 2.4$ to $\sim 0.7 \mu \mathrm{s}$.

19. T. R. Van Lyssel and G. W. Eccleston, "FAST Facility Delayed Neutron Interrogator Assay System Electronics Manual," Los Alamos National Laboratcry report LA-9850-M (March 1984).

The Fluorinel and Storage (FAST) Facility delayed neutron interrogator (DNI) is a dual-assay instrument used to assay spent fuel for a criticality control check before dissolution and also to measure waste solids for material accountability before disposal. A separate shielded cubicle located below the fluorinel fuel dissolution cell houses the DNI. Two tubes penetrate the dissolution cell floor and extend down through the instrument. The smaller tube enables precision assays on waste canisters containing 
small amounts of uranium, and the larger tube enables measurement of fuel packages of various shapes containing large quantities of uranium.

\begin{abstract}
A hard-copy operations terminal located in the crane corridor above the DNI cubicle is used to operate the DNI. This location allows the operator visual access for positioning and moving samples to and from the DNI tubes. The assay system is controlled by complex software programs (initiated through simple commands) that perform diagnostics and system checks and then the sequential operations required to complete measurements properly. This report describes the design of the control system and electronic components composing the DNI.
\end{abstract}

20. J. Blaise, M. Fred, and R. G. Gutmacher, "The Atomic Spectrum of Plutonium," Argonne National Laboratory report ANL-83-95 ('ugust 1984).

This monograph contains 30799 atomic emission lines of plutonium: their wavelengths. energy level classifications, isotope shıfts, and other spectroscopic $d_{-}: 1$. The atomic spectrum of plutonium has bee : $\because \cdots$. lied in a collaboration between three laboratories over the past tw :nty years. The spectra were produced by microwaveexcited electrodeless discharge tubes operating in a resonant cavity. Photographic exposures were made on the Argonne 9-m spectrograph and supplemented by measurements in the infrared region made with the Fourier Transform spectrometer at Laboratoire Aimè-Cotton. In addition to wavelengths, the photographic exposures also provided Zeeman data ( $\mathrm{J}$ - and $\mathrm{g}$ values) and isotope shifts. Zeeman patterns were obtained by placing the electrodeless discharge tubes and resonant cavity in a magnetic field of 24000 gauss produced by a well-regulated NMR magnet. The isotope shifts (240-239) were measured on exposures of separated isotopes or mixtures of separated isotopes. It was possible to classify slightly more than half the lines. Tables of $\mathrm{Pu} \mathrm{I}$ and Pu II energy levels, with their isolope shifts and $\mathrm{J}$ - and g-values, are also given.

21. C. Douglass, "Computer Center Viclations," presented at the Seventh DOE Computer Security Group Conference, New O:leans, LA, Apri! 1984 (published in the proceedings of that meeting).

\section{No abstract available.}

22. D. G. Harder, "What Is Your Center Doing for You," presented at the Seventh DOE Computer
Security Group Conference, New Orleans, LA, April 1984 (published in the proceedings of that meeting).

No abstract available.

23. R. E. Lewis, "Security in the OPMODEL Network," presented at the Seventh DOE Computer Security Conference, New Orleans, LA, April 1984 (published in the proceedings of that meeting).

No abstract available.

24. S. T. Smith and J. J. Lim, "Computer Security Evaluation Tools," presented at the Seventh DOE Computer Security Conference New Orleans, LA, April 1984 (published in the proceedings of that meeting).

No abstract available.

25. S. T. Smith and J. J. Lim, "Assessment of Computer Security Effectiveness for Safe Plant Oferation," presented at 1984 Annual Meeting of the American Nuclear Society in New Orleans, LA, June 3-8, 1984 (published in the proceedings of that meeting).

No abstract a vailable.

26. S. T. Smith and J. J. Lim, "An Automateó Interactive Method fcr Performing Vulnerability Assessments," presented at the Seventh DoD/NBS Computer Security Conference in Gaither,jurg, MD, September 24-26, 1984.

No abstract available.

27. S. T. Smith and J. J. Lim, "Risk Analysis in Computer Systems-An Automated Procedure," in press fo: January issue of Information Age (Vol. 7 , No. 1).

No abstract available.

28. E. Springer, "Current Status of the Link ACE Project," presented at the Seventh DOE Computer Security Conference. New Orleans, LA., April 1984 (published in the proceedings of that meeting).

No abstrac: available.

29. A. L. Baker and M. P. Baker, "Integration of NDA Instruments into the Savannah River Computer Network," invited paper presented at the $1984 \mathrm{Nu}$ clear Science Symposium, Orlando, FL, October 31-November 2, 1984; to be published in the Proceedings of the Institute of Electrical and Electronics Engineers. 
The Safeguards Systems Group at the Los Alamos National Laboratory is collaborating with several other national laboratories in designing an integrated, state-of-the-art nondestructive assay (NDA) system for a new facility being constructed at the Savannah River Plant. We have focused our efforts on the development of an Instrument Control Computer (ICC) that will perform interfacing and communication tasks among small computers controlling NDA instr?ments in the Simple Assay Room and the Feed Assay Room, the host computer for the process control system, and an existing nuclear materials accounting computer. Solutir: sample scheduling, feed-material sample verification, and other ICC functions will be described in detail.

30. A. L. Baker, W. Ford, R. M. Tisinger, W. J. Whitty, and R. C. Bearse, "Gas Centrifuge Enrichment Plant Integrated Data Acquisitiun System 90\% Design Review," Los Alamos National Laboratory, Safeguards Systems report Q-4/84-169 (March 23, 1984).

\section{No abstract available.}

31. A. L. Baker, "Functional Specifications for the NDA System Interface Computer for the New Special Recovery Facilities," Los Alamos National Laboratory, Safeguards Systems Group report Q-4/84-202 (April 1984).

No abstract available.

32. A. L. Baker, "Integration of NDA Instruments into the New Special Recovery Computer Network," presented at the 1984 Nuclear Science Symposium, Orlando, FL, October 31-November 2, 1984.

No abstract available.

33. C. A. Coulter and J. T. Markin, "Design and Evaluation of an Integrated Safeguards System, Vol. II: Example Application of the Principles," Los Alamos National Laboratory report LA-9964, Vol. II (March 1984).

To illustrate the use of the design and evaluation methods that have been described in Vol. I, we apply these methods to a hypothetica! vault building intended to store Category I quantities of specia! nuclear material at a DOE facility. The pro. definition and system analysi. hesis phases of the design process are - to construct two possible designs for the vauit building. The semiquantitative methods presented in Vol. I for evaluating detection and interruption performance of safeguards systems are then applied to these two designs. In addition, sources of additional costs and of possible operational interference due to the safeguards system are identified, and a catalogue of DOE regulations applicable to the vault building is given. From the evalıation process, we conclude that one of our designs is superior to the other but that neither one provides satisfactory interruption performance against certain adversary scenarios. Safeguards system modifications that might be considered in the next iteration of the design prosess are given.

34. H. A. Dayem, A. L. Baker, D. D. Cobb, E. A. Hakkila, and C. A. Ostenak, "Demonstration of Near-Real-Time Accounting: The AGNS 1980-81 Miniruns," Los Alamos National Laboraiory report LA-9942 (January 1984).

Near-real-time nuclear materials accounting was demonstrated in a series of experiments at the Allied-Ḡeneral Nuclear Services (AGNS) Barnwell Nuclear Fuels Dlant. For each experiment, the second and third plutonium cycles were operated continuously for 1 wk processing uranium solutions. Process data were coliected in near-real time by the AGNS computerized nuclear materials control and accounting system and were analyzed for uranium removals using decision analysis techniques developed and implemented by Los Alamos National Laboratory.

Although the measurement sysiem prinarily consisted of process-monitoring measurements that were not optimized for near-Ited-time accounting, the results of uranium-removal tests showed that removals and unexpected losses from the process area can be detected. Los Alamos used process-grade measurements to close hourly materials balances. Loss-detection sensitivities for 1 day of between 4 and $18 \mathrm{~kg}$ of uranium, at $50 \%$ detection probability and $2.5 \%$ false-alarm probability, were calculated for selected accounting areas. Using pulsed-column inventory estimators, we calculated a total fourcolumn inventory that was within $10 \%$ of column dump measurements. Los:-detection sensitivity could be ir tproved by incorporating online waste stream meacurements, improving laboratory measurements for process streams, and refining the pulsed-column inventory estimates. 
35. A. S. Goldman, "Sequential Testing Procedures for Materials Accounting," Los Alamos National Laboratory, Safeguards Systems Group document Q-4/84-120 (February 1984).

No abstract available.

36. A. S. Goldman, "Comparisons of Sequential Tests," Los Alamos National Laboratory, Safeguards Systems Group report Q-4/84-206 (April 1984).

No abstract available.

37. A. S. Goldman and A. M. Liebetrau, "The Analysis of Tank Calibration Data from Several Runs," presented at the 1984 INMM Annual Meeting, Co!umbus, OH, July 15-18, 1984.

The experimentally determined relationship between the level of liquid and volume of liquid in a tank can be used to obtain volume estimates that correspond to liquid-level measurements. Several calibration experiments (runs) are made to estimate the calibration equation. The calibration equation is usec to estimate the quantity of liquid transferred from a tank between measurement periods.

Difficulties can arise when iun-to-run differences are large relative to the precisions of liquid-level and volume measurements. This paper addresses the seldom-discussed but important problem of combining and analyzing data from two or more calibration runs. Emphasis is placed on exploratory methods such as diagnostic plots that are compatible with applicable statistical models.

38. A. S. Goldman, "An Assessment of the Measurement Control Program for Soiution Asca" Instruments at the Los Alamos National Labor $t$ tory Plutonium Facility," Los Alamos National Laboratory, Safeguards Systems Group document Q-4/84-343 (July 1984).

\section{No abstract available.}

39. A. S. Goldman, "Sequential Test Procedures for Detectitig Protracted Materials Losses," Los Alamos National Laboratory, Safeguards Systems Group report Q-4/84-394 (August 1984) (to be pubiished as Los Alamos National Laboratory report LA-10319-MS).

Sequential tests are required for detectiing protracted (trickle) l' clear materials from a single materials control unit (MCU) . We compared applicable tests including modified versions of Page's test and power-one procedures. We used simulated data from an MCU in a conversion/fabrication process that took into account process variations, materials holdup, and measurement uncertainties. Comparisons were made over a 60-day accounting period under different loss scenarios. Some important findings include:

(1) No single test procedure is best for all diversion scenarios.

(2) Power-one procedures are best for protracted losses that occur early in the accounting petiod and Page's test is best for late loss occurrence.

(3) If holdup and process variations are not included in the Inventory Difference model but are present in the process, then assuming steady-state conditions, false-alsi:-. probabilities can double.

40. A. S. Goldman and H. D. Lewis, "Particle Size Analysis: Theory and Statistical Methods," in Handbook of Powder Science and Technology, M. E. Fayed and L. Otten, Eds. (Van Nostrand Reinhold Company, Inc., 1984), Chap. I, pp. 1-30.

No abstract available.

41. J. T. Markin, C. A. Coulter, R. G. Gutmacher, C. C. Thomas, Jr., and W. J. Whitty, "Design and Evaluation of an Integrated Safeguards System, Vol. I: Principles," Los Alamos National Laboratory report LA-9964, Vol. I (March 1984).

Ar integrated safeguards system is dcíined as a collection of safeguards activities in which system components are ccordinated to meet safeguards objectives efficiently within constraints imposed by safeguards resources, facility operations, potential adversaries, and regulatory requirements. This report describes principles for designing and evaluating an integrated safeguards system that consists of four parts: (1) a problem definition phase that specifies resources and constraints composing the problem boundary values, (2) a system analysis/synthesis phase that describes how to select and integrate safeguards activities for efficient attainment of system objectives, (3) a system evaluation/optimization phase that defines measures of safeguards performance and develops methods for evaluating them, and (4) a decisionmaking phase that develops principles for selecting admissible designs and preference-ordering designs. 
42. J. T. Markin, "Optimal Allocation of Inspection Resources," presented at the Sixth Annual ESARDA Symposium on Safeguards and Material Management, Venice, Italy, May 14-18, 1984 (to be published in proceedings).

Allocation of inspection resources for international safeguards is considered as the problem of designing a complex system that is composed of individual inspection activities and that has the objective of detecting material loss. Optimization theory is applied in selecting those inspection activities that maximize a system performance measure within resource constraints. The method is applicable to a global allocation problem in which inspection resources are distributed throughout a hierarchy consisting of multiple countries, multiple facilities within each country, and multiple activities within each facility.

43. J. T. Markin, C. A. Coulter, R. G. Gutmacher, and W. J. Whitty, "Design and Evaluation of an Integrated Safeguards System: Principles," presented at the 25th Annual INMM Meeting, Columbus, $\mathrm{OH}$, July $15-18,1984$.

An integrated safeguards system is defined as a collection of safeguards activities in which system components are coordinated to meet safeguards objectives efficiently within constraints imposed by safeguards resources, facility operations, potential adversaries, and regulatory requirements. This paper describes principles for designing and evaluating an integrated safeguards system that consists of four parts: (1) a problem definition phase that specifies resources and constraints composing the problem boundary values, (2) a system analysis/synthesis phase that describes how to select and integrate safeguards activities for efficient attainment of system objectives, (3) a system evaluation/optimization phase that defines measures of safeguards performance and develops methods for evaluating them, and (4) a decisionmaking phase that develops principles for selecting admissible designs and preference-ordering designs.

44. P. E. Fehlau, K. L. Coop, and J. T. Markin, “Application of Wald's Sequential Probability Ratio Test to Nuclear Materials Control," presented at the FSARDA-INMM Joint Meeting on Error Propagation in NDA Measurements for Safeguards, Ispra, Italy, September 12-14, 1984.

We have replaced traditional analysis methods for nuclear material control monitoring with hypothesis testing, specifically with Wald's sequential-probability-ratio test. Our evaluation of Wald's method, applied in both vehicle and pedestrian SNM monitors, is by Monte Carlo calculation to determine the alarm probability and average monitoring times of the monitors. The vehicle monitor with Wald's test has a much shorter monitoring delay than with traditional methods, without serious compensating changes in operating characteristics. The pedestrian monitor with Wald's method also has advantages over traditional single-interval tests, in that the Wald method duplicates the advantages of a moving-average technique. We verified the Monte Carlo calculations for the pedestrian monitor by means of a special program for the monitor's microprocessor controller. The observations of false-alarm probability and average monitoring time for over 500000 tests verified the Monte Carlo results.

45. R. R. Picard, R. G. Gutmacher, and D. Stirpe, "Study of Waste Streams at the Portsmouth Gaseous Diffusion Plant," Los Alamos National Laboratory, Safeguards Systems Group report Q-4/84-219 (April 1984).

Normal quantities of uranium in waste streains at the Portsmouth Gaseous Diffusion Plant are small relative to plant throughput, but significant relative to inventory differences. This report presents results of a study of the waste streams: solutions from decontamination of equipment, vent gas releases, chemical trap materials, contaminated oils, and combustible waste. Present and past sampling and analysis practices were examined and evaluated.

We conclude that errors in flow measurements of the waste solutions and vent gas releases contribute the most to the overall uncertainty and that sampling errors are imporiant for all waste streams. The report contains specific recommendations for new flow instrumentation and improved sampling practices. Suggestions are also made for instrumentation that can provide continuous measurements of uranium concentration in vent gas streams.

46. R. R. Picard and K.K.S. Pillay, "Modeling Residual Holdup of Special Nuclear Materials," submitted for presentation at the ANS/ENS 1984 International Conference, Washington, DC, November 11-16, 1984.

The term "holdup" refers to material remaining in process equipment following shutdown, draindown, and cleanout. Holdup impacts 
materials accountability and, sometimes, criticality safety. This material may be difficult to locate and/or quantify. The objectives of our work, sponsored by the Research Branch of the Nuclear Regulatory Commission, were to

(1) examine the nature of holdup in a variety of process equipment,

(2) develop procedures to measure holdup, and

(3) evaluate the potential usefulness of statistical models for holdup estimation.

When compared to throughput, the quantity of holdup in a facility is small. In comparison to inventory differences, however, the quantity can be significant. Because holdup is not usually credited to the materials accounting system, changes in its amount over time become (apparert) gains or losses when inventory differences are computed. Although the estimation of holdup has not been a high priority in the past, recent emphasis on improved accountability motivates research in this area.

47. K.K.S. Pillay, "Estimation Methods for Special Nuclear Materials Holdup," presented at the 1984 INMM Annual Meeting, Columbus, $\mathrm{OH}$, July 15-18, 1984.

The potential value of statistical models for the estimation of residual inventories of special nuclear materials was examined using holdup data from processing facilities and through controlled experiments. Although the measurement of hidden inventories of special nuclear materials in large facilities is a challenging task, reliable estimates of these inventories can be developed through a combination of good measurements and the use of statistical models.

48. K.K.S. Pillay, R. R. Picard, and R. S. Marshall, "Estimation Methods for Process Holdup of Special Nuclear Materials," Los Alamos National Laboratory report LA-10038 (June 1984).

The US Nuclear Regulatory Commission sponsored a research ste.jy at the Los Alamos National Laboratory to explore the possibilities of developing statistical estimation methods for materials holdup at highly enriched uranium (HEU) processing facilities. Attempts at using historical holdup data from processing facilities and selected holdup measurements at two operating facilities confirmed the need for high quality data and reasonable control over process parameters in developing statistical models for holdup estimations. A major effort was therefore directed at conducting large-scale experiments to demonstrate th $e$ value of statistical estimaiion models from experimentally measured data oi good quality. Using data from these experiments, we developed statistical models to estimate residual inventories of uranium in large process equipment and facilities. Some of the important firdings of this investigation are the following:

- Prediction models for the residual holdup of special nuclear material (SNM) can be developed from good-quality historical data on holdup.

- Holdup data from some of the equipment used at HEU-processing facilities, such as air filters, ductwork, calciners, dissolvers, pumps, pipes, and pipe fittings, readily lend themselves to statistical modeling of holdup.

- Holdup profiles of process equipment such as glove boxes, precipitators, and rotary drum filters can change with time; therefore, good estimation of residual inventories in these types of equipment requires several measurements at the time of inventory.

- Although measurement of residual holdup of SNM in large facilities is a challenging task, reasonable estimates of the hidden inventories of holdup to meet the regulatory requirements can be accomplished through a combination of good measurements and the use of statistical models.

49. K.K.S. Pillay, "Radiation Effects on Ion Exchangers Used in Waste Management," presented at the Health Physics Society Annual Meeting, New Orleans, LA, June 3-8, 1984.

Radiation effects on ion exchangers used in waste management of aqueous wastes are important parameters in the processing, packaging, storage, and long-term isolation of radioactive wastes from human erivironment. Radiation induced changes in ion exchangers include (1) a decrease in exchange capacity leading to desorption, (2) extreme changes in $\mathrm{pH}$ of the wastc medium causing degradation and corrosion of containers, (3) gas generation combined with thermal effects causing pressure buildup with potentials for explosion, and (4) radiolytic decomposition of waste matrix leading to major changes in the physical and chemical characteristics of the waste form. An extensive literature survey started in 1976 and updated noriudically reveals that during the past 15 years there has been an increase in the number of 
reported process-related accidents associated with ion exchange materials, and some of them are directly aitributable to radiation induced changes. It is also apparent from this survey that systematic investigations to identify and resolve these problems are limited. There is, however, widely scattered information in the literature that is useful in designing and operating ionexchange-based waste management systems with reasonable assurance of safety.

This paper will update a review of ihe world literature on this topic and present some recent experimental studies on radiolytic changes and corrosion effects that are relevant to radioactive waste management.

50. I. Razvi, K.K.S. Pillay, R. R. Picard, and R. S. Marshall, "Uranium Holdup Measurements for the Development of Predictive Models," presented at the ANS/ENS 1984 International Conference, Washington, DC, November $11-16,1984$.

No abstract available.

5l. S. T. Smith and J. J. Lim, "An Automated Procedure for Performing Computer Security Risk Analysis," presented at the Sixth Annual ESARDA Symposium on Safeguards and Nuclear Material Management, Venice, Italy, May 14-18, 1984.

Computers, the invisible backbone of nuclear safeguards, monitor and control plant operations and support many materials accounting systems. Our automated procedure to assess computer security effectiveness differs from traditional risk analysis methods. The system is modeled as an interactive questionnaire, fully automated on a portable microcomputer. A set of modular event trees links the questionnaire to the risk assessment. Qualitative scores are obtained for target vulnerability, and qualitative impact measures are evaluated for a spectrum of threat-target pairs. These are then combined by a linguistic algebra to provide an accurate and meaningful risk measure.

52. S. T. Smith and J. J. Lim, "An Automated Method for Analyzing Computer Security Risk," presented at the 7th DOE Computer Security Conference, New Orleans, LA, April 17-19, 1984.

No abstract available.

53. S. T. Smith and J. J. Lim, " An Automated Method for Assessing the Effectiveness of Computer Security Safeguards," presented at the International Federation of Information Processing Societies Sec- ond International Congress on Computer Security, Toronto, Canada, September 10-12, 1984.

A qualitative method for performing computer security risk assessment is being developeci at Los Alamos. The methodology evaluates the inherent vulnerabilities and risks in a system of computer security safeguards. The method considers safeguards protecting four generic targets (computer physical plant, hardware, software, and documents) against three generic threats (natural hazards, direct human actions requiring the presence of the adversary, and indirect human actions wherein the adversary is not on the premises-perhaps using such access tools as wiretaps, dialup lines, and so forth). Our automated procedure to assess the effectiveness of computer security safeguards differs from traditional risk analysis methods. The safeguards system is modeled as an inieractive conversational questionnaire that elicits information about the presence and quality of system safeguards; it is fully automater in natural language on a portable microcomputir. A set oi modular event trees links the questionnaire to the risk assessment. An assessment is made of the safeguards vulnerabilities using a linguistic scoring method having a range of values from very low to very high. Specific pieces of equipment, software, and documents can be specified by the user for a more detailed assessment, and qualitative (linguistic) worths are placed upon these items. Qualitative impact measures are determined for the spectrum of outcome scenarios. The vulnerability worths, outcomes, and impacts are then combined using a probabilistic linguistic algebra based in part on fuzzy set theory to arrive at a hierarchical assessment of risk.

54. L. S. Blair and R. G. Gutmacher, "Optical Spectroscopic Techniques for Vent Gas Analysis," in "Proc. of Gaseous Effluent Analytical Instrumentation Information Meeting," Lexington, KY, June 19, 1984, Goodyear Atomic Corporation report GAT-T-3287 (Septembrr 1984).

Laser-induced breakdown spectroscopy (LIBS) and inductively coupled plasma (ICP) spectrometry are two optical spectroscopic techniques that may be suitable for on-line, realtime, noninvasive monitoring of uranium in vent gas streams. Characteristics of the two techniques, their applications at Los Alamos, and preliminary results on uranium are presented. Sensitivities of a few ppm and a wide dynamic range are possible with either technique. Design criteria and steps to be taken in the development of prototype instrumentation are discussed. 


\section{REFERENCES}

1. G. W. Eccleston, S. S. Johnson, H. O. Menlove, T. Van Lyssel, D. Black, B. Carlson, L. Decker, and M. W. Echo, "FAST Facility Spent-Fuel and Waste Assay Instrument," in Proc. ANS/INMM Conf. Safeguards Technol.: Process Safeguards Interface, Hilton Head Island, South Carolina, November 28-December 2, 1983 (US DOE/New Brunswick Laboratory, August 1984), CONF-831106, pp. 253-264.

2. J. R. Phillips, J. K. Halbig, P. M. Rinard, and G. E. Bosler, "NDA Mear:arement of the Demineralizers at TMI-2," Los Alai.،os National Laboratory report LA-9795-MS (August 1983).

3. J. K. Halbig, G. E. Bosler, J. R. Phillips, and P. M. Rinard, "A System for Measuring TRU Materials in a Three-Mile Island Demineralizer," presented at 1984 American Nuclear Society Annual Meeting, New Orleans, Louisiana, June 3-8, 1984; Los Alamos National Laboratory document LAUR-84-1757.

4. P. E. Fehlau, C. E. Moss, D. C. Amsden, J. Martinez, and K. P. Dutcher, "SNM Vehicle Portal Mcnitor," in "Safeguards and Security Progress Report, January_December 1983," D. B. Smith, Comp., Los Alamos National Laboratory report LA-10170-PR (September 1984).

5. P. E. Fehlau, "Hand-Heid Search Monitor for Special Nuclear Materials, User's Manual," Los Alamos iNational Laboratory broc '-ure LALP-84-15 (1984).

6. P. A. Russo, R. B. Strittmatter, E. L. Sandford, M. M. Stephens, J. K. Sprinkle, and R. W. Slice, “Oak Ridge/Y-12 Plant-Automated NDA Instruments for In-Line High-Enriched Uranium (HEU) Accounting," in "Safeguards and Security Progress F.eport, January-December 1983," Los Alamos National Laboratory report LA-10170-PR (September 1984), pp. 8-12.

7. P. A. Russo, R. B. Strittmatter, E. L. Sandford, I. W. Jeter, E. McCullough, and G. L. Bowers, "Operation of Automated NDA Instruments for In-Line HEU Accounting at Y-12," in Proc. ANS/INMM Conf. Safeguards Technol.: Process Safeguards Interface, Hilton Head Island, South Carolina, November 28-December 2, 1983 (US DOE/New Brunswick Laboratory, August 1984), CONF-831106, pp. 112-134.
8. P. A. Russo and R. B. Strittmatter, "On-Line Prototype NDA Instruments for Material Accounting and Monitoring of HEU Recovery Processes," Trans. Am. Nucl. Soc. 43, 274 (1982).

9. T. L. Brumfield, S. E. Smith, E. E. McCullough, and P. A. Russo, "On-Line Operation of NDA Instrumentation on a Solvent Extraction System," Martin Marietta Energy Systems, Inc., Oak Ridge Y-12 Plant report Y/DG-16602 (May 1984).

10. P. A. Russo, R. B. Strittmatter, E. L. Sandford, M. M. Stephens, T. L. Brumfield, S. E. Smith, E. E. McCullough, et al. "Automated Insiniments for InLine Accounting of Highly Enriched Lranium at the Oak Ridge Y-12 Plant," Los Alamos National Laboratory report LA-10243-MS (February 1985).

11. P. A. Russo, J. K. Sprinkle, Jr., R. W. Slice, and R. B. Strittmatter, "Uranium Concentration Monitor Manual (Secondary Intermediate Evaporator)," Los Alamos National Laboratory report LA-10510M (August 1985).

12. P. A. Russo, J. K. Sprinkle, Jr., and M. M. Stephens, "Uranium Concentration Monitor Manual (2300 System)," Los Alamos National Labu ratory report LA-10350-M (June 1985).

13. D. T. Bostick, J. F. Strain, D. D. McCue, R. E. Harper, and M. I Bauer, "In-Line Instrumentation for Control of $\mathrm{N}$, iear Fuel Reprocessing-In: InLine Heavy Metal and Oxidan:-Reductant Monitors," Trans. Am. Nucl. Soc. 43, 276 (1982).

14. G. Pfenningwerth, Martin Marieita Energy Systems, Oak Ridge Y-12 Plant document, 84G-1212-126, 1984.

15. C. A. Ostenak and A. F. Cermak, "Comparison of Predicted and Measured Pulsed Column Profiles and Inventories," in Proc. ANS/INMM Conf. Safeguards Technol.: Process Safeguards Interface, Hilton Head Island, South Carolina, November 28-December 2, 1983 (US DOE/New Brunswick Laboratory, August 19\%.1), CONF-831106, pp. 2氵6-247.

16. R. R. Picard, R. G. Gutmacher, and D. Stirpe, "Study of Waste Streams at the Portsmouth Gaseous Diffusicn Plant," Los Alamos National Laboratory, Safeguards Systems Group Q-4 document Q-4/84-219 (April 1984). 
17. M. L. Hanson, Comp., "Proceedings of Gaseous Effluent Analytical Instrumentation Information Meeting, June 19, 1984," Goodyear Atomic Corporation report GAT-T-3287 (September 1984).

18. H. O. Menlove, "rescription and Operation Manual for tive Acuive Weil Coincidence Counter," Los Alamos National Laboiatory report LA-7823-M (May 1979).

19. J. E. Stewart and H. O. Men!ove, "Direct Fissile Assay of Highly Enriched UF 6 Using Random SelfInterrogation and Neutron Coincidence Response," in Proc. ANS/INMM Conf. Safeguards Technol.: Process Safeguards Interface, Hilton Head Island. South Carolina, November 28-December 2, 1983 (US DOE/New Srunswick Laboratory, August 1984), CONF-831106, pp. 222-235

20. W. E. Kunz, J. D. Atencio, W. Bernard, G. C. Herrera, J. C. Pratt, and J. T. Caldwell, "A 1-mg Sensitivity Fissile Assay System," in Proc. Third Annu. ESARDA Symp. Safeglurds Nucl. Maler. Manage., Karlsruhe, F.R. Germany, May 6-8, 1981 (ESARDA, 1981), p. 119.

21. J. T. Caldwell, M. R. Cates, D. A. Close, T. W. Crane, W. E. Kunz, E. R. Shunk, C. J. Umbarger. and L. A. Franks, "Recent Developments ai Los Alamos for Measuring Alpha-Contaminated Waste," in Int. Symp. Manage. Alpha-Contaminated Waste, Vienna, Austria (Iritemational Atomic Energy Agency, Vienna, Austria, 1980), IAEA-SM-246/67.

22. E. R. Shunk, J. T. Caldwell, S. W. France, and G. C. Herrera, "A High Efficiency, Modular System inr the Assay of Plutonium in Large Waste Pachages," presented at the IEEE Nucl. Sci. Symp., San Francisco, California, October 21-23, 1981; Los Alamos National I :boratory document LA-UR-8 1-3078.

23. J. T. Caldwell, "Passive and Ac: ve Assay Measurements on Crate Size Waste Packages," Trans. Am. Nucl. Soc. 39, 339 (1981).

24 W. E. Kunz, J. D. Atencin W. Bernard, G. C. Horrera, H. H. Hsu, J. C. Pi łtt, and J. T. Caldwell, "Multi-Isotopic Waste Assay System," in Proc. Am. Nucl. Soc. Topical Meet. Treatment Handling Radioactive Wastes, Richland, Washington (Battelle-Columbus Press, Columbus, Ohio. 1982), p. 297.

25. J. T. Caldwell, W. E. Kunz, J. D. Atencio, G. C. Herrera, and I. C. Pratt, "Experimental Evaluation of the Differential Die-Away Pulsed Neutron Technique for the Fissile Assay of Hot Irradiated Fuel Waste," in Proc. Am. Nucl. Soc. Topical Meet. Treatment Handling Radioactive Wastes, Richland, Washington (Battelle-Columbus Press, Columbus, Ohio, 1982), pp. 302-305.

26. "LANL/RFP Crated Waste Assay System Report," Los Alamos National Laboratory, Group Q-2 technical note LA-Q2TN-84-410 (September 1984).

27. "US Enrichment Safeguards Program Development Activities with Potential International AEC Safcguards Applications," Martin Marietta Energy Systems (technical contribution, Los Alamos Nationa: Labcratory, Group Q-2), K/OA-5700/P-1 (July 1984).

28 T. D. Reilly, R. E. Walion, and J. L. Parker, "The 'Enrichment Meter'-A Simple Method for Mer. aring Isotopic Enrichmeut," in "Nuclear Safeguards Research and Developrnent-Program Status Report, September-December 1970," Los Alamos Scientific Laboratory report LA-4605-MS (1970).

29. J. G. Fleissner, "GRPAUT: A Program for $\mathrm{Pl}^{\prime}$ Isotopic Analysis (A User's Guide)," Monsanto Research Corporation report MLM-2799 (January 1981).

30. T. W. Crane, "Richland/Hanford PLREX: Screw Calciner Holdup Monitor," in "Safeguards and Security Progress Report, January-December 1983," D. B. Smith, Comp., Los Alamos Naticnal Laboratory report LA-10170-PR (Septenber 1984), pp. 16-17.

31. T. W. Crane, P. R. Collinsworth, and L. C. Osborn, "Hanford PUREX," in "Safcguards and Security Progress Keport, August 1982-January 1983," D. B. Smith, Comp., Los Alamos National Laboratory report LA-9821-PR (November 1983), pp. 18-19.

32. W. F. Nicaise and R. W. Dierr, "Calibration of al. NDA Neutron Monitor for Determinir.g Process Holdup," Nucl. Mater. Manage. XIII (Prcc. Issue), 42-47 (1984).

33. M. Baker, T. Sampson, A. Baker, S. -T. Hsue, S. Johnson, and L. Speir, "A Conceptual Design for an Integrated Nondestructive Assay System at the SRP New Special Recovery Facility," Los Alamos National Laboratory, Group Q-1 document Q-1/83-3?8 (April 1983). 
34. Alice Baker, "Functional Specifications for the NDA System Interface Computer for the New Special Recovery Facilities," Los Alamos National Laboratury, Group Q-4 document Q-4/84-202 (April 1984).

35. J. L. Parker, “Are 0.1\%-Accurate Gamma-Ray Assays Possible for ${ }^{235} \mathrm{U}$ Solutions?" in Proc. ANS/INMM Conf. Safeguards Technol.: Process Safeguards Interface, Hilton Head Island, South Carolina, November 28-December 2, 1983 (US DOE/New Brunswick Laooratory, August 1984), CONF-831106, pp. 142-154.

36. N. Ensslin. L. R. Cowder, G. E. Bosler, T. W. Crane, T. K. Li, and J. L. Parker, "Savannah River/Naval Fuel Materials Facility (FMF)," in "Safeguards and Security Progress Report, January-December 1983," D. B. Smith, Comp., Los Alamos National Laboratory report LA-10170-PR (September 1984), pp. 17-18.

37. J. K. Sprinkle and J. L. Parker, "Self-Exaggerating X-Ray Technique," in "Safeguards and Security Status Report, February-July 1982," Los Alamos National Laboratory report LA-9595-RR (February 1983), pp. 37-39.

38. T. E. Sampson, S. -T. Hsue, E. L. Sandford, S. S. Johnson, D. L. Cramer, and K. Kroncke, "Plutoliium Isotopic System for SRP," in "Program Status Report, Safeguards and Security Research and Development," Los Alamos National Laboratory report LA-9110-PR (April 1982), pp. 29-30.

39. C. S. Gunn, "Performance of an Active Well Coincidence Counter at the Y-12 Uranium Recovery Facility," Martin Marietta Energy Systems, Inc., Oak Ridge Y-12 Plant report Y/DG-16971 (August 1984).

40. T. R. Canada, D. G. Langner, and J. W. Tape, "Nuclear Safeguards Applications of Energy-Dispersive Absorption Edge Densitometry," ACS Symposium Series No. 79. Nuclear Safeguards Analysis (ACS, New York, 1979), pp. 96-123.

41. P. A. Russo, S. -T. Hsue, D. G. Langner, and J. K. Sprinkle, "Nuclear Safeguards Applications of Energy Dispersive Absorption Edge Densitometry," J. Instrum. Nucl. Mater. Manage. IX (Proc. Issue), 730 (1980).

42. P. A. Russo, T. R. Canada, D. G. Langner, J. W. Tape, S. -T. Hs; ^, L. R. Cowder, W. C. Mosley, L.
W. Reynolds, and M. C. Thompson, "An X-ray L LIIEdge Densitometer for Assay of Mixed SNM Solutions," in Proc. First Annu. ESARDA Symp. Safeguards Nucl. Mater. Manage., Brussels, Belgium, 1979 (ESARDA, 1979), pp. 235-240.

43. W. J. McGonnagle, M. K. Holland, C. S. Reynolds, N. M. Trahey, and A. C. Zook, "Evaluation and Calibration of a Los Alamos National Laboratory L III Edge Densitometer," US DOE/New Brunswick Laboratory report NBL-307 (July 1983).

44. P. A. Russo, T. Marks, Jr., M. M. Stephens, A. L. Baker, and D. D. Cobb, "Automated On-Line LEdge Measurement of SNM Concentration for Near-Real-Time Accounting," Los Alamos National Laboratory report LA-9480-MS (September 1982).

45. P. A. Russo and S. -T. Hsue, "The Effects of Fission Products on Demonstrated X-Ray and GammaRay NDA Techniques Applied to Nuclear Materials Accounting in Reprocessing," Los Alamos National Laboratory report LA-9254-MS (February 1982).

46. M. L. Brooks, P. A. Russo, and J. K. Sprinkle, Jr., "A Compact L-Edge Densitometer for Uranium Concentration Assay," Los Alamos National Laboratory report LA-10306-MS (1985).

47. S. -T. Hsue, T. Marks and S. F. Marsh, "Hybrid Assay System," in "Safeguards and Security Progress Report, January-December 1983," D. B. Smith, Comp., Los Alames National Laboratory report LA-101 70-PR (September 1984), p. 36.

48. S. - T. Hsue, S. F. Marsh and T. Marks, "Hybrid Chemical and Nondestructive Analysis Technique," in Proc. Fifth Annu. ESARDA Symp. Safeguards Nucl. Mater. Manage., Versailles, France, April 19-21, 1983 (ESARDA, 1983), ESARDA 16, pp. 209-212.

49. H. A. Smith, Jr., T. Marks, S. S. Johnson, L. R. Cowder, J. K. Sprinkle, Jr., C. O. Siınnrock, R. W. Slice, D. L. Garcia, K. W. MacMurdo, R. L. Pollard, L. B. Baker, P. Christie, and J. P. Clark, "Test and Evaluation of the In-Line Plutonium Solution KAbsorption-Edge Densitometer at the Savannah River Plant: Phase 1, Off-Line Testing Results," Los Alamos National Laboratory repurt LA-9124MS (April 1982). 
50. H. A. Smith, "K-Edge Plutonium Solution Densitometer," in "Safeguards and Security Progress Report, January-December 1983," Los Alamos National Laboratory report LA-10170-PR (September 1984), p. 32.

51. T. K. Li, "Determination of Plutonium Isotopic Ratios by Using Low-Energy Gamma-Ray Spectroscopy," TANSAO 45 (Suppl. 1) pp. 17-20 (1983); in Proc. ANS/INMM Conf. Safeguards Technol.: Process Safeguards Interface, Hilton Head Island, South Carolina, November 28-December 2, 1983 (US DOE/New Brunswick Laboratory, August 1984), CONF-831106.

52. J. E. Swansen, P. R. Collinsworth, and M. S. Krick, "Shift-Register Coincidence Electronics System for Thermal Neutron Counters," Los Alamos Scientific Laboratory report LA-8319-MS (April 1980); and Nucl. Instrum. Methods 176, 555 (1980).

53. K. Böhnel, "Die Plutoniumbestimmung in Kerbrennstoffen mit der Neutronen Koinzidenzmethode," Kernforschungszentrum, Karlsruhe report KfK 2203 (1975); AWRE translation No. $70(54 / 4252)$ (1978).

54. M. S. Krick and H. O. Menlove, "The High-Level Neutron Coincidence Counter (HLNCC): Users' Manual," Los Alamos Scientific Laboratory report LA-7779-M (June 1979).

55. Donald R. Rogers, "Handbook of Nuclear Safeguards Measurement Methods," US Nuclear Regulatory Commission, Washington, DC, NUREG/CR-2078 MLM-2855 (September 1983).

56. J. Swansen and P. Collinsworth, "High-Level Neutron Coincidence Counter Maintenance Manual," Los Alamos National Laboratory report LA-9662M (May 1983).

57. J. E. Swansen, "Deadtim: Reduction in Thermal Neutron Coincidence Counter," Los Alamos National Laboratory report LA-9936-MS (March 1984).

58. P. E. Fehlau, K. L. Coop, C. Garcia, Jr., and J. Martinez, "The Pajarito SNM Monitor: A HighSensitivity Monitoring System for Highly Enriched Uranium," in Proc. 25th Annu. Meeting INMM, Columbus, Ohio, July 15-18, 1984 (Nucl. Mater. Manage. XIII, Proc. Issue), p. 66.

59. P. E. Fehlau, K. L. Coop, and J. T. Markin, “Applications of Wald's Sequential Probability Ratio
Test to Nuclear Materials Control," Specialists Meeting (ESARDA), Ispra, Italy, September 10-12, 1984 (to be published).

60. P. E. Fehlau, "Calibrating the National Nuclear Corporation Personnel SNM Monitor, Model DM-2," Los Alamos National Laboratory, Group Q-2 technical note LA-Q2TN-84-404 (September 1984).

61. K. L. Coop, "Monte Carlo Simulation of the Sequential Probability Ratio Test for Radiation Monitoring," IEEE Trans. Nucl. Sci., 1984 Nucl. Sci. Symp., Orlando, Florida, October 31-November 2,1984 (to be published).

62. R. M. Hollen and D. D. Jackson, "Automáted Controlled-Potential-Coulometer for Plutonium Determination," Los Alamos National Laboratory report LA-8653 (May 1981).

63. N. M. Saponara and D. D. Jackson, "ControlledPotential-Coulometric Determination of Uranium at a Platinum Electrode," in Proc. 26th Conf. Anal. Chem. Energy Technol., Knoxville, Tennessee, October 11-13, 1983 (Elsevier, New York, 1984), Analytical Chemistry Symposia Series, Vol. 19, pp. 345-348.

64. Jonathan B. Sanborn, "Attributes Mode Sampling Schemes for International Material Accountancy and Verification," INMM XI, 4, 34-41 (1982).

65. John L. Jaech, "Sample Size Determination for the Variables Tester in the Attributes Mode," INMM XII, 2, 20-32 (1983).

66. D. B. Smith, Comp., "Safeguards and Security Status Report, January—December 1983," Los Alamos National Laboratory report LA-9821-PR, Part 4, Sec. A (September 198.1).

67. D. W. Swindle, Jr., "US Enrichment Safeguards Program Development Activites with Potential International Atomic Energy Agency Safeguards Applications, Part l. Executive Summaries," Martin Marietta Energy Systems, Inc., report K/OA-5700/Pl (July 1984).

68. J. N. Cocley, L. W. Fields, M. R. Hughes, T. A. Nolan, D. W. Swindle, D. A. Close, J. C. Pratt, and R. B. Strittmatter, "Results from the Study of $U_{6}$ Consumption on Centrifuge Process Piping and Its Influence on Gamma Ray Measurements," in Proc. Sixth Annu. ESARDA Symp. Safeguards Nucl. 
Mater. Manage., Venice, Italy, May 14-18, 1984 (ESARDA, 1984), ESARDA 17, pp. 393-3!6.

69. J. K. Aaldijk, R.J.S. Harry, J. L. Wieman, J. T. Markin, J. E. Stewart, "Neutron Area Mon itoring in the Cascade Hall of a Centrifuge Errichment Plant," in Proc. Sixth Annu. ESARDA Symp. Safeguards Nucl. Mater. Manage, Venice, Italy, May 14-18, 1984 (ESARL ।, 1984), ESARDA 17, pp. 103-109.

70. R. B. Strittmatter, R. R. Picard, J. K. Sprinkle, Jr., and J. R. Tarrant, "Data Evaluaticn of a Gas-Phase UF, Enrichment Monitor," in Proc. ESARDA/INMM Joint Specialist Meet. Error Propagation NDA Meas. Safeguards, Ispra, Italy, September 12-14, 1984 (ESARDA, 1984), ESARDA 18; Los Alamos National Laboratory document LAUR-84-2831.

71. D. A. Close, J. C. Pratt, J. J. Malanify, and H. F. Atwater, "X-Ray Fluorescent Determination of Uraniurn in the Gaseous Phase," Nucl. Instrum. Methods Phys. Res. A234, 556(1985).

72. W. D. Lauppe, B. Richter, and G. Stein, "NDA Measurements in the Cascade Area of a Gas Centrifuge Enrichment Plant," in Proc. Sizak Annu. ESARDA Symp. Safeguards Nucl. Mater. Manage., Venice, Italy, May 14-18, 1984 (ESARDA, 1984), ESARDA 17, pp. 387-392.

73. I. W. Packer, R. Howsley, and E. W. Lees, "Measurement of Enrichment of Uranium in the Pipework of a Gas Centrifuge Plant," in Proc. Sixth Annu. ESARDA Symp. Safeguards Nucl. Mater. Manage., Venice, Italy, May 14-18, 1984 (ESARDA, 1984), ESARDA 17, pp. 243-248.

74. R.J.S. Harray, J. K. Aaldijk, and J. P. Braak, "Some Measurements for Centrifuge Enrichment Plant Safeguards," in Proc. Third Annu. ESARDA Symp. Sajeguards Nucl. Mater. Manage., Karlsruhe, F.R. Germany, May 6-8, 1981 (ESARDA, 1981).

75. D. M. Gordon and J. B. Sanborn, "IAEA Verification of the Nuclear Material Balance at the Portsmouth Gaseous Centrifuge Enrichment Plant (GCEP)," Brookhaven National Laboratory report BNL30118 (September 1981).

76. D. M. Gordon et al., "An Approach to IAEA Material-Balance Verification at the Portsmouth Gaseous Centrifuge Enrichment Plant," in Proc.
Fifth Annu. ESARDA Symp. Safeguards Nucl. Mater. Manage., Ve sailles, France, April 19-21, 1983 (ESARDA, 1983), ESARDA 16, p. 39.

77. P. DeBievre et al., "1983 Target Values for Uncertainty Components in Fissile Element and Isotope Assay," in Proc. Sixth Annu. ESARDA Symp. Safeguards Nucl. Mater. Manage., Venice, Italy, May 14-18, :984 (ESARDA, 1984), ESARDA 17, Table 3.

78. J. E. Stewart, S. C. Bourret, R. W. Slice, J. T. Markin, and C. A. Spirio, "An Area Neutron-Monitoring Strategy for International Inspections at Centrifuge Enrichment Plants," in "Safeguards and Security Status Report, February-July 1982," J. P. Shipley and D. B. Smith, Comps., Los Alamos National Laboratory report LA-9595-PR (February 1983), pp. 53-56.

79. Los Alamos Monte Carlo Group, "MCNP-A General Monte Carlo Code for Neutron and Photon Transport, Version 2B," Los Alamos Scientifíc Laboratory report LA-7396-M, Rev. (November 1979). Additional revisions are available from Los Alamos Group X-6.

80. H. O. Menlove, O. R. Holbronks, and A. Ramalho, "Inventory Sample Coincidence Counter Manual," Los Alamos National Laboratory report LA-9544 M (ISPO-1 81) (November 1982).

81. A. Prosdocimi and P. Dell'Oro, “A Photoneutron Active Interrogation Device: Physical Design, Calibration and Operational Experience," in Proc. Annu. ESARDA Symp. (Brussels, 1979), p. 297.

82. L. R. Cowder, S. F. Klosterbuer, R. H. Augustson, A. Emailpour, R. Hawkins, and E. Kuhn, "A Compact K-Edge Densitometer," in Proc. Sixth Annu. ESARDA Symp. Safeguards Nucl. Mater. Manage., Venice, Italy, May 14-18, 1984 (ESARDA, 1984), ESARDA 17.

83. S. T. Smith and J. J. Lim, "An Automated Procedure for Performing Computer Security Risk Analysis," in Proc. Sixth Annu. ESARDA Symp. Safeguards Nucl. Mater. Manage., Venice, Italy, May 14-18, 1984 (ESARDA, 1984), ESARDA 17.

84. J. T. Markin, W. H. Chambers, and H. S. Vaccaro, "Optimal Allocation of Inspection Resources," in Proc. Sixth Annu. ESARDA Symp. Safeguards Nucl. Mater. Manage., Venice, Italy, May 14-18, 1984 (ESARDA, 1984), ESARDA 17. 
85. W. Alston, R. Augustson, W. DeMerschman, J. Merrill, and D. Reilly, "Analysis of NDA Data from Simulated Physical Inventory Verification Exercise at Mixed-Oxide Fuel Fabrication Facility," in Proc. ESARDA/INMM Joint Specialists Meet. Error Propagation NDA Meas. Safeguards, Ispra, Italy. September 12-14, 1984 (ESARDA, 1984), ESARDA 18.

86. "International Training Course on Implementation of State Systems of Accounting for and Control of Nuclear Weapons," Charles R. Hatcher and Hastings A. Smith, Comps., Los Alamos National Laboratory report LA-10135-C (September 1984).

87. D. Stirpe, A. S. Goldman, and R. G. Gutmacher, "MC\&A Reform Amendment: Example System Beta Variance Estimates and Performance Evaluation," Los Alamos National Laboratory report LA-9708-MS (NUREG/CR-3221) (May 1983).

88. K.X.S. Pillay, R. R. Picard, and R. S. Marshall, "Estimation Methods for Process Holdup of Special
Nuclear Materials," Los Alamos National Laboratory report LA-10038 (NUREG/CR-3678)(June 1984).

89. T. D. Reilly, R. H. Augustson, J. L. Parker, R. B. Walton, T. L. Atwell, C. J. Umbarger, and C. E. Burns, "Fundarnentals of Passive Nondestructive Assay of Fissionable Material, Laboratory Workbook," Ln's Alamos Scientific Laboratory report LA-5651-M (May 1978).

90. M. P. Baker, S. -T. Hsue, J. N. Leavitt, L. G. Speir, P. M. Rinard, and T. VanLyssel, "A Sodium lodide Monitor Array for the SRP HB-Line," Los Alamos National Laboratory Group Q-1 document. Q-1-84-1184 (November 1984).

S1. W. Ford, R. S. Marshall, L. C. Osborn, R. Picard, and C. C. Thomas, Jr.. "Solution Mass Measurement," Les Alamos National Laboratory report LA-9316-MS (July 1982). 